\title{
Fundamental Studies on the Recovery of Rare Earth Elements from Acid Mine Drainage
}

\author{
Xue Huang \\ xz0001@mix.wvu.edu
}

Follow this and additional works at: https://researchrepository.wvu.edu/etd

Part of the Mining Engineering Commons

\section{Recommended Citation}

Huang, Xue, "Fundamental Studies on the Recovery of Rare Earth Elements from Acid Mine Drainage" (2020). Graduate Theses, Dissertations, and Problem Reports. 7909.

https://researchrepository.wvu.edu/etd/7909

This Dissertation is protected by copyright and/or related rights. It has been brought to you by the The Research Repository @ WVU with permission from the rights-holder(s). You are free to use this Dissertation in any way that is permitted by the copyright and related rights legislation that applies to your use. For other uses you must obtain permission from the rights-holder(s) directly, unless additional rights are indicated by a Creative Commons license in the record and/ or on the work itself. This Dissertation has been accepted for inclusion in WVU Graduate Theses, Dissertations, and Problem Reports collection by an authorized administrator of The Research Repository @ WVU.

For more information, please contact researchrepository@mail.wvu.edu. 
Graduate Theses, Dissertations, and Problem Reports

2020

Fundamental Studies on the Recovery of Rare Earth Elements from Acid Mine Drainage

Xue Huang

Follow this and additional works at: https://researchrepository.wvu.edu/etd

Part of the Mining Engineering Commons 


\title{
Fundamental Studies on the Recovery of Rare Earth Elements from Acid Mine Drainage
}

\section{Xue Huang}

\author{
Dissertation Submitted \\ to the Benjamin M. Statler College of Engineering and Mineral Resources \\ at West Virginia University \\ In partial fulfillment of the requirements for the degree of \\ Doctor of Philosophy in \\ Mining Engineering
}

\author{
Aaron Noble, PhD., Chair \\ Felicia Peng, PhD. \\ Berk Tulu, PhD. \\ Xingbo Liu, PhD. \\ Paul Ziemkiewicz, PhD. \\ Department of Mining Engineering
}

Morgantown, WV

2020

Keywords: rare earth elements, acid mine drainage, leaching and precipitation, humidity cell testing.

Copyright 2020, Xue Huang 


\title{
Fundamental Studies on the Recovery of Rare Earth Elements from Acid Mine Drainage
}

\begin{abstract}
The Rare Earth Elements (REEs) are a group of 17 chemically similar elements that are essential raw materials for modern society. Given their increasing importance in civil and defense applications, many national governments, including the US, have denoted the REEs as critical materials and emphasized the need to identify and develop both conventional and unconventional resources to meet the growing demand. To address this challenge, the US Department of Energy has recently spearheaded efforts to evaluate the technical and economic feasibility of recovering REEs from coal and coal byproducts, which have been shown to contain REEs at an elevated concentration relative to surrounding strata. One promising resource identified in this program is acid mine drainage (AMD) and its subsequent treatment precipitates (AMDp).

Prior studies have shown that the AMD produced from the coal measures acts as a heap leach reactor that mobilizes common transition metals as well as REEs. Per Section 404 of the Clean Water Act, mine operators are required to collect and treat AMD prior to discharge by raising the $\mathrm{pH}$ and in turn removing the transition metals. During this process, the REEs tend to deport with bulk transition metal, and are ultimately recovered to the AMDp. While a select number of studies have evaluated the content and quantity of REEs in AMD, the scientific literature is generally lacking fundamental information on the mechanisms that control the deportment of REEs from the initial coal strata to the AMD and ultimately to the AMDp.

The research in this study seeks to overcome this knowledge gap through a combination of both fundamental and empirical studies. Initially, thermodynamic simulations were conducted to evaluate the solubility of REEs in aqueous systems. HSC Chemistry 9.0 was used to generate Eh-pH diagrams for both REEs and other transition metals. Data from these simulations were then used to inform experimental investigations on the leaching of REEs from AMDp as well as the selective separation of REEs from major metals by staged precipitation. Collectively, this data showed that the REEs in AMDp are readily soluble in nitric acid and subsequent $\mathrm{pH}$ adjustment with $\mathrm{NaOH}$ prompted significant separation of REEs from iron and other major contaminants. Lastly, to better understand the initial leaching of REEs into AMD, humidity cell tests were conducted over a period of 80 weeks using feed material from a coarse refuse site in Central Appalachia. Data showed that the leaching of REEs was hindered until nearly full depletion of the calcium was achieved, and the REE leaching was typically accompanied by release of iron and aluminum.

Altogether, these results provide insights on the mechanisms controlling content and characteristics of REEs in AMD. This information thus supports the development and design of integrated processes to recover REEs from AMD, while prompting superior economic and environmental outcomes for localities impacted by AMD.
\end{abstract}




\section{Acknowledgements}

There are many who helped me along the way on this journey. I want to take a moment to thank them. First, I want to express my thanks to my patient and supportive supervisor, Dr. Aaron Noble. He has supported me throughout this research project and my 4-year Ph.D. program. His support, guidance and overall insights in this field have made this an inspiring experience for me. I am extremely grateful for his personal support and understanding in both an emotional and professional way.

Second, I wish to thank my dissertation committee. Without their guidance, I would not have made it. Dr. Felicia Peng guided me through my courses and exams. Dr. Berk Tulu' critical insight and attention to detail is greatly appreciated. Dr. Xingbo Liu served as a wise committee member and continually suggested new, out-of-the box ideas. Dr. Paul Ziemkiewicz expertise in acid mine drainage has served as a critical backbone in this research, particularly in the work with humidity cells.

Finally, I want to thank my family for their love and understanding, which helped me through many challenges. Without them believing in me, I never would have made it.

This material is partially based upon work supported by the U.S. Department of Energy under Award Number DE-FE0026927. Other financial support from the Society for Mining, Metallurgy \& Exploration is also acknowledged.

This report was prepared as an account of work sponsored by an agency of the United States Government. Neither the United States Government nor any agency thereof, nor any of their employees, makes any warranty, express or implied, or assumes any legal liability or responsibility for the accuracy, completeness, or usefulness of any information, apparatus, product, or process disclosed, or represents that its use would not infringe privately owned rights. Reference herein to any specific commercial product, process, or service by trade name, trademark, manufacturer, or otherwise does not necessarily constitute or imply its endorsement, recommendation, or favoring by the United States Government or any agency thereof. The views and opinions of authors expressed herein do not necessarily state or reflect those of the United States Government or any agency thereof. 


\section{Table of Contents}

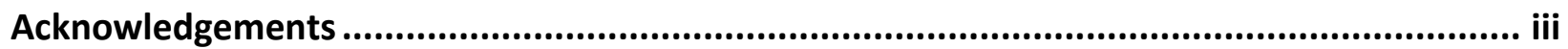

List of Figures ...................................................................................................................

List of Tables .............................................................................................................................ii

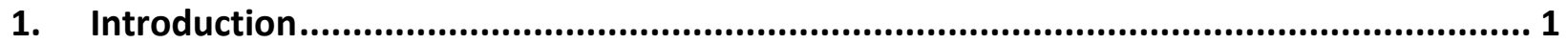

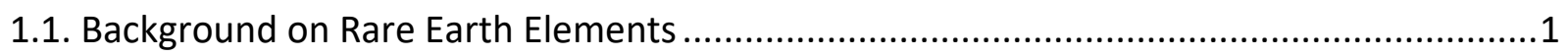

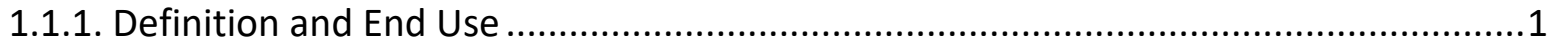

1.1.2. Rare Earth Elements Production ..........................................................................

1.1.3. Secondary Sources of Rare Earth Elements ..............................................................

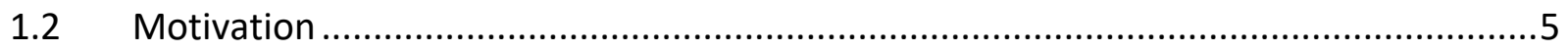

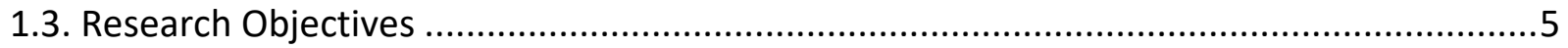

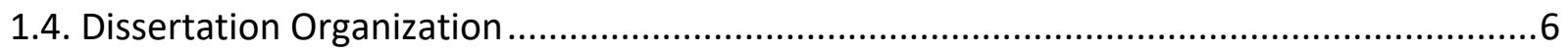

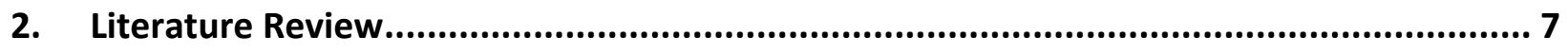

2.1. Extraction of Rare Earth Elements from Mineral Concentrates ........................................

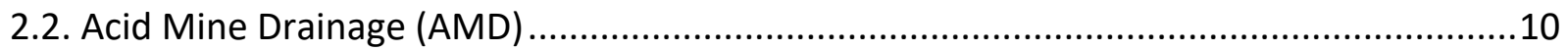

2.3. Rare Earth Elements in Acid Mine Drainage .............................................................13

2.4. Characterization Methods ........................................................................................15

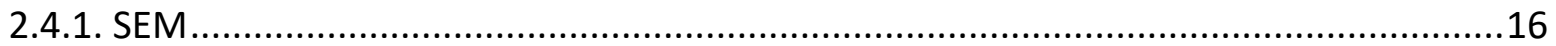

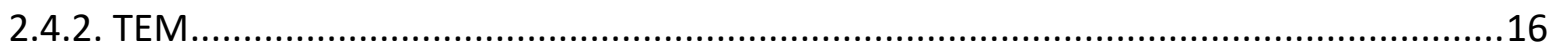

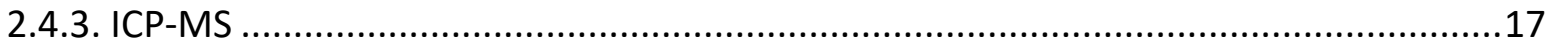

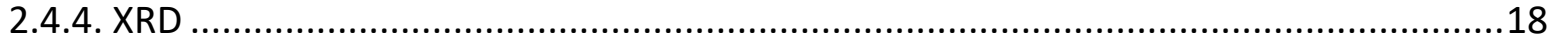

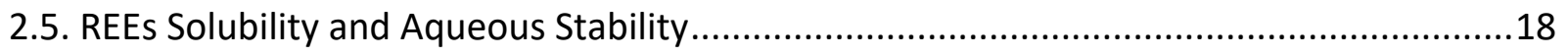

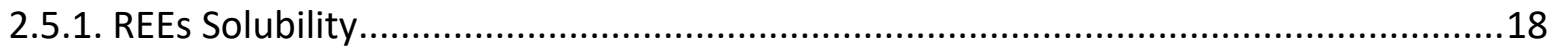

2.5.2. Eh-pH Diagrams Background ………......................................................................19

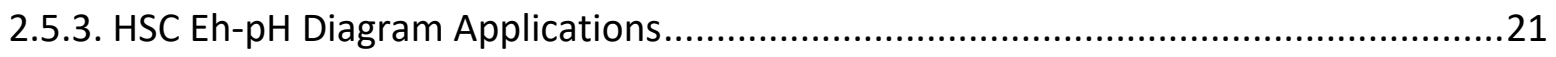

3. Thermodynamic Modeling of Rare Earth Element Aqueous Stability ............................... 24

3.1. Introduction and Modeling Objectives .............................................................................

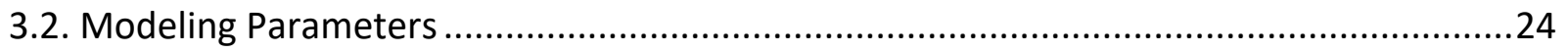

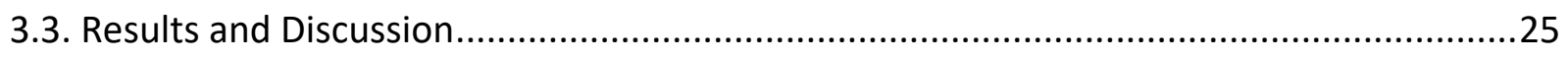

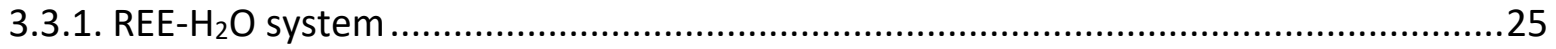




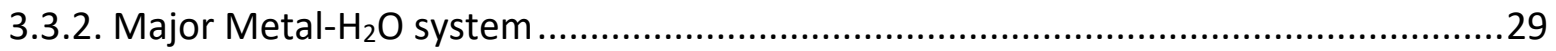

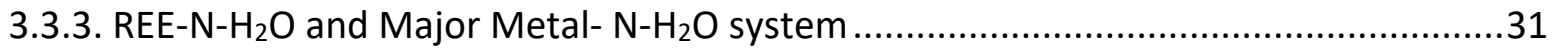

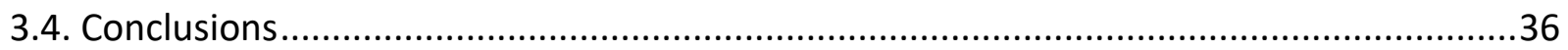

4. Leaching of Rare Earth Elements from Acid Mine Drainage Precipitates (AMDp) .......... 37

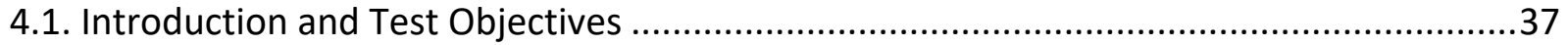

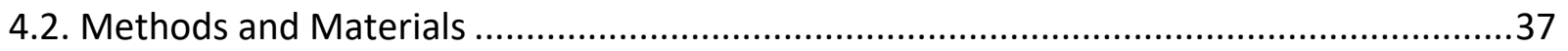

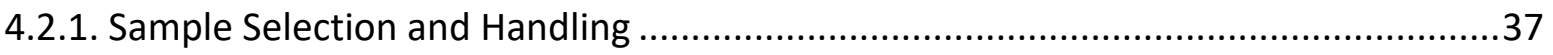

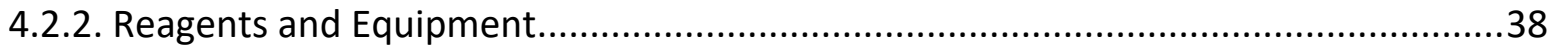

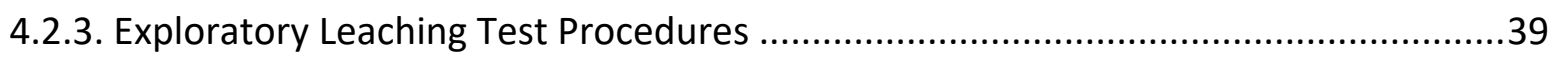

4.2.4. Leaching Kinetics Test Procedures................................................................40

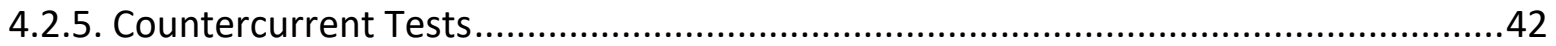

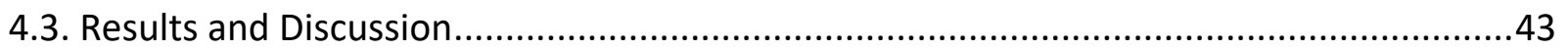

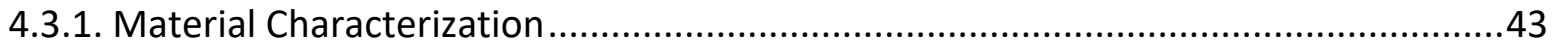

4.3.2. Effect of Acid and Sample Type ...............................................................46

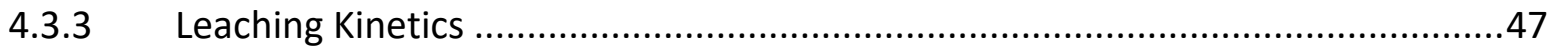

4.3.4 Leaching $\mathrm{pH}$ assessment ...................................................................... 58

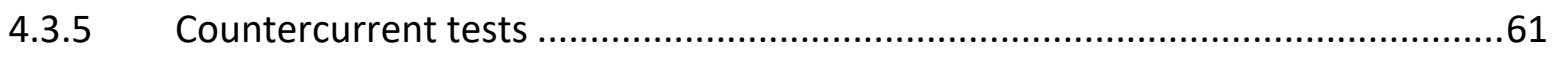

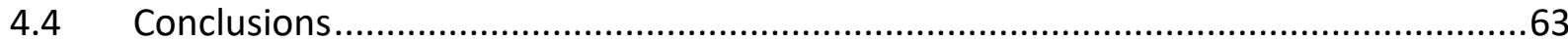

5 Recovery of Rare Earth Elements from Leach Solutions via Selective Precipitation ........ 64

5.1 Introduction and Test Objectives ...................................................................64

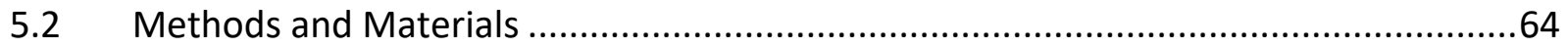

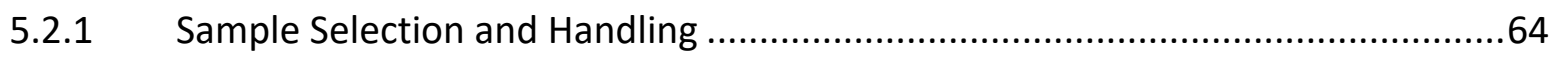

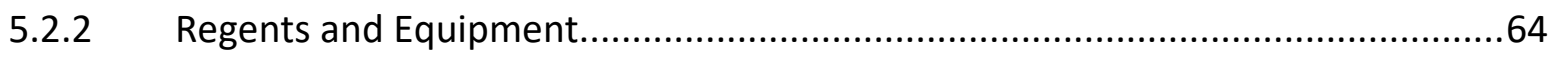

5.2.3 Exploratory Precipitation Test Procedures ......................................................65

5.2.4 Precipitate Grade Test Procedures ...............................................................66

5.2.5 Reagent Evaluation Test Procedures ........................................................68

5.2.6 Oxidization-Precipitation Test Procedures .................................................69

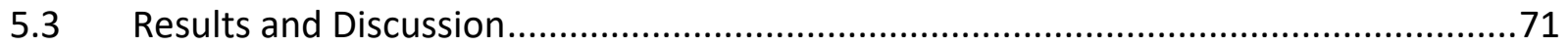

5.3.1 Exploratory Precipitation Tests................................................................ 71

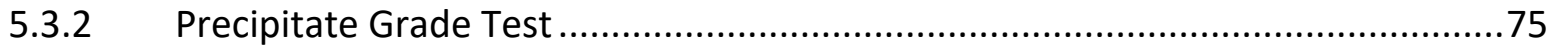

5.3.3 Reagent Evaluation Test ........................................................................ 78 


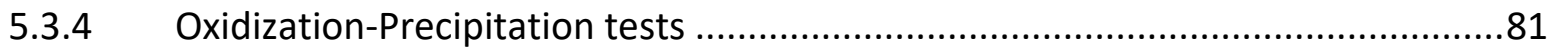

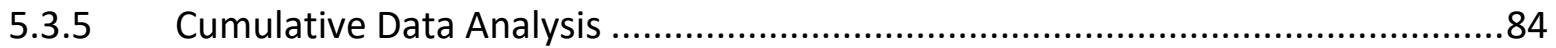

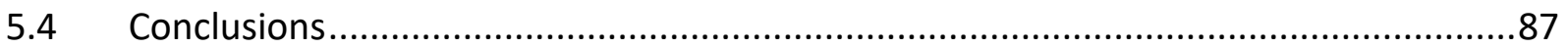

6 Investigation of Rare Earth Elements Release from Coal Refuse into Acid Mine Drainage 88

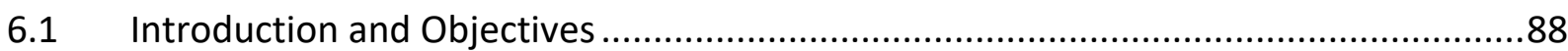

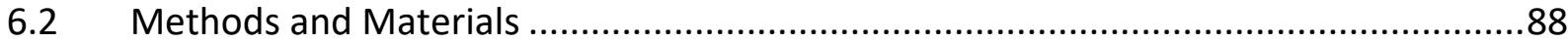

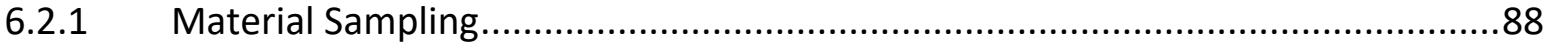

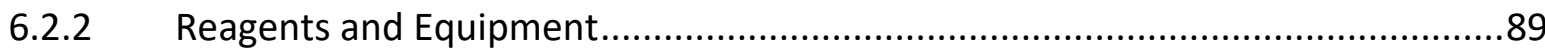

6.2.3 Experimental Procedures ............................................................................91

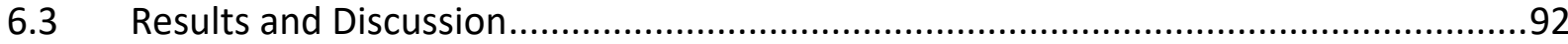

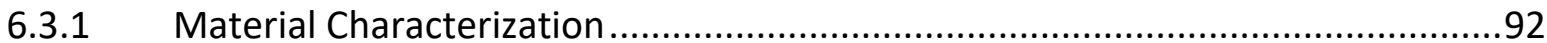

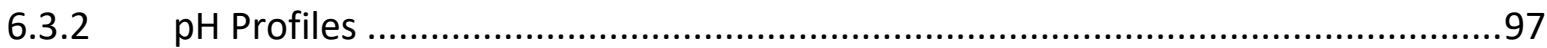

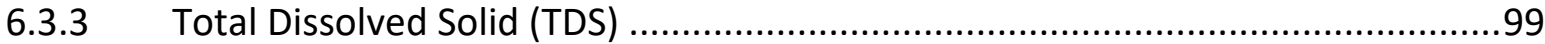

6.3.4 Sulfate Release over time ........................................................................100

6.3.5 Rare Earth Elements Release .....................................................................101

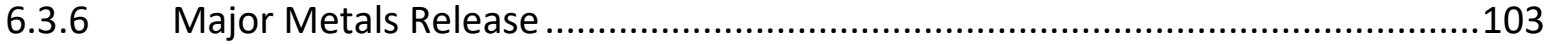

6.3.7 Influence of pH on Rare Earth Elements Release ........................................107

6.3.8 Influence of $\mathrm{pH}$ on Major Metal Release ....................................................107

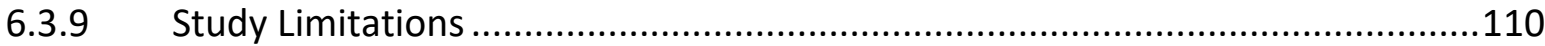

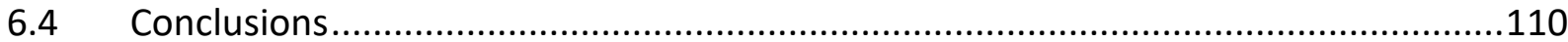

7 Summary, Conclusions, and Recommendations …................................................112

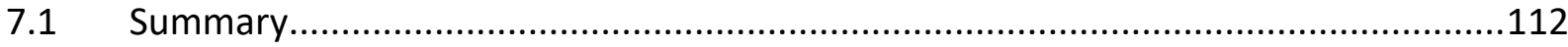

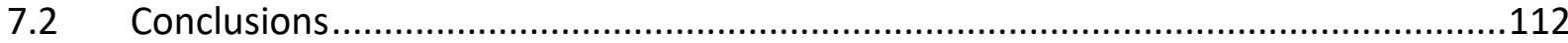

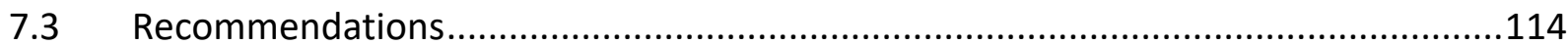

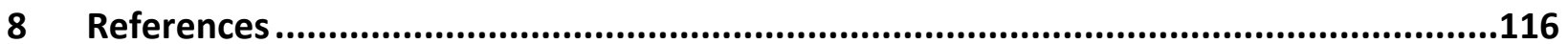




\section{List of Figures}

Figure 1. REEs in periodical table with designations for light, heavy, and critical........................1

Figure 2. Global REEs production (Cordier, 2013).............................................................

Figure 3. Simplified schematic representation of the REE extraction process. .......................... 7

Figure 4. Conventional and Novel REEs separation methods.............................................9

Figure 5. Example of acid mine drainage (Fourie, 2018)......................................................11

Figure 6. Carbonate equilibrium as a function of $\mathrm{pH}$ (USU, 2004). .......................................14

Figure 7. Example of an Eh-pH diagram for Ce..................................................................21

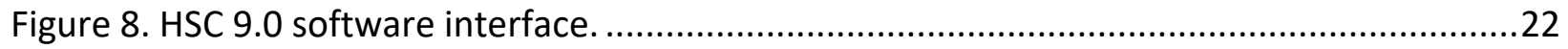

Figure 9. $\mathrm{RE}-\mathrm{H}_{2} \mathrm{O}$ system for MV Leachate (Sc, Y, La, and Ce)..........................................26

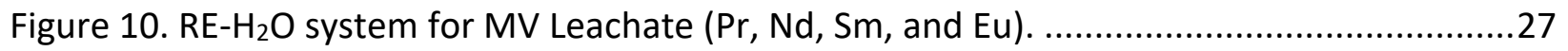

Figure 11. $\mathrm{RE}-\mathrm{H}_{2} \mathrm{O}$ system for MV Leachate $(\mathrm{Gd}, \mathrm{Tb}$, Dy, and Ho) .........................................28

Figure 12. $\mathrm{RE}-\mathrm{H}_{2} \mathrm{O}$ system for MV Leachate (Er, Tm, Yb, and Lu). .......................................29

Figure 13. $\mathrm{MM}-\mathrm{H}_{2} \mathrm{O}$ system for $\mathrm{MV}$ Leachate ( $\mathrm{Al}, \mathrm{Ca}, \mathrm{Fe}, \mathrm{Mg}, \mathrm{Mn}$, and Th). ...........................30

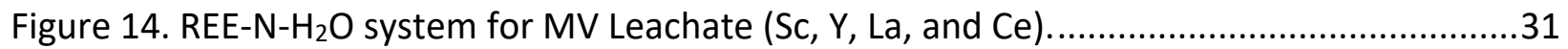

Figure 15. REE-N-H ${ }_{2} \mathrm{O}$ system for MV Leachate (Pr, Nd, Sm, and Eu) .....................................32

Figure 16. REE-N-H ${ }_{2} \mathrm{O}$ system for MV Leachate (Gd, Tb, Dy, and Ho). ....................................33

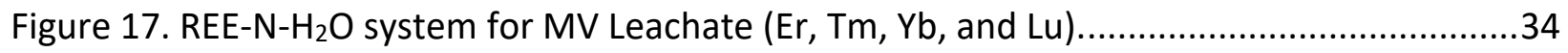

Figure 18. $\mathrm{MM}-\mathrm{N}-\mathrm{H}_{2} \mathrm{O}$ system for $\mathrm{MV}$ Leachate $(\mathrm{Al}, \mathrm{Ca}, \mathrm{Fe}, \mathrm{Mg}, \mathrm{Mn}$, and Th)..........................35

Figure 19. Experimental Apparatus used in leaching tests................................................38

Figure 20. Experimental flowsheet for exploratory leaching tests........................................40

Figure 21. Experimental flowsheet for kinetic leaching tests...........................................41

Figure 22. Experimental flowsheet for countercurrent leaching test. ..................................42

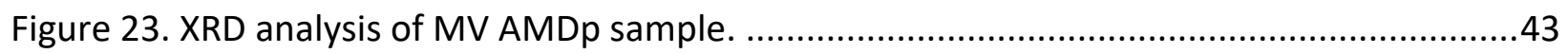

Figure 24. SEM Micrograph of the MV AMDp sample .....................................................44

Figure 25. Total REE concentration in leachate for various AMDp samples and acid types. .......47

Figure 26. Leachate composition for various AMDp samples and acid types. .........................48

Figure 27. Relationship between major metal concentration and TREE concentration in leachates generated during exploratory testing. Data includes three different samples (MV, BG, and DM) as well as two different acids (nitric and sulfuric) ............................................49

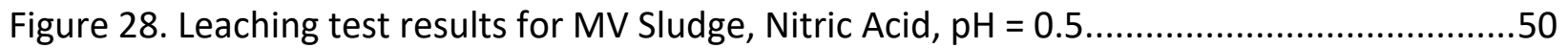




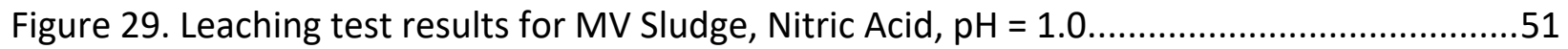

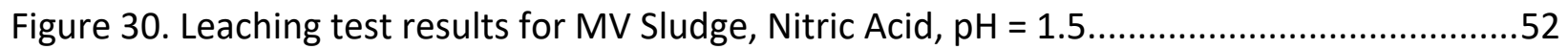

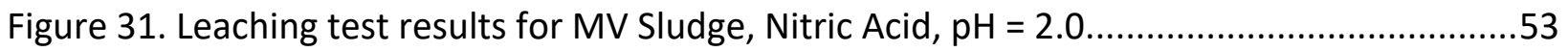

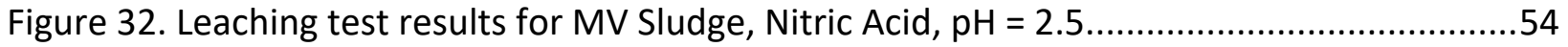

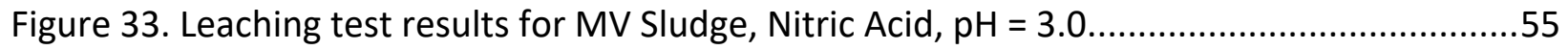

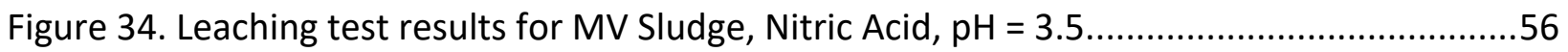

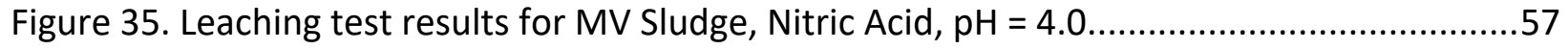

Figure 36. Leaching test results for MV sludge, Nitric Acid, time $=30$ minutes, presented as a

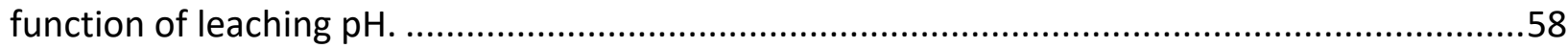

Figure 37. Leaching test results for MV Sludge, Nitric Acid, time = 30 minutes, presented

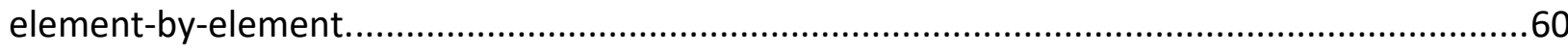

Figure 38. Leaching test results for MV Sludge, Nitric Acid, time = 30 minutes, presented as a function of recovered REE value. REE prices based on medium/standard conditions, 2008 to 2016.

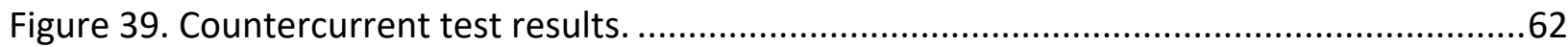

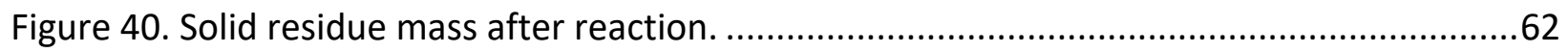

Figure 41. Leach solution concentrations as a function of $\mathrm{pH}$ for countercurrent leaching tests.

Figure 42. Experimental flowsheet for exploratory selective precipitation tests.....................66

Figure 43. Experimental flowsheet for precipitate grade test procedures. ............................67

Figure 44. Experimental flowsheet for reagent evaluation tests. ..........................................68

Figure 45. Experimental Flowsheet for Oxidation-Precipitation Tests. ...................................70

Figure 46. Indicative example of solutions produced during exploratory precipitation tests at

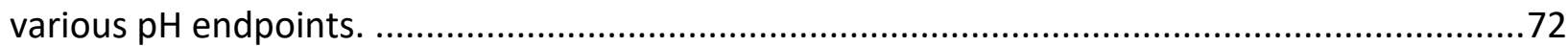

Figure 47. Experimental results from the exploratory precipitation tests. REE data only. .........73

Figure 48. Experimental results from the exploratory precipitation tests. Ca and Mg were not removed at a significant rate under these test conditions and were thus removed from the figure.

Figure 49. Indicative example of solutions produced during precipitate grade tests at various pH endpoints.

Figure 50. Precipitation test results. Data show assay of precipitated solids after full dissolution at $\mathrm{pH} \approx 0.5$ and adjustment back to higher $\mathrm{pH}$ values. 77 
Figure 51. Reagent evaluation test result. \% removed plotted as a function of $\mathrm{pH}$ endpoint for TREE and various major metals. $\mathrm{Mg}$ has been removed from the analysis, given the additional $\mathrm{Mg}$ included in the $\mathrm{MgO}$ reagent.

Figure 52. REE vs. major metal separation efficiency for reagent evaluation tests. Here separation efficiency is defined as \% removal of major metal minus \% removal of REEs. 80

Figure 53. Comparison of REE precipitation and leaching data across similar pH points.

Figure 54. Oxidation-precipitation test result. \% removed plotted as a function of $\mathrm{pH}$ endpoint for TREE and various major metals. Data series show the various doses of $\mathrm{H}_{2} \mathrm{O}_{2}$......

Figure 55. REE vs. major metal separation efficiency for oxidation-precipitation tests. Here separation efficiency is defined as \% removal of major metal minus \% removal of REEs. .83

Figure 56. TREEs to total metal ratio, estimated from incremental analysis of precipitation results.

Figure 57. Aqueous TREE concentration vs. $\mathrm{pH}$ for all leaching and precipitation test data.........85

Figure 58. Individual REE/TREEs ratio vs. $\mathrm{pH}$ for all test conditions. .......................................86

Figure 59. Surface refuse site sampled for test material..................................................89

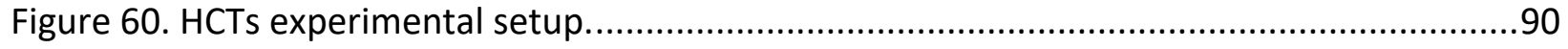

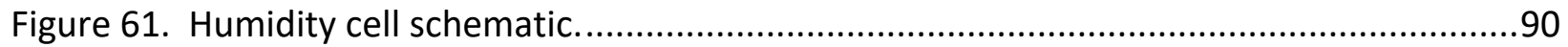

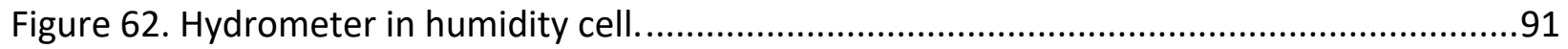

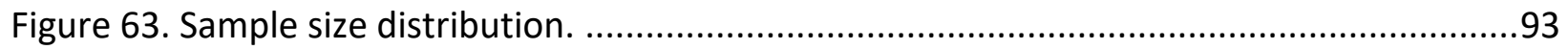

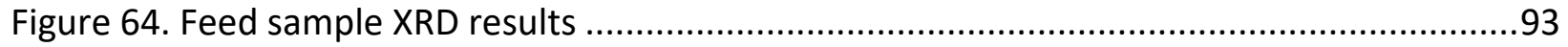

Figure 65. SEM Micrograph of feed sample with $1.00 \mathrm{~mm}$ scale bar. .....................................94

Figure 66. SEM Micrograph of various HCT samples after 40-weeks of test progression...........95

Figure 67. $\mathrm{pH}$ of HCT flush liquid as a function of week number. ........................................98

Figure 68. TDS of HCTs flush liquid as a function of week number. ......................................100

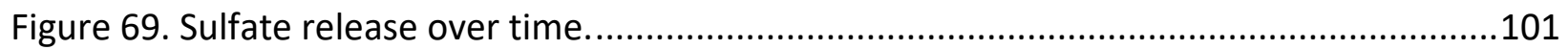

Figure 70. Cumulative release of REE into HCT leach solution over time, top $=$ all data, bottom =

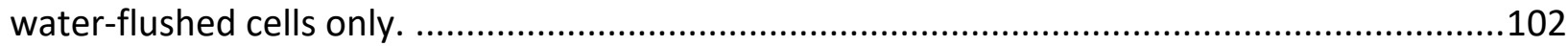

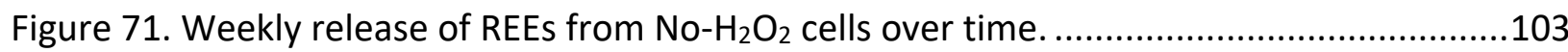

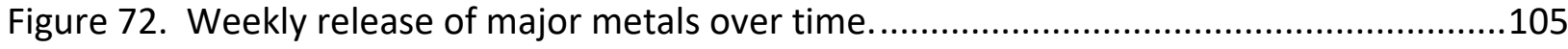

Figure 73. Relationship between REE and major metal release .........................................106

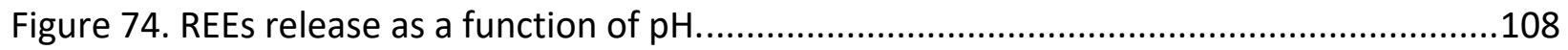

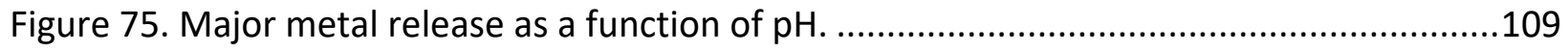


Figure 76. Block flow diagram showing a process to recover REEs from AMDp. Blocks highlighted in yellow were the focus of this study. 


\section{List of Tables}

Table 1. Potential Secondary Sources of REEs .....................................................................

Table 2. REE concentrations for raw aqueous AMD influent in Appalachian basin study (after

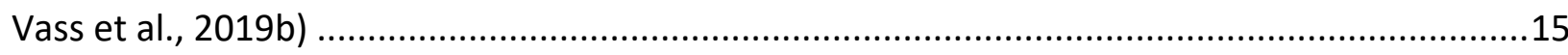

Table 3. Rare earth elements and major metals concentration in typical AMDp Leachate.........24

Table 4. Experimental Parameters for Exploratory Leaching Tests ........................................39

Table 5. Experimental Parameters for Parametric Leaching Tests ...........................................41

Table 6. Bulk Chemical Characterization of MV AMDp via ICP-MS .......................................44

Table 7. Bulk Chemical Characterization of DL AMDp via ICP-MS .........................................45

Table 8. Bulk Chemical Characterization of BG AMDp via ICP-MS ........................................46

Table 9. Experimental Parameters for Parametric Precipitation Tests ...................................65

Table 10. Experimental Parameters for Precipitate Grade Tests ..........................................67

Table 11. Experimental Parameters for Reagent Evaluation Tests .........................................69

Table 12. Experimental Parameters for Oxidation-Precipitation Tests ...................................71

Table 13. pH 0.5 Leachate Concentrations for Exploratory Precipitation Tests (Major Metals) .72

Table 14. pH 0.5 Leachate Concentrations for Exploratory Precipitation Tests (REEs) ...............73

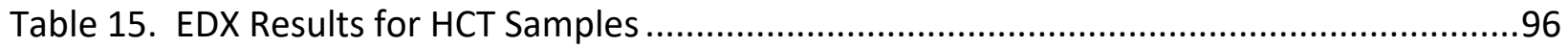




\section{Introduction}

\subsection{Background on Rare Earth Elements}

\subsubsection{Definition and End Use}

The rare earth elements (REEs) are group of 17 chemically similar elements including those of the lanthanide series, as well yttrium and scandium (Figure 1) (DOE, 2017). These elements share similar physiochemical characteristics so that they often occur as a group in similar host minerals. Although relatively abundant in the earth's crust, REEs rarely occur in concentrated forms, making them economically challenging to recover. Despite the limited supply, these elements are critical to many important civil and defense technologies, such as hybrid vehicles, wind turbines, cell phones, and lasers. Given the increasing global demand for green and sustainable products in the energy, military and manufacturing industries, the need for REEs is increasing both in the US and throughout the world (Long, 2010).

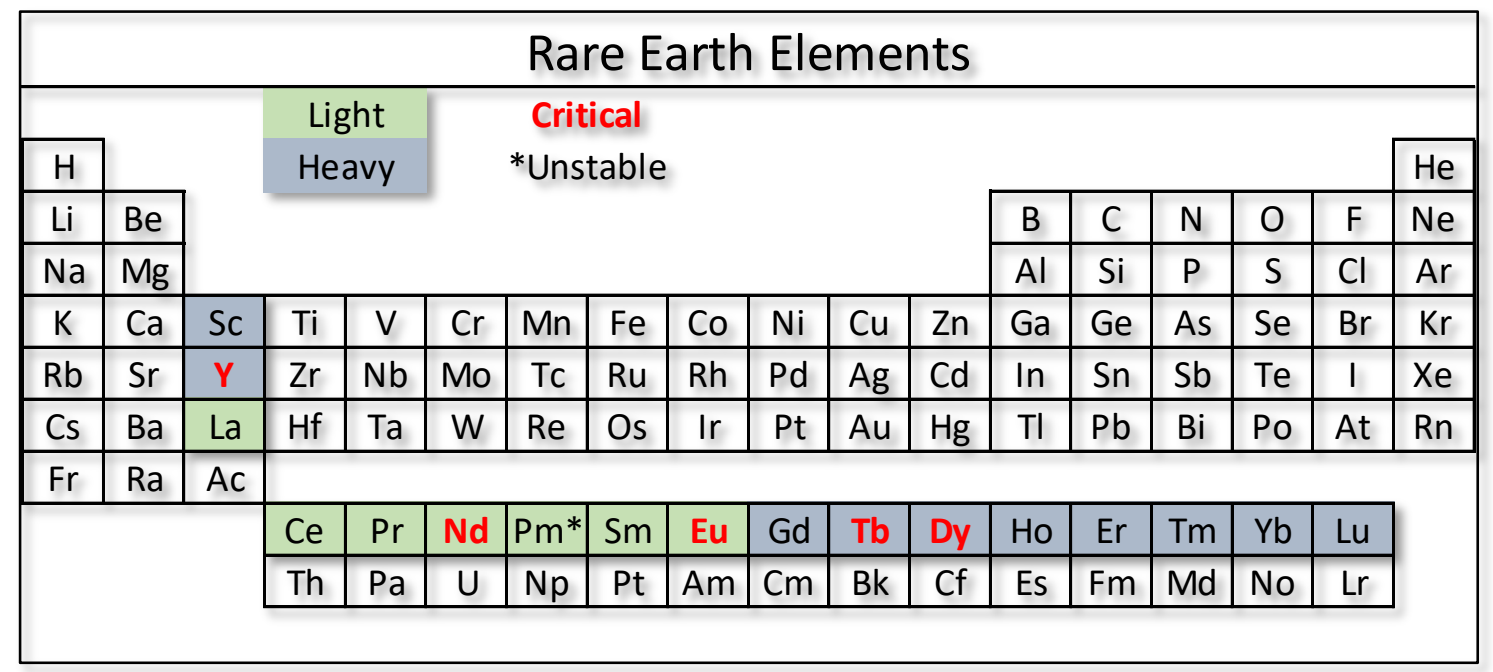

Figure 1. REEs in periodical table with designations for light, heavy, and critical.

Given the difficulties in extracting REEs from minerals ore as well as the difficulty of separating individual elements in the series, the term "rare" was used in 1940s and kept through the present day (Gupta, 1992). Despite this nomenclature, REEs are common in the earth's crust having a crustal abundance similar to other economic metals such as copper and cobalt (Long, The Principal Rare Earth Elements Deposits of the United States: A Summary of Domestic Deposits and a Global Perspective, 2010) Individual REEs have the similar chemical and physical properties, and those with even atomic numbers are more common in nature. Additionally, geochemists observed (EPA, 2012) that lanthanides with lower atomic numbers (Condie, 1991) were more common in REE mineral ores and generally occurred in greater abundance than the rare earth elements with higher atomic numbers. Such trends suggest a divide between light and heavy REEs-enriched minerals. Light REEs are made up of the first seven elements of the lanthanide series which are Lanthanum, Cerium, Praseodymium, Neodymium, Promethium, Samarium and Europium. Heavy REEs have higher atomic numbers including Europium, 
Gadolinium, Terbium, Dysprosium, Holmium, Holmium, Erbium, Thulium, Ytterbium and Lutetium whose value relatively are higher than other REEs (Fernandez, 2017). Some investigators classify gadolinium and dysprosium as medium-weight lanthanides due to their physiochemical properties (Chakhmouradian, 2012).

The elemental forms of REEs that are extracted from mineral ores, as oxides (i.e., REOs), are iron gray to silvery lustrous metals that are typically soft, malleable, ductile, and usually reactive, especially at elevated temperatures or when finely ground. The REEs are used in a wide variety of applications due to their unique properties (Morteani, 1989). For instance, magnets made with REEs are much more powerful, weigh less, and can be made smaller than conventional magnets (Dent, 2012). Some REEs also have high electrical conductivity, can withstand extreme heat, and give off intense white light when heated (Chen, 2011).

In aqueous systems, REEs typically occur in the trivalent state. However, cerium can be present as $\mathrm{Ce}^{4+}$ and europium can occur in both the divalent and trivalent states. The chemical behaviors of all REEs are very similar, but small variations in the aquatic system can be attributed to their atomic number and ionic radii, which are inversely correlated. Therefore, REEs are considered suitable to study the processes of complexation, sorption, precipitation, and the formation of colloids (Merten, 2004).

\subsubsection{Rare Earth Elements Production}

Rare earths are relatively abundant in the Earth's crust, but discovered minable concentrations are less common than for most other ores (Hu, 2006). U.S. and world resources are contained primarily in bastnaesite $\left((\mathrm{Ce}, \mathrm{La}) \mathrm{CO}_{3}(\mathrm{~F}, \mathrm{OH})\right)$ and monazite ((Ce,La,Nd,Th)PO $\left.\mathrm{PO}_{4}\right)($ Kynicky, 2012). Bastnaesite deposits in China and the United States constitute the largest percentage of the world's rare-earth economic resources, while monazite deposits in Australia, Brazil, China, India, Malaysia, South Africa, Sri Lanka, Thailand, and the United States constitute the second largest segment (Kanazawa, 2006). Also, another type of REEs-ion-adsorption clays accounted for 35\% China's RREs production (Yang X. J., 2013).

According to the US Geological Survey (Long, 2010), in 2010, the whole world REOs reserves were about 110 million tones: China has the largest reserves, with more than $60 \%$ (55 million tons); CIS (Commonwealth of Independence States - former Soviet Union) is the second, with about 17\% (19 million tons); United States are the third, with about 12\% (13 million tons); then follow India (3.1 million tons), Australia (1.6 million tons), Brazil (0.48 million tons), Malaysia ( 0.3 million tons) and other countries ( 22 million tons, $20 \%$ of total).

Currently, the largest global producer is China: in 2010, 130,000 t of REOs on a world estimated production of 134,000 ones, equal to $97 \%$ of them, came from there (Figure 2) (Massari, 2013). Today, many of these reserves are located in the regions of Inner Mongolia (Bayan Obo mine), Shandong, Jiangxi, Guangdong, Hunan, Guangxi, Fujian, Sichuan (Hurst, 2010).

According to the 2013 Worldwide Threat Assessment of the National Intelligence Office, rare earths are "essential to civilian and military technologies and to the 21st-century global economy, including green technologies (e.g., wind turbines and advanced battery systems) and 
advanced defense systems." This is why developing a domestic source particularly a secondary resource is critical since the primary resources are difficult to find and extract.

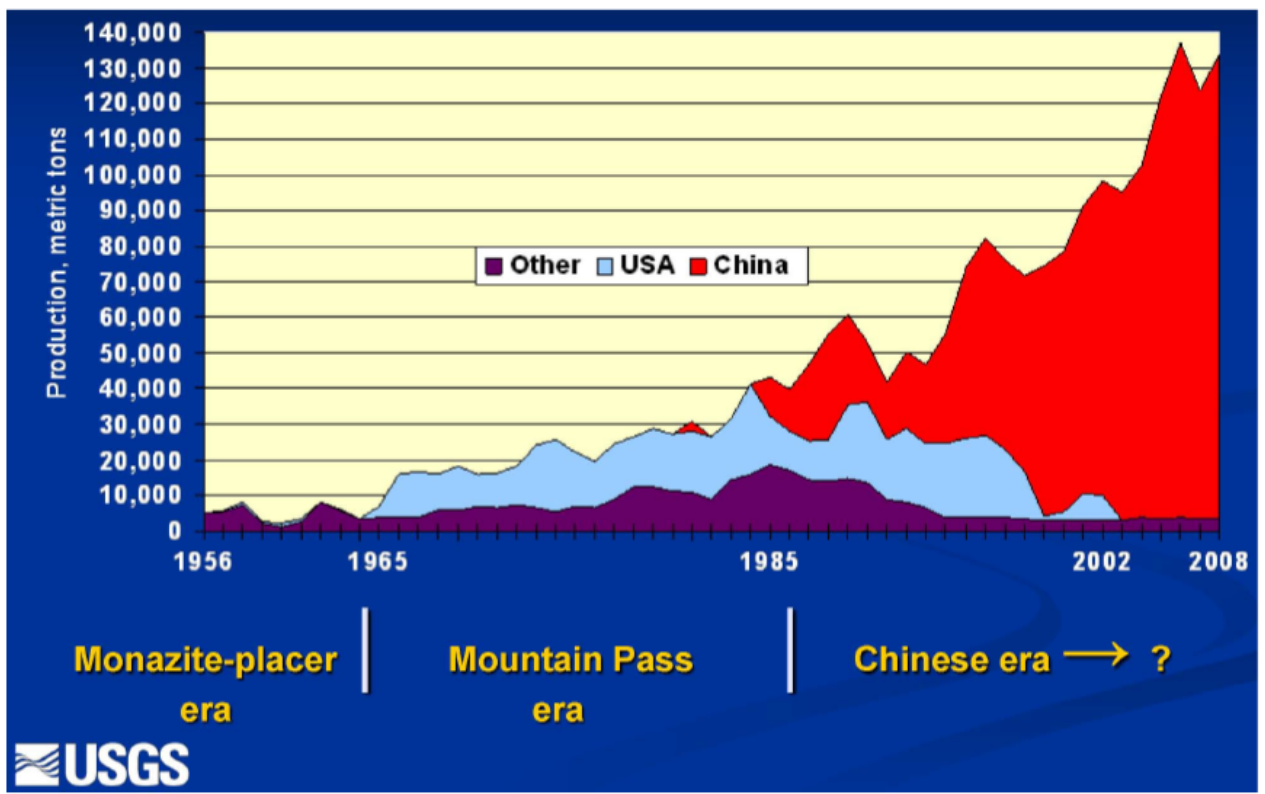

Figure 2. Global REEs production (Cordier, 2013).

\subsubsection{Secondary Sources of Rare Earth Elements}

In addition to the primary sources from direct mining process, recycling of REE from end-of-life products, tailings and other by-products from previous mining activities may potentially provide significant amounts of REEs (Innocenzi, 2016). Utilization of such materials may actually help not only to provide additional source of REEs but also to environmentally friendly solution for the mining and processing wastes and to post-mining remediation (Jowitt, 2018). Besides coal and electronic wastes, acid mine drainage is considered a new secondary source of REEs and is becoming popular in recent research worldwide (Table 1).

Acid mine drainage (AMD) is a longstanding environmental issue and one of the largest threats to stream health in Appalachia (Lukacs, 2013). Prior research, however, has shown that AMD can serve as an autogenous "heap leach" reactor that mobilizes and concentrates REEs. The REE concentrations in AMD can be several orders of magnitude higher than in naturally occurring water bodies. With respect to the REE content of standard shale specimens, the REE distribution pattern in AMD is enriched in the less-abundant REEs, such as Tb and Dy (Ayora, 2016). The reasons for the REEs enrichment in AMD with respect to other natural waters are grounded in their aqueous geochemistry (H.Johannesson, 1996). The majority of REEs in igneous and sedimentary rocks are occasionally located as major components of carbonates (bastnaesite) and phosphates (monazite). These minerals react with $\mathrm{CO}_{2}$ and humic acids normally in the soil. But when in solution, REEs remain as trivalent cations or, above $\mathrm{pH} 7$ complexed with $\mathrm{CO}_{3}{ }^{2-}$ and $\mathrm{OH}^{-}$. Due to its large positive charge and ionic potential, trivalent cations are strongly absorbed onto the negative charged surface of clays (Bradbury, 2002). If the primary rock is rich in REEs, the weathered clays from residue deposits are the potential 
reservoir of REEs. A strong correlation between high REEs concentrations and acidity has been reported in both the surface and ground waters (Beltrami, 2015).

Prior research on mine-wastes and stream sediments showed a light REEs (LREEs) and middle REEs (MREEs) enrichment related to heavy REEs (HREEs) (Li X. , 2017). In contrast, acid mine effluents and surface waters are enriched in HREEs relative to LREEs. These results suggest that the LREEs released during the oxidation of sulfides are captured by secondary (weathering) minerals, while the MREEs are removed from the altered rocks. The low concentrations of LREEs in acid stream water suggest that these elements can be retained in the sediments more strongly than HREEs and MREEs. One possible explanation for the sharp decrease in dissolved LREEs might be their retention by low-solubility secondary minerals such as anglesite, barite and jarosite.

Table 1. Potential Secondary Sources of REES

\begin{tabular}{|c|c|}
\hline Description & Indicative Sources \\
\hline Coal and coal refuse & $\begin{array}{l}\text { (Zhang W. , 2015); (Zhang W. , 2020); (Seredin, 2012); } \\
\text { (Jurkovic, 2014) (Lin, 2017) }\end{array}$ \\
\hline Fly Ash & $\begin{array}{l}\text { (Franus, 2015); (Huang, 2020); (Hower, 2016); (Pan, 2020) } \\
\text { (Franus, 2015) (DanutaSmolka-Danielowska, 2010) }\end{array}$ \\
\hline Acid Mine Drainage & $\begin{array}{l}\text { (Vass C. R., 2019b) (Vass C. R., 2019a); (Stewart, 2017) (Ayora, } \\
\text { 2016) (Zhao, 2007) (Lozano, 2019) }\end{array}$ \\
\hline Electronic Waste & $\begin{array}{l}\text { (Binnemans, 2013); (Rademaker, 2013); (R.Mueller, 2015) } \\
\text { (Brewer, 2019) (Li Z. , 2019) }\end{array}$ \\
\hline Scrap Magnets & $\begin{array}{l}\text { (Kim D. , 2015) (Itoh, 2009) (Kumari, 2018) (Bian, 2015) } \\
\text { (Gergoric, 2018) }\end{array}$ \\
\hline $\begin{array}{l}\text { Phosphoric Acid By- } \\
\text { product }\end{array}$ & (Preston, 1996); (Zhang L. , 2016) (Hérès, 2018) (Salem, 2019) \\
\hline Phosphogysum Tailings & (Zmemla, 2020) (Yang X. , 2019) \\
\hline Red Mud & $\begin{array}{l}\text { (Binnemans, 2015); (Akcil, 2017) (Tsakanika, 2004) (Davri, } \\
\text { 2016) (Zhan, 2019) (Rivera, 2018) (Wag, 1987) }\end{array}$ \\
\hline
\end{tabular}




\subsection{Motivation}

In 2014, the US Department of Energy initiated a research program to investigate the potential to extract REEs from coal and coal products. Initial studies focused on solid feedstocks, including pre-combustion coal material (e.g. tailings, refuse, underclay, etc.) as well as postcombustion residuals (e.g. fly ash, bottom ash, etc.). The extraction of REEs from these sources requires a complex processing route and often includes high temperature or high-pressure leaching, which is cost prohibitive. As an alternative, research collaborators at West Virginia University and Virginia Tech invested the acid mine drainage produced from the coal measures as well as the subsequent treatment precipitates (AMDp) as potential feedstocks for REE recovery.

Abundant AMD sources and AMDp stockpiles are present in the Appalachian coal basin. If fully developed, this new resource could serve as a critical component of a purely domestic REE supply chain. Moreover, by incentivizing the treatment of AMD and the removal of legacy AMDp material, this research may also catalyze improved environmental stewardship for the region. Lastly, a new domestic REE industry may prompt significant economic development in a region that has recently been hamstrung due to the downturn and exodus of historic industries. When taken together, this research has enormous positive potential with respect to economic, environmental, social, and national security outcomes.

\subsection{Research Objectives}

While a select number of small studies have been conducted, the scientific literature is generally lacking fundamental data on the occurrence of REEs in AMD. The available data is available is usually regional in scope and not explained in the context of fundamental thermodynamic considerations. Considering these missions as well as the large potential REE resource, this study proposes to conduct a series of fundamental experiments to better understand how REEs report to AMD, how they are concentrated in AMD treatment processes, and how they can be extracted and concentrated from these waste streams. The itemized objectives of this work include:

- Investigate and identify the mechanisms that cause REEs to be concentrated in AMD. The knowledge obtained from this research will help better understand the causal factors leading to REE enrichment, which can in turn be leveraged to promote increased REE production from both autogenous and anthropogenic acid sources.

- Investigate the nature of REE enrichment in AMD precipitate (AMDp) from coal refuse and evaluate the solubility of these compounds. The understanding of REEs behaviors in these solid matrixes will provide a means to improve extraction efficiency for leaching processes.

- Develop conceptual and thermodynamic models for the behavior of REEs in both AMD and leachate solutions. By incorporating both thermodynamic simulation and laboratory data, the knowledge gained from this study will provide a basis for improved process design in recovering REEs from acidic solutions. 
- Use the fundamental knowledge gained from these studies to develop an efficient and environmentally benign process to extract REEs from AMD and/or AMDp.

\subsection{Dissertation Organization}

The body of this dissertation is organized as follows:

-Chapter 1 provides an introduction to REE supply and demand challenges and discusses the objectives of this research.

-Chapter 2 provides a literature review on the state-of-the art for REE extraction and recovery with a focus on hydrometallurgical processing routes

-Chapter 3 provides a thermodynamic simulation on the aqueous stability of rare earth elements. This fundamental data will be used as the basis to guide and interpret the experimental studies in subsequent chapters.

-Chapter 4 describes an experimental study on leaching of rare earth elements from acid mine drainage precipitates. These results are used to assess the solubility and reactivity of REEs in this solid matrix as compared to other solid forms.

-Chapter 5 describes an experimental study on the selective precipitation of REEs from acid solutions. This data demonstrates how REEs can be recovered following acid leaching processes.

-Chapter 6 describes an experimental study on the natural leaching of REEs in coal refuse using the humidity cell testing procedure. Data from this study provides insights on the mineral forms that are leached during acid mine drainage formation and propagation.

-Chapter 7 summarizes the key findings from this work and provides recommendations for future work. 


\section{Literature Review}

\subsection{Extraction of Rare Earth Elements from Mineral Concentrates}

The conventional processing route for REEs involves physical beneficiation followed by hydrometallurgical processing (Figure 3). Physical beneficiation is often achieved a combination of magnetic, gravity, and flotation separations, with the resulting mineral concentrates typically assaying $>50 \%$ TREE (Jordens, 2003).After concentration, the mineral concentrates or ores are first exposed to acidic or basic leaching (Sadri, 2017). Since the leaching is often non-selective, other contaminant metals report to the leachate, which then requires additional purification processes prior to elemental separations. In the case of the REEs separation, the first purification step includes only a preliminary separation of metals into broad groups, i.e., light rare earth elements and heavy rare earth elements (Isshiki, 1996). Unfortunately, a specific element often cannot be separated from the elements composing these groups in a simple and economical way due to their very similar physicochemical properties. In addition, the uneven distribution of individual REEs composing common minerals further complicates the separation process (Florek, 2016).

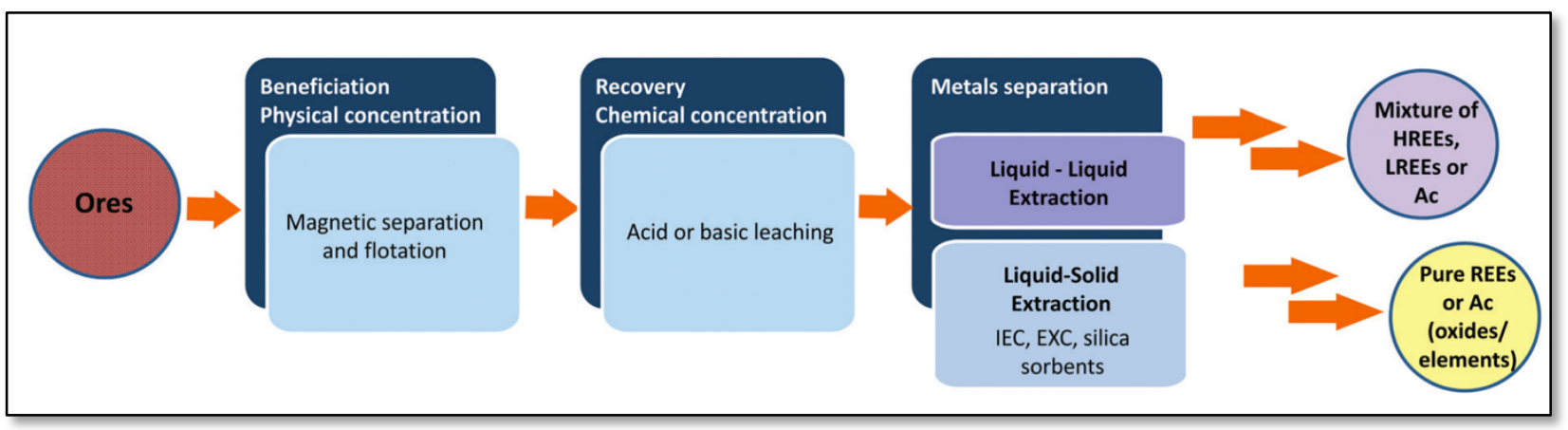

Figure 3. Simplified schematic representation of the REE extraction process.

Acid leaching is the main method to recover rare earth elements from different mineral ores in industry. Study on the recovery of rare earth elements from an apatite ore sample by using sulphuric acid leaching, solvent extraction, and precipitation processes showed that the most effective dissolutions of light REEs (>85\%) and heavy REEs (>89\%) from the apatite ore sample were achieved with a dilute sulphuric acid solution $\left(1 \mathrm{M} \mathrm{H}_{2} \mathrm{SO}_{4}\right)$ at a temperature of $20^{\circ} \mathrm{C}$ in an hour. The heavy REEs present in the pregnant leach solution were almost entirely extracted using 1.2 M di-(2-ethylhexyl) phosphoric acid (D2EHPA) as a cation exchanger, while the most light REEs remained in the raffinate. The heavy REEs loaded into the organic phase were stripped completely by $3 \mathrm{M} \mathrm{H}_{2} \mathrm{SO}_{4}$ solution. REEs remained in raffinate and stripped into the aqueous solution were precipitated as RE oxalates by the addition of $0.08 \mathrm{M}$ oxalic acid (Battsengel, 2018). Walawalkar investigated the acid leaching of rare earth elements from phosphogypsum using $\mathrm{HCl}, \mathrm{HNO}_{3}$, and $\mathrm{H}_{2} \mathrm{SO}_{4}$. His results indicated the optimal operation conditions are $1.5 \mathrm{M}, 80^{\circ} \mathrm{C}$ and solid-to-liquid ratio (S/L) of $1 / 8$ and 20 min residence time for all three acid, but the leaching efficiency using nitric and hydrochloric acids are higher than the sulfuric acid (Walawalkar, 2016). Moldoveanu used ammonium sulfate as a lixiviant in the 
recovery of rare earth elements (REE) from clays. His results showed the optimum leaching conditions, leading to $80-90 \%$ total REE extraction, required $\mathrm{pH}$ values in the range 3-4 and moderate temperatures $\left(<50^{\circ} \mathrm{C}\right)$ in order to avoid lanthanide precipitation/loss via hydrolysis (Moldoveanu, 2013). Tang conducted study on a two-stage hydrometallurgical process (alkali fusion-acid leaching) was developed to recover REEs from coal fly ash. Results indicated that the two-stage method was more efficient compared with direct leaching method. Optimum conditions of alkali fusion were $1: 1$ (mass ratio of $\mathrm{CFA} / \mathrm{Na}_{2} \mathrm{CO}_{3}$ ), heating in $860^{\circ} \mathrm{C}$ for $0.5 \mathrm{~h}$. The $72.78 \%$ leaching REEs efficiency can be obtained in the optimal operation conditions: leaching time (2 h), stirring speed (400 rpm), the $\mathrm{HCl}$ concentration ( $3 \mathrm{~mol} / \mathrm{L}$ ) and the solid-liquid ratio (1/20) (Tang, 2019).

In the past, various separation and concentration methods have been used to recover rare earth metals from aqueous solutions (see Figure 4). Currently, liquid-liquid extraction (or solvent extraction) is the most common approach due to its high selectivity and capacity (Xie, 2014). However, in order to obtain high purity fractions of REEs required for industrial applications, multiple sequential extraction steps are required in either a continuous or a batch system. The number of separation steps increases with the requirement in purity of each element produced. Pure REE oxides are generally obtained after liquid-liquid extraction by calcination of oxalate salts obtained after precipitation of the dissolved REEs in the concentrated solution (Jorjani, 2016). Finally, pure metallic forms can be prepared by either molten salt electrolysis or metallothermic reduction (Habashi, 2013).

The liquid-liquid extraction in industry uses the extractants contained mostly oxygen, nitrogen, sulfur and/or phosphorus atoms (Xie F. , 2014). Among the different ligands reported in the literature, a large portion are carboxylic-based ligands (such as ethylenediamine- tetraacetic acid, EDTA, and its derivatives), sulfoxide derivatives (RR'SO), quaternary ammonium salts (usually in the presence of chelating agents like EDTA and diethylenetri- aminepentaacetic acid (DTPA)), amines, amides (diglycolamide- type ligands, DGA or malonamide, MA), organophosphoric analogues, such as 2-ethylhexyl phosphoric acid (HDEHP), TBP, and calixarenes, pillararenes or tripodal framework-based ligands (Florek, 2016). The choice of the extracting medium depends not only on the extraction affinity of the ligand, its separation factors and its solubility, but also on the economic costs (Fray, 2000). Unfortunately, such multiple sequential extractions in industry generate significant amount of waste which are not environmentally friendly (Vahidi, 2017). Moreover, many of the extractants used in liquid-liquid extraction (i.e., cationic, anionic or neutral exchangers) counter the problems of slow extraction kinetics, low solubility in aliphatic diluents, degraded performances under acidic conditions or a lack of reusability rendering the liquid-liquid extraction procedures, despite being relatively straightforward, solvent- and time-consuming while producing large amounts of environmentally harmful wastes (Vahidi, 2016).

Nasab found that Cyanex 272 could separate thorium and rare elements more efficiently compared with the conventional process (TBP) by solvent extraction.As a result, thorium was extracted selectively from $0.5 \mathrm{M}$ nitric acid solution of Zarigan ore with the extraction efficiency of $83 \%$. Also, yttrium was separated from lanthanides by synergistic mixture containing Cyanex272 and TBP (Nasab, 2011). 


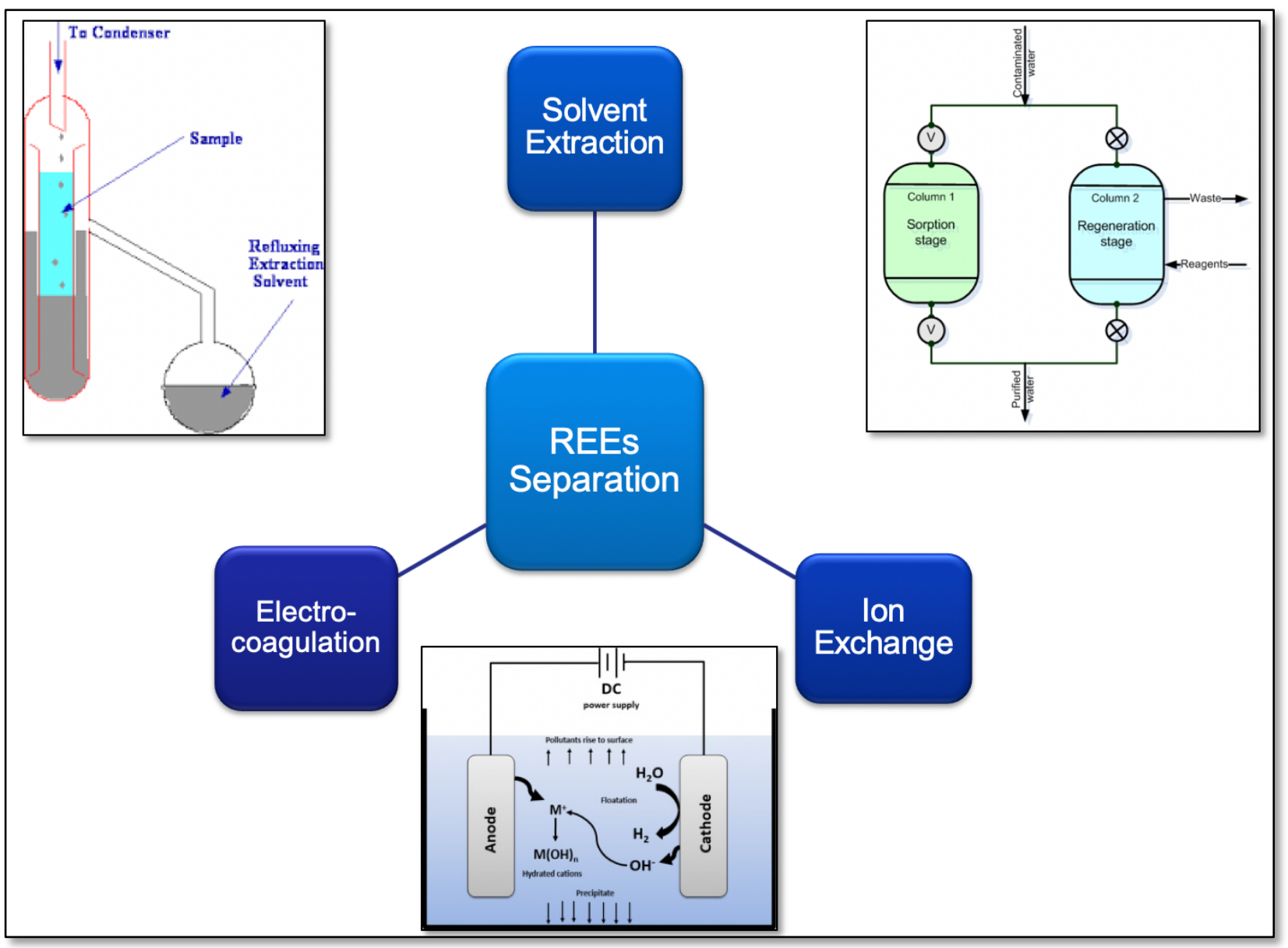

Figure 4. Conventional and Novel REEs separation methods.

A more environmentally-friendly extraction/pre-concentration procedure are expected to be discovered from the liquid-solid extraction perspective, other than liquid-liquid extraction and etc (Harmer, 2001). In industry, the most common alternatives used for the separation/purification steps are ion-exchange and extraction chromatographic-based resins, which have an insoluble polymer matrix with cross-linked polystyrene (Rozelle, 2016). Normally, a variety of functional groups can be introduced either by co-condensation of functional monomers or by physical mixture of different polymers. Most of the sorbents used for the extraction/separation steps are based on the physical addition (impregnation) of the ligands to the solid support, which in turn often results in leaching problems, limiting the lifetime of the extraction resins (Pahan, 2019). Moreover, as a result of stripping of the extractant, diminishing extraction performances are often observed. In contrast, ion-exchanged resins offer good separation capacity and reusability, but poor elemental selectivity for further separation (Abreu, 2014). To overcome these limitations, the development of new extraction strategies, such as solid-liquid extraction, has emerged over the past few years. Particularly the solidliquid extraction approach usually provides faster reaction kinetics, greater separation factors 
and better reusability than its liquid-liquid extraction counterpart. These inherent benefits could eventually reduce the operation costs and environmental footprints (Hidayah, 2018).

Therefore, the environmental-friendly and cost-efficient purification sorbents that will benefit the industry by mitigating environmental concerns should be developed. Such mesoporous materials with very attractive properties as solid-phase chromatographic supports are getting popular (Lim, 1999). First, these materials have a remarkably high specific surface area contributing higher contact efficiency, better adsorption capacity and less extraction time (Matsumoto, 2014). In addition, with the chemical anchoring of the ligand on the pore surface through covalent bonds, the thus-synthesized porous sorbents show greater regenerative capacities, ultimately increasing their commercial potential (Diagboya, 2018).

Pinat (Pin, 1997) reported that a transuranic-element specific extraction chromatographic material, provided a simple and rapid method for the separation of the LREE, Th and $U$ from $\mathrm{HNO}_{3}$ solutions of silicate rock with reducing separation times by ca. $50 \%$ compared to conventional techniques. Only $\mathrm{Fe}^{3+}$ was found to have detrimental effects on the LREE yields. For iron-rich samples, this troublesome interference was overcome by pretreatment on a short cation exchange column. The methods described in this work isolate the elements of interest in a high degree of purity, as required for thermal ionization mass spectrometric analyses, with good yields and desired blank levels for ICP-MS analysis.

\subsection{Acid Mine Drainage (AMD)}

Acid mine drainage (AMD) is a longstanding environmental issue resulting from the acidic outflow of discharge water from mine sites (Skousen J. G., 2005) (Figure 5). This acid is primarily generated from oxidation of iron sulfide that associates with various host rocks (Akcil, 2006). As the major problem for most rock type mines, acid mine drainage presents in almost all mines including gold, copper, and nickel where the metal ore is bounding with sulfur (Singh, 1987). Coal mines with higher sulfur content also suffer from acid mine drainage (Gazea, 1996). 


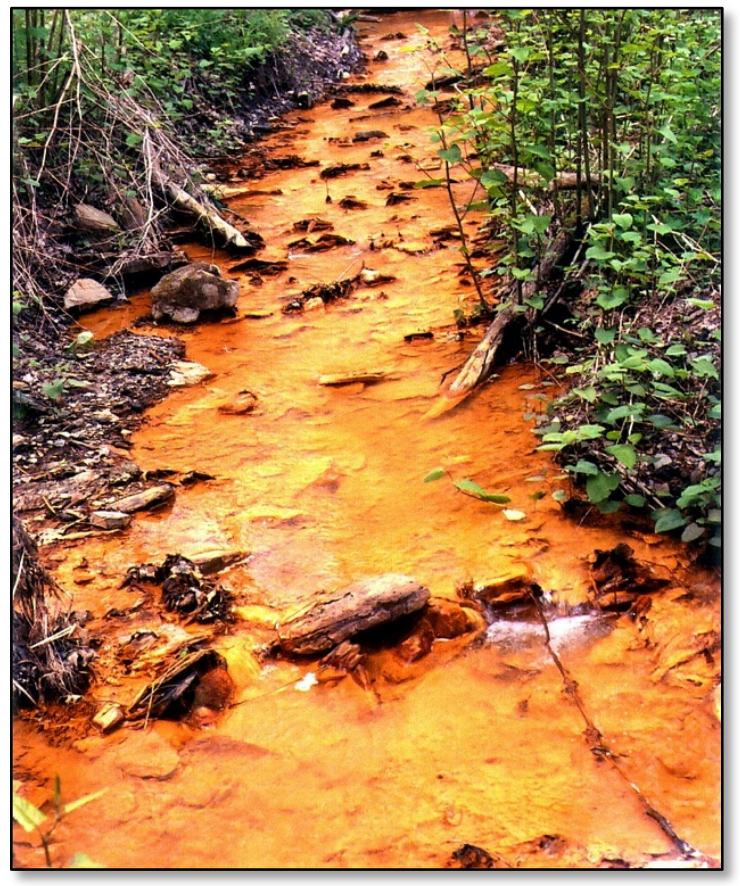

Figure 5. Example of acid mine drainage (Fourie, 2018).

Normally, the acid mine drainage has significant amount of dissolved metals that damage the downstream waters, as well as the surrounding biosystem (Johnson, 2005). Although mining is by far the major cause of this type of acidic waste, the process can also occur during nonmining land disturbances such as construction, or even naturally in some environments, in the form of acid rock drainage (ARD) (Nordstrom, 2009). Pyrite is one of the most important sulfides found in the waste rock of mines. When exposed to water and oxygen, it can react to form sulfuric acid $\left(\mathrm{H}_{2} \mathrm{SO}_{4}\right)$. The following oxidation and reduction reactions express the breakdown of pyrite that leads to acid mine drainage (COTF, 2004).

1. $2 \mathrm{FeS}_{2}+7 \mathrm{O}_{2}+2 \mathrm{H}_{2} \mathrm{O}->2 \mathrm{FeSO}_{4}+2 \mathrm{H}_{2} \mathrm{SO}_{4}$

2. $2 \mathrm{Fe}^{2+}+1 / 2 \mathrm{O}_{2}+2 \mathrm{H}^{+}->2 \mathrm{Fe}^{3+}+\mathrm{H}_{2} \mathrm{O}$

3. $\mathrm{Fe}^{3+}+3 \mathrm{H}_{2} \mathrm{O}->\mathrm{Fe}(\mathrm{OH})_{3}+3 \mathrm{H}^{+}$

4. $\mathrm{FeS}_{2}(\mathrm{~s})+15 / 4 \mathrm{O}_{2}+7 / 2 \mathrm{H}_{2} \mathrm{O}<-->4 \mathrm{H}^{+}+2 \mathrm{SO}_{4}^{-}+\mathrm{Fe}(\mathrm{OH})_{3}(\mathrm{~s})$

Acid mine drainage is a worldwide problem (Skousen J. , 2017), impacting human water sources by sulfuric acid and heavy metals generated during mining, such as arsenic, copper, and lead. Once sulfur bearing rock is crushed and exposed to oxygen and water, it is very hard to stop the acid generation until the available sulfide minerals are exhausted. For example, the Roman-era mines are still producing acid mine drainage. Due to its long hazard cycle and tremendous volume, acid mine drainage is a very serious and persistent issue (Jurkovic, 2014).

Those valuable metals such as copper, gold, lead, silver, zinc always coexist with iron sulfide in the ores. Ordinarily, these potentially toxic ores exist abundantly underground and are nonharmful. They are isolated deeply underground from the atmosphere and surface water 
leaving relatively little surface area for them to react with water and oxygen. Acid generation in these buried deposits occurs at a slow and usually harmless rate. Extracting the valuable metals from these rocks, however, makes the ore more chemically available for acid-forming reactions (Shokes, 1999).

When iron sulfide is exposed to air or dissolved oxygen in water, the sulfide oxidizes then turns to sulfuric acid. Sulfuric acid is a highly corrosive chemical, used in many industrial processes as well as in car batteries. It is also one of the primary constituents in acid rain and is toxic to most living organisms (Mitsch, 1998). The sulfuric acid produced in sulfide mine tailings makes the surrounding water more acidic. For instance, the Iron Mountain Mine in California contains water with a pH as low as -3.6 (Nordstrom, 2000), which is about 1000 times more acidic than battery acid. In addition to the direct effects of this acidity, acid water leaches toxic heavy metals such as lead and arsenic from the surrounding rocks into the water (Luís, 2009).

The mining process allows these acid and heavy metal generating reactions to occur at much higher rates than observed in nature. Metal mining produces waste rock and mine tailings with a surface area that is vastly greater than the undisturbed rock. Extracting valuable metals from ore usually involves crushing the ore rock into a mud slurry, where each particle can be less than 50 microns. This increases the surface area of the sulfide rock by a factor of 100,000 or more, which proportionally increases the rate of acid formation (Kleinmann, 1981).

Theoretically, acid formation is neutralized where sulfide ores occur alongside more alkali minerals, since alkali is the opposite of acidic. Limestone is a typical basic mineral sometimes associated with sulfides (Watten, 2005). Where acid and alkali minerals co-occur, the ratio of acid-generating material to neutralizing material is an important component of predicting whether a mine will have acid mine drainage. For example, metal at the historic Kennecott Copper Mine in Alaska was found in conjunction with large amounts of carbonate that neutralized any acid-forming compounds (Simate, 2014).

Acid mine drainage is often encouraged by a biological feedback loop (Gibert, 2004). Once acid mine drainage starts, certain microbes thrive in the acidic environment. These microbes increase the production of sulfuric acid from the surrounding rock, further poisoning the downstream environment for other organisms (Baker, 2003). This feedback loop is an important component in the most severe cases of acid mine drainage (Natarajan, 2008).

Therefore, AMD treatment and control becomes very important. Researcher found that three of the most important factors to control AMD are: overburden geochemistry, method and precision of overburden handling and placement in the backfill during reclamation, and the postmining hydrology of the site (Skousen J. G., 1995). Some studies showed significant effective way to control and treat AMD targeting these three factors. Siriwardane performed a study of the use of fluidized-bed combustion ash in an underground coal mine for control of acid mine drainage and subsidence. His results show that a grout made of fluidized-bed combustion ash can be successfully placed in a mine cavity by hydraulic backfilling in order to reduce the problems caused by subsidence and acid mine drainage (Siriwardane, 2003). Skousen showed that the passive systems can provide long-term, efficient, and effective treatment for many acid mine drainage (AMD) sources (Skousen J. , 2017). In Simmons' study 
(Simmons, 2002), steel slag leach beds were used for the treatment of acid mine drainage. Results indicated that the slag was very effective at neutralizing acidity. The treated water is still net alkaline and has a neutral $\mathrm{pH}$ after it encounters several other acidic seeps downstream.

\subsection{Rare Earth Elements in Acid Mine Drainage}

Several prior authors have noted the existence of REEs in AMD. In Zhao's study (Zhao, 2007) the concentrations of $\mathrm{SO}_{4}{ }^{2-}$ was shown to affect the concentrations of REEs in AMD samples from the Sitai coal mine. Higher concentrations of $\mathrm{SO}_{4}{ }^{2-}$ contribute to the formation of stable $\mathrm{LnSO}_{4}{ }^{+}$, thereby increased the REEs enrichment in AMD samples whose $\mathrm{pH}$ range from 3.5 to 7.7. The concentrations of $\mathrm{Fe}, \mathrm{Al}, \mathrm{Mn}$ and $\mathrm{SO}_{4}{ }^{2-}$ in $\mathrm{AMD}$ samples decrease with increases in $\mathrm{pH}$, implying the occurrences of coagulation and precipitation of Fe-Al-Mn oxide/ hydroxide colloids. It also indicates that REE sulfate complexes $\left(\mathrm{LnSO}_{4}{ }^{+}\right)$are possibly adsorbed onto the $\mathrm{Fe}-\mathrm{Al}-\mathrm{Mn}$ oxide/hydroxide colloids and then co-precipitate with them, thereby resulting in the REEs removal from AMD samples with the $\mathrm{pH}$ increase, especially at $\mathrm{pH}=6.76$. Compared with the AMD samples at $\mathrm{pH}=6.76$, the Shili River sample at $\mathrm{pH}=7.76$ has a lower concentration of $\mathrm{SO}_{4}{ }^{2-}$, as well as a lower REEs concentration. Also, the REEs concentration in AMDp sample with higher S/Fe ratios is higher than the one with lower S/Fe ratios which implies again that $\mathrm{SO}_{4}{ }^{2-}$ influences the REEs concentrations in AMD precipitates.

Anja also reported that the mobility of REE strongly depends on chemical conditions (Cánovas, 2018). With increasing $\mathrm{pH}$, they partition from aqueous to solid phase and become enriched e.g. in secondary Fe (hydr)oxides (Bau, 1999), whereas the complexation in solution is important for fractionation. Sorption studies showed that HREEs are complexed with carbonate, while LREEs are preferentially sorbed to ferric oxides (Quinn, 2006). Since the AMD $\mathrm{pH}$ is lower than 7 , and due to the carbonate equilibrium, there is no carbonate ion at a $\mathrm{pH}$ less than 8 (see Figure 6). Therefore, in AMD, there are less carbonate ligands and sulfate complexes dominate; HREEs are also sorbed to Fe oxides (Verplanck, 2004).

The processes that control the REEs partitioning from aqueous to solid phase could be the precipitation of REEs-bearing phases and/or sorption onto Fe and Al precipitates. Although water is supersaturated in some trace minerals, such as phosphates, the sorption mechanism has never been detected in previous studies (Gammonsa, 2005). Therefore, most authors point to sorption as the process accounting for REEs scavenging from AMD (Verplanck, 2004). No experimental sorption studies of REEs into AMD till this study of REEs recovery from AMDp. 


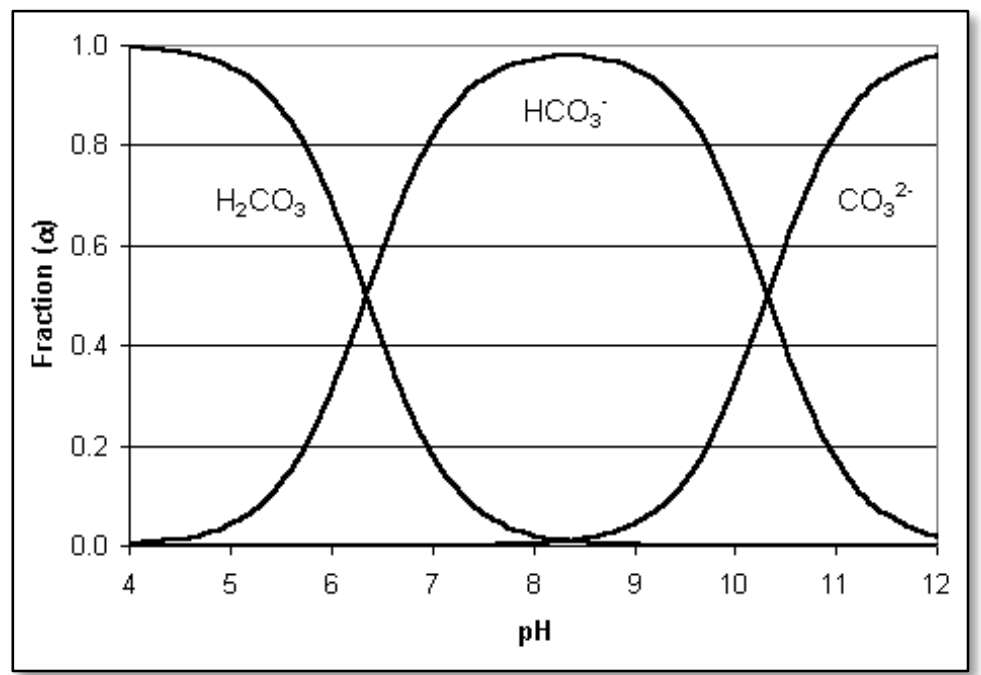

Figure 6. Carbonate equilibrium as a function of $\mathrm{pH}$ (USU, 2004).

Other studies showed that Fe has the same effect as pH on REEs behavior. Bau (Bau, 1999) carried the study of scavenging of dissolved rare earths and yttrium (REY) by precipitating Fe oxyhydroxides in the $\mathrm{pH}$ range from 3.6 to 6.2 in a REY- and Fe-bearing matrix of $0.01 \mathrm{M} \mathrm{HCl}$ and in acidified natural Fe and Al-rich water from Nishiki-numa spring, Hokkaido, Japan.

Fractionation of $\mathrm{Y}$ from REE occurred in all experiments, and at $\mathrm{pH} \leq 5 \mathrm{Ce}$ was precipitated from the synthetic solutions with Fe oxyhydroxide. Moreover, at $\mathrm{pH} \geq 5$ patterns of apparent REY distribution coefficients, REY between Fe oxyhydroxide and solution display the M-type lanthanide tetrad effect, and indicate anomalous behavior of La, Gd, and possibly Lu. Compared to the other REY, these elements show a significantly lower affinity for the Fe oxyhydroxide. This fractionation of non-redox-sensitive REY cannot be explained by differences between their ionic radii and is additional evidence that the electron structure exerts a strong control on REY behavior in aqueous environments. Cerium (III) oxidation rates determined from a time-series experiment decrease significantly during the first minutes after particle formation, suggesting that the $\mathrm{Ce}$ (III) oxidizing capacity of Fe oxyhydroxide-precipitating systems is considerably higher than that of systems in which dissolved REEs interact with preformed Fe oxyhydroxides (Bau, 1999).

Vass conducted the regional survey of rare earth elements in acid mine drainage where the Northern Appalachian (NAPP) and Central Appalachian samples were compared. The results showed that the difference in REE content between these two basins was not significant. However, the NAPP AMD samples were significantly enriched in Sc when compared to the CAPP AMD samples (see Table 2) (Vass C. R., 2019b). While NAPP samples were significantly enriched in $\mathrm{Al}, \mathrm{Fe}, \mathrm{Mg}, \mathrm{Na}, \mathrm{Si}$, and $\mathrm{SO}_{4}$ due to its marine origin formation. Vass (Vass C. R., 2019a) also reported that the $\mathrm{pH}$ value affected the REEs concentration in raw AMD. When the $\mathrm{pH}$ increased, the total REEs concentration decreased. Also, his study confirmed that REEs were first leached from the coal bed and its surroundings over a long time, then enriched into AMDp as a treatment byproduct. 
Table 2. REE concentrations for raw aqueous AMD influent in Appalachian basin study (after Vass et al., 2019b)

\begin{tabular}{|c|c|c|c|c|c|c|c|c|}
\hline \multirow[b]{3}{*}{ Element } & \multicolumn{3}{|c|}{ CAPP AMD $(\mathrm{N}=52)$} & \multicolumn{3}{|c|}{ NAPP AMD (N=133) } & \multirow{2}{*}{\multicolumn{2}{|c|}{ CAPP vs. NAPP 1}} \\
\hline & & Confidence & Cl:Mean & & Confidence & Cl:Mean & & \\
\hline & Mean & Interval & Ratio & Mean & Interval & Ratio & $p$ value & $<\partial ?$ \\
\hline \multicolumn{9}{|l|}{ REE(ug/L) } \\
\hline Sc & 3.09 & 1.11 & 0.36 & 6.38 & 1.56 & 0.25 & 0.01 & yes \\
\hline Y & 49.69 & 20.38 & 0.41 & 81.08 & 24.17 & 0.3 & 0.13 & \\
\hline La & 26.82 & 15.08 & 0.56 & 21.21 & 6.76 & 0.32 & 0.44 & \\
\hline $\mathrm{Ce}$ & 53.66 & 27.43 & 0.51 & 63.57 & 19.29 & 0.3 & 0.58 & \\
\hline $\operatorname{Pr}$ & 8.03 & 3.92 & 0.49 & 9.85 & 2.84 & 0.29 & 0.49 & \\
\hline $\mathrm{Nd}$ & 37.22 & 17.06 & 0.46 & 46.12 & 13.29 & 0.29 & 0.46 & \\
\hline Sm & 9.7 & 4.01 & 0.41 & 13.33 & 3.61 & 0.27 & 0.26 & \\
\hline $\mathrm{Eu}$ & 2.64 & 0.98 & 0.37 & 3.8 & 1.03 & 0.27 & 0.19 & \\
\hline Gd & 12.39 & 4.92 & 0.4 & 18.66 & 5.22 & 0.28 & 0.16 & \\
\hline $\mathrm{Tb}$ & 1.95 & 0.71 & 0.36 & 3.15 & 0.84 & 0.27 & 0.09 & \\
\hline Dy & 10.57 & 4.28 & 0.4 & 17.06 & 4.83 & 0.28 & 0.12 & \\
\hline Ho & 1.95 & 0.73 & 0.37 & 3.31 & 0.9 & 0.27 & 0.08 & \\
\hline $\mathrm{Er}$ & 4.99 & 2.08 & 0.42 & 8.34 & 2.42 & 0.29 & 0.11 & \\
\hline $\mathrm{Tm}$ & 0.81 & 0.24 & 0.3 & 1.29 & 0.3 & 0.23 & 0.06 & \\
\hline $\mathrm{Yb}$ & 3.89 & 1.57 & 0.4 & 6.4 & 1.81 & 0.28 & 0.11 & \\
\hline Lu & 0.71 & 0.21 & 0.29 & 1.08 & 0.25 & 0.23 & 0.08 & \\
\hline TREE & 228.14 & & & 304.67 & & & 0.32 & \\
\hline HREE/TREE & $39.50 \%$ & & & $48.20 \%$ & & & & \\
\hline CREE/TREE & $44.70 \%$ & & & $49.60 \%$ & & & & \\
\hline \multicolumn{9}{|c|}{ Major Ions (mg/L) } \\
\hline $\mathrm{Al}$ & 12.99 & 5.18 & 0.4 & 23.14 & 4.86 & 0.21 & 0.02 & yes \\
\hline $\mathrm{Ca}$ & 167.95 & 27.18 & 0.16 & 177.47 & 22.77 & 0.13 & 0.64 & \\
\hline $\mathrm{Fe}$ & 22.37 & 14.57 & 0.65 & 60.07 & 22.32 & 0.37 & 0.04 & yes \\
\hline Mg & 123.84 & 26.96 & 0.22 & 75.82 & 10.79 & 0.14 & 0 & yes \\
\hline $\mathrm{Mn}$ & 10.74 & 3.36 & 0.31 & 9.49 & 2.44 & 0.26 & 0.58 & \\
\hline $\mathrm{Na}$ & 36.72 & 18.74 & 0.51 & 523.52 & 187.96 & 0.36 & 0 & yes \\
\hline $\mathrm{Si}$ & 10.98 & 2.25 & 0.21 & 14.28 & 1.66 & 0.12 & 0.03 & yes \\
\hline $\mathrm{Cl}$ & 5.3 & 2.92 & 0.55 & 306.42 & 242.47 & 0.79 & 0.12 & \\
\hline $\mathrm{SO}_{4}$ & 1090.94 & 196.48 & 0.18 & 1717.29 & 340.54 & 0.2 & 0.03 & yes \\
\hline
\end{tabular}

1: $p$ value as determined by two-tailed, equal variance t-test, a value of 0.05 used for significance

\subsection{Characterization Methods}

Technical studies on REE materials often employ one or more advanced characterization methods to resolve the morphology, composition and crystalline structure of the REEcontaining materials. Some of the major analytical instruments are described in further detail below. 


\subsubsection{SEM}

A scanning electron microscope (SEM) is a type of electron microscope that produces images of a sample by scanning the surface with a focused beam of electrons. The electrons interact with atoms in the sample, producing various signals that contain information about the surface topography and composition of the sample. The electron beam is scanned in a raster scan pattern, and the position of the beam is combined with the detected signal to produce an image. SEM can achieve resolution better than 1 nanometer.

Scanning electron microscopy (SEM) combined with a suitable software package for acquisition of backscatter electron and X-ray signals, phase assignment and image analysis is one of the most efficient tools for quantitative REEs mineralogy.

Study of rare earth elements on the physical and mechanical properties of different martials had been done by applying SEM. Guo's (2008) study showed that appropriate addition of rare earth elements $(\mathrm{Re})$ can effectively improve the physical properties determined by SEM images.

$\mathrm{Yu}$ (2004) found that with the addition of trace rare earth (RE) elements the tensile strength and elongation of the lead-free solder alloys were improved by analyzing SEM images, indicating that adding trace rare earth elements was an efficient way to develop new solders. Cheng (2003) applied SEM-EDX on the investigation of effect of rare earth elements (RE) on erosion resistance of nitrided $40 \mathrm{Cr}$ steel.

Study had shown that the image analysis approach, using the electron microscope for mineralogical studies, has significant potential as a supplement to optical microscopy in quantitative coal characterization (Creelman, 1996).

SEM was also used to investigate extensive mineralogical characterization of iron ore in order to develop downstream processing routines for iron ore and to understand the behavior of the ore during processing. SEM systems can provide much more detailed information on the gangue minerals (Donskoi, 2013).

\subsubsection{TEM}

Transmission electron microscopy (TEM, also sometimes conventional transmission electron microscopy or CTEM) is a microscopy technique in which a beam of electrons is transmitted through a specimen to form an image. The specimen is most often an ultrathin section less than $100 \mathrm{~nm}$ thick or a suspension on a grid. An image is formed from the interaction of the electrons with the sample as the beam is transmitted through the specimen. The image is then magnified and focused onto an imaging device, such as a fluorescent screen, a layer of photographic film.

Versatile materials like metal-organic frameworks require careful characterization. Transmission electron microscopy is a very powerful method that can address a multitude of investigative challenges. TEM studies yielded valuable insights into the investigated MOFs to illustrate the potential of TEM despite the sensitivity of MOFs to the electron beam (Wiktor, 2017). 
Transmission electron microscopy can be applied to several aspects of coal chemistry. First, examination can be made of the structure and characteristics of the mineral constituents. Second, the concentration and distribution of organic elements can be determined. These techniques are closely related to methods by which materials scientists have examined alloys and ceramic materials for many years (Wert, 1987).

Many studies related to the rare earth elements in material science have been done by using TEM. Wang applied TEM on discovering the photoluminescence properties of rare earth ions in the TiO2 host nanofibers (Wang H. , 2009). Effect of rare earth elements on the microstructures and properties of a low expansion superalloy was examined by TEM in Wang's study (Wang R. , 2000). Moghadam investigated the effects of $\mathrm{Ce}$, La and activation conditions on sorption characteristics of $\mathrm{Zr}$-Co sintered porous getters by TEM (Moghadam, 2015). TEM was also used to characterize the microstructural features in some 1: 5 and 2:17 RECo magnets (Mishra, 1978).

\subsubsection{ICP-MS}

Inductively coupled plasma mass spectrometry (ICP-MS) is a type of mass spectrometry which is capable of detecting metals and several non-metals at concentrations as low as one part in 1015 (part per quadrillion, ppq) on non-interfered low-background isotopes. This is achieved by ionizing the sample with inductively coupled plasma and then using a mass spectrometer to separate and quantify those ions. It is the most popular method today for the REEs concentration determination.

The data for the elements: $\mathrm{Li}, \mathrm{Cs}, \mathrm{Rb}, \mathrm{Sr}, \mathrm{Ba}, \mathrm{Zr}, \mathrm{Hf}, \mathrm{Nb}, \mathrm{Ta}, \mathrm{Y}, \mathrm{Sc}, \mathrm{U}, \mathrm{Th}, \mathrm{Pb}$ and all 14 of the REE was reported in Jenner's study (Jenner, 1990). In addition, the procedure acquired data for Be, Mo, W, Ti and Bi. Many elements in this array are crucial for the evaluation of petrogenetic models and source tracing which showed real power of ICP-MS by applying one technique, one dissolution, small sample size, good limits of detection, good to excellent accuracy and good precision for many geochemically important elements (McLaren, 1990).

Rare earth elements in seawater were preconcentrated 20-fold (from 50 to $2.5 \mathrm{ml}$ ) by a chelating resin-packed mini-column device and determined by inductively coupled plasma mass spectrometry (ICP-MS). With the data obtained from ICP-MS, the recoveries for REEs were able to be calculated which were in the range from $90 \%$ for Eu and Dy to $98 \%$ for $\mathrm{Yb}$, and their standard deviations were less than $4 \%$ (Zhu, 2004).

Zhang obtained vertical profiles of yttrium and all the rare earth elements (REEs) in seawater by using inductively coupled plasma mass spectrometry (ICP-MS). Based on the data, the interREE(III) relationships were analyzed. The results showed that REE(III)s heavier than Dy and particularly close neighbors show strong coherencies in their oceanic behavior (Zhang J. , 1996).

The effect of ICP-MS instrumental parameters on the determination of the rare earth elements was studied with a commercial inductively coupled plasma-mass spectrometer. Parameters included variations in ion-lens settings, nebulizer argon flow rate, rf power, distance from load coil to sampler and changes in design of the sampler and skimmer. Results showed that these parameters resulted in varying formation of detected oxide ions (Longerich, 1987). 


\subsubsection{XRD}

X-ray diffraction (XRD) is one of the most important non-destructive tools to analyze all kinds of matter-ranging from fluids, to powders and crystals. From research to production and engineering, XRD is an indispensable method for materials characterization and quality control. Rigaku has developed a range of X-ray diffractometers, in co-operation with academic and industrial users, which provide the most technically advanced, versatile and cost-effective diffraction solutions available today.

X-ray powder diffraction is most widely used for the identification of unknown crystalline materials (e.g. minerals, inorganic compounds). Determination of unknown solids is critical to studies in geology, environmental science, material science, engineering and biology. Other applications include characterization of crystalline materials, identification of fine-grained minerals such as clays and mixed layer clays that are difficult to determine optically, determination of unit cell dimensions and measurement of sample purity.

Study showed that XRD analysis provided quantitative mineral evaluation of clayey soils that was an essential step to provide the reliable soil recognition and behavior (Ouhadi, 2003). In Dunn's study the XRD technique presented an effective alternative to traditional methods for determining modal mineral abundances, such as optical point counting and electron microprobe phase (EMP) mapping (Dunn, 2009). Parian combined element-to-mineral conversion by using quantitative XRD with Rietveld refinement that not only delivered the required turnover for geometallurgy, but also overcame the shortcomings if quantitative X-ray diffraction or element-to-mineral is used alone (Parian, 2015). Wu's study applied XRD and SEM on the analysis of mineral composition and microstructure of gravel aggregate that provided information on aggregate morphology characteristics and chemical composition.

\subsection{REEs Solubility and Aqueous Stability}

In order to understand and simulate the REEs behavior in different aqueous system, Eh-pH diagrams are applied by many researchers.

\subsubsection{REEs Solubility}

Solubility is a chemical property referring to the ability for a given substance, the solute, to dissolve in a solvent. It is measured in terms of the maximum amount of solute dissolved in a solvent at equilibrium. The resulting solution is called a saturated solution. Certain substances are soluble in all proportions with a given solvent, such as ethanol in water. This property is known as miscibility. Under various conditions, the equilibrium solubility can be exceeded to give a so-called supersaturated solution, which is metastable. The solvent is often solid, which can be a pure substance or a mixture. The species that dissolves, the solute, can be a gas, another liquid, or a solid (Tack, 1996).

Solubilities range widely, from infinitely soluble such as ethanol in water, to poorly soluble, such as silver chloride in water. The study of REEs solubility in the aquatic system is very helpful for understanding the REEs behaviors in aquatic system (Dyer, 2006). 
In Cetiner's study, the solubilities of end-member La (III)-, Nd(III)-, Sm(III)-, and Y(III)phosphates were determined at 23 and $50^{\circ} \mathrm{C}$ in $\mathrm{NaCl}-\mathrm{HCl}$ and $\mathrm{NaClO}_{4}-\mathrm{HClO}_{4}$ solutions with $\mathrm{pH}_{\mathrm{m}}$ from 0 to 2 and ionic strengths of $0.1,0.5,1.0$, and $5.0 \mathrm{~m}$. The solubility of $\mathrm{Nd}$ (III)-phosphate was also determined in chloride solutions at $150^{\circ} \mathrm{C}$ (Cetiner, 2005). The La (III)- and Nd(III)phosphates had the monazite structure, and Sm(III)-phosphate and Y(III)- phosphate had the rhabdophane and xenotime structures, respectively. The dependence of solubility on $\mathrm{pH}$ and chloride concentration, together with data from the literature, indicated that $\mathrm{H}_{3} \mathrm{PO}_{4}$ and $\mathrm{Ln}^{3+}$ were the predominant species in his experimental solutions. At each ionic strength and temperature investigated, conditional equilibrium constants $\left(Q_{s 3}\right)$ were determined for reactions of the following type: $\mathrm{LnPO}_{4}+3 \mathrm{H}^{+} \leftrightarrow \mathrm{Ln}^{3+}+\mathrm{H}_{3} \mathrm{PO}_{4}{ }^{0}$.

Lokshin (2005) studied the solubility of hydrated lanthanum, cerium, and neodymium orthophosphates in 1-5 M nitric acid solutions, which found that for the targeted REE increased with the $\mathrm{HNO}_{3}$ concentration reached a concentration of 70-100ppm (in terms of oxides) at $20^{\circ} \mathrm{C}$. The solubility varied in the order $\mathrm{Ce} \approx \mathrm{Nd}>\mathrm{La}$; however, the solubility of hydrated lanthanum orthophosphate at $100^{\circ} \mathrm{C}$ significantly exceeded that of hydrated neodymium orthophosphate. To recovery the REEs concentrated in phosphogypsum and phosphosemihydrate formed from apatite in phosphoric acid, the most promising method is their leaching-out with sulfuric acid.

It has been found that the solubility of yttrium, lanthanum, and cerium hydrophosphates in a 2$10 \%$ sulfuric acid solution mixed with $2.76 \mathrm{ppm} \mathrm{H}_{3} \mathrm{PO}_{4}$ increases with the $\mathrm{H}_{2} \mathrm{SO}_{4}$ concentration, to reach values of $11.8,11.1$, and $10.7 \mathrm{ppm}$, respectively (in terms of $\mathrm{Ln} 2 \mathrm{O} 3$ ). In a $2 \% \mathrm{H}_{2} \mathrm{SO}_{4}$ solution, their solubility decreased by a factor of 1.8-2.0 as the $\mathrm{H}_{3} \mathrm{PO}_{4}$ concentration was raised from 0 to $14 \mathrm{ppm}$.

Lokshin determined the solubility of $\mathrm{YPO}_{4} \cdot 2 \mathrm{H}_{2} \mathrm{O}, \mathrm{LaPO}_{4} \cdot 1.5 \mathrm{H}_{2} \mathrm{O}, \mathrm{CePO}_{4} \cdot 1.5 \mathrm{H}_{2} \mathrm{O}$, and $\mathrm{NdPO}_{4} \cdot \mathrm{H}_{2} \mathrm{O}$ at room temperature depends on the concentration of sulfuric (Lokshin, 2005). He found that as the concentration of sulfuric acid is raised, the solubility of the hydrated lanthanide phosphates studied first increases and then drops. Also, the solubility of the hydrated lanthanide phosphates in his study in sulfuric-phosphoric acid solutions is sufficiently high and does not limit the accumulation of lanthanides in sulfuric-phosphoric acid solutions for leaching of phosphogypsum at the sulfuric acid concentrations used in his study.

\subsubsection{Eh-pH Diagrams Background}

Eh-pH diagrams are also known as Pourbaix Diagrams, after the author of the famous Pourbaix diagram handbook. The basic concept of these diagrams presents a chemical system consisting of one element and a water solution, for example, the $\mathrm{Fe}-\mathrm{H}_{2} \mathrm{O}$ system. Normally several types of species, such as dissolved ions, condensed oxides by combustion, hydroxides, oxides, etc. exist in one system. The Eh- $\mathrm{pH}$ diagram shows the stability areas of these species in the redox potential-pH coordinates (Brookins D. G., 1988).

Usually, the redox potential axis is based on the Standard Hydrogen Electrode (SHE) scale designated Eh, but other scales can also be used, which represents the ability of redox potential to change electrons. The system tends to remove electrons from the species when the potential 
is high ( $\mathrm{E}>0)$. These conditions may exist near the anode in an electrochemical cell but can also be generated with some oxidizing agents $\left(\mathrm{Cu}+\mathrm{H}_{2} \mathrm{O}_{2}=\mathrm{CuO}+\mathrm{H}_{2} \mathrm{O}\right)$. In reducing conditions, when the potential is low $(E<0)$, the system is able to supply electrons to the species, for example, with a cathode electrode or with some reducing agents.

The $\mathrm{pH}$ of the system describes its ability to supply protons $(\mathrm{H}(+\mathrm{a}))$ to the species. When $\mathrm{pH}<7$, the concentration of protons is high and when $\mathrm{pH}>7$ the concentration of protons is low.

Usually, an aqueous system is consisted of various different species simultaneously in fixed Eh $\mathrm{pH}$ conditions. The Eh-pH diagrams simplify this complicated situation a lot by presenting only the predominant species whose content is highest in each stability area. The lines in the diagrams represent the Eh- $\mathrm{pH}$ conditions where the content of the adjacent species is the same in the equilibrium state. However, these species always exist in small amounts on both sides of these lines which may affect the practical applications. The lines in the diagrams can also be represented with chemical reaction equations. These reactions may be divided into three groups according to the reaction types: 1 . Horizontal lines. These lines represent reactions that are involved with electrons but are independent of $\mathrm{pH}$. Neither $\mathrm{H}(+\mathrm{a})$ ions nor $\mathrm{OH}(-\mathrm{a})$ ions participate in these reactions. 2. Diagonal lines with either a positive or negative slope. These lines represent reactions that are involved with both electrons and $\mathrm{H}(+\mathrm{a})-$ and $\mathrm{OH}(-$ a) ions. 3. Vertical lines. These lines represent reactions that are involved either with $\mathrm{H}(+\mathrm{a})$ - or $\mathrm{OH}(-\mathrm{a})$ ions, but are independent of $\mathrm{E}$. In other words, electrons do not participate in these reactions.

The chemical stability area of the water is shown in the E-pH diagrams by dotted lines. The upper stability limit of water is based on the potential when oxygen generation starts on the anode.

In Cao's study (Cao, 2001) the equilibrium release experiments were conducted under three different $\mathrm{pH}$ values and different redox potentials to study the influence of redox potential and $\mathrm{pH}$ value on $\mathrm{La}, \mathrm{Ce}, \mathrm{Gd}$ and $\mathrm{Y}$ release in the SRA soil. His results showed that REEs release increased with the decrease of $\mathrm{pH}$ value, when solubilities were compared under same redox potential, and REEs release increased as redox potential decreased with the same $\mathrm{pH}$ values. It seemed that the mobility of $\mathrm{La}, \mathrm{Gd}$ and $\mathrm{Y}$ depended mainly upon $\mathrm{pH}$ value, wheareas the release of Ce not only upon $\mathrm{pH}$ but also upon redox potential. REEs release was positively correlated with the release of Fe and Mn elements. REEs were mostly adsorbed onto or occluded into $\mathrm{Fe}-\mathrm{Mn}$ oxyhydroxides. It was proposed that REEs release originate from dissolution of $\mathrm{Fe}-\mathrm{Mn}$ oxyhydroxides under reduction and low $\mathrm{pH}$ conditions. Moreover, it was found that alteration of $\mathrm{pH}$ value and redox potential could result in REEs mobilities with concomitant redistribution of REEs in the soil. The concentrations of REEs in exchangeable fraction and $\mathrm{Fe}-\mathrm{Mn}$ oxide fraction of the solid phase from soil suspension separation decreased with the decline of $\mathrm{pH}$ or redox potential. Multiple stepwise regression analysis showed that exchangeable fraction and Fe-Mn oxide fraction predominately contributed to the REEs release. Briefly, $\mathrm{pH}$ and redox potential are important factors that affect the REEs fraction and REEs mobility in soil, and low pH and reducing condition favor the release of REEs from soil. 
The HSC Chemistry provides such convenient Eh-pH diagrams (see Figure 7) which allow the construction of diagrams in a highly flexible and fast way by the users exactly at the desired temperature and concentration.

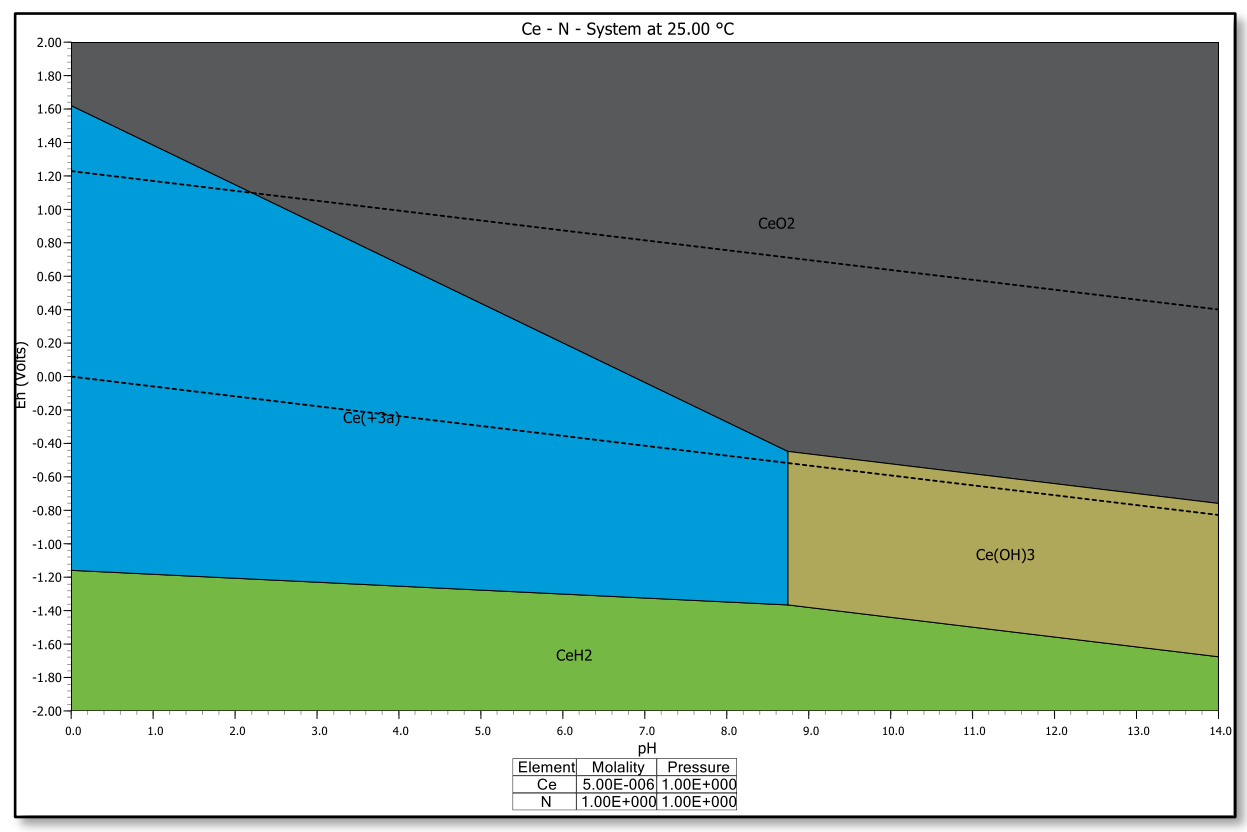

Figure 7. Example of an Eh-pH diagram for Ce.

\subsubsection{HSC Eh-pH Diagram Applications}

The HSC 9.0 Eh-pH (Figure 8) module enables fast and easy creation of Pourbaix diagrams for the required chemical system in user-specified conditions. The basic information of the aqueous system is provided in a compact and illustrative form. These diagrams have been applied in corrosion engineering, geochemistry, and hydrometallurgy since the publication of the famous Pourbaix Atlas handbook. In hydrometallurgy, Eh-pH diagrams were already used by some researchers, for instance, to specify the conditions for selective leaching or precipitation. In corrosion engineering, they may be used to analyze the dissolution and passivation behavior of different metals in aqueous environments. These diagrams may also be used to illustrate the chemical behavior of different ions in aqueous solutions. Geochemists use Eh-pH diagrams quite frequently to study the weathering process and chemical sedimentation. The weathering process is used to predict what will happen to a mineral exposed to acid oxidizing conditions at high temperature and pressure. The Eh-pH diagrams can also be used to estimate the conditions needed to form certain sediments and other minerals in the geological field. 


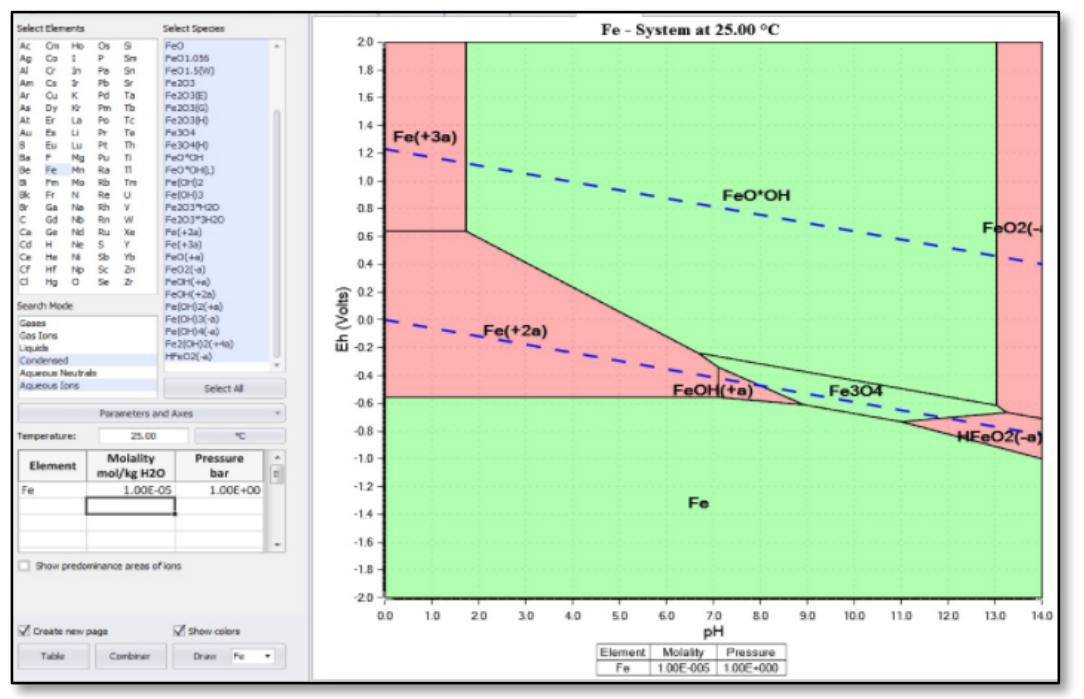

Figure 8. HSC 9.0 software interface.

Pourbaix's research included Eh-pH diagrams for the REEs metals whose concern was with reactions of metals in the presence of water only. Later, the chemical stability of rare earth elements in aqueous carbonate systems was discovered (Brookins D. G., 1988) with nonupdated thermodynamic data of rare earth elements. The reliable thermodynamic data for the relevant species is very necessary to properly predict the equilibrium relationships among solid compounds and dissolved species in a given system. It is also very challenging to retrieve and assess the pertinent data from literature sources. Normally the data was calculated and took more effort. Kim used the HSC5.0 software to generate the aqueous system for Th-, La-, Nd-, $\mathrm{Ce}-,\left(\mathrm{PO}_{4}\right)-\left(\mathrm{SO}_{4}\right)-\mathrm{H}_{2} \mathrm{O}$ at $25^{\circ} \mathrm{C}$. The thermodynamic data available in the HSC software were supplemented with additional data for the rare earth metal phosphates in his research. The diagrams for the $\mathrm{M}-\mathrm{H}_{2} \mathrm{O}$ systems show that rare earth hydroxides, such as $\mathrm{Nd}(\mathrm{OH})_{3}, \mathrm{La}(\mathrm{OH})_{3}$, and $\mathrm{Ce}(\mathrm{OH})_{3}$ form in alkaline solutions (i.e. $\mathrm{pH}>7.5$ ); in contrast $\mathrm{ThO}_{2}$ is stable down to relatively low $\mathrm{pH}(\mathrm{pH} \approx 1)$. For the $\mathrm{Th}-, \mathrm{Nd}-, \mathrm{Ce}-$, and $\mathrm{La}-\mathrm{PO}_{4}-\mathrm{H}_{2} \mathrm{O}$ systems, the size of the stability region of a given $\mathrm{REPO}_{4}$ solid is highly dependent on the degree of crystallinity of the material, as reflected in the value of the corresponding solubility product. The more crystalline the RE phosphate, the larger the stability field. Addition of sulfate ions to the $\mathrm{M}-\mathrm{PO}_{4}-\mathrm{H}_{2} \mathrm{O}$ systems introduces soluble metal-sulfate complexes and insoluble sulfates in the relatively acidic regions of the Eh-pH diagrams. The trends revealed by the diagrams are related to monazite hydrometallurgy (Kim E. , 2012).

Eh-pH diagrams for elements from $Z=40(\mathrm{Zr})$ to $Z=52$ (Te) were constructed in order to comment on migration/retention of these elements at Oklo. Results demonstrated the usefulness of Eh-pH diagrams for the Oklo fossil nuclear reactor but, more important, allow constraints to be placed on repositories for nuclear waste now under consideration (Brookins D. , 1978).

In Sato's study, a new set of diagrams called persistency-field Eh-pH diagrams were constructed for binary metal sulfides on the basis of electrochemical and other experimental data. Each 
diagram delineated the persistency field, which was a combined field of thermodynamic stability and reaction path-controlled metastability, for a specific sulfide mineral. When applied to the supergene assemblages, these new diagrams showed much better correspondence to the field observations. The new diagrams appeared to provide a strong visual aid to the understanding of the behavior of sulfide minerals in the supergene conditions (Sato, 1992).

Chesworth reported that Eh-pH diagrams provided a concise graphical way in which to depict Earth surface environments in terms of the activities of electrons, the operators involved in the two commonest types of reaction in the weathering zone on land, i.e., redox and acid-base reactions. Peatlands tended to fall on the acid side of the diagrams with ombrotrophic bogs showing least overlap with common soil-forming environments.

Minerotrophic mires overlapped the field of ombrotrophic bogs under relatively high redox conditions, though with depth they moved along a line defined by ferrous-ferric equilibria, to a near-neutral $\mathrm{pH}$. The same kind of equilibria also played a controlling influence on ambient conditions in mineral soils at the low limit of their $\mathrm{pH}$ range (Chesworth, 2006).

Eh-pH diagrams of a Ca-S- $\mathrm{H}_{2} \mathrm{O}$ system at different conditions were described in He's study with thermodynamic calculations to investigate the leaching of sulphur from desulphurization slag. The results showed that the leaching reactions occurred spontaneously under normal conditions and that the sulphur leached into the leachate as $\mathrm{S}^{2-}, \mathrm{HS}^{-}, \mathrm{H}_{2} \mathrm{~S}_{(\mathrm{aq})}, \mathrm{S}_{(\mathrm{s})}$ and $\mathrm{SO}_{4}{ }^{2-}$. When the activity of the dissolved species was reduced, elemental Sulphur converted into other ions in redox reactions. Simultaneously, the predominant area of $\mathrm{Ca}(\mathrm{OH})_{2(\mathrm{~s})}$ decreased, which indicated that $\mathrm{Ca}(\mathrm{OH})_{2(\mathrm{~s})}$ may dissolve into $\mathrm{Ca}^{2+}$ and increased the loss of calcium (He, 2019). 


\section{Thermodynamic Modeling of Rare Earth Element Aqueous Stability}

\subsection{Introduction and Modeling Objectives}

Pourbaix diagrams, or Eh-pH diagrams, are widely used for mapping the solubilities of metals in the aqueous system, which is useful to determine the process conditions that favor certain metals. An Eh-pH diagram plots the dominant aqueous species and stable solid phases on a coordinate system defined by the Eh and $\mathrm{pH}$ axes. The diagrams are divided into areas, each of which represents a locally predominant species. Eh represents the oxidation-reductions potential based on the standard hydrogen potential, while $\mathrm{pH}$ represents the activity of the hydrogen ion. Thus, an Eh-pH diagram not only shows the effects of potential and $\mathrm{pH}$, but they can also show how metal complexes and ligands can influence solubility.

In this study, the Eh-pH diagrams were generated using the HCS 9.0 Chemistry software to investigate the solubility of REEs and major gangue elements in AMD. The input conditions were selected to mirror those for the selective leaching and precipitation processes, which were experimentally evaluated in subsequent chapters.

\subsection{Modeling Parameters}

First of all, the chemical system was selected including elements, modes, species, temperature, molality and pressure. Secondly, the dominant element was chosen to be displayed in the Eh$\mathrm{pH}$ diagrams. The concentrations of rare earth elements used were shown in Table 3 . In this study, the MV feed sample's parameters were used in the HSC software at $25^{\circ} \mathrm{C}$ and 1 bar pressure.

Table 3. Rare earth elements and major metals concentration in typical AMDp leachate

\begin{tabular}{|c|r|r|r|}
\hline Elements & $\begin{array}{c}\text { Concentration } \\
\mathbf{m o l} / \mathbf{k g}\end{array}$ & Elements & $\begin{array}{c}\text { Concentration } \\
\mathrm{mol} / \mathbf{k g}\end{array}$ \\
\hline $\mathrm{Sc}$ & 0.001305 & $\mathrm{Er}$ & 0.000129 \\
\hline $\mathrm{Y}$ & 0.002303 & $\mathrm{Tm}$ & 0.000013 \\
\hline $\mathrm{La}$ & 0.000442 & $\mathrm{Yb}$ & 0.000090 \\
\hline $\mathrm{Ce}$ & 0.001274 & $\mathrm{Lu}$ & 0.000011 \\
\hline $\mathrm{Pr}$ & 0.000220 & $\mathrm{Th}$ & 0.000045 \\
\hline $\mathrm{Nd}$ & 0.001147 & $\mathrm{U}$ & 0.000076 \\
\hline $\mathrm{Sm}$ & 0.000374 & $\mathrm{Al}$ & 2.831000 \\
\hline $\mathrm{Eu}$ & 0.000087 & $\mathrm{Ca}$ & 1.840150 \\
\hline $\mathrm{Gd}$ & 0.000413 & $\mathrm{Fe}$ & 1.465923 \\
\hline $\mathrm{Tb}$ & 0.000054 & $\mathrm{Mg}$ & 25.616090 \\
\hline $\mathrm{Dy}$ & 0.000267 & $\mathrm{Mn}$ & 0.222804 \\
\hline $\mathrm{Ho}$ & 0.000051 & & \\
\hline
\end{tabular}




\subsection{Results and Discussion}

\subsection{1. $\mathrm{REE}-\mathrm{H}_{2} \mathrm{O}$ system}

The solubilities of the rare earth elements were simulated in Eh-pH diagrams by applying the laboratory experimental parameters in this study. The Eh-pH diagrams for the MV sample's REE $-\mathrm{H}_{2} \mathrm{O}$ system at $25^{\circ} \mathrm{C}$ and 1 bar pressure were shown in Figure 9 through Figure 12. These diagrams show that rare earth hydroxides such as $\mathrm{Ce}(\mathrm{OH})_{3}, \mathrm{La}(\mathrm{OH})_{3}, \mathrm{Eu}(\mathrm{OH})_{3}, \mathrm{Tm}(\mathrm{OH})_{3}$, $\mathrm{Yb}(\mathrm{OH})_{3}, \mathrm{Lu}(\mathrm{OH})_{3}$ appeared at alkaline conditions where $\mathrm{pH}>7$, while $\mathrm{Y}(\mathrm{OH})_{3}$ and $\mathrm{Sc}(\mathrm{OH})_{3}$ were stable even at relatively low $\mathrm{pH}$ around $\mathrm{pH} 4$. The $\mathrm{ThO}_{2}$ remains stable even at very acidic condition at $\mathrm{pH} 1.5$. This indicated that mixed REE-hydroxides produced after alkaline decomposition may be separated by selective dissolution in acidic environment. Therefore, some REE-hydroxides resulting from alkaline treatment of AMD sludge can be dissolved as $\mathrm{RE}$ (III) species in acidic solutions, while the $\mathrm{ThO}_{2}$ still remaining in a very strong acidic solution around $\mathrm{pH}$ 1.5. Others can be selectively separated in natural to alkaline conditions.

Conversely, the REE metals initially presented as dissolved species in acidic solution, can be separated by $\mathrm{pH}$ adjustment-precipitation. When the $\mathrm{pH}$ is raised from $\mathrm{pH} 0.5$ during leaching precipitation, the $\mathrm{ThO}_{2}$ is expected to form first at $\mathrm{pH}$ 1.5. The REE-hydroxide forms as the $\mathrm{pH}$ increases in the order: $\mathrm{Y}<\mathrm{Sc}<\mathrm{Dy}<\mathrm{Er}<\mathrm{Nd}<\mathrm{Pr}<\mathrm{Ho}<\mathrm{Ce}<\mathrm{Yb}<\mathrm{Sm}<\mathrm{Tm}<\mathrm{Eu}<\mathrm{Gd}<\mathrm{La}<\mathrm{Lu}$. 

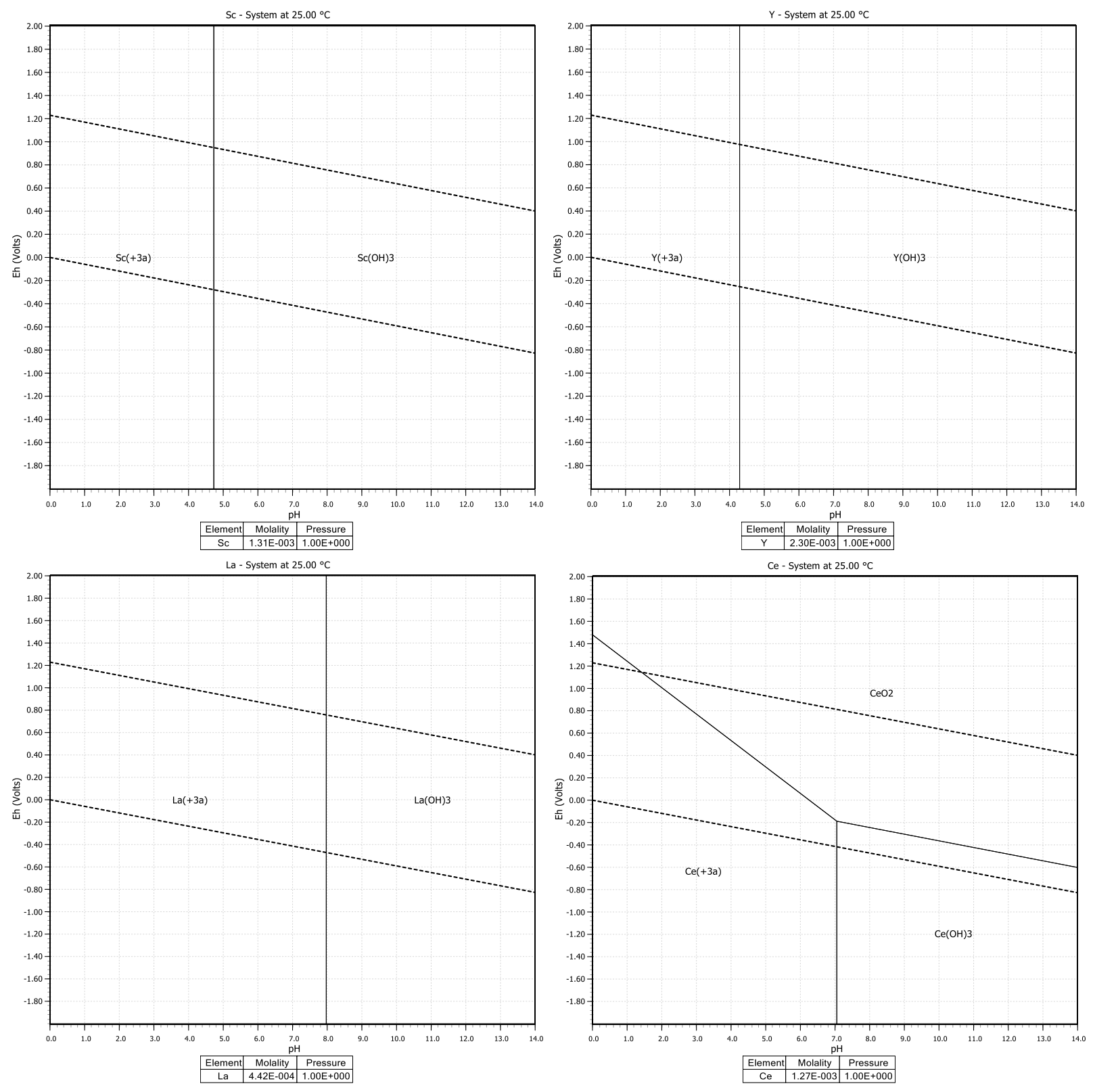

Figure 9. $\mathrm{RE}-\mathrm{H}_{2} \mathrm{O}$ system for MV Leachate (SC, Y, La, and Ce). 

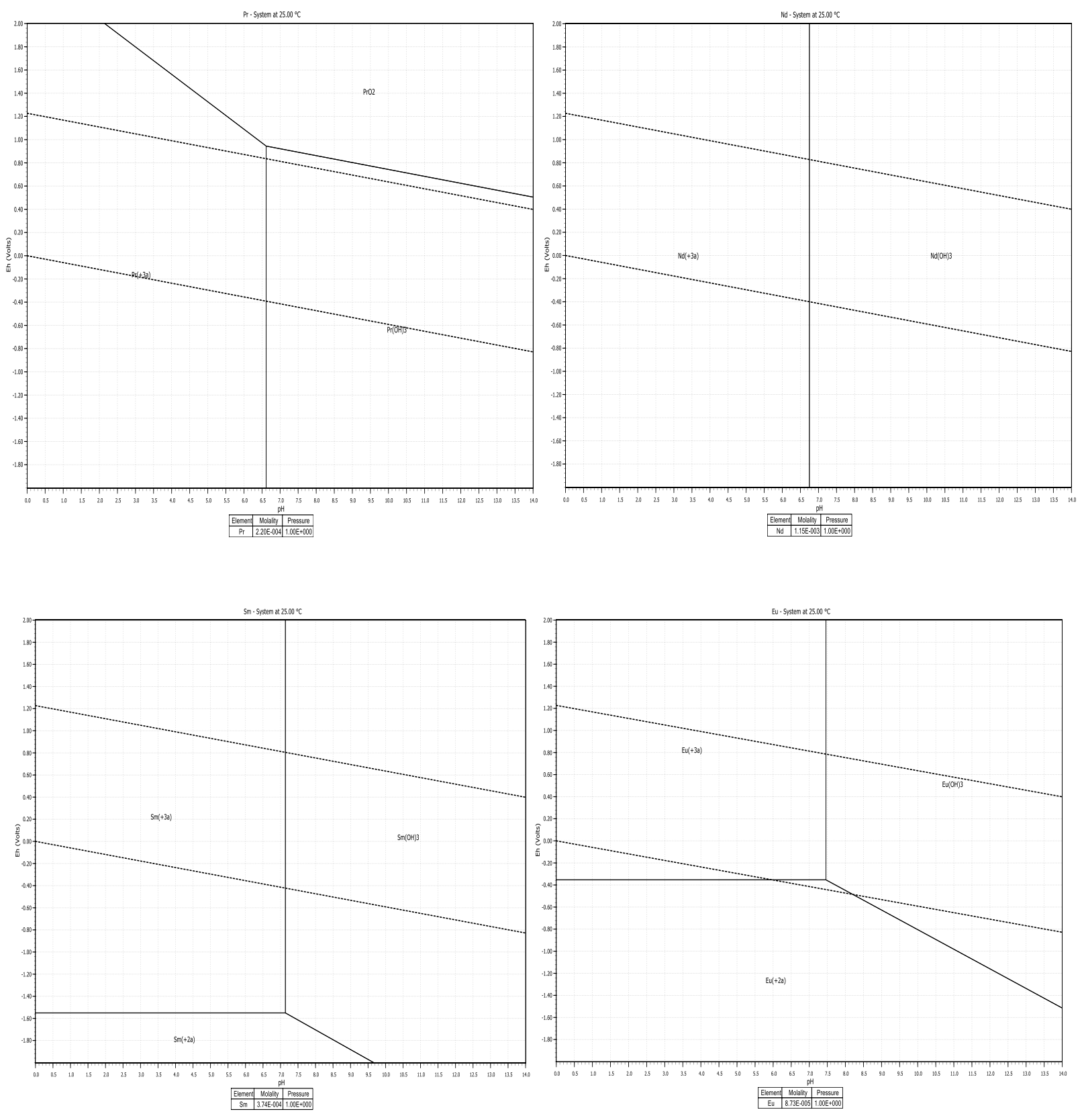

Figure 10. $\mathrm{RE}-\mathrm{H}_{2} \mathrm{O}$ system for MV Leachate ( $\mathrm{Pr}, \mathrm{Nd}, \mathrm{Sm}$, and $\left.\mathrm{Eu}\right)$. 

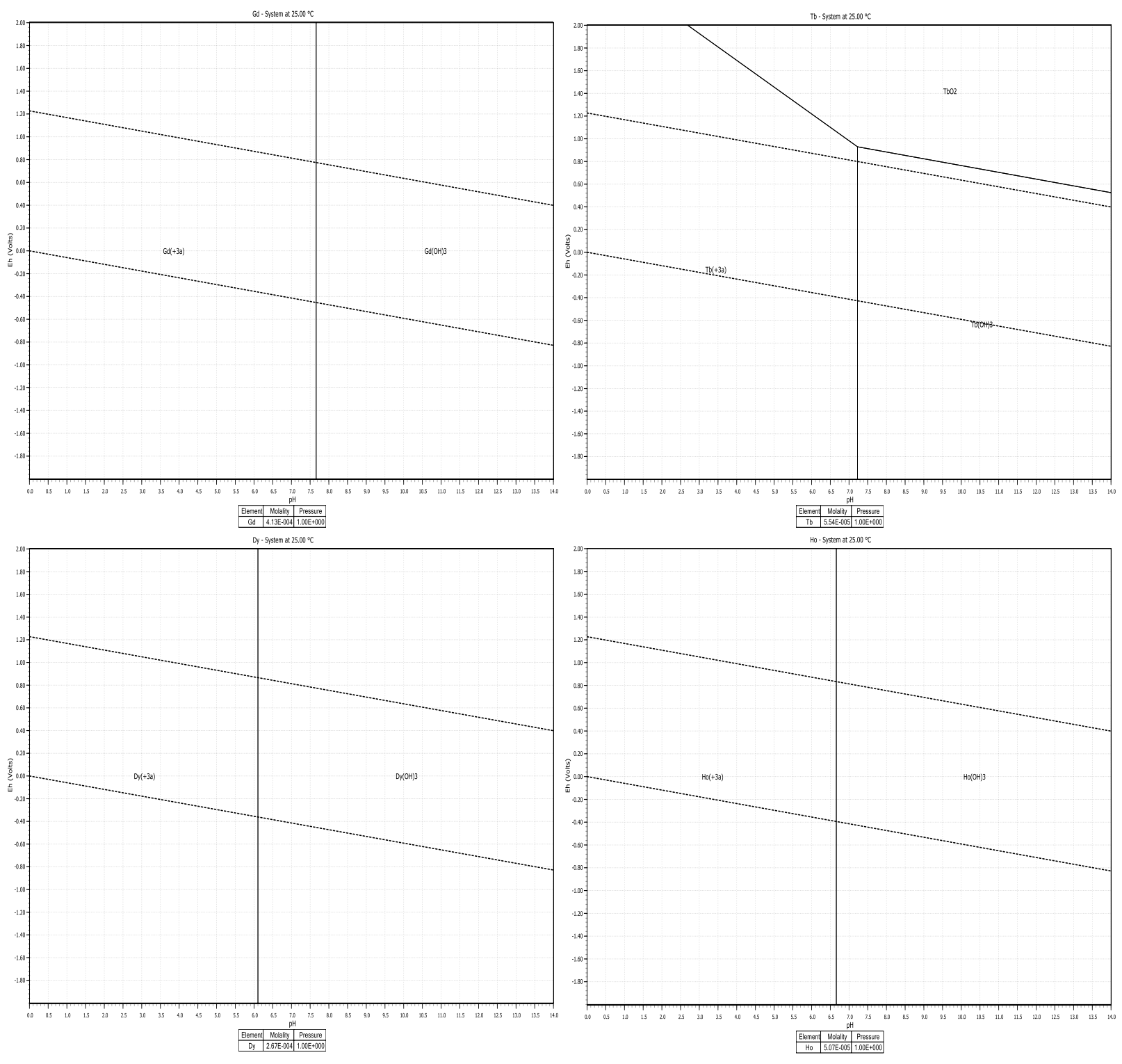

Figure 11. $\mathrm{RE}-\mathrm{H}_{2} \mathrm{O}$ system for MV Leachate ( $\mathrm{Gd}, \mathrm{Tb}, \mathrm{Dy}$, and Ho). 

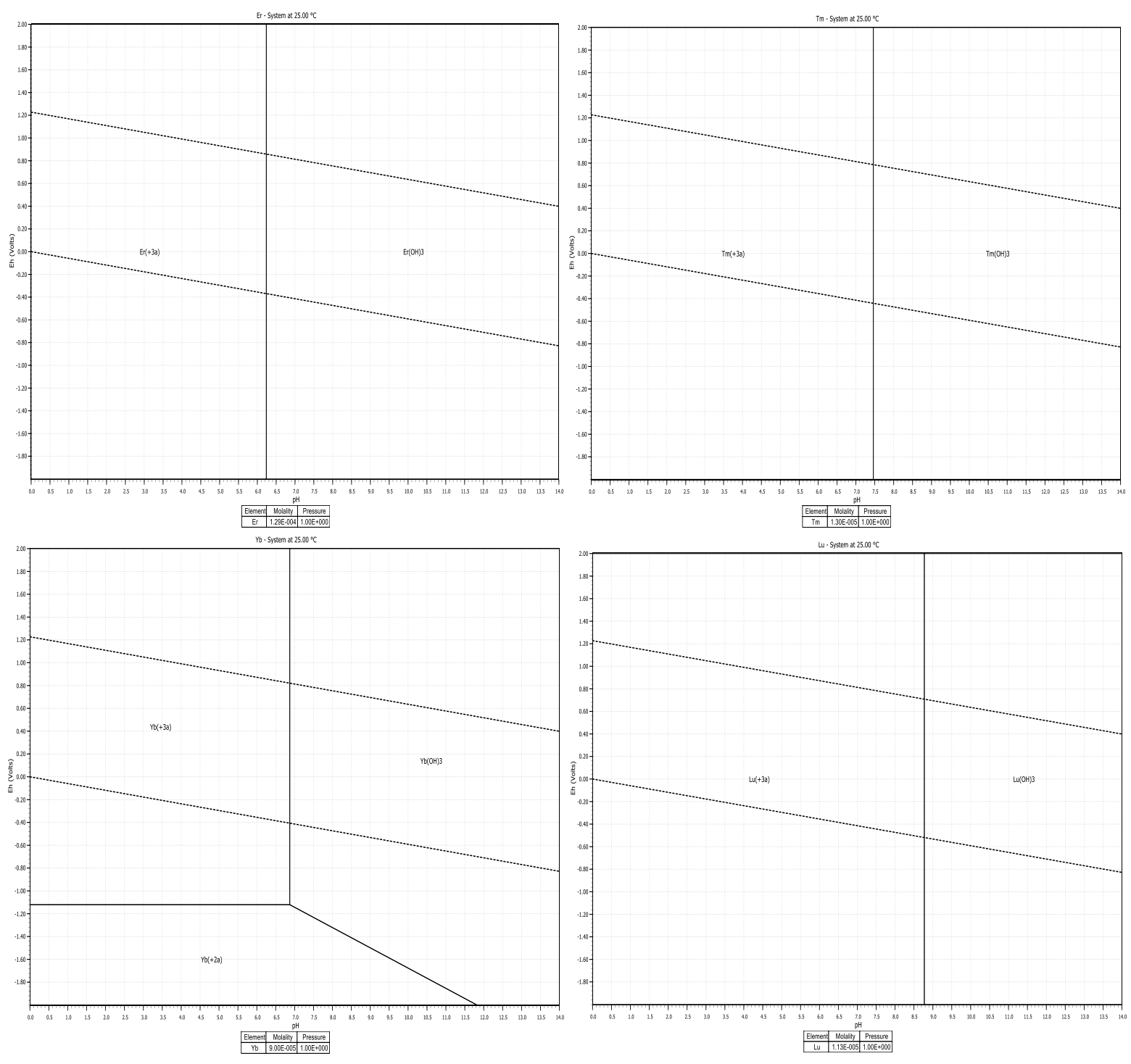

Figure 12. $\mathrm{RE}-\mathrm{H}_{2} \mathrm{O}$ system for MV Leachate (Er, Tm, Yb, and Lu).

\subsubsection{Major Metal- $\mathrm{H}_{2} \mathrm{O}$ system}

The Eh-pH diagrams for the major metals in AMDp are shown in Figure 13. In the $\mathrm{MM}-\mathrm{H}_{2} \mathrm{O}$ system, $\mathrm{Al}_{2} \mathrm{O}_{3}$ presented in acidic condition where $\mathrm{pH}$ was around 3 , and Fe-oxides appeared from $\mathrm{pH}$. But Ca-hydroxides appeared in very high alkaline condition around $\mathrm{pH} 11 . \mathrm{Mg}$ - and $\mathrm{Mn}$-hydroxides presented in relatively natural condition where the $\mathrm{pH}=7.5$. Therefore, $\mathrm{Al}$ and Fe ions in AMDp can be simply removed by $\mathrm{pH}$ adjustment from $\mathrm{pH} 3$ to 4 while all REEs remaining in the solution. To remove $\mathrm{Ca}$, the material can be dissolved by strong acid completely first at a lower $\mathrm{pH}$, then predicated by base till $\mathrm{pH} 8$ where most the REEs remain as precipitates leaving the $\mathrm{Ca}$ ions in the solution. Conversely, during natural weathering process, Ca always is the first to be dissolved into surrounding aqueous system than other metal elements. 

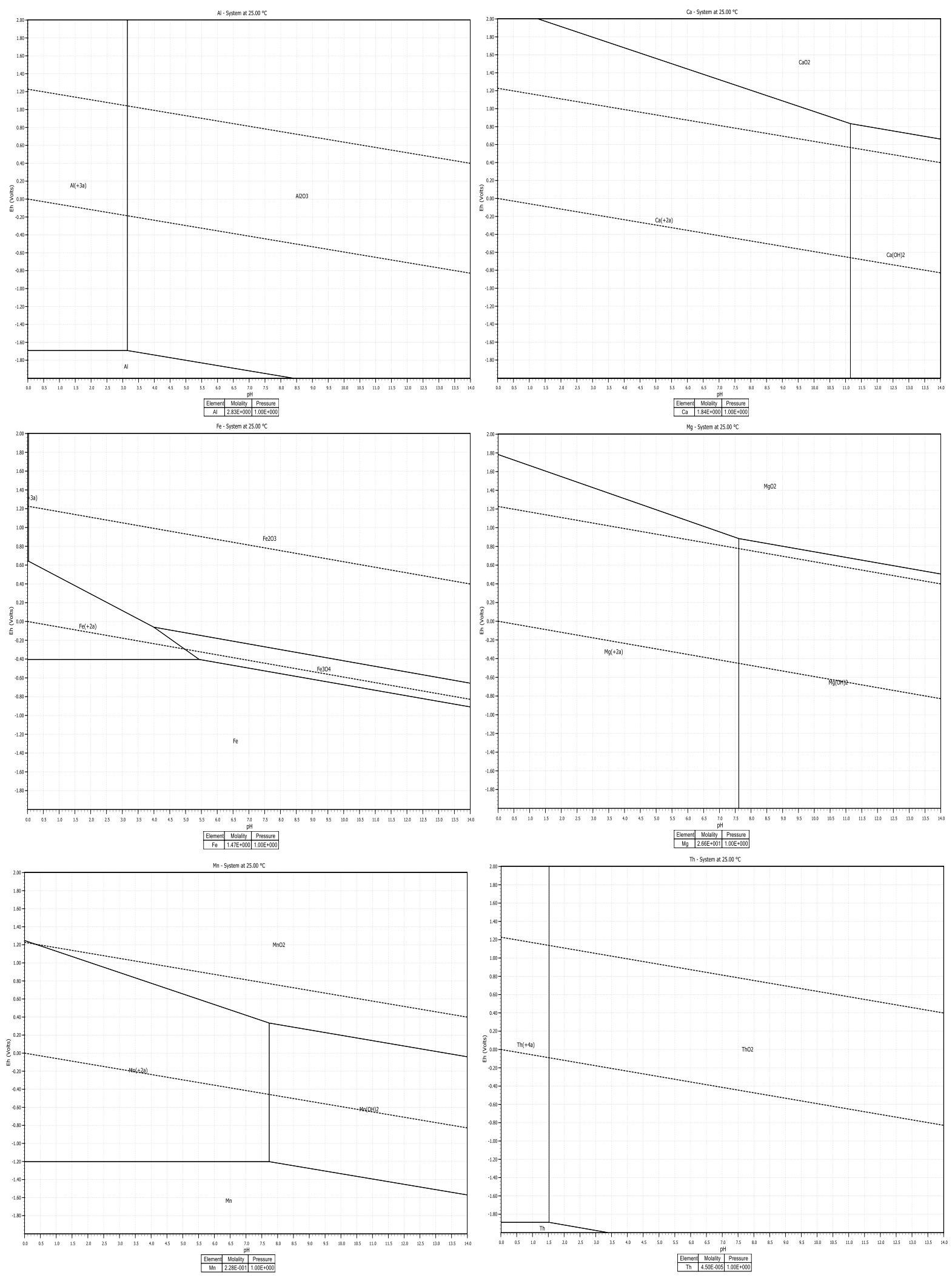

Figure 13. $\mathrm{MM}-\mathrm{H}_{2} \mathrm{O}$ system for MV Leachate ( $\mathrm{Al}, \mathrm{Ca}, \mathrm{Fe}, \mathrm{Mg}, \mathrm{Mn}$, and Th). 


\subsection{3. $\mathrm{REE}-\mathrm{N}-\mathrm{H}_{2} \mathrm{O}$ and Major Metal- $\mathrm{N}-\mathrm{H}_{2} \mathrm{O}$ system}

The REE-N- $\mathrm{H}_{2} \mathrm{O}$ and $\mathrm{MM}-\mathrm{N}-\mathrm{H}_{2} \mathrm{O}$ system were also simulated and shown in Figure 14 through Figure 18. Even with additional $3 \mathrm{M} \mathrm{HNO}_{3}$ simulated in the AMDp sample, except the $\mathrm{Sc}$, no other differences were observed. The extra oxidant shifted the preinitiation line of $\mathrm{Sc}_{2} \mathrm{O}_{3}$ to the left to $\mathrm{pH} 2.8$.
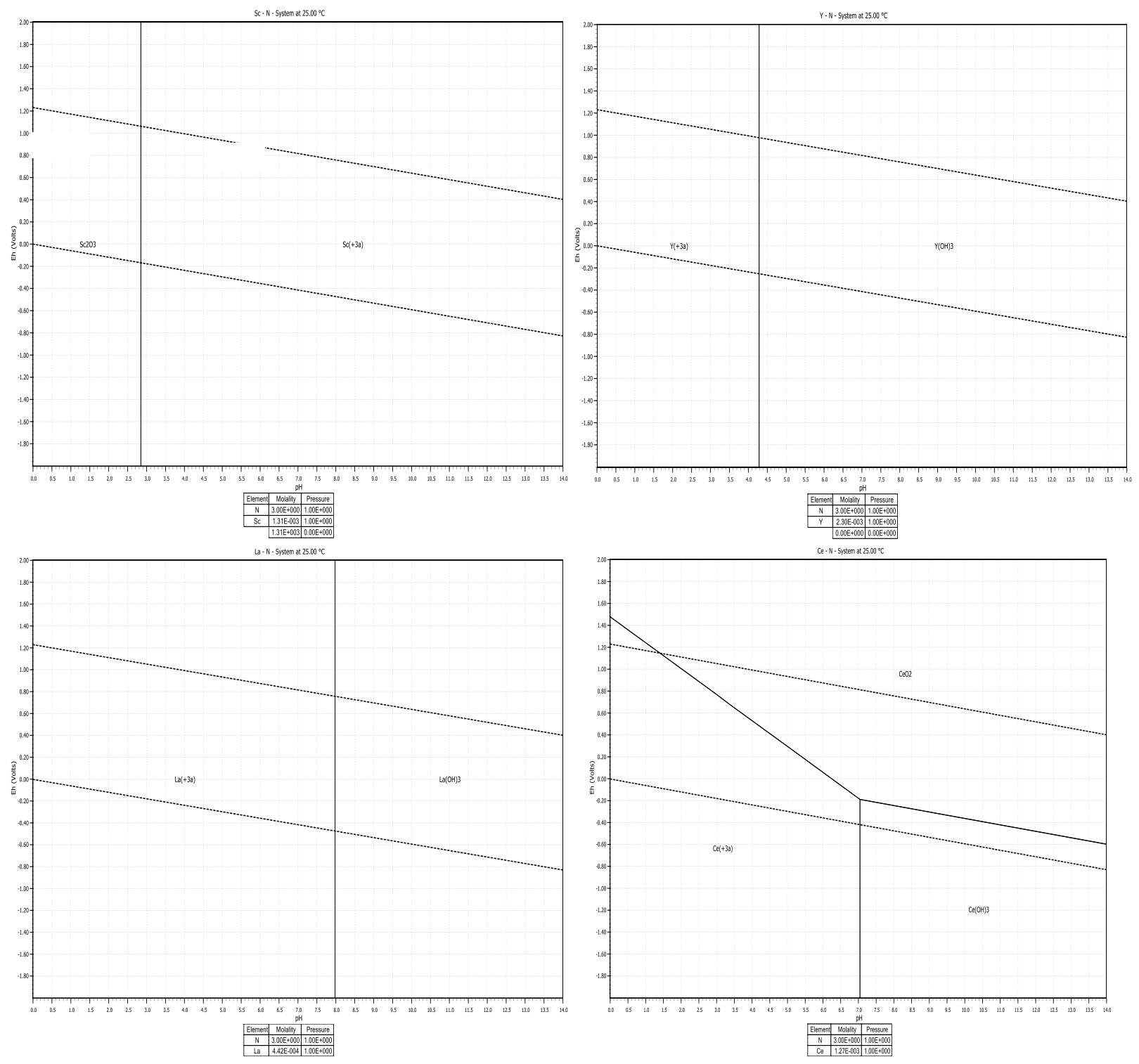

Figure 14. REE-N-H ${ }_{2} \mathrm{O}$ system for MV Leachate (SC, Y, La, and Ce). 

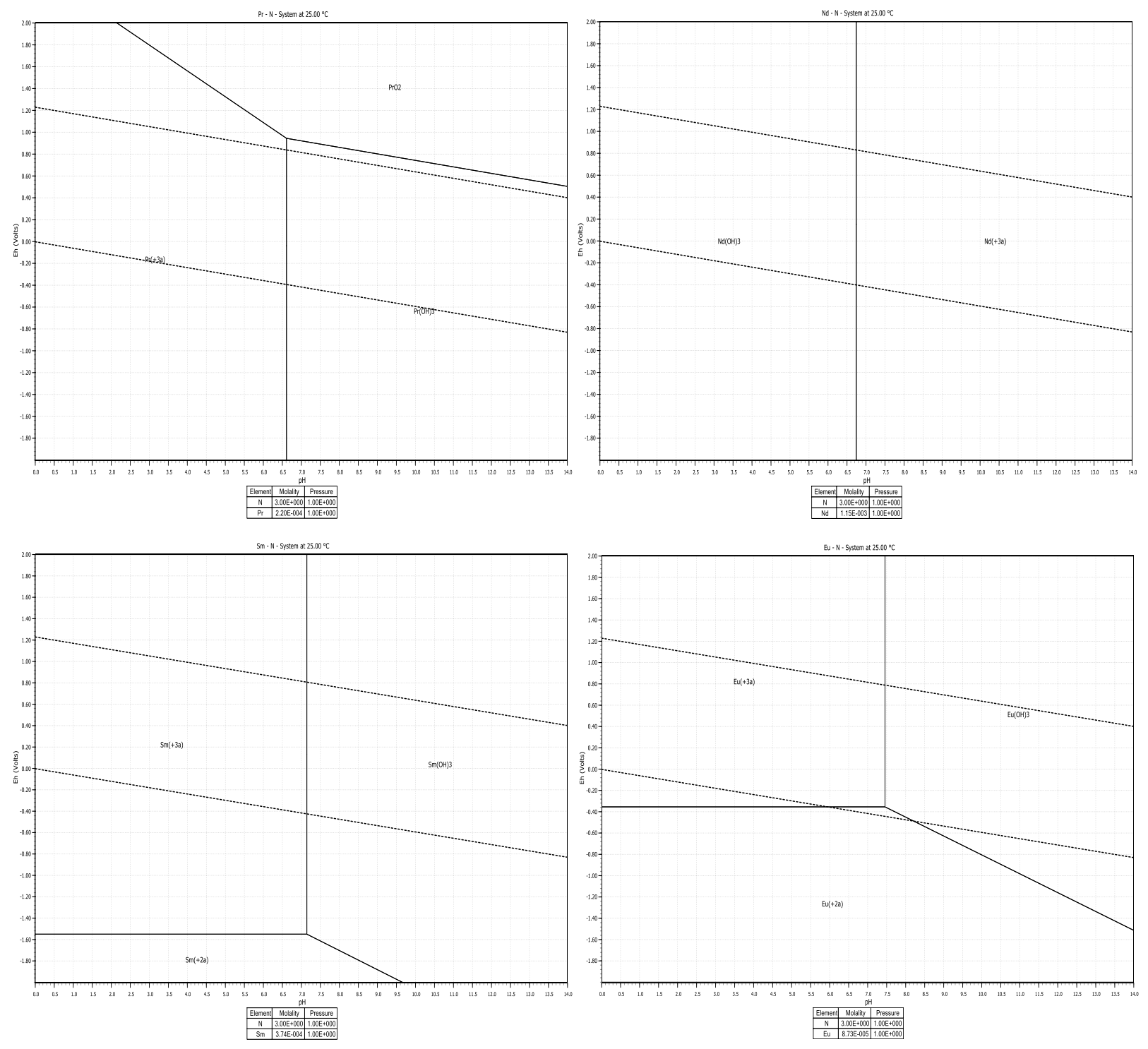

Figure 15. REE-N- $\mathrm{H}_{2} \mathrm{O}$ system for MV Leachate ( $\mathrm{Pr}, \mathrm{Nd}, \mathrm{Sm}$, and $\left.\mathrm{Eu}\right)$. 

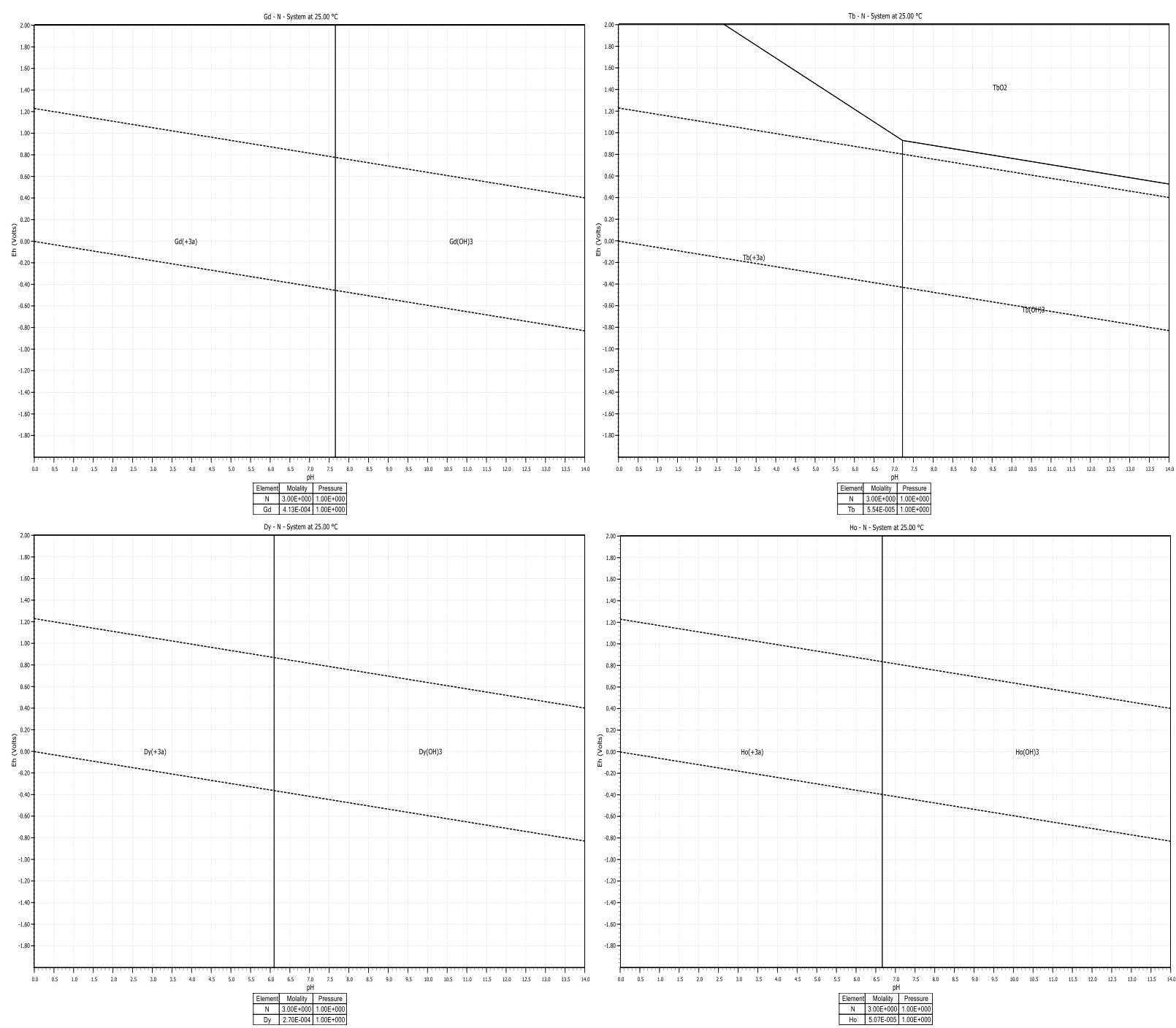

Figure 16. REE-N-H $\mathrm{H}_{2} \mathrm{O}$ system for MV Leachate ( $\mathrm{Gd}, \mathrm{Tb}, \mathrm{Dy}$, and Ho). 

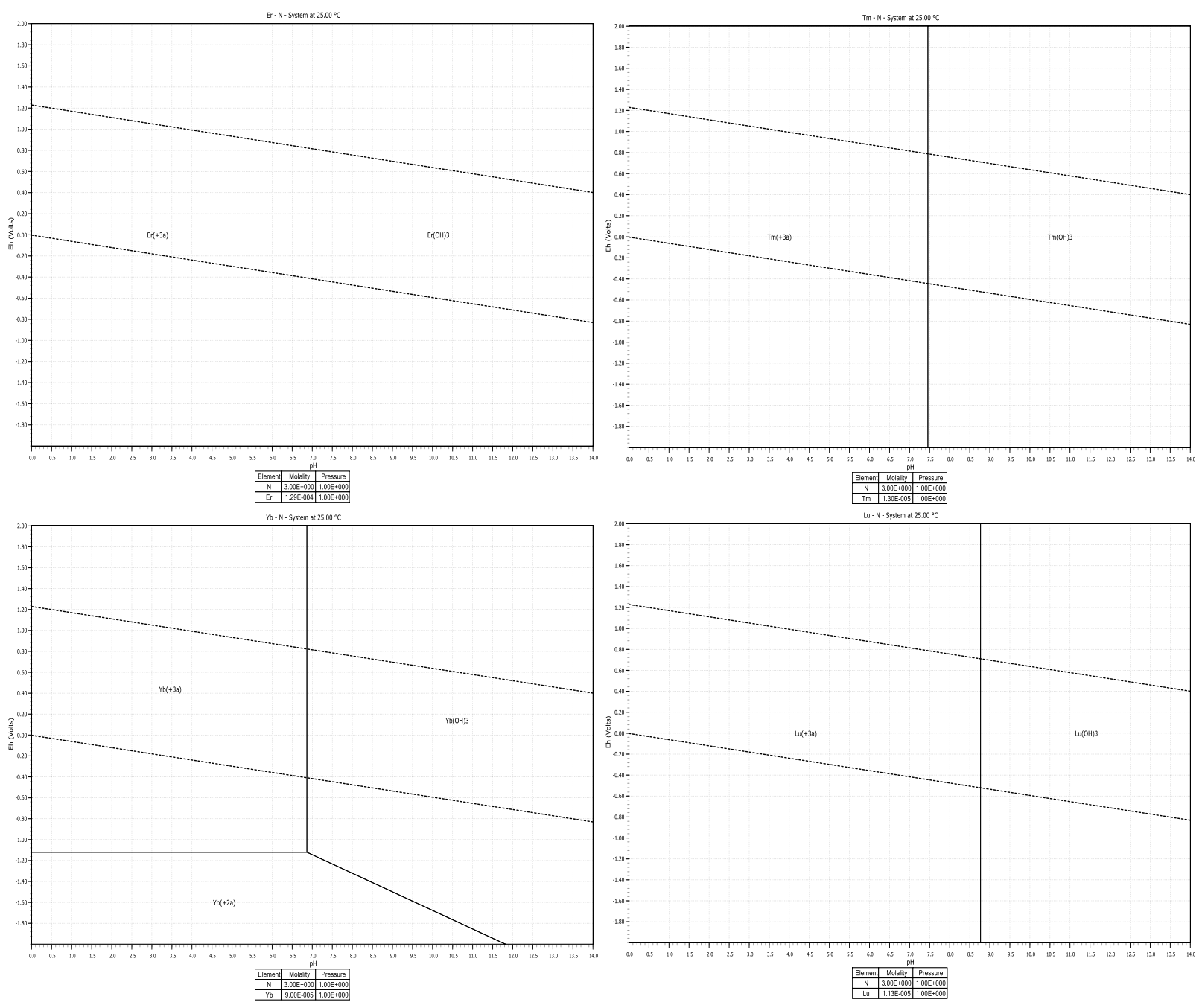

Figure 17. REE-N-H ${ }_{2} \mathrm{O}$ system for MV Leachate ( $\mathrm{Er}, \mathrm{Tm}, \mathrm{Yb}$, and Lu). 

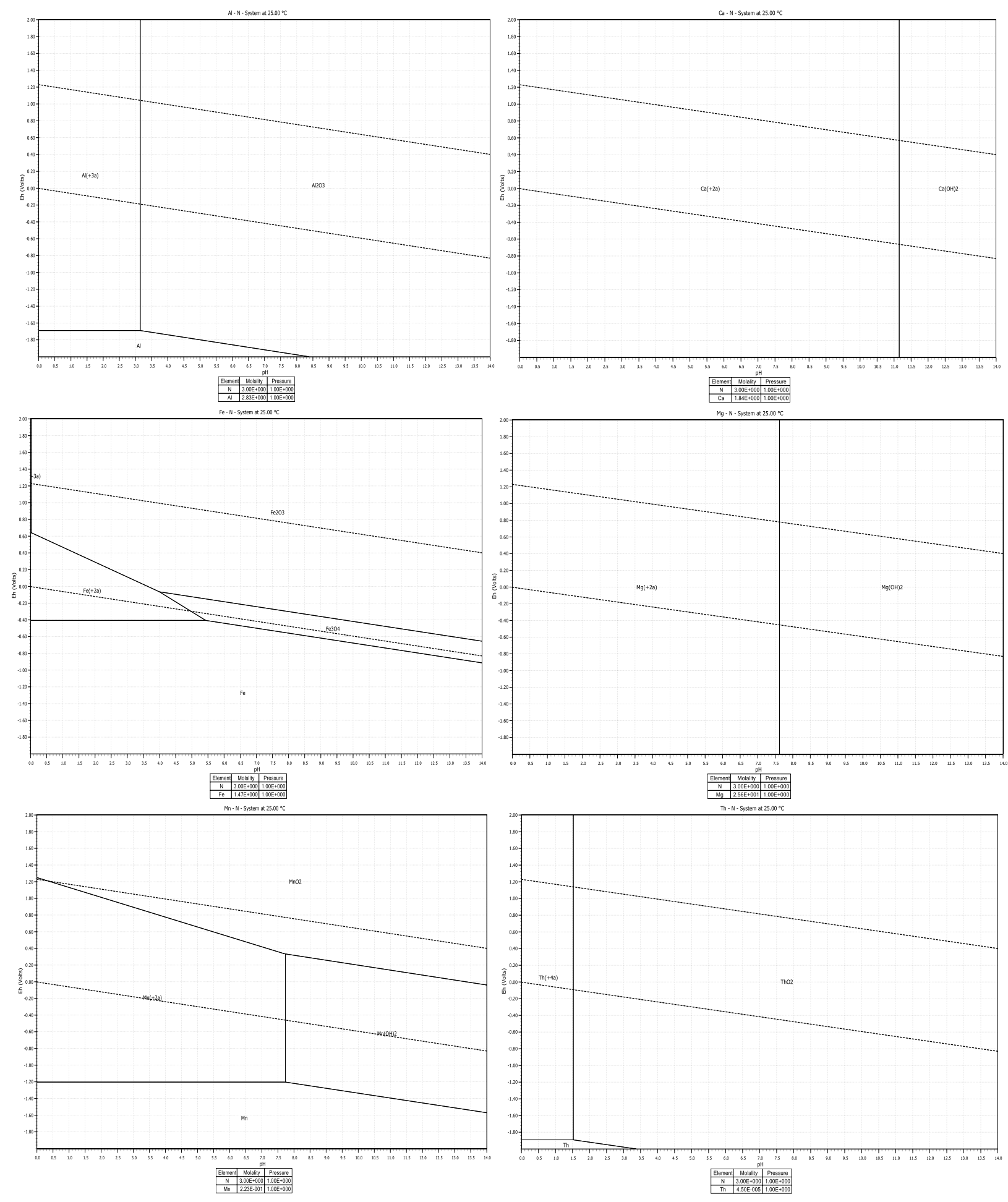

Figure 18. MM-N-H $\mathrm{H}_{2} \mathrm{O}$ system for $\mathrm{MV}$ Leachate ( $\mathrm{Al}, \mathrm{Ca}, \mathrm{Fe}, \mathrm{Mg}, \mathrm{Mn}$, and $\mathrm{Th}$ ). 


\subsection{Conclusions}

The HSC9.0 was used in this study to generate the Eh-pH diagrams of the rare earth elements based on the MV AMDp sample data. The diagrams showed results as following:

In the REE- $\mathrm{H}_{2} \mathrm{O}$ system, the solubilities of rare earth elements and their (hydr)oxidants were different. Therefore, the mixed REE-hydroxides produced after alkaline decomposition can be separated by selective dissolution in acidic environment.

Conversely, the REE metals initially presented as dissolved species in acidic solution, can be separated by $\mathrm{pH}$ adjustment by precipitation. The REE-hydroxide forms as the $\mathrm{pH}$ increased in the order: $\mathrm{Y}<\mathrm{Sc}<\mathrm{Dy}<\mathrm{Er}<\mathrm{Nd}<\mathrm{Pr}<\mathrm{Ho}<\mathrm{Ce}<\mathrm{Yb}<\mathrm{Sm}<\mathrm{Tm}<\mathrm{Eu}<\mathrm{Gd}<\mathrm{La}<\mathrm{Lu}$.

In the $\mathrm{MM}-\mathrm{H}_{2} \mathrm{O}$ system, $\mathrm{Al}_{2} \mathrm{O}_{3}$ presented in acidic condition where $\mathrm{pH}$ was around 3 , and $\mathrm{Fe}-$ oxides appeared from $\mathrm{pH} 4$. But Ca-hydroxides appeared in high alkaline condition around $\mathrm{pH} 11$. $\mathrm{Mg}$ - and $\mathrm{Mn}$-hydroxides presented in relatively natural condition where the $\mathrm{pH}=7.5$. Therefore, $\mathrm{Al}$ and Fe ions in AMDp can be simply removed by $\mathrm{pH}$ adjustment from $\mathrm{pH} 3$ to 4 while all REEs remaining in the solution. To remove $\mathrm{Ca}$, the sample can be dissolved by strong acid completely first at a lower $\mathrm{pH}$, then predicated by base till $\mathrm{pH} 8$ where most the REEs remain as precipitates leaving the $\mathrm{Ca}$ ions in the solution. Conversely, during natural weathering process, $\mathrm{Ca}$ always is the first to be dissolved into surrounding aqueous system than other metal elements. 


\section{Leaching of Rare Earth Elements from Acid Mine Drainage Precipitates (AMDp)}

\subsection{Introduction and Test Objectives}

Prior work has shown that the treatment byproducts of AMD (herein denoted AMD precipitates, AMDp) have significantly elevated concentrations of REE relative to that of the surrounding strata (Vass C. R., 2019a). Given these elevated concentrations, AMDp may serve as a suitable feed source for REE production. To investigate the potential to recovery REEs from AMDp, a parametric acid leaching study was conducted. Acid leaching is often the preferred extraction process for conventional REE processing and given the small particle size and high reactivity of $A M D p$, it is anticipated to be adequate for the given feedstock.

To investigate the most effective acid leaching conditions and the design parameters, the following tests were conducted: (1) leaching with different acids $\mathrm{HNO}_{3}$, and $\mathrm{H}_{2} \mathrm{SO}_{4}$ at different concentrations, (2) leaching of different samples representing a variety of geographic and geologic settings (3) kinetic tests were used to determine the optimum length of leaching time for AMD sludge, and (4) countercurrent tests that recycled the acid in a closure loop. In all tests, leaching efficiency was determined by comparing leached REEs from each treatment with the AMDp feedstock characterization as determined by ICP-MS.

\subsection{Methods and Materials}

\subsubsection{Sample Selection and Handling}

The AMDp precipitate samples utilized in these tests were recovered from the host sites and stored in 1-gallon buckets prior to use in the lab. Details on the sampling procedure have been reported elsewhere (Vass C. R., 2019a); however, the procedure typically involved the collection of the AMDp from surface storage pond at the AMD treatment site. Fully representative sampling of AMDp from ponds can be extremely difficult, but efforts were made to sample material slightly below the surface and free of dirt, trash, organic matter, and other contaminants.

Three unique samples were utilized throughout the leaching test campaign, namely the DL, BG, and MV samples. The DL AMDp sample is a dark grey to black sludge procured from Upsher County, WV. At this site, AMD is collected from a surface mine/refuse pile and treated with $\mathrm{NaOH}$. The influent $\mathrm{pH}$ is approximately 3.5. Likewise, the BG sample is derived from an above drainage underground mine operating in the Freeport seam in Preston Country, WV. The influent $\mathrm{pH}$ is approximately 2.7 and is treated with lime. The primary sample used in the parametric leaching tests, $M V$, is an iron-rich, orange sludge procured from a surface refuse mine in Armstrong County, PA. The influent $\mathrm{pH}$ at this site is approximately 3.2 , and the treatment is conducted using lime. Upon delivery to the lab, the samples were stored in sealed buckets to prevent loss of moisture. The averaged moisture of the samples was obtained by drying three groups of small samples in the oven for 24 hours before any tests. For the SEM and XRD analyses, 500mg samples were dried in the oven for 48 hours then ground by hand with a mortar and pistil. 


\subsubsection{Reagents and Equipment}

Mineral acids (i.e. nitric, hydrochloric, and sulfuric) of ACS grade were used throughout the leaching tests. All acids were diluted to a concentration of $3 \mathrm{M}$ for use in the tests, and fresh acid was made prior to each test.

All tests were conducted under a fume hood using proper personal protective equipment. The actual leaching tests were performed in a three-neck reaction vessel on a stirring hot plate with magnetic stir bars. For the leaching tests, the reaction vessel was equipped with a reflux condenser to ensure no acid losses due to evaporation during testing. The experimental setup is shown in Figure 19.

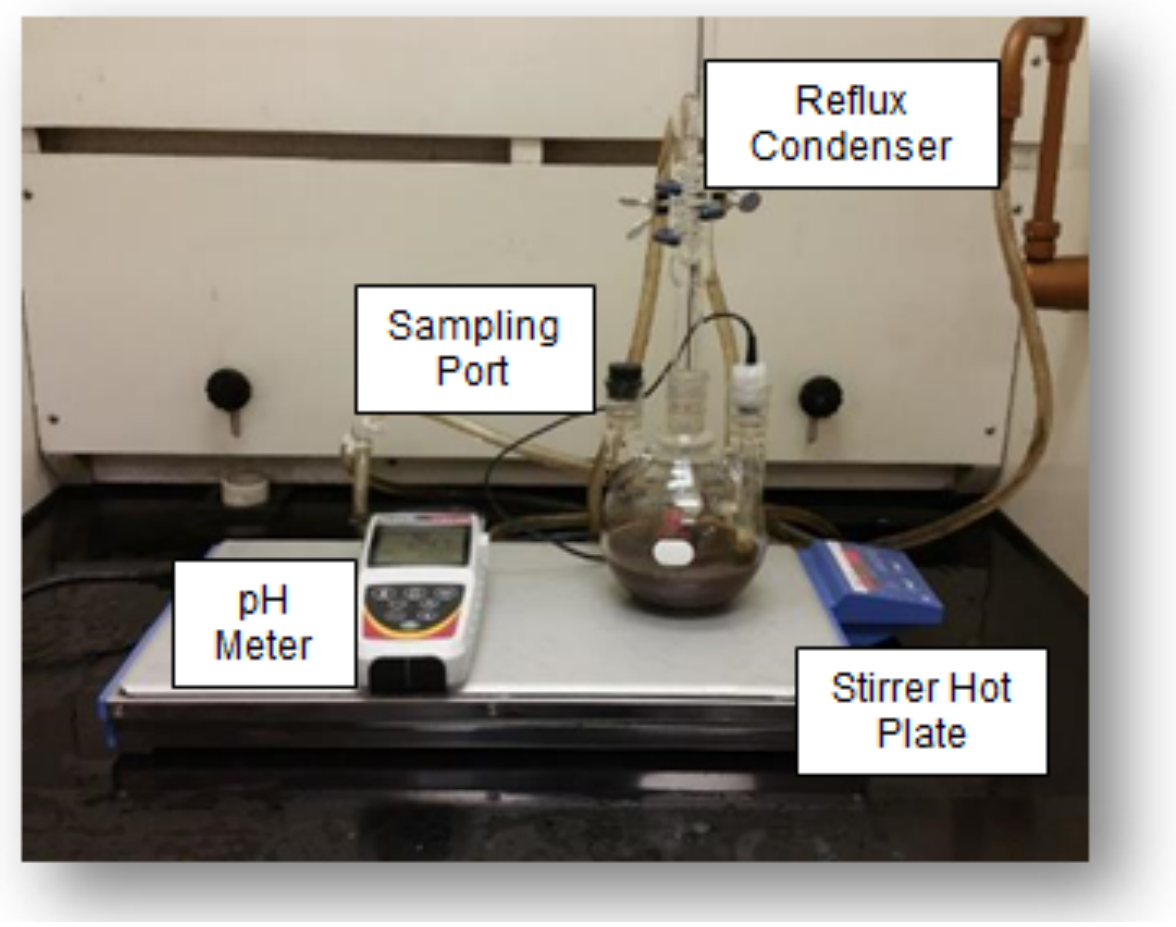

Figure 19. Experimental Apparatus used in leaching tests.

Following the tests, ICP-MS and ICP-OES analyses were used for determining the REEs and major metals concentrations, respectively. For these tests, ICP-MS was conducted at the SGS Canada Laboratory, while ICP-OES was performed at the NRCCE analytical lab at West Virginia University. For solid samples, the AMDp was first digested using a sodium peroxide fusion followed by hydrochloric acid dissolution. In addition, the SEM-EDX (Hitachi S-4700) and XRD (Panalytical X'pert Pro), both accessed at the WVU Shared Facilities Laboratories, were used to determine the physical properties of the feed samples. 


\subsubsection{Exploratory Leaching Test Procedures}

An initial series of leaching tests was conducted to assess the influence of acid type and sample type in extraction efficiency. Table 4 summarizes the experimental parameters used during testing.

The tests were performed by first splitting several representative samples of the sludge from the sample bucket. Three sub-samples were then retained for moisture analysis, three were retained for REE analysis, and the remaining samples were used in the experiments. During the test runs, 100 grams of wet sludge was placed in a specially designed leach reactor. The sample was mixed with $100 \mathrm{~mL}$ of deionized water, and a $5 \mathrm{~mL}$ pipette was used to slowly add the acid in a dropwise fashion until a $\mathrm{pH}$ of 0.7 to 0.8 was achieved. The reaction was then conducted until near full dissolution was achieved. Upon completion, a $20 \mathrm{~mL}$ liquid was withdrawn from the reactor and filtered using a $20 \mu \mathrm{m}$ syringe filter. The leachate was then analyzed for REE and major metal content via ICP-MS. A diagram of the test flowsheet is shown in Figure 20.

Table 4. Experimental Parameters for Exploratory Leaching Tests

\begin{tabular}{lll}
\hline Parameter & Unit & Value \\
\hline Experimental Parameters & & \\
\hline Sample & -- & MV, DL, BG \\
Acid Type & -- & Nitric, Sulfuric \\
\hline Constant Parameters & & \\
\hline Leaching Time & -- & To completion \\
Leaching pH & -- & 0.7 to 0.8 \\
Acid Concentration & $\mathrm{Mol} / \mathrm{L}$ & 3 \\
Leach Temperature & ${ }^{\circ} \mathrm{C}$ & Ambient \\
Solid to Liquid Ratio & -- & $1: 1$ \\
Stirrer Speed & $\mathrm{RPM}$ & 350 \\
Sludge Wet Mass & $\mathrm{Grams}$ & 100 \\
\hline Responses & & \\
\hline REE Leachate Concentration & $\mathrm{mg} / \mathrm{L}$ & Measured \\
Major Metal Leachate & $\mathrm{mg} / \mathrm{L}$ & Measured \\
Concentration &
\end{tabular}




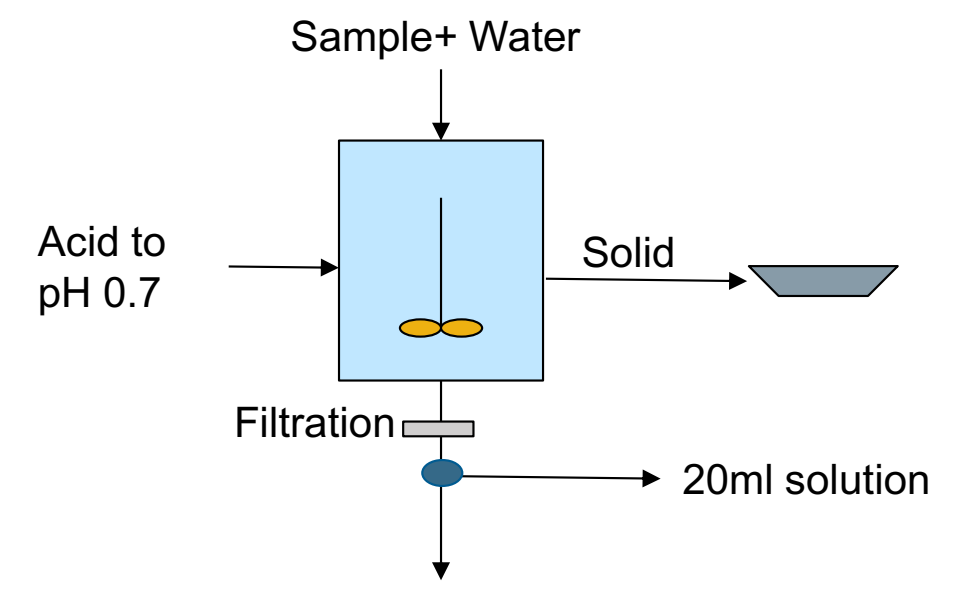

Figure 20. Experimental flowsheet for exploratory leaching tests.

\subsubsection{Leaching Kinetics Test Procedures}

The experimental design for the parametric leaching tests performed isolated the leach $\mathrm{pH}$ and the leaching time as the sole experimental parameters of interest. All other variables, including temperature, mixing speed, solid to liquid ratio, sample type and acid type, were held constant. Prior exploratory testing revealed optimal values for these parameters, and overall, they were observed to be of a smaller significance with respect to system design and economic assessment. Table 5 summarizes the experimental parameters used during testing. The initial test setup was conducted in a manner similar to that described above. After initiating the leaching reaction, $20 \mathrm{~mL}$ of leach solution was withdrawn from the reactor and filtered using a $20 \mu \mathrm{m}$ syringe filter at specific times throughout the test. The filtrate (i.e. pregnant leach solution) was then split and retained for ICP-MS (REE) and ICP-OES (major metal) analysis. This process was repeated for each test increment, and at the maximum increment, the remaining residue was filtered, dried, weighed, and sent for REE analysis. All tests were performed with the appropriate personal protective equipment under a laboratory fume hood. Experimental wastes were discarded according to university guidelines. A graphical depiction of this process is shown in Figure 21.

After obtaining the ICP-MS and ICP-OES results from the analytical laboratories, leach recovery was determined by dividing the aqueous metal concentrations $(\mathrm{mg} / \mathrm{L})$ by the feed material concentration normalized to the total test volume ( $\mathrm{mg} / \mathrm{kg} x$ dry mass feed / test volume). Results were aggregated for total rare earths, heavy rare earths, major metals, actinides (uranium and thorium), and rare earth value. 
Table 5. Experimental Parameters for Parametric Leaching Tests

\begin{tabular}{lll}
\hline Parameter & Unit & Value \\
\hline Experimental Parameters & & \\
\hline Leaching Time & minutes & $3.75,7.5,15,30$ \\
Leaching pH & -- & $0.5,1,1.5,2,2.5,3,3.54$ \\
\hline Constant Parameters & & \\
\hline Sample & -- & MV \\
Acid Type & -- & Nitric \\
Acid Concentration & Mol/L & 3 \\
Leach Temperature & ${ }^{\circ} \mathrm{C}$ & Ambient \\
Solid to Liquid Ratio & -- & $1: 1$ \\
Stirrer Speed & $\mathrm{RPM}$ & 350 \\
Sludge Wet Mass & $\mathrm{Grams}$ & 100 \\
\hline Responses & & \\
\hline REE Leach Recovery & $\%$ & Measured \\
Actinide Leach Recovery & $\%$ & Measured \\
Major Metal Leach Recovery & $\%$ & Measured \\
\hline
\end{tabular}

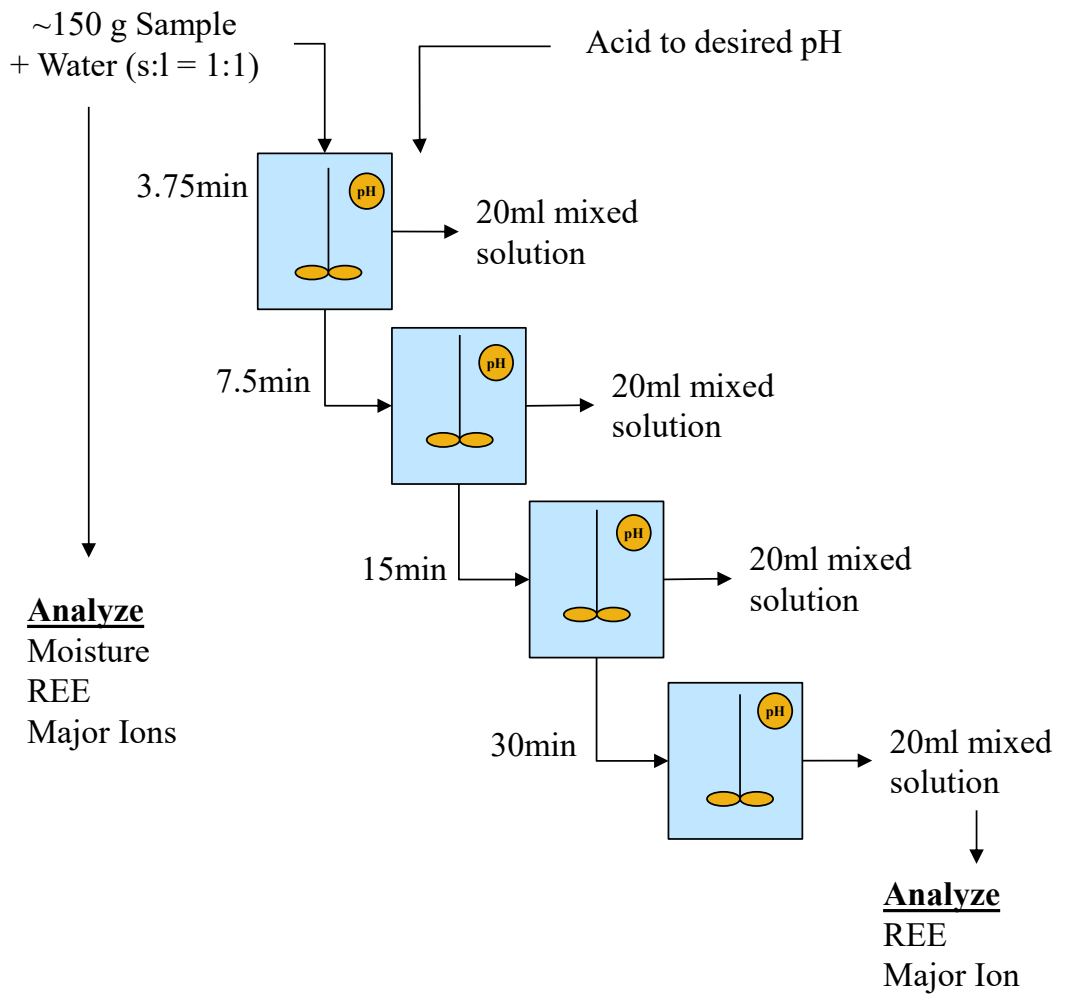

Figure 21. Experimental flowsheet for kinetic leaching tests. 


\subsubsection{Countercurrent Tests}

To reduce the environmental impact and increase the leaching efficiency, the countercurrent test was performed in this study. One set of a three-stage test was designed by recycling the filtrate of the leachate that was used as the acid in the next stage of leaching. A flowsheet for this experiment is shown in Figure 22.

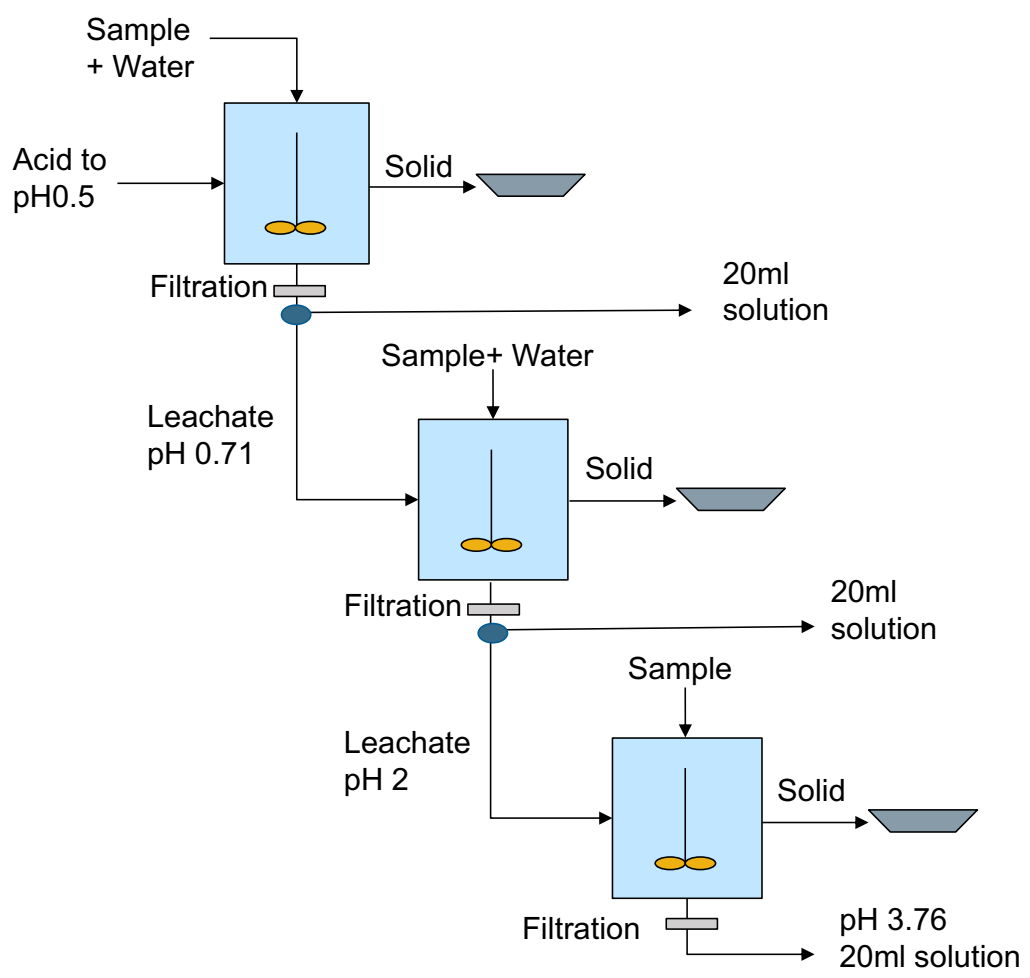

Figure 22. Experimental flowsheet for countercurrent leaching test.

The MV AMDp sample was used in this test. First the moisture of the feed sample was obtained by averaging three groups of drying samples. Then $150 \mathrm{~g}$ feed sample was mixed with $150 \mathrm{ml} \mathrm{DI}$ water by the magnet bar on a hotplate. The $\mathrm{pH}$ of the mixture was adjusted by $3 \mathrm{M} \mathrm{HNO}_{3}$ and measured by $\mathrm{pH}$ meter till $\mathrm{pH} 0.5$. After $20 \mathrm{~min}$ reaction, the mixture was filtered, and the filtrate was collected for the next stage leaching. After measuring the $\mathrm{pH}$ of the filtrate from the first stage test, two sets of $20 \mathrm{ml}$ filtrate solution were collected for the ICP-MS tests. The remaining filtrate was added into a mixture of $150 \mathrm{~g}$ feed sample and $150 \mathrm{ml}$ DI water. After 20min reaction, the filtrate of the second stage test leachate was collected for the tests and the rest was added into the third stage test with $150 \mathrm{~g}$ feed sample and no DI water. After $20 \mathrm{~min}$ reaction, filtrate sample was collected for ICP tests. The $\mathrm{pH}$ and volumes of each filtrates were recorded. 


\subsection{Results and Discussion}

\subsubsection{Material Characterization}

XRD was used to characterize the mineral in the MV feed sample. The AMDp material was dried in oven and grinded by hand prior to the XRD tests. The results (Figure 23 ) indicate that the main mineral of this sample was anhydrite, owing to the use of lime in the treatment process. It should be noted, however, that the large amount of noise in the XRD result suggests a high prevalence of amorphous phase.

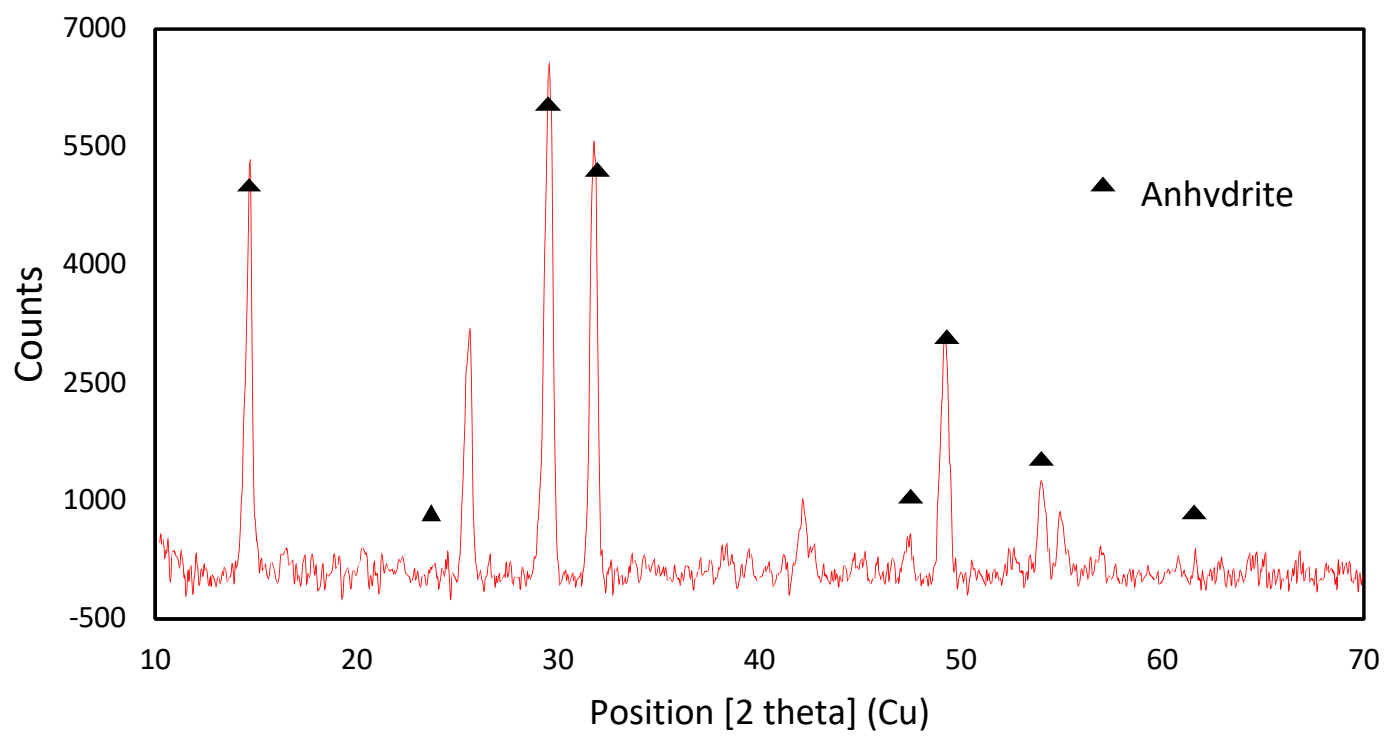

Figure 23. XRD analysis of MV AMDp sample.

A Hitachi S-4700 Scanning Electron Microscope was used to determine the characterization of MV feed sample. The feed sample's SEM results were shown as below. The Figure 24 shows that the MV sample's particle size was small and uneven which offered large surface areas during chemical reaction. The surface was also very rough and covered by fine complex structures which were determined to be metal oxide compounds. These complexes were the targets for the leaching and precipitation tests.

Bulk chemical characterization of the MV sludge material was conducted by SGS Canada. REE concentrations were determined by four replicate analysis, while major contament metals were only determind in a single analysis. Resutls from this analysis are shown in Table 6. As shown, the TREE content of this material is $375 \mathrm{mg} / \mathrm{kg}$, a value notably lower than the average NAPP AMDp sample reported by Vass (Vass C. R., 2019b), $750 \mathrm{mg} / \mathrm{kg}$. In addition to the bulk concentration, the moisture content was determined by full dessication overnight in a laboratory oven at $105^{\circ} \mathrm{C}$. Results of this repeat analysis show that the feed moisture content is $86 \%$ with a standard deviation of $1.34 \%$. REE analyses for the DL and BG sample sare shown in Table 7 and Table 8, respectively. Typical moisture content for the BG samples was determined to be $94 \%$, while DL was $61 \%$ 

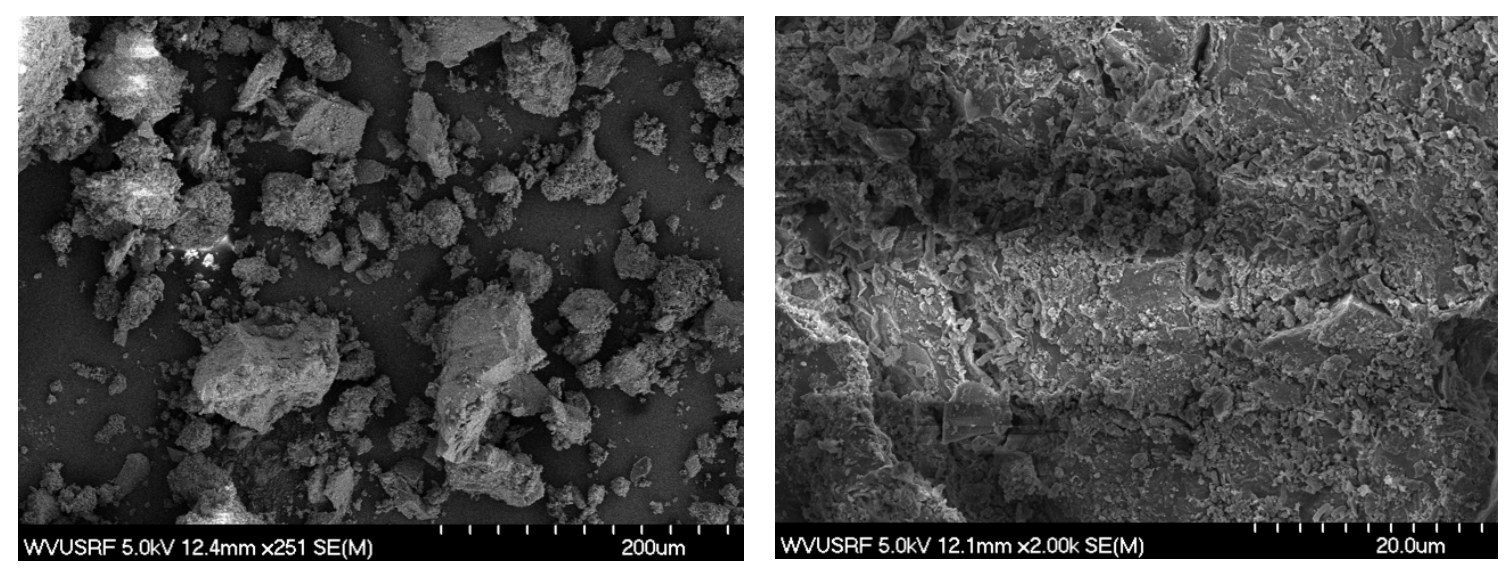

Figure 24. SEM Micrograph of the MV AMDp sample.

Table 6. Bulk Chemical Characterization of MV AMDp via ICP-MS

\begin{tabular}{|c|c|c|c|c|c|c|}
\hline Element & Unit & Rep 1 & Rep 2 & Rep 3 & Rep 4 & Average \\
\hline Sc & $\mathrm{mg} / \mathrm{kg}$ & $<25$ & $<25$ & $<25$ & 8.00 & 8.00 \\
\hline Y & $\mathrm{mg} / \mathrm{kg}$ & 129 & 128 & 129 & 128 & 128.50 \\
\hline La & $\mathrm{mg} / \mathrm{kg}$ & 13.0 & 13.0 & 14 & 9.20 & 12.30 \\
\hline $\mathrm{Ce}$ & $\mathrm{mg} / \mathrm{kg}$ & 44.0 & 44.0 & 46 & 36.4 & 42.60 \\
\hline $\operatorname{Pr}$ & $\mathrm{mg} / \mathrm{kg}$ & 8.30 & 8.20 & 8.6 & 7.79 & 8.22 \\
\hline $\mathrm{Nd}$ & $\mathrm{mg} / \mathrm{kg}$ & 54.0 & 55.0 & 57 & 46.7 & 53.18 \\
\hline Sm & $\mathrm{mg} / \mathrm{kg}$ & 23.1 & 22.1 & 22.5 & 22.6 & 22.58 \\
\hline $\mathrm{Eu}$ & $\mathrm{mg} / \mathrm{kg}$ & 5.50 & 5.50 & 5.6 & 6.06 & 5.67 \\
\hline $\mathrm{Gd}$ & $\mathrm{mg} / \mathrm{kg}$ & 35.3 & 36.7 & 36.8 & 33.2 & 35.50 \\
\hline $\mathrm{Tb}$ & $\mathrm{mg} / \mathrm{kg}$ & 4.70 & 5.10 & 5.1 & 4.82 & 4.93 \\
\hline Dy & $\mathrm{mg} / \mathrm{kg}$ & 27.9 & 28.9 & 28.3 & 27.1 & 28.05 \\
\hline Ho & $\mathrm{mg} / \mathrm{kg}$ & 4.40 & 4.60 & 4.5 & 4.86 & 4.59 \\
\hline $\mathrm{Er}$ & $\mathrm{mg} / \mathrm{kg}$ & 11.1 & 11.5 & 11.2 & 11.2 & 11.25 \\
\hline $\mathrm{Tm}$ & $\mathrm{mg} / \mathrm{kg}$ & 1.30 & 1.40 & 1.3 & 1.44 & 1.36 \\
\hline $\mathrm{Yb}$ & $\mathrm{mg} / \mathrm{kg}$ & 7.90 & 8.00 & 8.00 & 7.60 & 7.88 \\
\hline Lu & $\mathrm{mg} / \mathrm{kg}$ & 1.00 & 1.00 & 1.00 & 1.13 & 1.03 \\
\hline TREE & $\mathrm{mg} / \mathrm{kg}$ & 370.5 & 373.0 & 378.9 & 356.1 & 375.6 \\
\hline $\mathrm{Al}$ & $\mathrm{mg} / \mathrm{kg}$ & & & & 30000 & 30000 \\
\hline $\mathrm{Ca}$ & $\mathrm{mg} / \mathrm{kg}$ & & & & 129000 & 129000 \\
\hline $\mathrm{Fe}$ & $\mathrm{mg} / \mathrm{kg}$ & & & & 160000 & 160000 \\
\hline $\mathrm{Mg}$ & $\mathrm{mg} / \mathrm{kg}$ & & & & 33200 & 33200 \\
\hline $\mathrm{Mn}$ & $\mathrm{mg} / \mathrm{kg}$ & & & & 6269 & 6269 \\
\hline Th & $\mathrm{mg} / \mathrm{kg}$ & 5.5 & 6.1 & 5.8 & 3.2 & 5.15 \\
\hline U & $\mathrm{mg} / \mathrm{kg}$ & 3.9 & 3.4 & 3.6 & 6.39 & 4.32 \\
\hline
\end{tabular}


Table 7. Bulk Chemical Characterization of DL AMDp via ICP-MS

\begin{tabular}{ccrrrr|r}
\hline Element & Unit & Rep 1 & Rep 2 & Rep 3 & Rep 4 & Average \\
\hline $\mathrm{Sc}$ & $\mathrm{mg} / \mathrm{kg}$ & $<25$ & $<25$ & $<25$ & $<25$ & $\mathrm{NA}$ \\
$\mathrm{Y}$ & $\mathrm{mg} / \mathrm{kg}$ & 329.0 & 389.0 & 405.0 & 318.0 & 360.3 \\
$\mathrm{La}$ & $\mathrm{mg} / \mathrm{kg}$ & 108.0 & 124.0 & 135.0 & 96.0 & 115.8 \\
$\mathrm{Ce}$ & $\mathrm{mg} / \mathrm{kg}$ & 295.0 & 325.0 & 353.0 & 261.0 & 308.5 \\
$\mathrm{Pr}$ & $\mathrm{mg} / \mathrm{kg}$ & 35.5 & 39.9 & 45.7 & 32.7 & 38.5 \\
$\mathrm{Nd}$ & $\mathrm{mg} / \mathrm{kg}$ & 153.0 & 170.0 & 191.0 & 139.0 & 163.3 \\
$\mathrm{Sm}$ & $\mathrm{mg} / \mathrm{kg}$ & 39.0 & 42.6 & 49.4 & 35.4 & 41.6 \\
$\mathrm{Eu}$ & $\mathrm{mg} / \mathrm{kg}$ & 10.3 & 11.2 & 14.6 & 9.5 & 11.4 \\
$\mathrm{Gd}$ & $\mathrm{mg} / \mathrm{kg}$ & 56.0 & 60.5 & 68.8 & 51.0 & 59.1 \\
$\mathrm{~Tb}$ & $\mathrm{mg} / \mathrm{kg}$ & 9.6 & 10.0 & 13.2 & 8.8 & 10.4 \\
$\mathrm{Dy}$ & $\mathrm{mg} / \mathrm{kg}$ & 57.5 & 62.2 & 71.2 & 53.4 & 61.1 \\
$\mathrm{Ho}$ & $\mathrm{mg} / \mathrm{kg}$ & 11.8 & 12.8 & 14.1 & 10.8 & 12.4 \\
$\mathrm{Er}$ & $\mathrm{mg} / \mathrm{kg}$ & 30.8 & 32.5 & 36.7 & 28.0 & 32.0 \\
$\mathrm{Tm}$ & $\mathrm{mg} / \mathrm{kg}$ & 4.3 & 4.5 & 5.2 & 3.9 & 4.5 \\
$\mathrm{Yb}$ & $\mathrm{mg} / \mathrm{kg}$ & 23.1 & 25.4 & 28.1 & 21.3 & 24.5 \\
$\mathrm{Lu}$ & $\mathrm{mg} / \mathrm{kg}$ & 3.3 & 3.6 & 4.2 & 3.1 & 3.6 \\
\hline $\mathrm{TREE}$ & $\mathrm{mg} / \mathrm{kg}$ & 1166.2 & 1313.2 & 1435.2 & 1071.9 & 1246.6 \\
\hline
\end{tabular}


Table 8. Bulk Chemical Characterization of BG AMDp via ICP-MS

\begin{tabular}{ccrrr|r}
\hline Element & Unit & Rep 1 & Rep 2 & Rep 3 & Average \\
\hline $\mathrm{Sc}$ & $\mathrm{mg} / \mathrm{kg}$ & $<25$ & $<25$ & $<25$ & $\mathrm{NA}$ \\
$\mathrm{Y}$ & $\mathrm{mg} / \mathrm{kg}$ & 100.0 & 92.0 & 95.0 & 95.7 \\
$\mathrm{La}$ & $\mathrm{mg} / \mathrm{kg}$ & 45.0 & 37.0 & 37.0 & 39.7 \\
$\mathrm{Ce}$ & $\mathrm{mg} / \mathrm{kg}$ & 152.0 & 130.0 & 133.0 & 138.3 \\
$\mathrm{Pr}$ & $\mathrm{mg} / \mathrm{kg}$ & 22.6 & 19.3 & 19.5 & 20.5 \\
$\mathrm{Nd}$ & $\mathrm{mg} / \mathrm{kg}$ & 102.0 & 90.0 & 91.0 & 94.3 \\
$\mathrm{Sm}$ & $\mathrm{mg} / \mathrm{kg}$ & 28.1 & 24.7 & 25.8 & 26.2 \\
$\mathrm{Eu}$ & $\mathrm{mg} / \mathrm{kg}$ & 6.3 & 5.3 & 5.4 & 5.7 \\
$\mathrm{Gd}$ & $\mathrm{mg} / \mathrm{kg}$ & 29.5 & 27.1 & 27.4 & 28.0 \\
$\mathrm{~Tb}$ & $\mathrm{mg} / \mathrm{kg}$ & 4.2 & 3.8 & 3.9 & 4.0 \\
$\mathrm{Dy}$ & $\mathrm{mg} / \mathrm{kg}$ & 22.9 & 20.2 & 20.9 & 21.3 \\
$\mathrm{Ho}$ & $\mathrm{mg} / \mathrm{kg}$ & 4.2 & 3.7 & 3.8 & 3.9 \\
$\mathrm{Er}$ & $\mathrm{mg} / \mathrm{kg}$ & 10.7 & 9.8 & 10.0 & 10.2 \\
$\mathrm{Tm}$ & $\mathrm{mg} / \mathrm{kg}$ & 1.4 & 1.2 & 1.2 & 1.3 \\
$\mathrm{Yb}$ & $\mathrm{mg} / \mathrm{kg}$ & 7.9 & 6.8 & 7.3 & 7.3 \\
$\mathrm{Lu}$ & $\mathrm{mg} / \mathrm{kg}$ & 1.1 & 1.0 & 1.0 & 1.0 \\
\hline $\mathrm{TREE}$ & $\mathrm{mg} / \mathrm{kg}$ & 537.9 & 471.9 & 482.2 & 497.3 \\
\hline
\end{tabular}

\subsubsection{Effect of Acid and Sample Type}

Figure 25 and Figure 26 show the results from the exploratory acid leaching test. In all plots, the dependent variables are shown as leachate concentration $(\mathrm{mg} / \mathrm{L})$. Comparing the sample types, the DLM consistently produced the high leachate concentration, nearly an order of magnitude greater than that of the two other samples. This result is partially explained by the relatively high feed concentration for this material, which in turn prompts higher aqueous concentrations in a fixed volume. With respect to the acid type, sulfuric acid typically leads to higher REE and major metal leaching in the MV and DL samples; however, BG did not respond as well to sulfuric acid. The chemical composition of $B G$ appears to be unique from the other two, as the leachate showed relatively high $\mathrm{Al}$ and Ca concentrations. DL is notable for the relatively low degree of Fe leaching and the low concentration of $\mathrm{Ca}$.

With respect to the individual REEs, $Y$ is often the most the dominant species, thus suggesting greater initial concentrations and greater solubility than the other REEs. Ce and $\mathrm{Nd}$ are also prominent, but overall, the behavior of individual REEs (Figure 26) largely matches that of the total (Figure 25). 


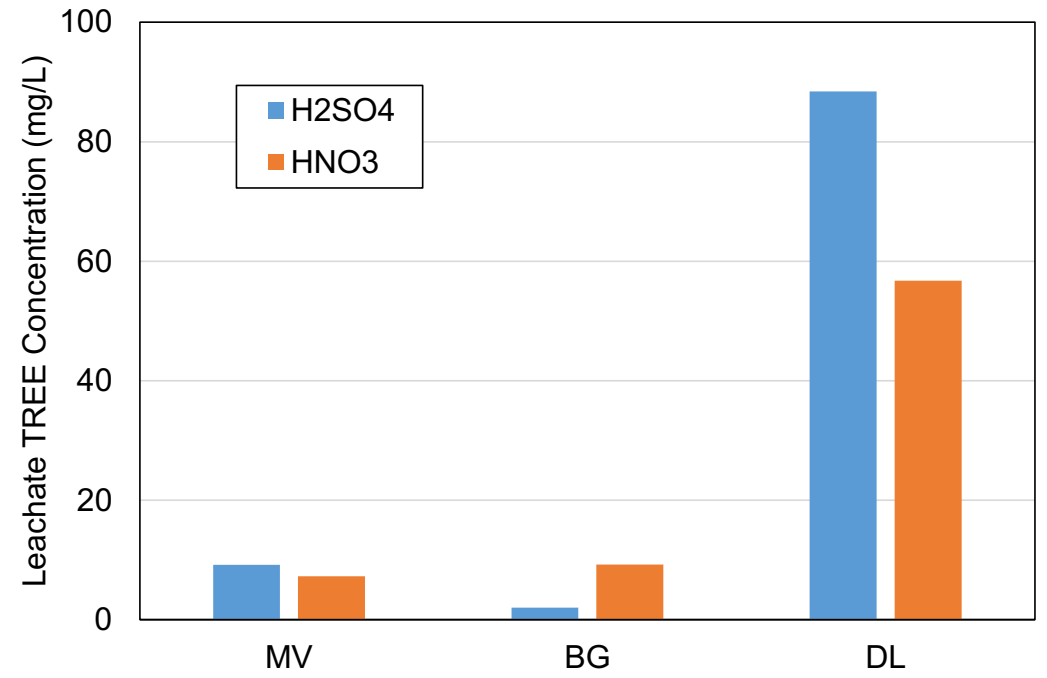

Figure 25. Total REE concentration in leachate for various AMDp samples and acid types.

Figure 27 shows the correlation between individual major metals and TREE leachate concentrations for all tests conducted in this campaign. The concentration of most elements, including $\mathrm{Ca}$, $\mathrm{Fe}$, and $\mathrm{Mn}$, show little or no correlation with TREE content; however, $\mathrm{Al}$ and $\mathrm{Mg}$ both show strong correlations, thus suggesting that the REE solubility may be closely linked to these elements. This trend is particularly noteworthy given the disparate host settings and treatment approaches used to generate these AMDp materials. Moreover, the trend is apparent in both nitric and sulfuric acid, suggesting that any anion complexation is also following a similar trend.

\subsubsection{Leaching Kinetics}

Figure 28 through Figure 35 show the results for the kinetic leaching tests. With the exception of $\mathrm{pH} 2$, all test data indicated that the leaching reaction occurs very quickly, and the maximum recovery was often achieved by the first time increment of 3.75 minutes. When compared to leaching reactions for other minerals, the kinetics of sludge leaching were much faster, indicating that process kinetics will not likely be a significant factor in design and scale-up. Since reaction kinetics were anticipated to increase as experimental scale increases, these results indicated that a modest retention time of 3 to 5 minutes is more than sufficient to complete the reaction, even after accounting for an appreciable safety factor. 

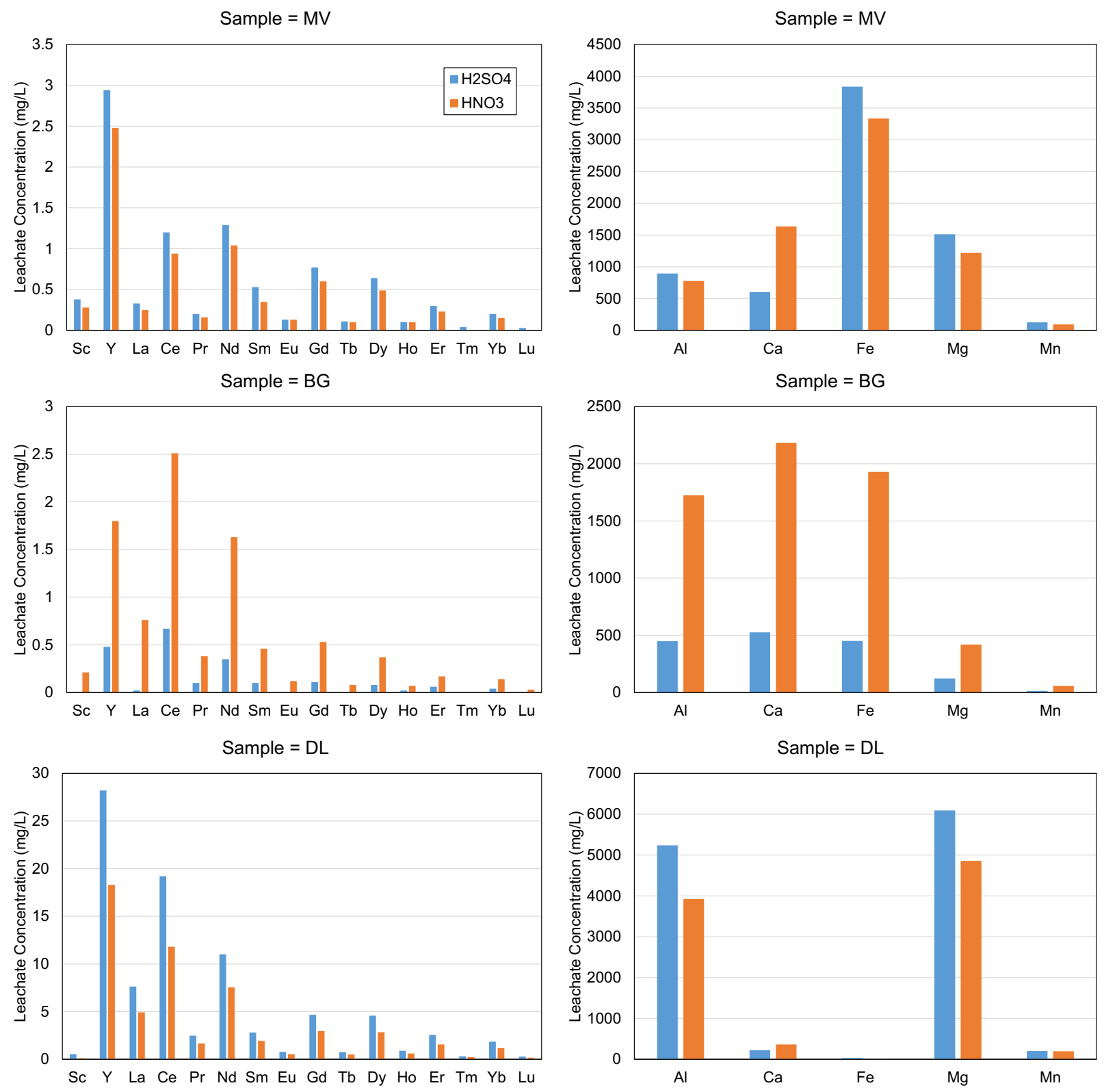

Figure 26. Leachate composition for various AMDp samples and acid types. 

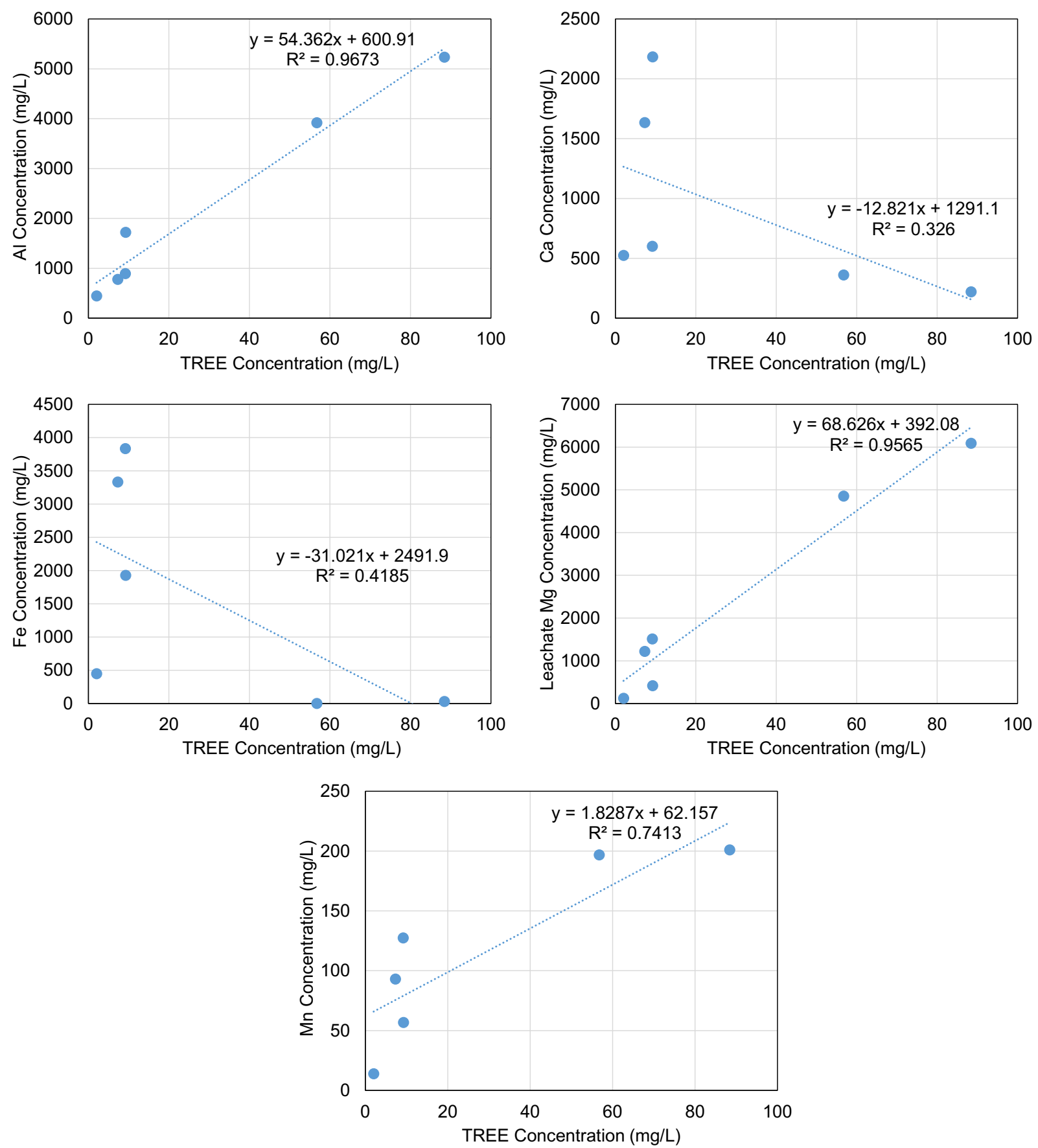

Figure 27. Relationship between major metal concentration and TREE concentration in leachates generated during exploratory testing. Data includes three different samples ( $M V, B G$, and $D M)$ as well as two different acids (nitric and sulfuric). 


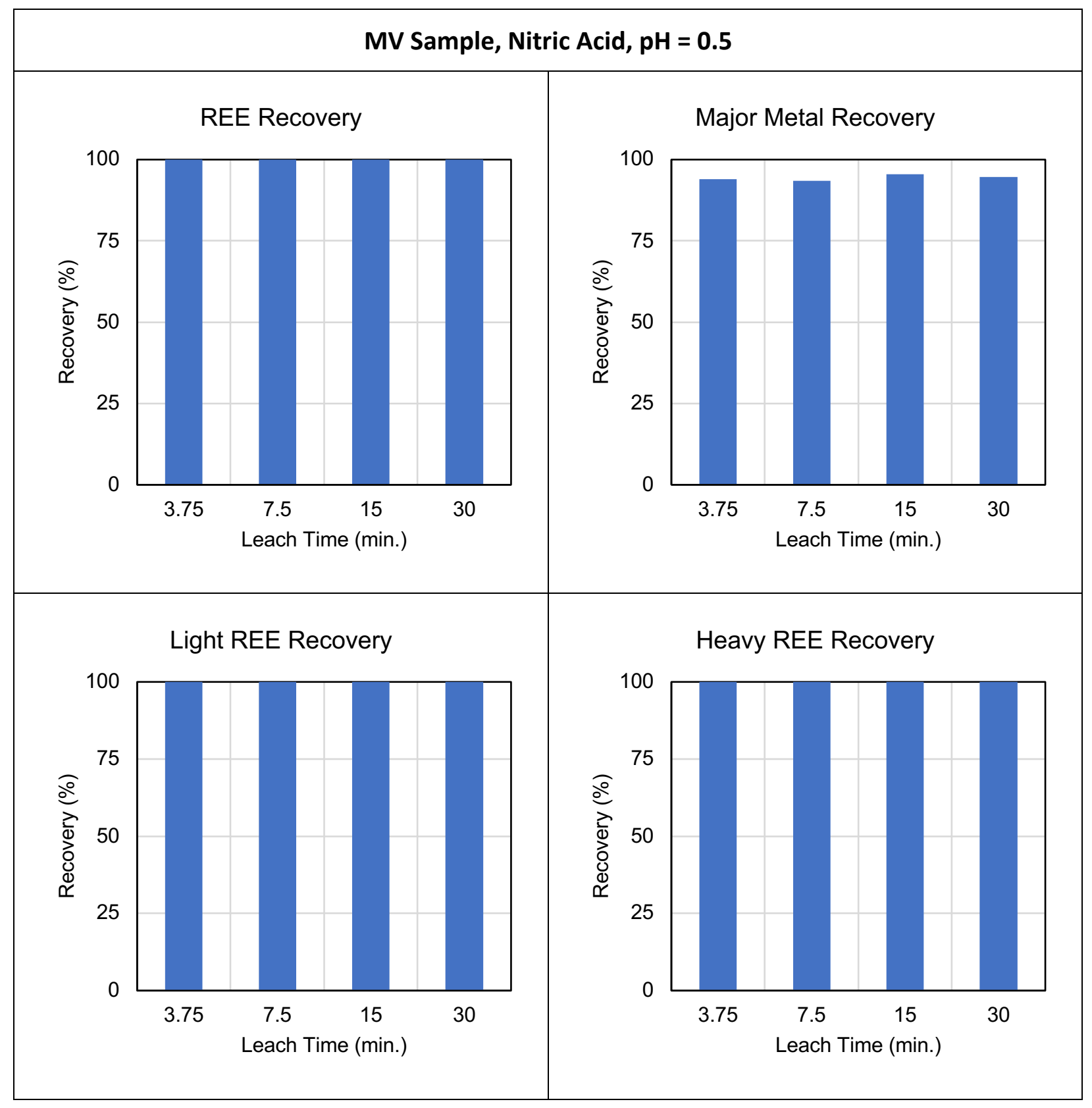

Figure 28. Leaching test results for MV Sludge, Nitric Acid, $p H=0.5$. 


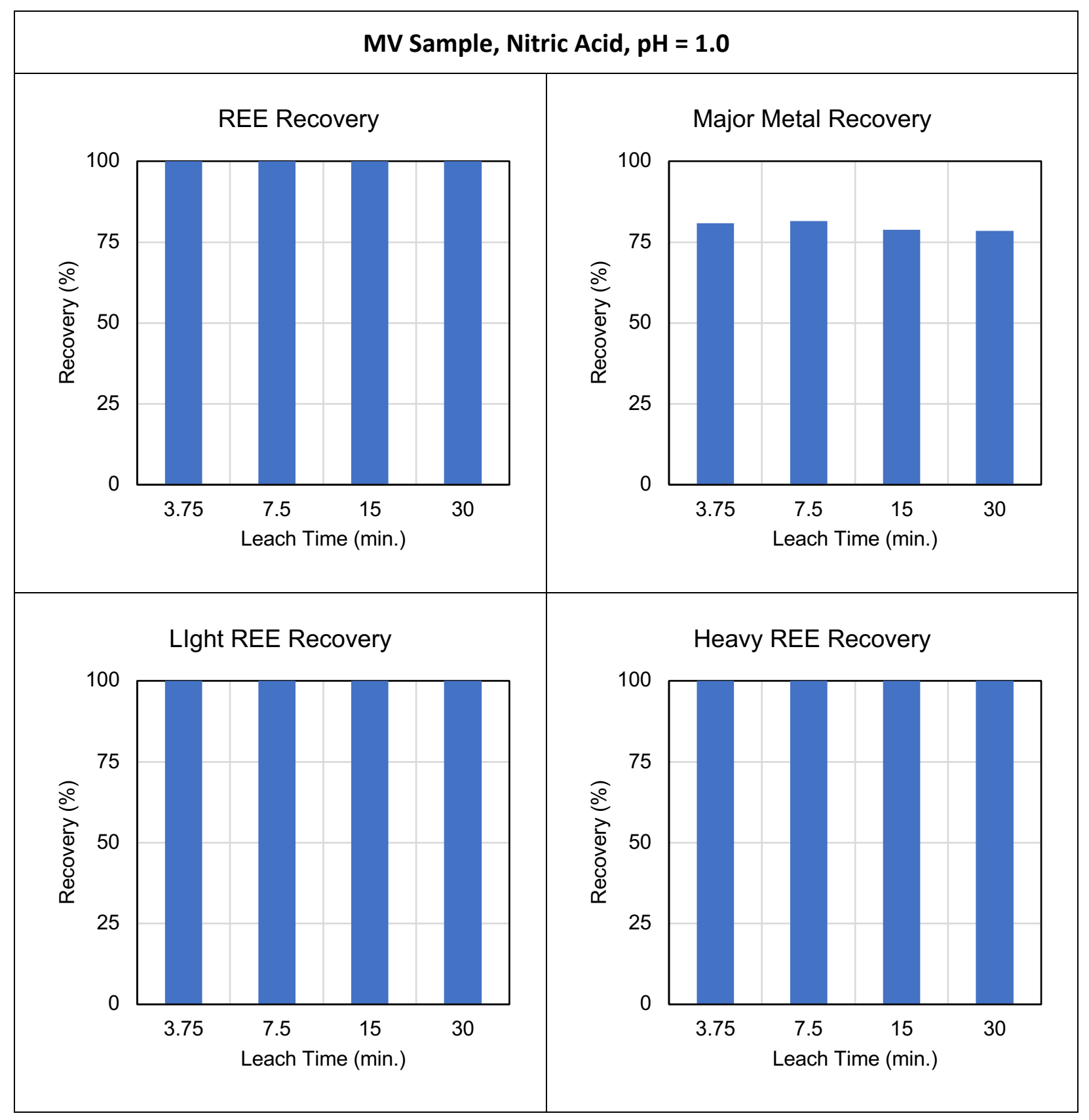

Figure 29. Leaching test results for MV Sludge, Nitric Acid, $p H=1.0$. 


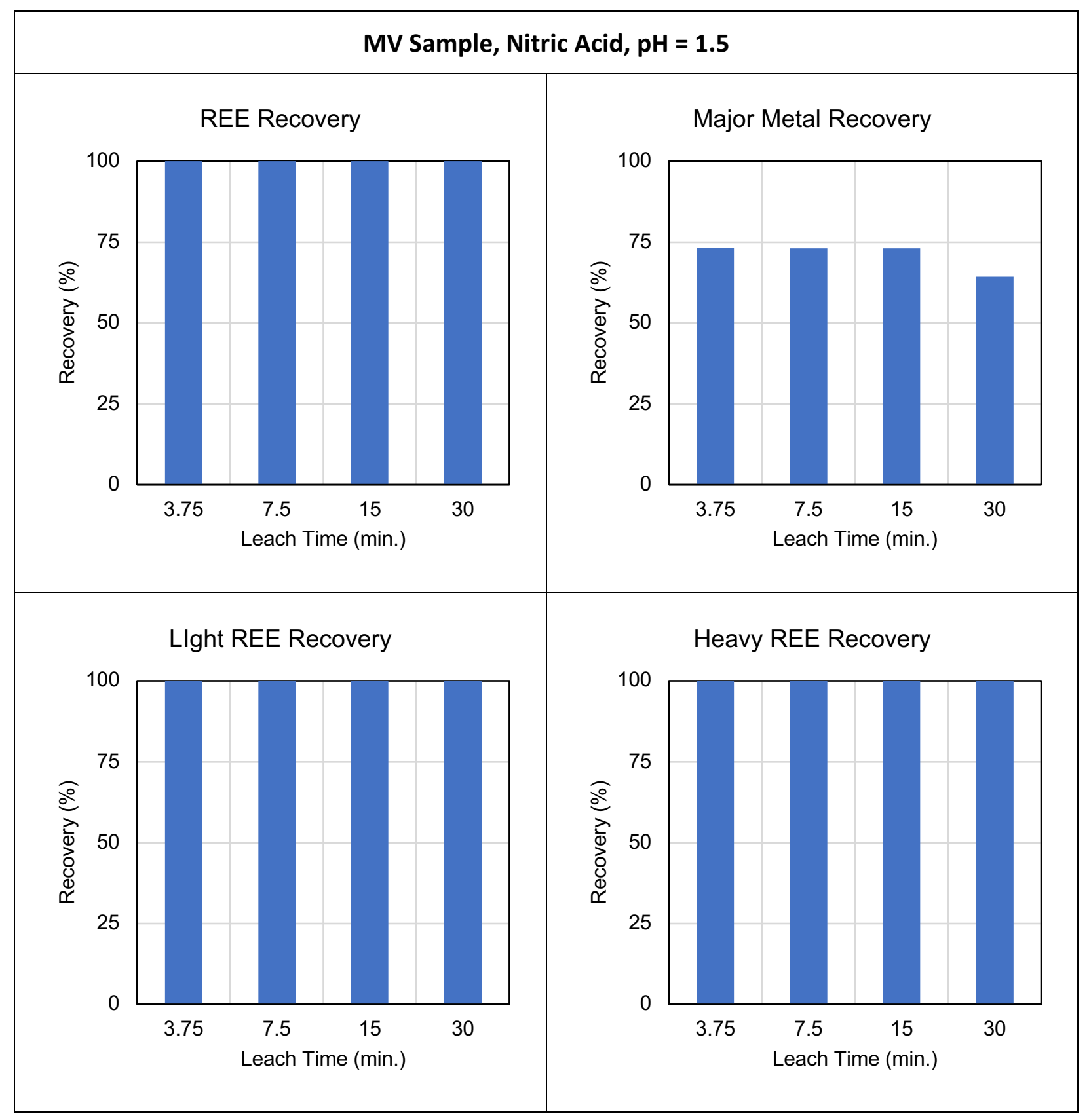

Figure 30. Leaching test results for MV Sludge, Nitric Acid, $p H=1.5$. 


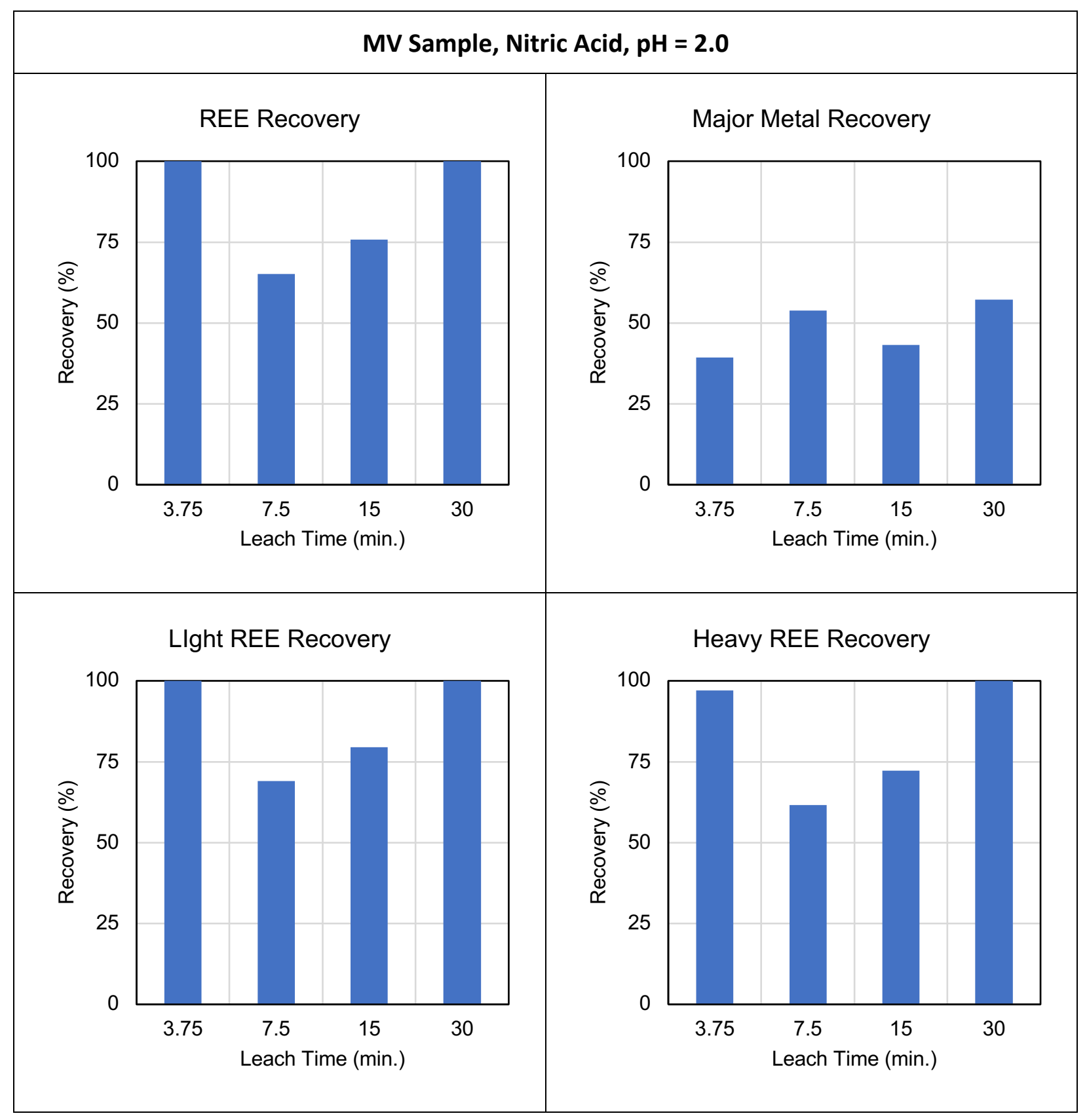

Figure 31. Leaching test results for MV Sludge, Nitric Acid, $p H=2.0$ 


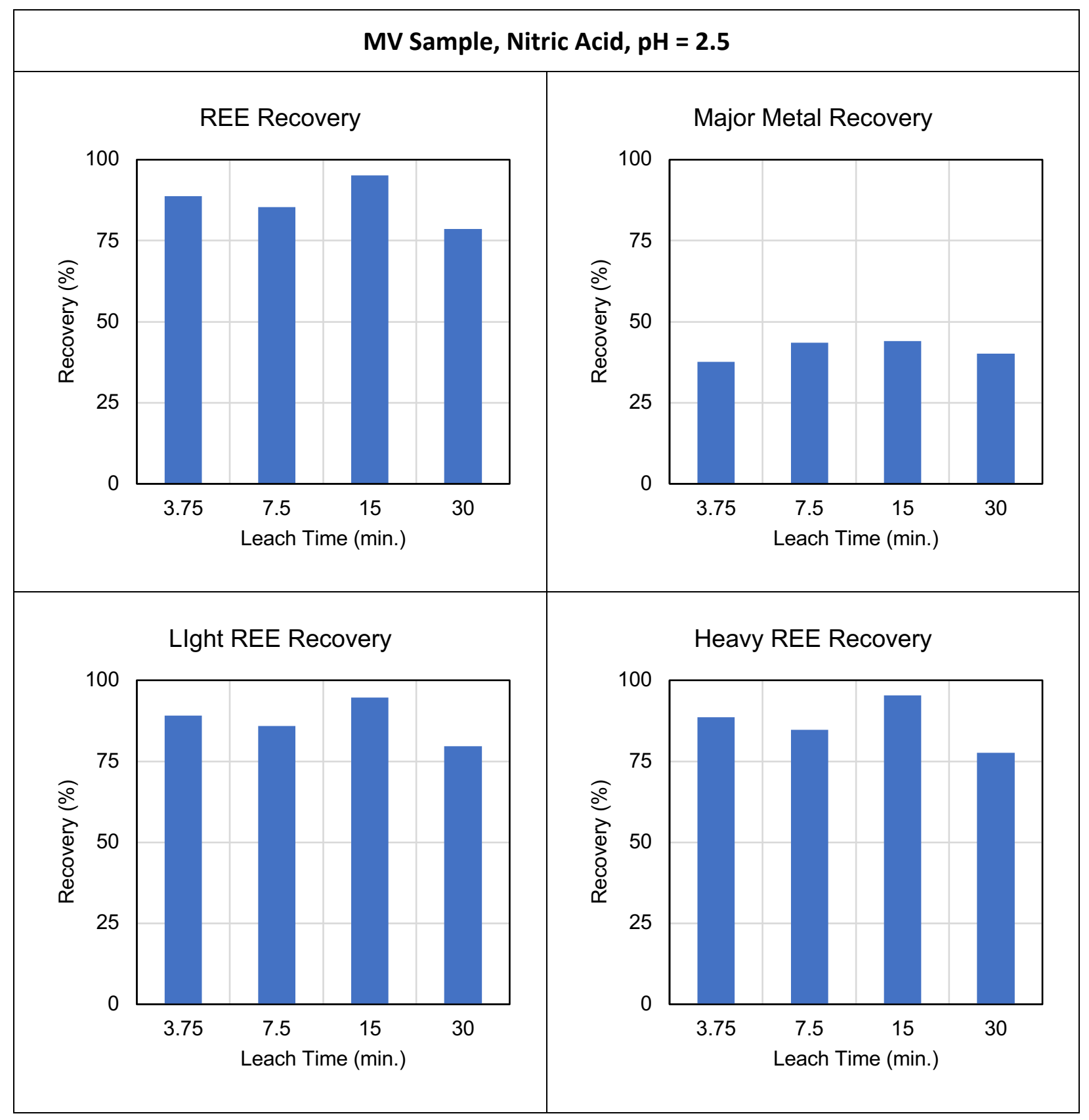

Figure 32. Leaching test results for MV Sludge, Nitric Acid, $p H=2.5$. 


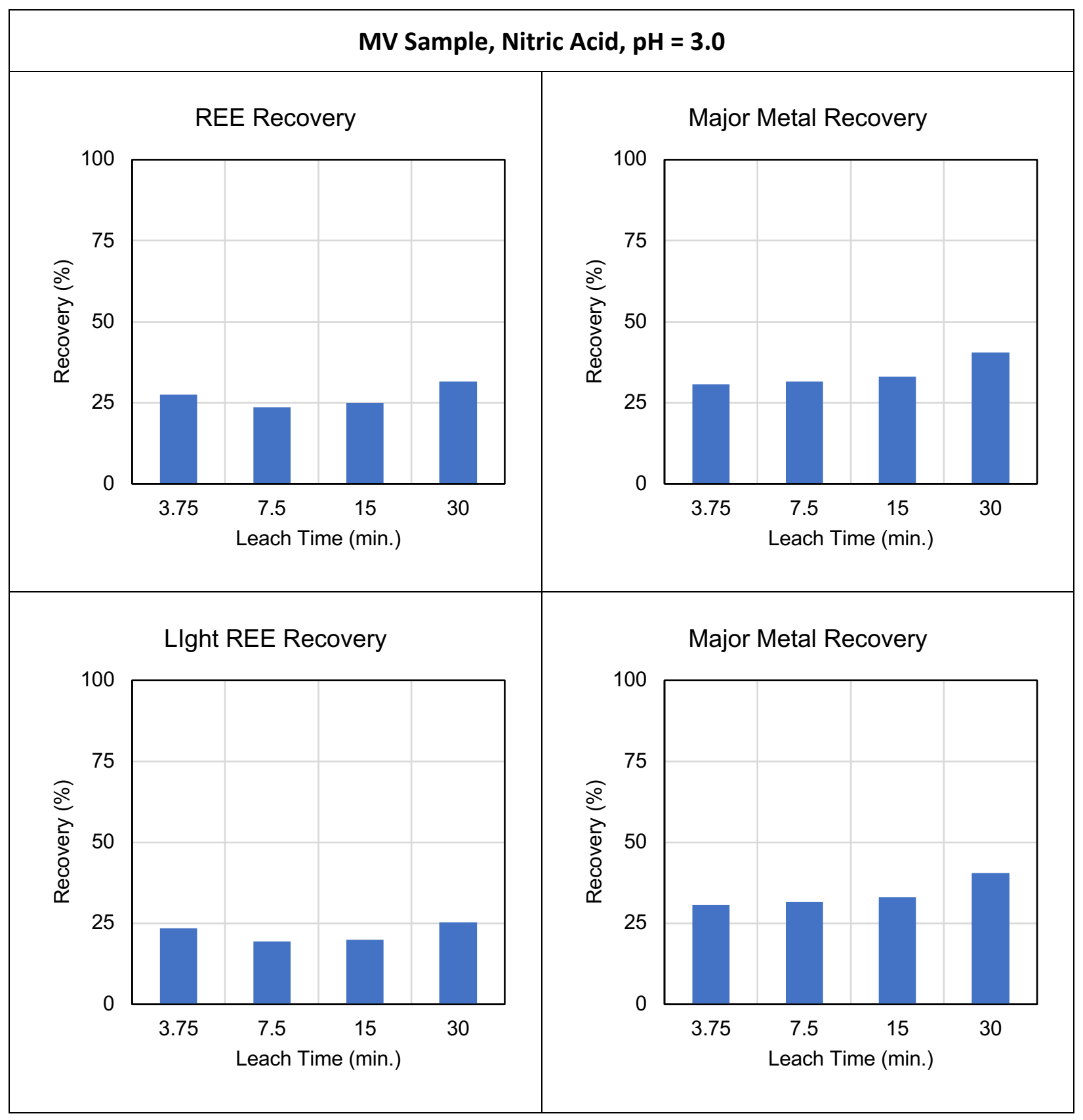

Figure 33. Leaching test results for MV Sludge, Nitric Acid, $p H=3.0$. 


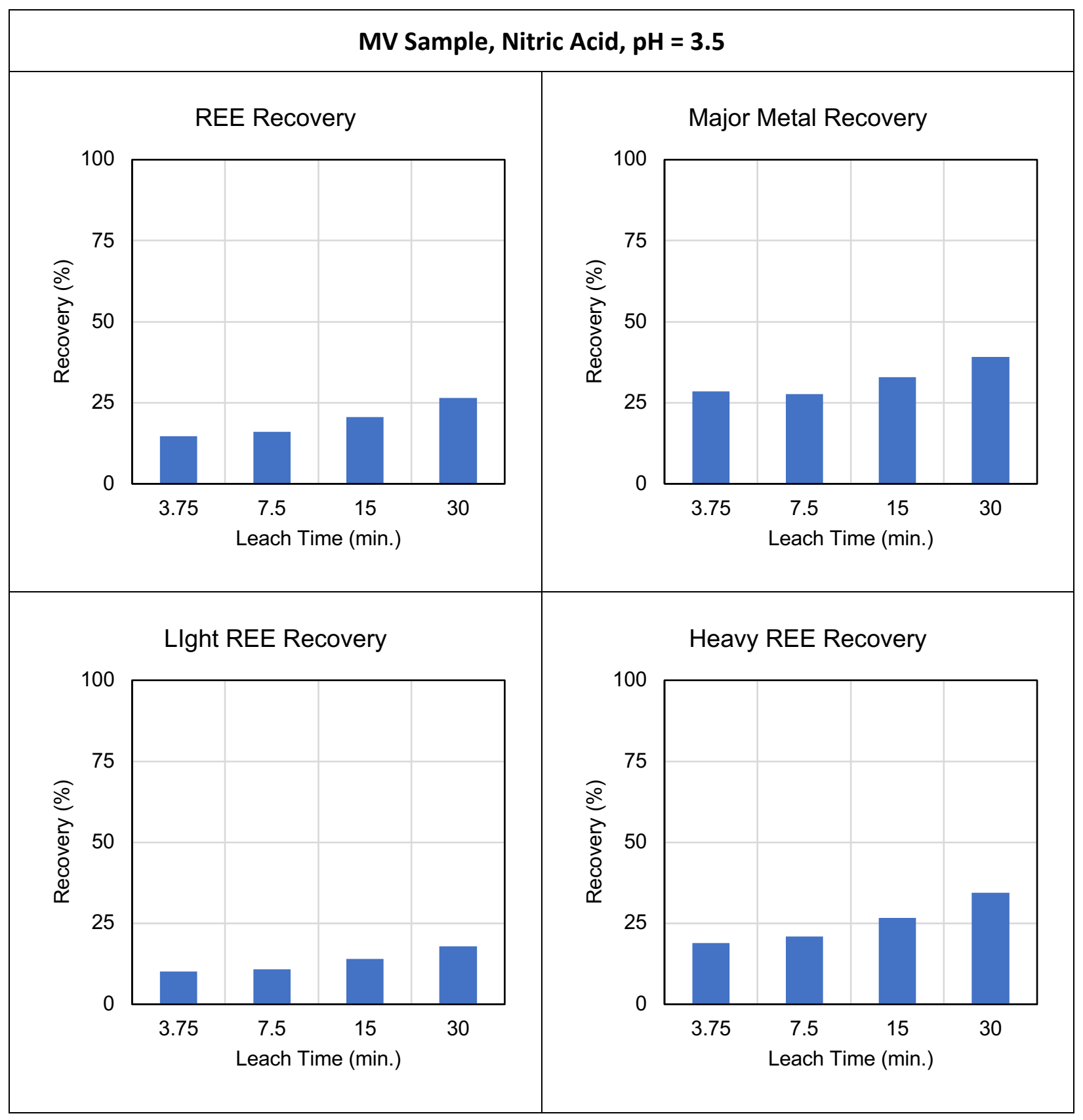

Figure 34. Leaching test results for MV Sludge, Nitric Acid, $p H=3.5$. 


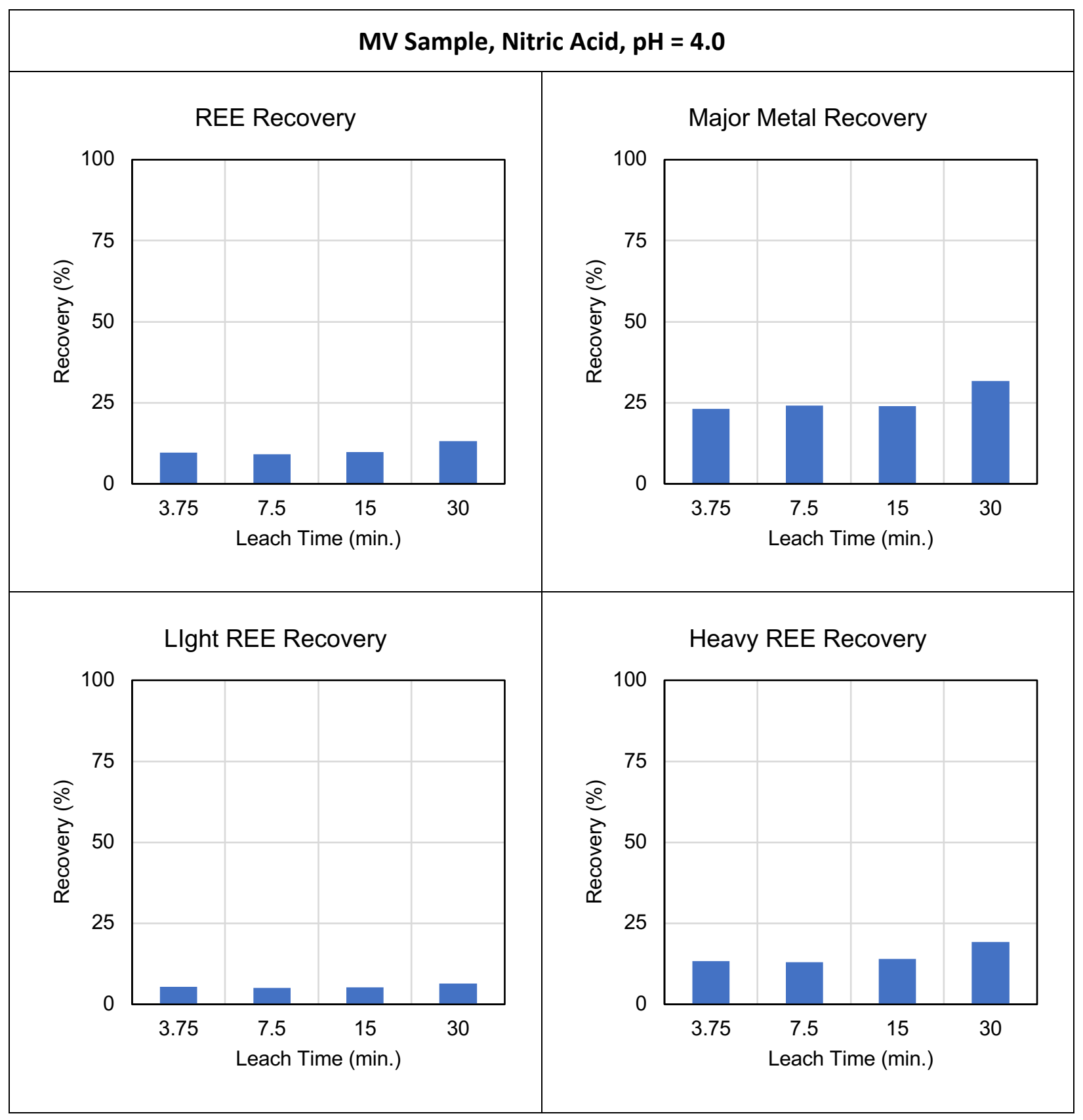

Figure 35. Leaching test results for MV Sludge, Nitric Acid, $p H=4.0$. 


\subsubsection{Leaching $\mathrm{pH}$ assessment}

In addition to leaching kinetic considerations, the parametric leaching tests conducted in this study evaluated the influence of solution $\mathrm{pH}$ on the leaching recovery and leaching selectivity. Figure 36 and Figure 37 show the results of the leaching tests at the 30-minute time increment as a function of solution $\mathrm{pH}$. Figure 36 shows the aggregated recovery results for rare earths, actinides (uranium and thorium), and major metals. As expected, the sludge material becomes more soluble at low $\mathrm{pH}$ values, with nearly all components being fully dissolved at $\mathrm{pH} 0.5$ (i.e. full digestion). However, this plot interestingly showed that efficient and selective leaching was possible at higher $\mathrm{pH}$ values, such as 2.0 . At this point, rare earth recovery was nearly $100 \%$, but major metal recovery (largely driven by iron) was less than $60 \%$. In this particular sample, iron constituted $40-50 \%$ of the gangue metals, so this reduction was significant and would improve downstream solvent extraction selectivity. This data showing high REE leaching recoveries at modest $\mathrm{pH}$ values was very promising with respect to process economics and overall process efficiency.

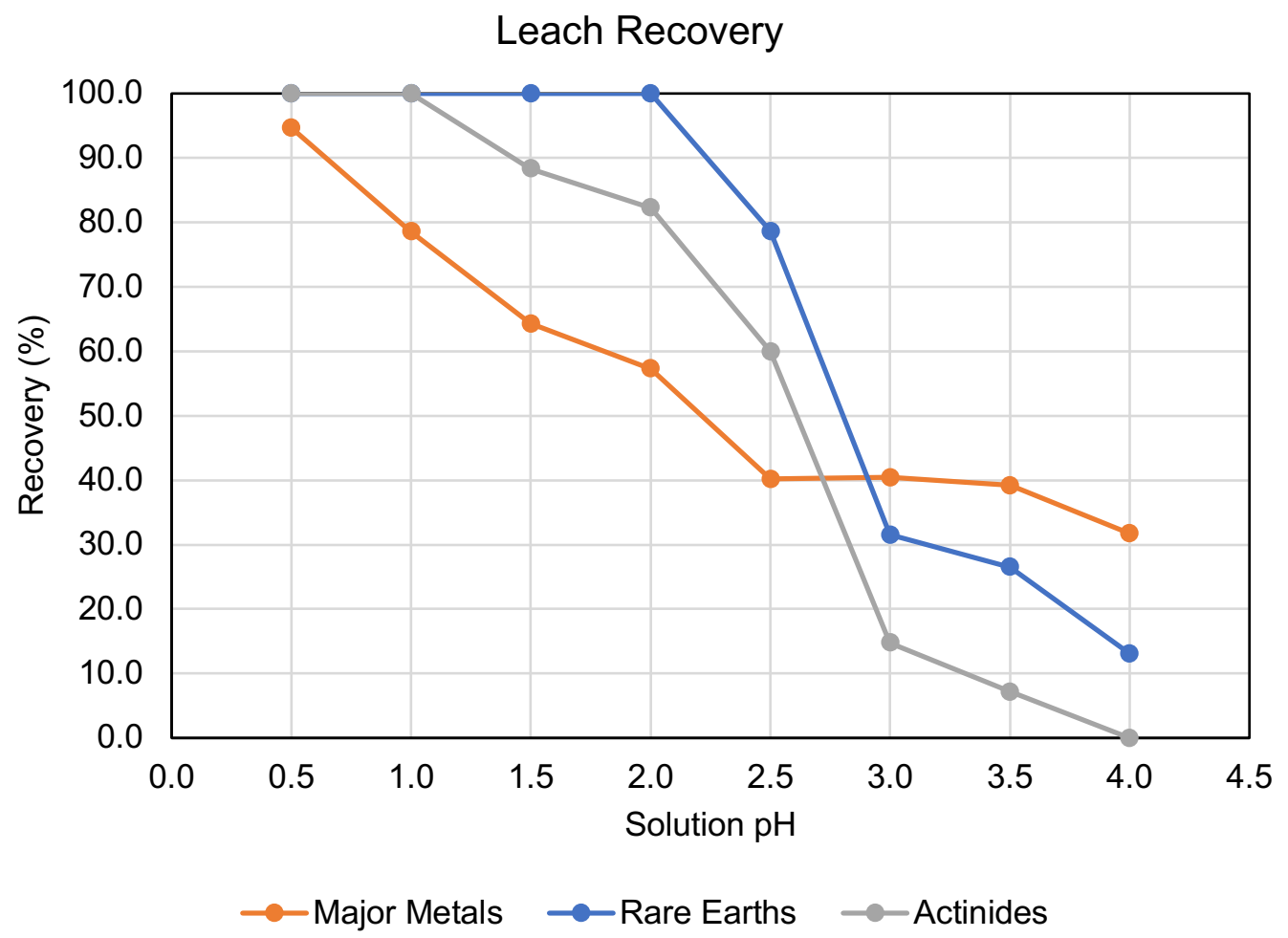

Figure 36. Leaching test results for MV sludge, Nitric Acid, time $=30$ minutes, presented as a function of leaching $\mathrm{pH}$. 
Figure 37 expands upon the Figure 36 data by showing element-by-element grouped by major designation. Overall, the data shows that most elements in the same group behaved similarly with a couple minor exceptions. Lanthanum had higher recovery values than the other light rare earth elements at high $\mathrm{pH}$ points, while Lutetium was slightly lower than other heavy rare earths at high $\mathrm{pH}$ points. The difference for Lutetium may be due to extremely low concentration values below the detection limits.

Major metal recovery varied considerably element-to-element, with iron showing a clear reduction in recovery from $\mathrm{pH}$ values from 2 to 3 . Aluminum showed a similar reduction, but at higher $\mathrm{pH}$ values of 3 to 4 . The recovery for all other major metals' values showed no clear dependence on $\mathrm{pH}$. In this particular sludge feedstock, iron and calcium were the major gangue metals, with iron accounting for $44 \%$ and calcium accounting for $36 \%$ of the total major metal concentration. At $\mathrm{pH}=2$, both of these elements were rejected at significant rates, with only $37 \%$ of the iron and $47 \%$ of the calcium reporting to the liquid phase. Finally, while the magnesium recovery was high at all $\mathrm{pH}$ points, this metal was not very significant $(<2 \%)$ in this sludge sample. Furthermore, as a divalent cation, magnesium is less likely to interfere in the solvent extraction phase, when compared to trivalent cations similar to the desired REEs.

While the actinide recovery values closely followed the REE's, it was important to note that the actinide concentration in sludge was already very low. The ratio of REEs to thorium in this particular sample was 111:1, while the ratio of REEs to uranium is 55:1. These ratios were much higher than those of other coal materials, which averaged about 20:1.

To demonstrate the economic implications of the leaching tests, Figure 38 shows the recovery values plotted as "recovered value" (cf. recovered mass) using average REE prices over the past decade. Interestingly, this plot suggested that even higher $\mathrm{pH}$ points may be suitable for the leaching reaction, as nearly $90 \%$ of the value can be recovered at a $\mathrm{pH}$ of 2.5 . Alternatively, the mass recovery value at $\mathrm{pH}=2.5$ was less than $80 \%$ (Figure 36 ), which may be misleading depending on the specific process objective (economic vs. technical). 

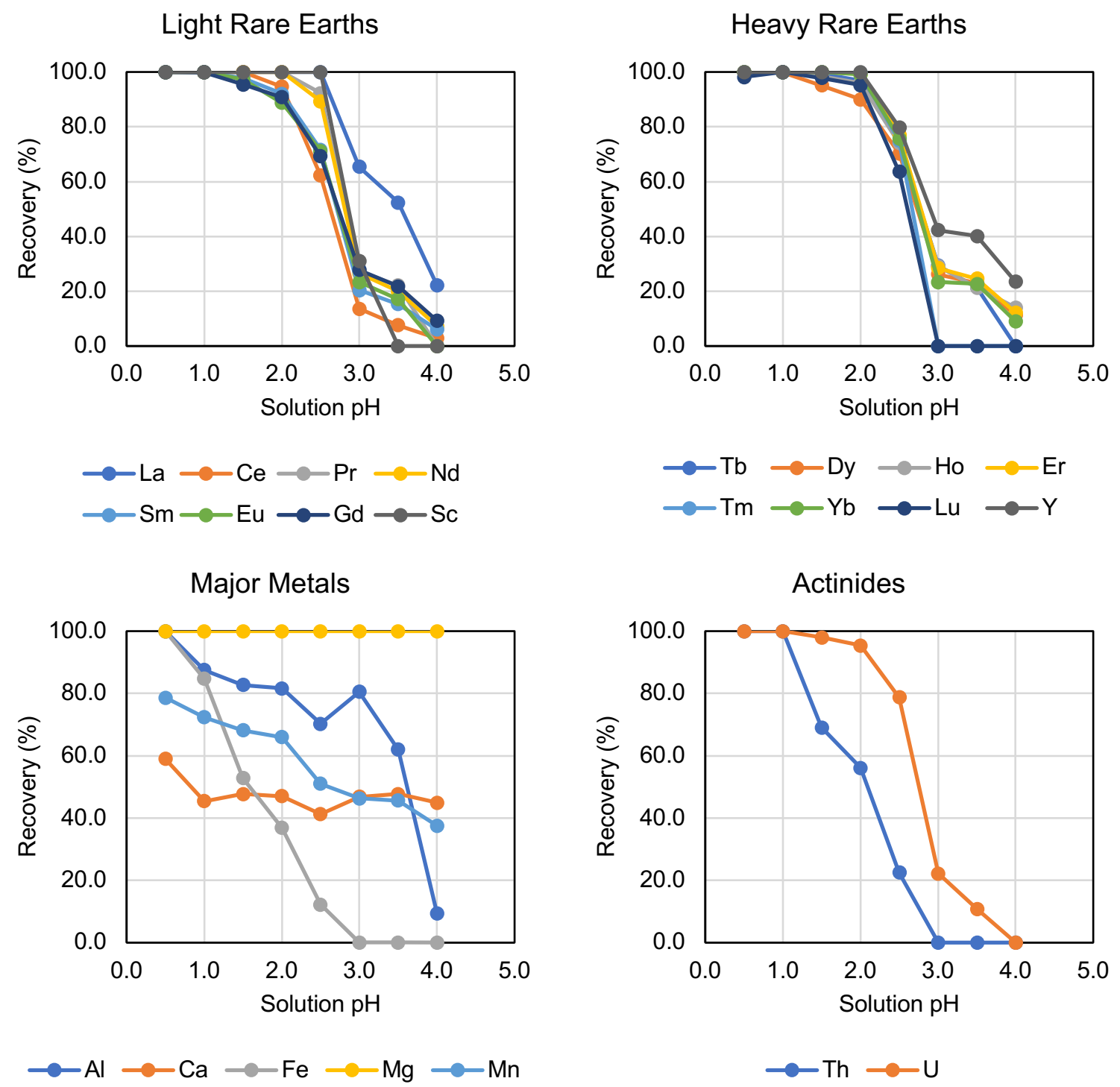

Figure 37. Leaching test results for MV Sludge, Nitric Acid, time $=30$ minutes, presented element-byelement. 


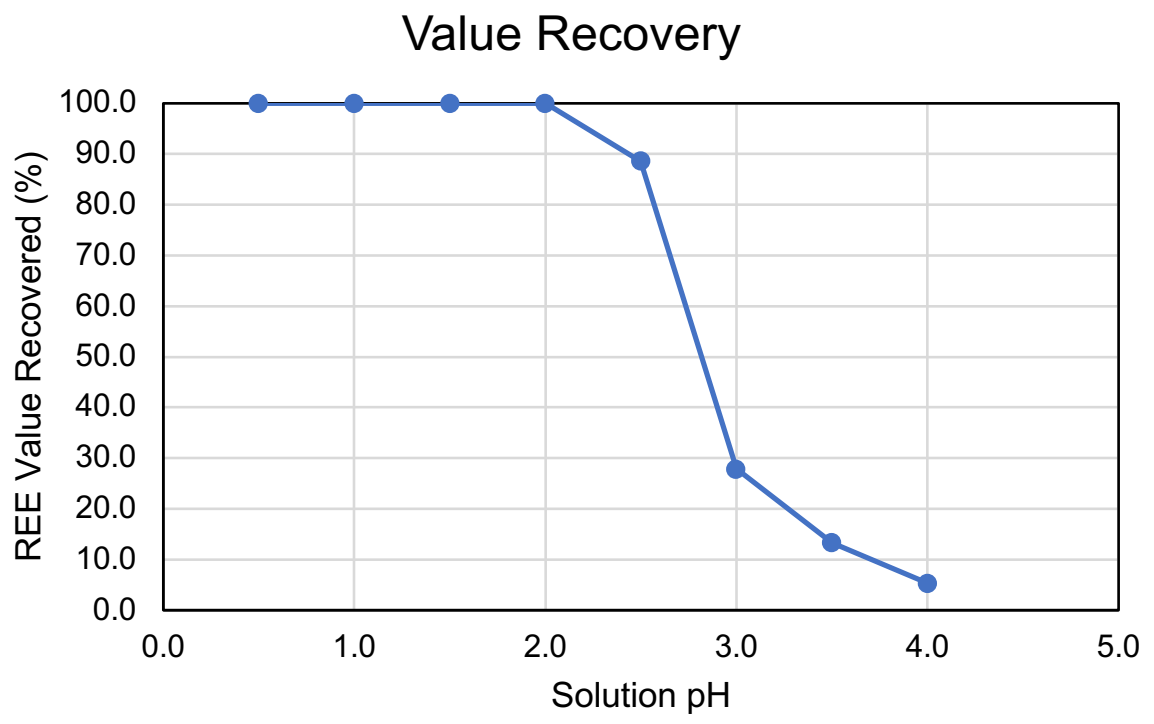

Figure 38. Leaching test results for MV Sludge, Nitric Acid, time $=30$ minutes, presented as a function of recovered REE value. REE prices based on medium/standard conditions, 2008 to 2016.

\subsubsection{Countercurrent tests}

The three stages countercurrent test results were shown in Figure 39 and Figure 40. In the first stage, the REEs recovery into solution was $98 \%$ at the initial $\mathrm{pH} 0.5$. The $\mathrm{pH}$ of the filtered leachate after reaction that was used as the acid in the second stage was 0.71 . After $20 \mathrm{~min}$ reaction, the $\mathrm{pH}$ of the second stage leachate increased to $\mathrm{pH} 2$. In the second stage the REEs recovery was $69 \%$ which included the REEs concentrated from stage one. The reduction of REEs recovery in the second stage was due to the solubility of REEs ions reached equilibration in the solution with the extra REEs concentrated from stage one even at a low $\mathrm{pH}$ point. The recovery of major metals dropped to negative indicating the precipitation of major metals also due to the ions saturation in the entire solution system. The $\mathrm{pH}$ of the filtrate of the second stage reaction used as the acid in the third stage was $\mathrm{pH} 3.76$. However, the REEs recovery of the third stage leaching decreased to negative indicating the occurrence of REEs precipitation shown in Figure 39. This result may be caused by the higher $\mathrm{pH}$ of the solution which was 3.76. Figure 41 shows the relationship of metal concentration and $\mathrm{pH}$ throughout the test steps. The major metals recovery increased because of the $\mathrm{Mg}$ dissolved more into the solution. 


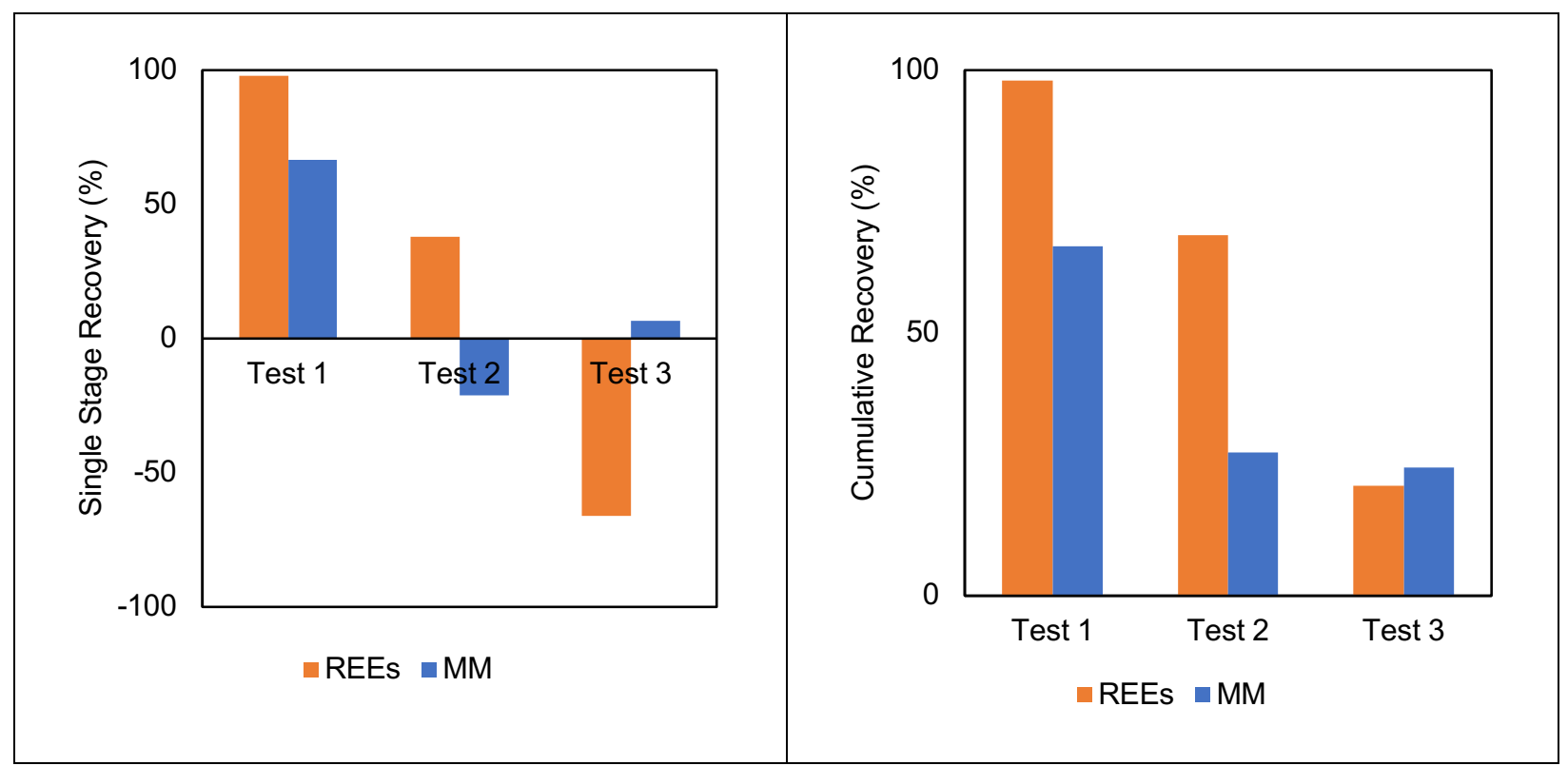

Figure 39. Countercurrent test results.

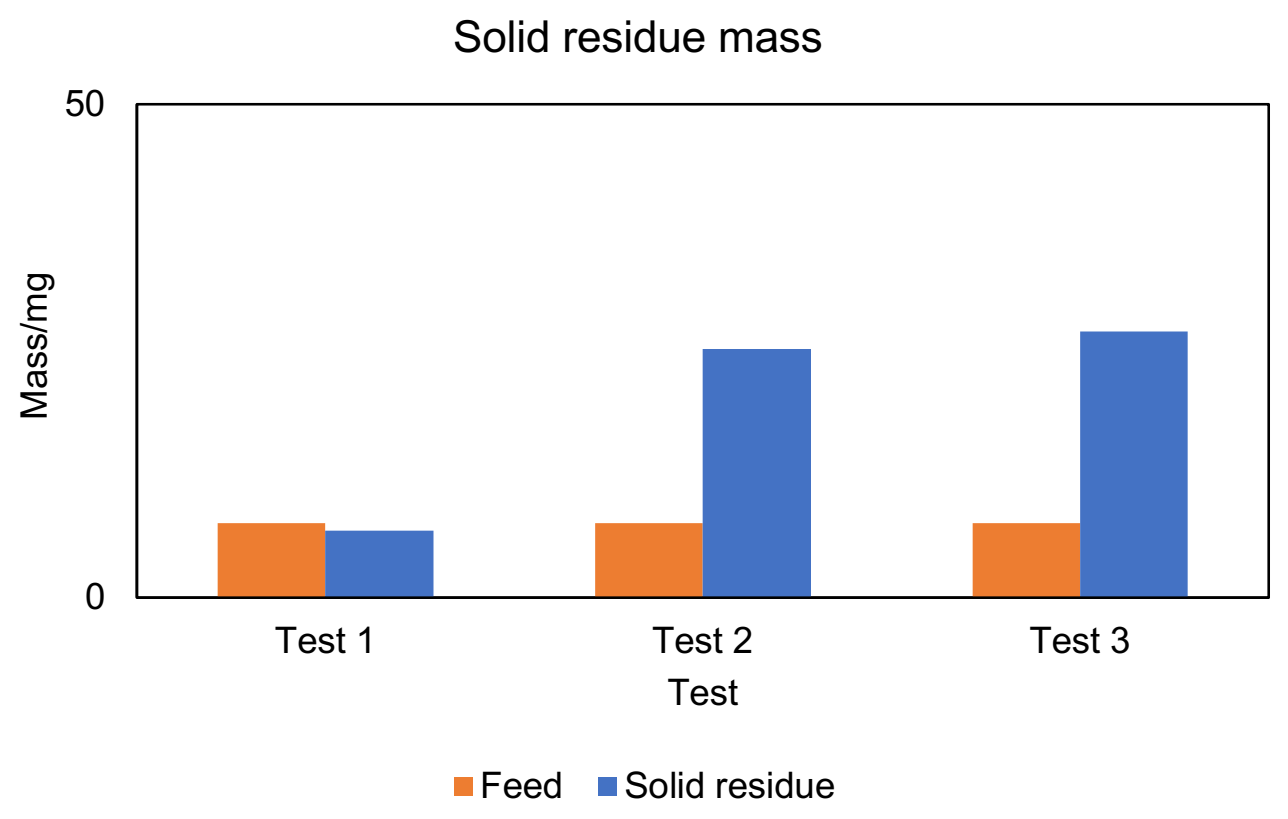

Figure 40. Solid residue mass after reaction. 
TREE

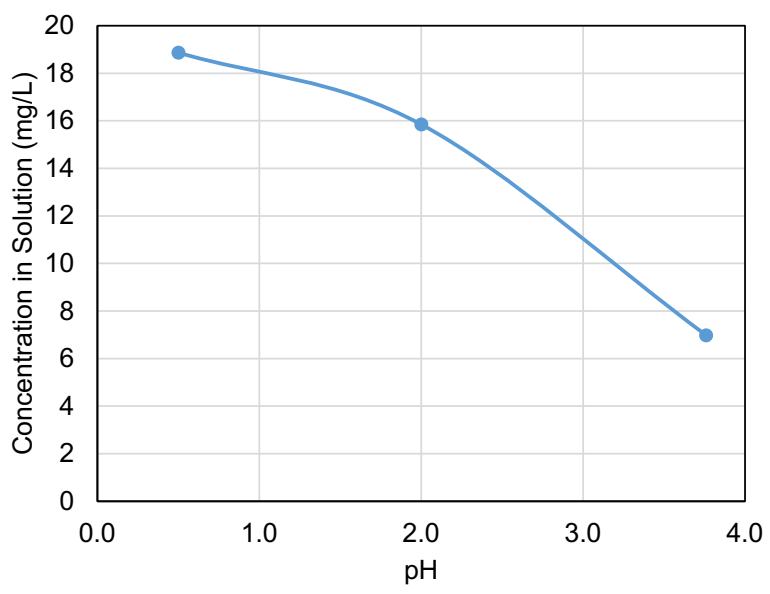

Major Metals

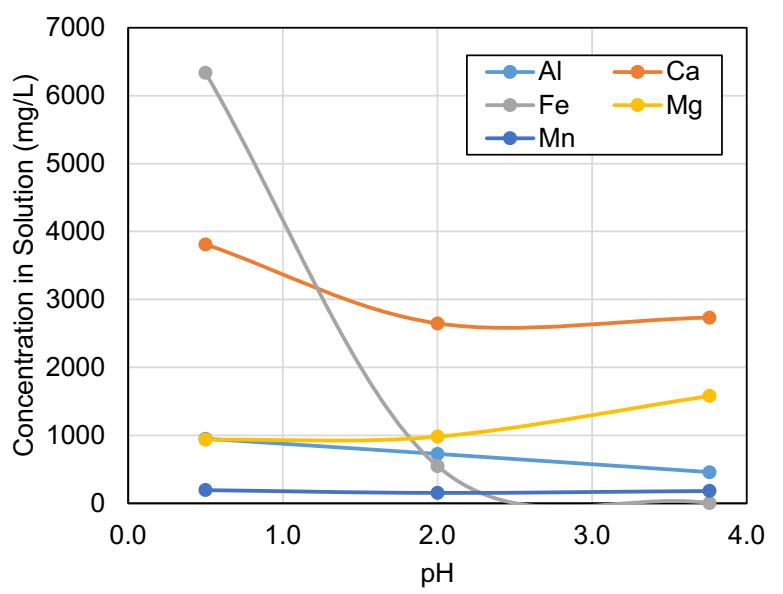

Figure 41. Leach solution concentrations as a function of $\mathrm{pH}$ for countercurrent leaching tests.

\subsection{Conclusions}

To investigate the solubility of REEs in AMDp, a parametric laboratory leaching study was conducted. Tests were performed in a small laboratory-scale leaching reactor using 100 wet grams of AMDp in each test. From this work, several key conclusions are derived:

- The REE content of the MV AMDp sample $(375 \mathrm{mg} / \mathrm{kg})$ is notably lower than the average content for NAPP AMDp samples as reported by Vass et al. (750 mg/kg). One contributing factor may be dilution from the relatively high concentration of iron and aluminum, which were $16 \%$ and $12.9 \%$ on a dry, elemental basis. XRD analysis also confirmed a high concentration of anhydrite $\left(\mathrm{CaSO}_{4}\right)$.

- Leaching kinetics tests with $3 \mathrm{M}$ nitric acid showed extremely rapid kinetics, with equilibrium conditions often achieved at the first-time increment ( $3.75 \mathrm{~min})$. This effect was particularly noted at the low $\mathrm{pH}$ points below 1.5 .

- The leaching recovery vs. $\mathrm{pH}$ data show that the REEs begin dissolving around $\mathrm{pH} 3.0$ and reach full dissolution at $\mathrm{pH}$ 2.0. These values are lower than those predicted by the Eh-pH diagrams (Chapter 2) and suggest that the speciation of REEs in AMDp may not be simple hydroxides but possibly chelated or adsorbed to other species.

- The dissolution curves for REEs fall between that of Fe (which occurs at a lower $\mathrm{pH}$ ) and $\mathrm{Al}$ (higher $\mathrm{pH}$ ). With respect to the other contaminant metals, $\mathrm{Ca}$ and $\mathrm{Mn}$ did not show distinguishable solubility patterns (possibly due to ionic strength limits), and $\mathrm{Mg}$ was fully dissolved at all pH points. When compared to the actinides, the acid solubility of REEs closely matches that of the $U$ and is slightly higher than that of Th.

- The countercurrent tests failed to produce superior leaching results, likely due to stage dilution and the gradual $\mathrm{pH}$ increase prompted by the fresh solids. In the third stage of fresh solid addition, a significant content of REEs was lost from solution due to precipitation. If implemented in an industrial process, the fresh solids should be amended with fresh acid to maintain a low $\mathrm{pH}$ and prevent subsequent precipitation. 


\section{Recovery of Rare Earth Elements from Leach Solutions via Selective Precipitation}

\subsection{Introduction and Test Objectives}

Data from Chapter 4 shows that acid leaching is a highly effective process for extracting REEs from AMDp. While both high recovery and fast kinetics were observed during testing, the resulting leachates also typically contained high concentrations of contaminants such as Fe, Al, $\mathrm{Mn}, \mathrm{Ca}$, and $\mathrm{Mg}$. Thermodynamic modeling in Chapter 3 suggests that many of these contaminants can be adequately removed by using a selective precipitation step prior to downstream solvent extraction and oxalic acid precipitation.

To optimize this process and develop better insight on the aqueous stability of REEs in acidic solutions, several series of parametric precipitation tests were conducted. These tests investigated the role of $\mathrm{pH}$, oxidation-reduction potential, acid matrix, base type, and other factors on the recovery of REEs and rejection of metal contaminants.

\subsection{Methods and Materials}

\subsubsection{Sample Selection and Handling}

As in the leaching test series, the AMDp precipitate samples utilized in these tests were recovered from the various host sites and stored in sealed 1-gallon buckets prior to use in the lab. In addition to the MV, DM, and BG samples introduced in the prior chapter, a fourth sample TT was added for this test series. The TT sample is very similar to that of the BG sample, as in the same geologic setting (i.e. Freeport coal seam, above drainage underground mine) and is subject to a similar treatment process. The average REE assay of the TT sample based three replicate samples was determined to be $543.5 \mathrm{mg} / \mathrm{kg}$, with an individual REE distribution very similar to that of the other AMDp materials evaluated in this study.

Throughout collection and storage, all AMDp samples were carefully sealed in the HDPE buckets to minimize incidental loss of moisture. As in the leaching tests, the raw samples were first well mixed in the bucket and withdrawn immediately prior to the test. Moisture content was determined simultaneously with teach test by fully desiccating three replicate samples in a laboratory oven overnight. These moisture samples were taken at the same time as the fresh freed and new moisture analyses were conducted for each individual test. Moisture content for the MV, BG, and DL samples is provided in Chapter 4.

\subsubsection{Regents and Equipment}

Mineral acids (i.e. nitric, hydrochloric, and sulfuric) of ACS grade were used throughout the leaching tests. All acids were diluted to a concentration of $3 \mathrm{M}$ for use in the tests, and fresh acid was made prior to each test. For the precipitation portion of the experiment, various bases ( $\mathrm{NaOH}, \mathrm{NH}_{3} \mathrm{OH}$, and $\mathrm{MgO}$ ) were utilized to selective raise the $\mathrm{pH}$ to specific inputs. All bases were diluted to a concentration of $3 \mathrm{~N}$ for use in the tests, and fresh base was periodically generated as needed. 
The same triple neck leach reactor introduced in Chapter 4 was used for the precipitation tests. After leaching, the reflux condenser was removed to allow easier addition of the base solutions. During the tests, liquid samples were collected using a fresh $20 \mu \mathrm{m}$ syringe filter. All liquid samples were analyzed via ICP-MS at SGS Canada. Typical moisture for the TT sample was $96 \%$

\subsubsection{Exploratory Precipitation Test Procedures}

To assess the feasibility of caustic precipitation prior to solvent extraction, a preliminary experimental program evaluated the influence of $\mathrm{pH}$, leaching acid type, and sample type on the precipitation removal efficiency for both REEs and major metals. Table 9 provides a summary of the experimental conditions of this test program. In these tests, approximately 150 grams of wet sludge was first dissolved in acid ( $1: 1$ solid to liquid ratio) at $\mathrm{pH}=0.5$ to achieve near complete digestion of all AMDp material. $\mathrm{NaOH}$ was then used to incrementally raise the $\mathrm{pH}$ to values of 2,4 , and 6 . At each $\mathrm{pH}$ point, the reaction was first given sufficient time to stabilize, after which, a $20 \mathrm{~mL}$ sample was extracted using a $20 \mu \mathrm{m}$ syringe filter. The other reactor contents, including the leachate and any precipitated solids were retained in the reactor and the solution was then raised to the next $\mathrm{pH}$ point. This process was then repeated for all three desired $\mathrm{pH}$ endpoints. A graphical depiction of the test process is shown in Figure 42.

Table 9. Experimental Parameters for Parametric Precipitation Tests

\begin{tabular}{lll}
\hline Parameter & Unit & Value \\
\hline Experimental Parameters & & \\
\hline Sample Type & -- & MV, BG, DL \\
Leaching Acid & -- & Nitric, Sulfuric \\
pH Endpoint & -- & $2,4,6$ \\
\hline Constant Parameters & & \\
\hline Base Type & -- & $\mathrm{NaOH}$ \\
Base Concentration & $\mathrm{N}$ & 3 \\
Leach Acid Concentration & $\mathrm{Mol} / \mathrm{L}$ & 3 \\
Leach pH & -- & 0.5 \\
Leach Temperature & ${ }^{\circ} \mathrm{C}$ & Ambient \\
Leaching Solid to Liquid Ratio & -- & $1: 1$ \\
Stirrer Speed & RPM & 350 \\
Sludge Wet Mass & Grams & 150 \\
\hline Responses & & \\
\hline REE Removed & $\%$ & Measured \\
Major Metal Removed & $\%$ & Measured \\
\hline
\end{tabular}




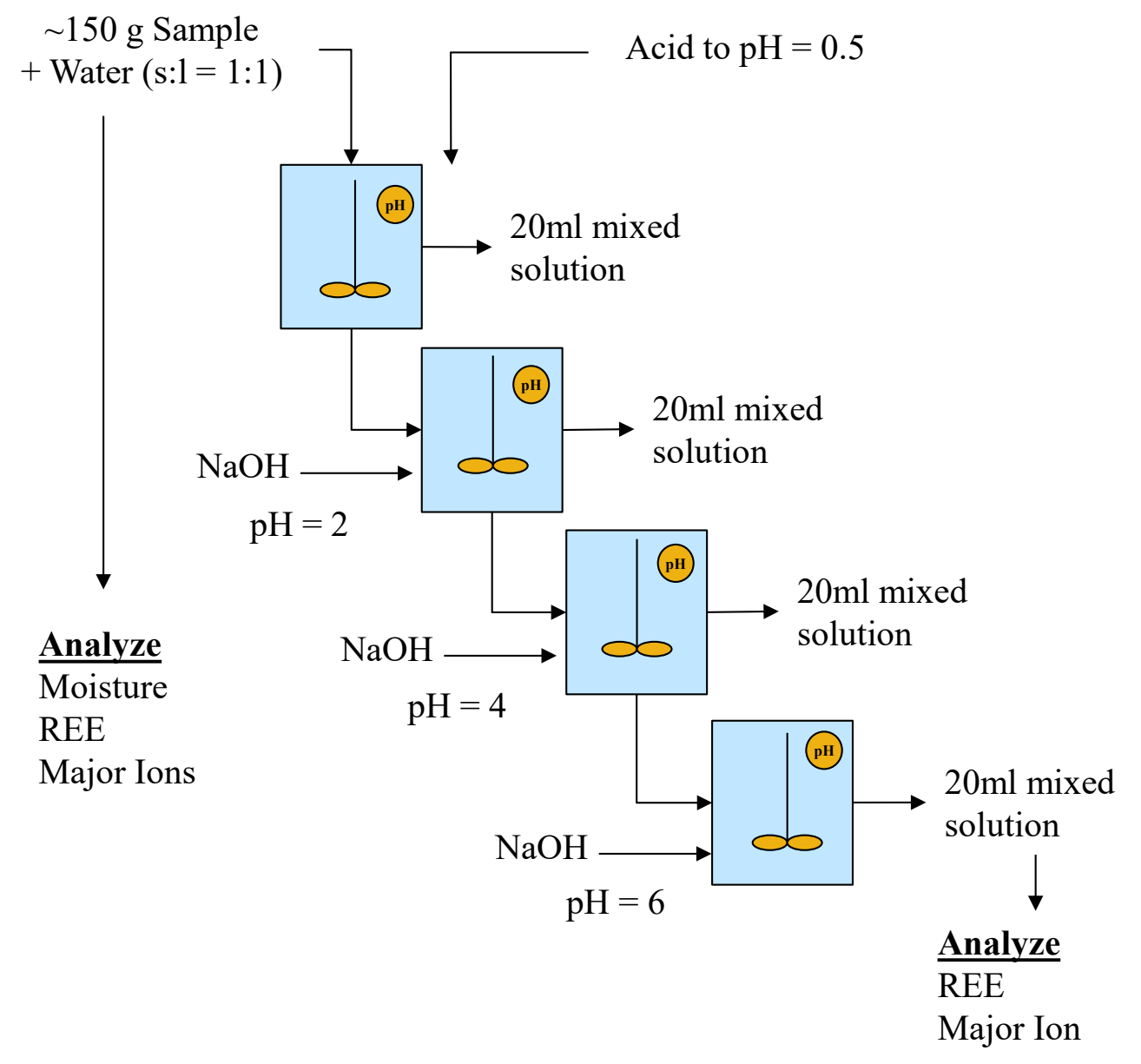

Figure 42. Experimental flowsheet for exploratory selective precipitation tests.

\subsubsection{Precipitate Grade Test Procedures}

Given the success in the initial test series, a follow-on test series was conducted to measure the elemental composition of the precipitate at each pH endpoint. In this series, the general procedures from the exploratory tests were repeated, with several minor distinctions. First, at each desired $\mathrm{pH}$ endpoint, the reaction was halted, and the precipitated solids were filtered away from the liquid. The solids were then dried overnight in a laboratory oven and assayed for REE and major metal content. For the subsequent $\mathrm{pH}$ endpoint, a fresh leachate sample was generated, and base was added until the desired endpoint was achieved. This base addition was administered in a single step. This procedure thus reflects the cumulative solids generated by precipitating at particular $\mathrm{pH}$ endpoint, not the incremental solids precipitated between two intermediate $\mathrm{pH}$ points. Figure 43 shows the experimental flowsheet, which was repeated for all $\mathrm{pH}$ endpoints included in the experimental design.

The test parameters for this experiment followed a similar experimental design to that of the exploratory test, with a couple minor changes. First, the TT material was added as a fourth AMDp sample. Moreover, $\mathrm{HCl}$ was tested as the leaching acid in addition to the $\mathrm{H}_{2} \mathrm{SO}_{4}$ and $\mathrm{HNO}_{3}$ utilized in prior tests. Table 10 summarizes the experimental parameters in this test. 


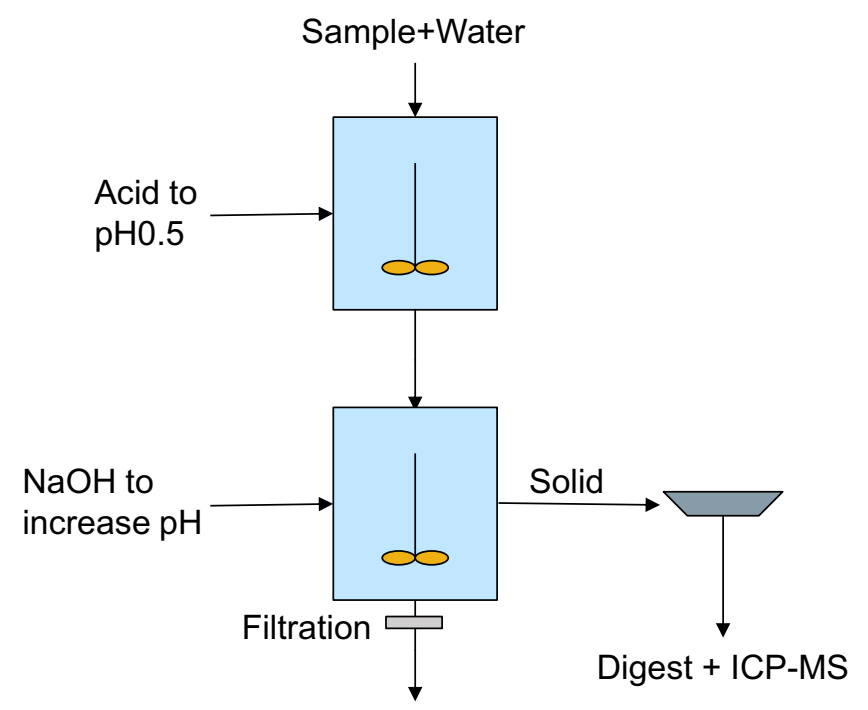

Figure 43. Experimental flowsheet for precipitate grade test procedures.

Table 10. Experimental Parameters for Precipitate Grade Tests

\begin{tabular}{lll}
\hline Parameter & Unit & Value \\
\hline Experimental Parameters & & \\
\hline Sample Type & -- & $\mathrm{MV}, \mathrm{BG}, \mathrm{DL}, \mathrm{TT}$ \\
Leaching Acid & -- & Nitric, Sulfuric, Hydrchloric \\
$\mathrm{pH}$ Endpoint & -- & $2,4,6,8,10,12$ \\
\hline Constant Parameters & & \\
\hline Base Type & -- & $\mathrm{NaOH}$ \\
Base Concentration & $\mathrm{N}$ & 3 \\
Leach Acid Concentration & $\mathrm{Mol} / \mathrm{L}$ & 3 \\
Leach pH & -- & 0.5 \\
Leach Temperature & ${ }^{\circ} \mathrm{C}$ & $\mathrm{Ambient}$ \\
Leaching Solid to Liquid Ratio & -- & $1: 1$ \\
Stirrer Speed & $\mathrm{RPM}$ & 350 \\
Sludge Wet Mass & Grams & 150 \\
\hline Responses & & \\
\hline REE Precipitate Grade & $\mathrm{ppm}$ & Measured \\
Major Metal Precipitate Grade & $\%$ & Measured \\
\hline
\end{tabular}




\subsubsection{Reagent Evaluation Test Procedures}

Following the initial test series, additional tests investigated the use of different bases during the precipitation tests to determine if different bases prompted selective precipitation of REEs or gangue metals at disparate $\mathrm{pH}$ points. $\mathrm{NaOH}, \mathrm{MgO}$ and $\mathrm{NH}_{3} \mathrm{OH}$ were used in this study. As in prior tests, AMDp samples were first fully dissolved by $3 \mathrm{M} \mathrm{HNO}_{3}$ at $\mathrm{pH} 0.5$. Next, the $\mathrm{pH}$ of the leachate was adjusted by different bases from 0.5 to 6 with a 0.5 interval. As in the precipitate grade tests, each $\mathrm{pH}$ interval was assessed using a fresh leachate sample, and as a result, the tests represent the cumulative, rather than the incremental removal of metals at a desired $\mathrm{pH}$ endpoint. After a $20 \mathrm{~min}$ reaction, $20 \mathrm{ml}$ leachate was withdrawn from each beaker respectively at each $\mathrm{pH}$ point then was filtered and packed into specimen containers for ICP-MS analysis.

The experimental flowsheet is shown in Figure 44, while Table 11 summarizes the experimental parameters.

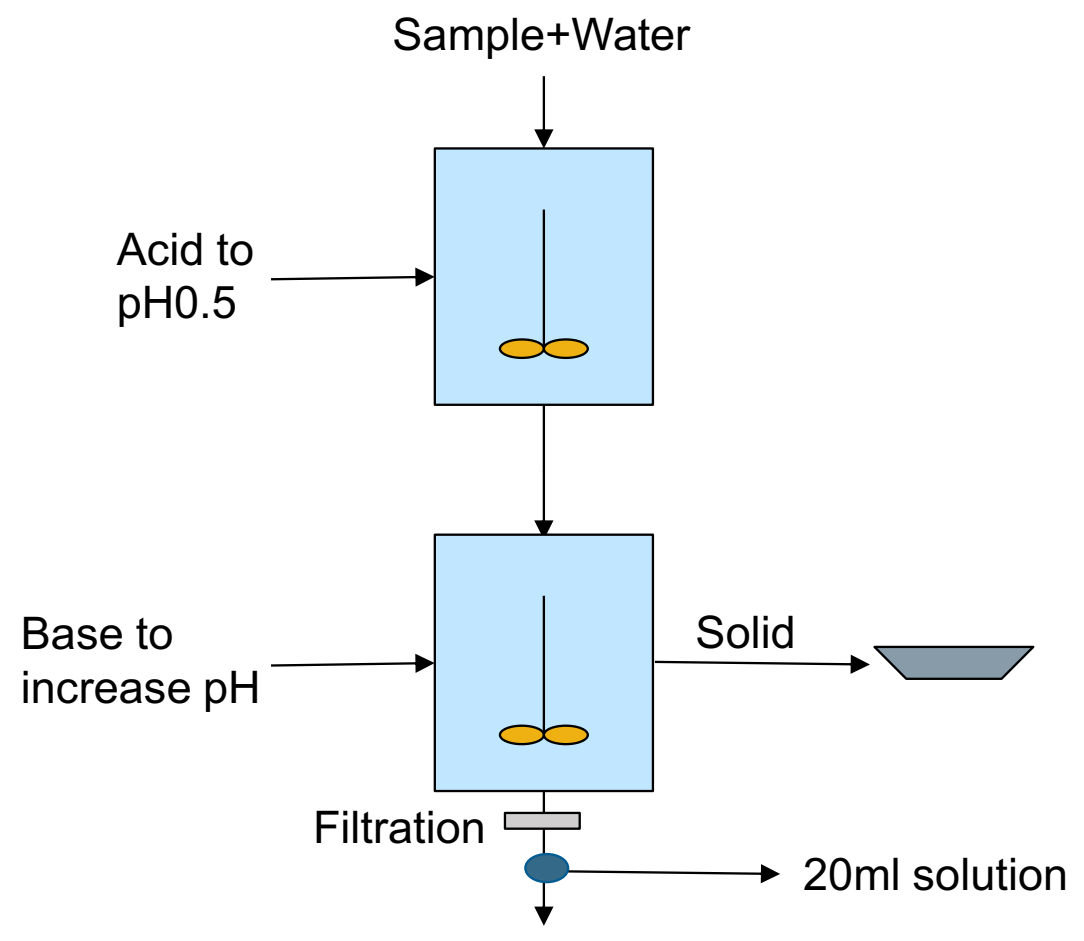

Figure 44. Experimental flowsheet for reagent evaluation tests. 
Table 11. Experimental Parameters for Reagent Evaluation Tests

\begin{tabular}{lll}
\hline Parameter & Unit & Value \\
\hline Experimental Parameters & & \\
\hline Base Type & -- & $\mathrm{NaOH}, \mathrm{NH}_{3} \mathrm{OH}, \mathrm{MgO}$ \\
pH Endpoint & -- & $2,3,3.5,4,4.5,5.5,6$ \\
\hline Constant Parameters & & \\
\hline Sample & -- & $\mathrm{MV}$ \\
Base Concentration & $\mathrm{N}$ & 3 \\
Leaching Acid & -- & $\mathrm{Nitric}$ \\
Leach Acid Concentration & $\mathrm{Mol} / \mathrm{L}$ & 3 \\
Leach pH & -- & 0.5 \\
Leach Temperature & ${ }^{\circ} \mathrm{C}$ & Ambient \\
Leaching Solid to Liquid Ratio & -- & $1: 1$ \\
Stirrer Speed & $\mathrm{RPM}$ & 350 \\
Sludge Wet Mass & Grams & 150 \\
\hline Responses & & \\
\hline REE Removed & $\%$ & Measured \\
Major Metal Removed & $\%$ & Measured \\
\hline
\end{tabular}

\subsubsection{Oxidization-Precipitation Test Procedures}

The oxidation precipitation tests were conducted to determine if the addition of $\mathrm{H}_{2} \mathrm{O}_{2}$ could benefit the precipitation process by oxidizing the metal species and thus reduce the metal solubility. Three groups of different dosages of $\mathrm{H}_{2} \mathrm{O}_{2}$ were added into the precipitation process at $\mathrm{pH} 0.5$. Then the $\mathrm{pH}$ was adjusted by $3 \mathrm{M} \mathrm{NaOH}$ from $\mathrm{pH} 0.5$ to 6 with a 0.5 interval.

During each test, the MV AMDp samples were diluted with DI water, then dissolved by $3 \mathrm{M}$ $\mathrm{HNO}_{3}$ to $\mathrm{pH} 0.5$ and divided evenly into 4 groups in the $1000 \mathrm{ml}$ beakers. Next, $0 \mathrm{ml}, 1 \mathrm{ml}, 5 \mathrm{ml}$ and $10 \mathrm{ml} \mathrm{H} \mathrm{H}_{2}$ was added into the leachate respectively for $20 \mathrm{~min}$ reaction. After taking samples of the initial leachate, the $\mathrm{pH}$ was increased to 2.0 using $\mathrm{NaOH}$, the reaction was run for 20 minutes, and additional samples were taken for analysis. The $\mathrm{pH}$ was then incremented upward to each of the designated titration endpoints $(3,3.5,4,4.5,5.5,6$.) for a total of 7 increments. After each increment, a small amount of leach solution was sampled from the leach vessel and filtered. The filtrate was then analyzed for major metal and REE concentrations. The test flowsheet is shown in Figure 45 and a summary of the experimental conditions is shown in Table 12. 


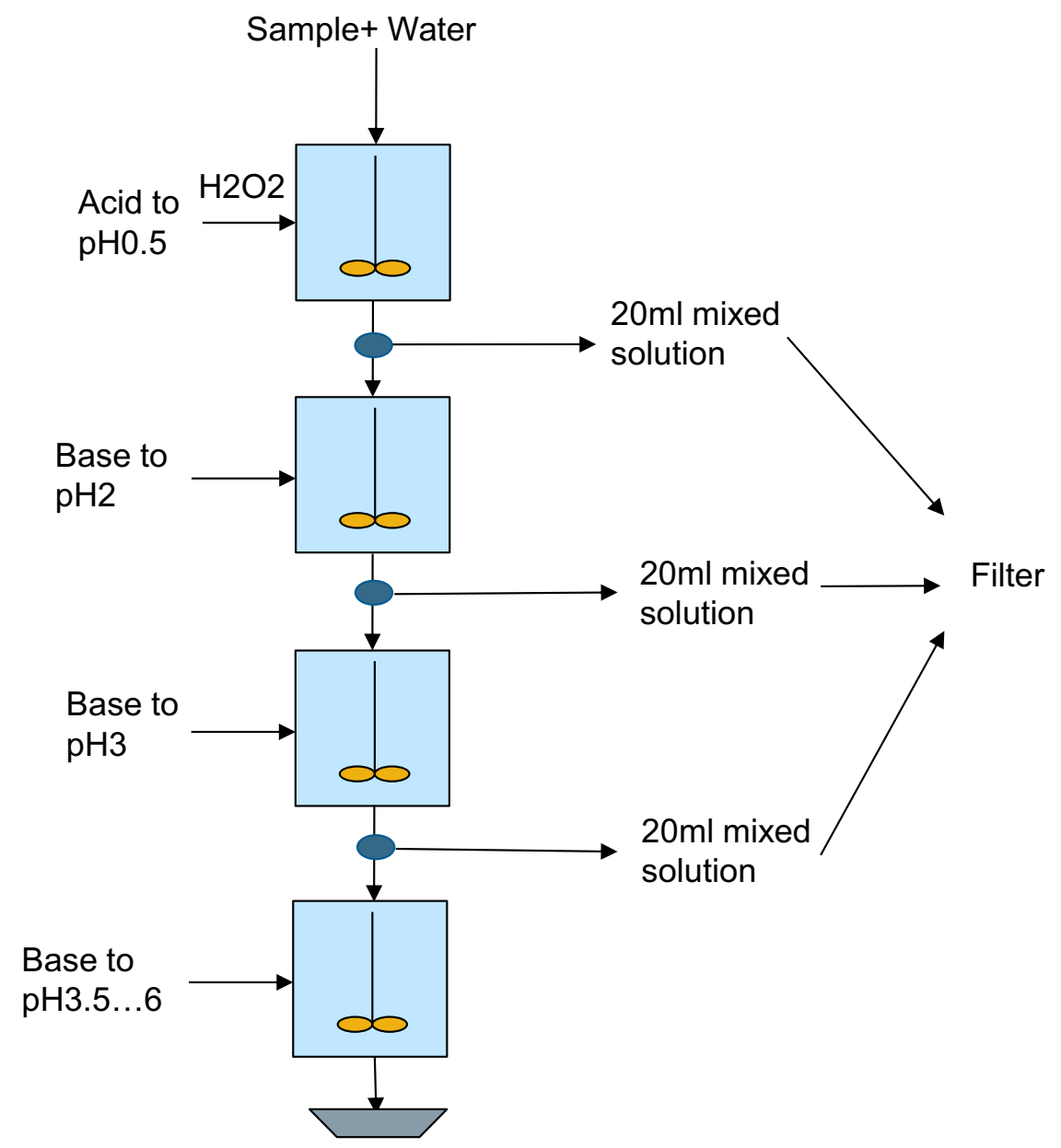

Figure 45. Experimental Flowsheet for Oxidation-Precipitation Tests. 
Table 12. Experimental Parameters for Oxidation-Precipitation Tests

\begin{tabular}{lll}
\hline Parameter & Unit & Value \\
\hline Experimental Parameters & & \\
\hline Oxidant Dose & Mol/L & $0,0.04,0.21,0.42$ \\
pH Endpoint & -- & $2,3,3.5,4,4.5,5.5,6$ \\
\hline Constant Parameters & & \\
\hline Sample & -- & $\mathrm{MV}$ \\
Base Type & -- & $\mathrm{NaOH}$ \\
Base Concentration & $\mathrm{N}$ & 3 \\
Oxidant Type & -- & $\mathrm{H}_{2} \mathrm{O}_{2}$ \\
Leaching Acid & -- & $\mathrm{Nitric}$ \\
Leach Acid Concentration & $\mathrm{Mol} / \mathrm{L}$ & 3 \\
Leach pH & -- & 0.5 \\
Leach Temperature & ${ }^{\circ} \mathrm{C}$ & $\mathrm{Ambient}$ \\
Leaching Solid to Liquid Ratio & -- & $1: 1$ \\
Stirrer Speed & $\mathrm{RPM}$ & 350 \\
Sludge Wet Mass & Grams & 150 \\
\hline Responses & & \\
\hline REE Removed & $\%$ & Measured \\
Major Metal Removed & $\%$ & Measured \\
\hline
\end{tabular}

\subsection{Results and Discussion}

\subsubsection{Exploratory Precipitation Tests}

For the exploratory test series, various AMDp samples were first dissolved in acid at $\mathrm{pH} 0.5$ and subsequently precipitated at $\mathrm{pH}$ endpoints for 2,4 , and 6 . Figure 46 shows an indicative example of the solutions produced during this test sequence. At $\mathrm{pH} 0.5$, nearly all solids were fully dissolved; however, a small residual (likely silica) remained. At $\mathrm{pH} 4$ and $\mathrm{pH} 6$, rapid settling of the solids was observed, often producing clear supernatant. Alternatively, at this $\mathrm{pH}$, the top solution often remained cloudy despite extended settling times. In addition, visual observation shows that the increased $\mathrm{pH}$ produced progressively larger volumes of settled solids in all conditions evaluated. 


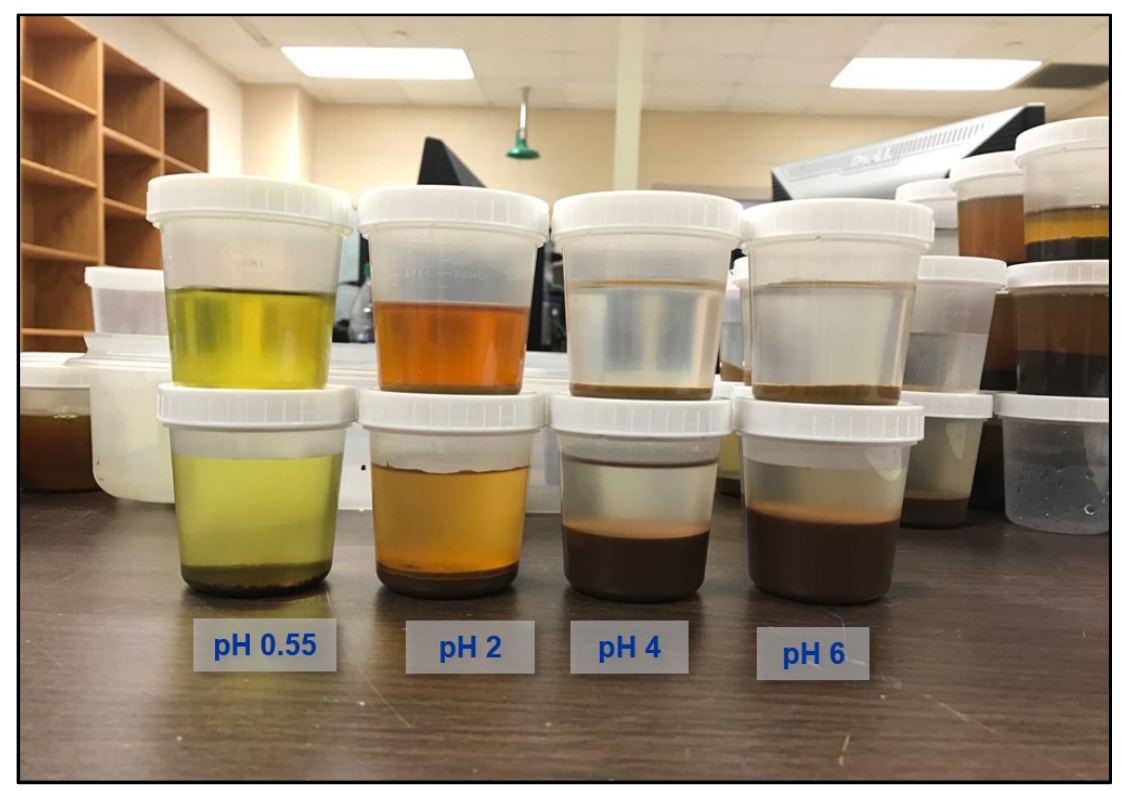

Figure 46. Indicative example of solutions produced during exploratory precipitation tests at various $\mathrm{pH}$ endpoints.

ICP analysis of the $\mathrm{pH} 0.5$ leachate solutions from each test are shown in Table 13 and Table 14 for major metal and element-by-element REE concentrations, respectively. This data shows that the major contaminants include Al (DL and BG samples), Fe (BG and MV samples), and Mg (MV and DL samples). Calcium was also a major contaminant for the MV and BG samples (recall: these treatment systems use lime, rather than caustic), particularly when using nitric acid. Sulfuric acid was shown to substantially reduce the calcium content in the leachate, likely though the formation of insoluble gypsum $\left(\mathrm{CaSO}_{4} \cdot 2 \mathrm{H}_{2} \mathrm{O}\right)$. With respect to the REEs, all leachate samples had a clear $\mathrm{Y}$ enrichment as has been discussed in Chapter 4.

Table 13. pH 0.5 Leachate Concentrations for Exploratory Precipitation Tests (Major Metals)

\begin{tabular}{ll|rrrrrr}
\hline Sample & Acid & \multicolumn{6}{|c}{ Metal Concentration (mg/L) } \\
& Type & \multicolumn{1}{c|}{ TREE } & \multicolumn{1}{c}{ Al } & \multicolumn{1}{c}{ Ca } & \multicolumn{1}{c}{ Fe } & \multicolumn{1}{c}{ Mg } & \multicolumn{1}{c}{ Mn } \\
\hline MV & $\mathrm{H}_{2} \mathrm{SO}_{4}$ & 9.19 & 896.41 & 601.49 & 3836.58 & 1512.79 & 127.49 \\
MV & $\mathrm{HNO}_{3}$ & 7.30 & 778.43 & 1635.28 & 3334.13 & 1220.35 & 93.08 \\
BG & $\mathrm{H}_{2} \mathrm{SO}_{4}$ & 2.03 & 449.36 & 525.31 & 450.59 & 123.17 & 13.96 \\
BG & $\mathrm{HNO}_{3}$ & 9.26 & 1724.49 & 2184.31 & 1928.65 & 419.36 & 56.79 \\
DL & $\mathrm{H}_{2} \mathrm{SO}_{4}$ & 88.43 & 5236.74 & 221.21 & 32.76 & 6090.43 & 201.06 \\
DL & $\mathrm{HNO}_{3}$ & 56.75 & 3922.56 & 361.68 & 3.2 & 4855.89 & 196.86 \\
\hline
\end{tabular}


Table 14. pH 0.5 Leachate Concentrations for Exploratory Precipitation Tests (REES)

\begin{tabular}{|c|c|c|c|c|c|c|c|c|c|c|c|c|c|c|c|c|c|}
\hline \multirow{2}{*}{$\begin{array}{l}\text { SpI } \\
\text { ID }\end{array}$} & \multirow{2}{*}{$\begin{array}{l}\text { Acid } \\
\text { Type }\end{array}$} & \multicolumn{16}{|c|}{ REE Concentration (mg/L) } \\
\hline & & Sc & $\mathbf{Y}$ & La & $\mathrm{Ce}$ & $\mathrm{Pr}$ & Nd & Sm & $\mathrm{Eu}$ & Gd & Tb & Dy & Ho & $\mathrm{Er}$ & $\mathrm{Tm}$ & $\mathrm{Yb}$ & Lu \\
\hline MV & $\mathrm{H}_{2} \mathrm{SO}_{4}$ & 0.38 & 2.94 & 0.33 & 1.2 & 0.2 & 1.29 & 0.53 & 0.13 & 0.77 & 0.11 & 0.64 & 0.1 & 0.3 & 0.04 & 0.2 & 0.03 \\
\hline MV & $\mathrm{HNO}_{3}$ & 0.28 & 2.48 & 0.25 & 0.94 & 0.16 & 1.04 & 0.35 & 0.13 & 0.6 & 0.1 & 0.49 & 0.1 & 0.23 & ND & 0.15 & ND \\
\hline BG & $\mathrm{H}_{2} \mathrm{SO}_{4}$ & ND & 0.48 & 0.02 & 0.67 & 0.1 & 0.35 & 0.1 & ND & 0.11 & ND & 0.08 & 0.02 & 0.06 & ND & 0.04 & ND \\
\hline BG & $\mathrm{HNO}_{3}$ & 0.21 & 1.8 & 0.76 & 2.51 & 0.38 & 1.63 & 0.46 & 0.12 & 0.53 & 0.08 & 0.37 & 0.07 & 0.17 & ND & 0.14 & 0.03 \\
\hline $\mathrm{DL}$ & $\mathrm{H}_{2} \mathrm{SO}_{4}$ & 0.52 & 28.2 & 7.63 & 19.2 & 2.48 & 11.0 & 2.79 & 0.77 & 4.67 & 0.74 & 4.57 & 0.9 & 2.55 & 0.3 & 1.84 & 0.27 \\
\hline $\mathrm{DL}$ & $\mathrm{HNO}_{3}$ & 0.11 & 18.3 & 4.92 & 11.8 & 1.65 & 7.53 & 1.92 & 0.52 & 2.96 & 0.49 & 2.84 & 0.6 & 1.55 & 0.23 & 1.17 & 0.16 \\
\hline
\end{tabular}

Figure 47 and Figure 48 show the experimental results from these exploratory tests as percent metal removed as a function of $\mathrm{pH}$ endpoint. Assessing the REE data by itself (Figure 47), all tests show that the removal of REEs begins between $\mathrm{pH} 2$ and 4 , and nearly $100 \%$ of the REEs are removed by $\mathrm{pH} 6$. This data closely matches the thermodynamic predictions described in Chapter 3, suggesting that the primary removal mechanism may by precipitation as REEhydroxides rather than via co-precipitation or adsorption. In all cases, the influence of both acid type and sample type was shown to be negligible, as all data generally follow the same pattern. The lone anomaly was $\mathrm{BG}-\mathrm{H}_{2} \mathrm{SO}_{4}$, which had a notably lower concentration of REEs and major metals in the original leachate.

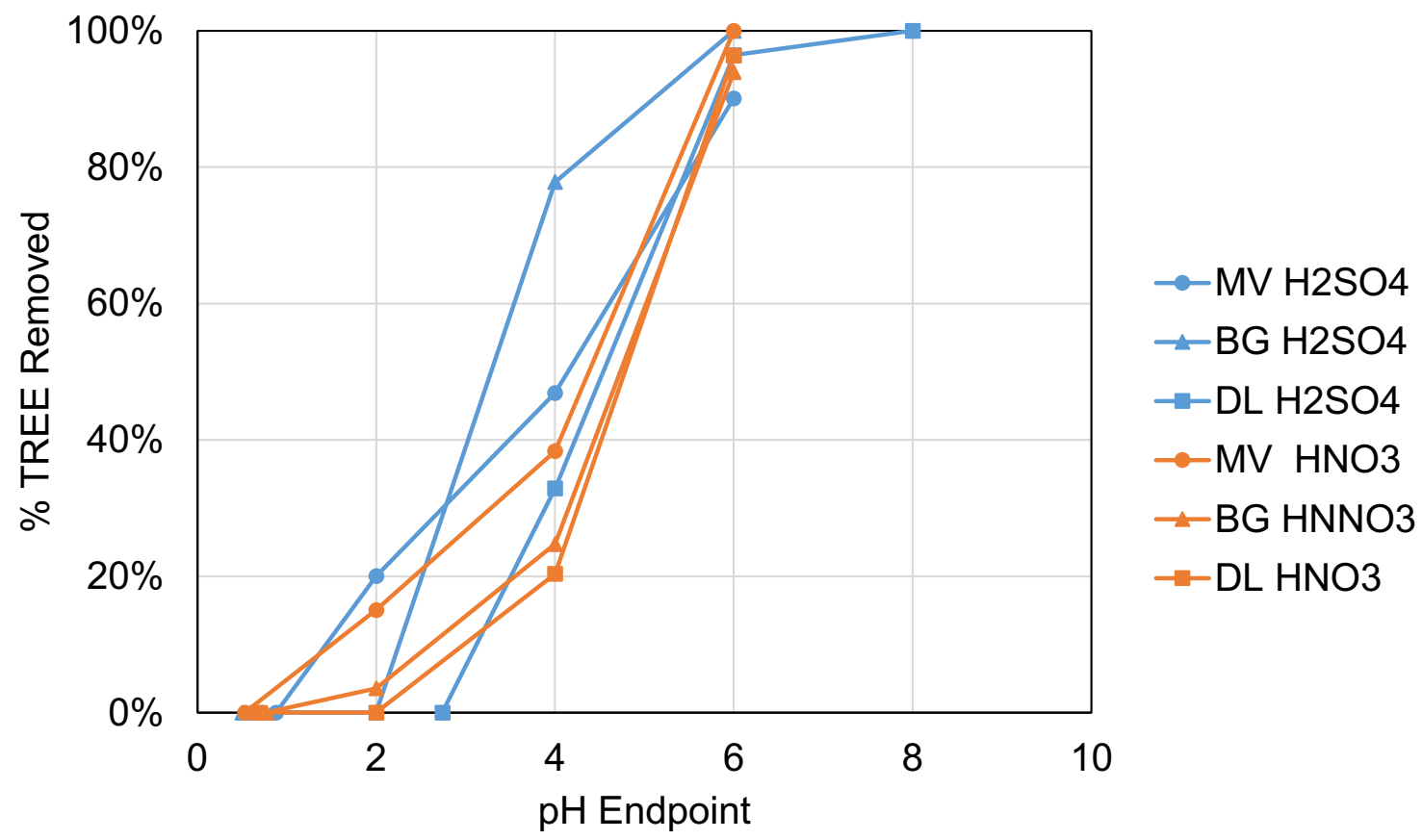

Figure 47. Experimental results from the exploratory precipitation tests. REE data only. 
In Figure 48, the various sub-plots refer to different AMDp samples and leaching acid types. Both REE and major metals are shown; however, the data for $\mathrm{Ca}$ and $\mathrm{Mg}$ have been removed, since significant removal was not observed in any test. While Al and Mn generally followed the same behavior between sample and acid types, the behavior of Fe was shown to be sensitive to the acid type.
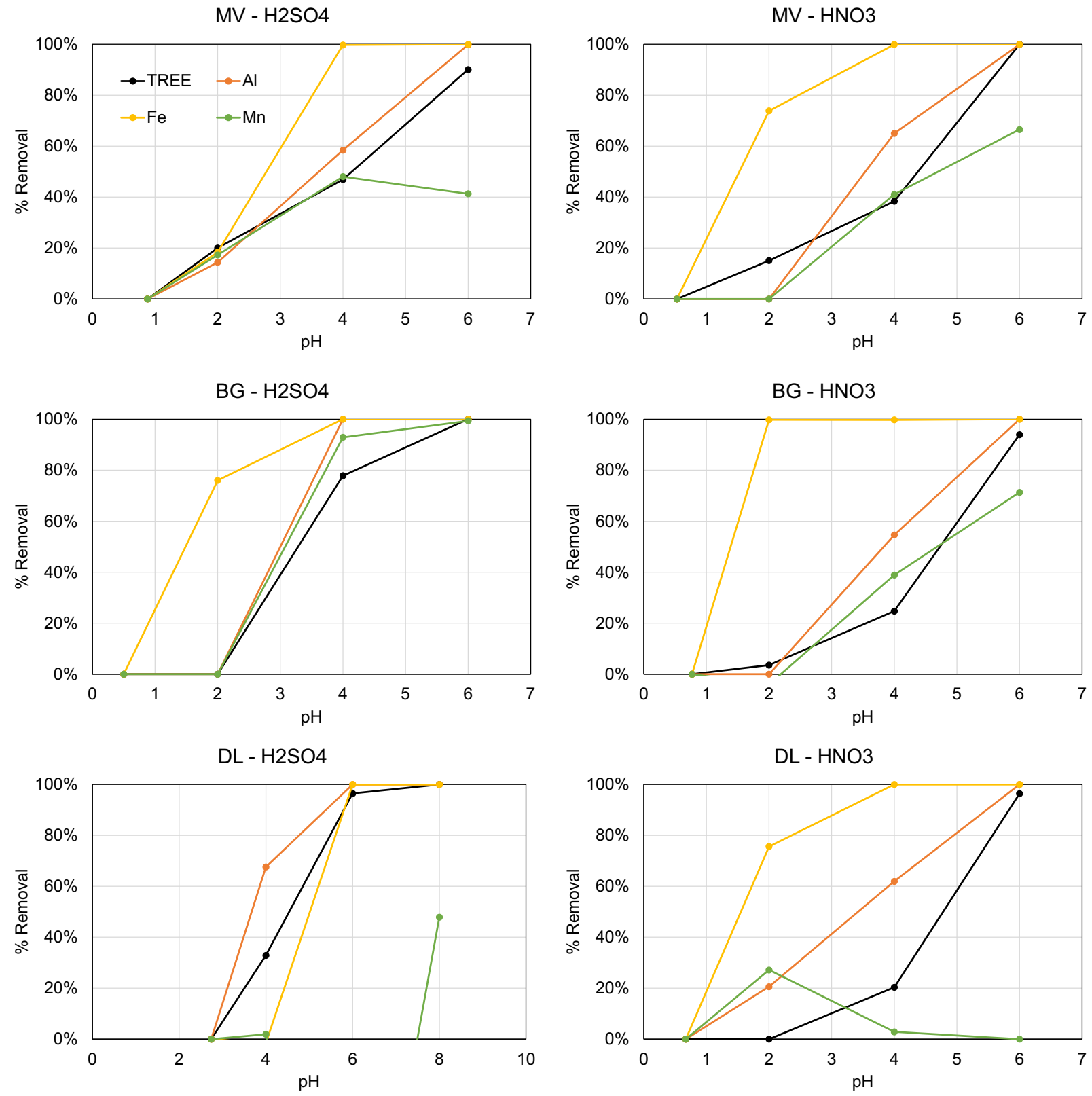

Figure 48. Experimental results from the exploratory precipitation tests. Ca and $\mathrm{Mg}$ were not removed at a significant rate under these test conditions and were thus removed from the figure. 
For tests using $\mathrm{H}_{2} \mathrm{SO}_{4}$, the Fe was shown to precipitate at a higher $\mathrm{pH}$, likely due the formation of semi-soluble Fe-sulfate species. Alternatively, in the nitrate medium, Fe tended to precipitate at a lower $\mathrm{pH}$, with large fractions (75\% to $100 \%)$ removed at $\mathrm{pH} 2$. This trend is particularly noteworthy for the $\mathrm{DL}-\mathrm{H}_{2} \mathrm{SO}_{4}$ sample where Fe was precipitated at $\mathrm{pH}$ higher than that of $\mathrm{Al}$ and the REEs. It is worth noting, though, that the Fe concentration in this leachate was several orders of magnitude lower than that of other materials. Given this result, it can be concluded that $\mathrm{HNO}_{3}$ provides a larger separation window for Fe and the REEs and thus may be more suitable for selective separation of the REEs from the contaminants.

With respect to other contaminant metals, the REEs tended to precipitate along a curve very similar to that of $\mathrm{Al}$ and $\mathrm{Mn}$. For all cases of acid type and sample type, the separation window for $\mathrm{Al}$ and REEs was quite narrow, with the $50 \%$ removal point often occurring within $0.5 \mathrm{pH}$ points. This data suggests that selective removal of Al from the REEs may be difficult with precipitation alone, and as a result, downstream processes, such as solvent extraction and oxalic acid precipitation may need to be tailored to reject contaminant. Nevertheless, the data does show that Fe can be successfully removed with minimal REE losses, particularly when leaching with nitric acid. Lastly, the behavior of $\mathrm{Mn}$ varied drastically between various samples, likely due to differences in the valance of the $\mathrm{Mn}$ in these materials. Overall, the general order of decreasing solubility can be summarized as Fe $>\mathrm{Al}>\mathrm{REES}=\mathrm{Mn}$.

\subsubsection{Precipitate Grade Test}

An indicative example of the solutions produced during the precipitate grade tests is shown in Figure 49. Overall, similar trends were observed to those of the exploratory tests (Figure 46); however, this figure also includes higher $\mathrm{pH}$ endpoints in the strongly alkaline range. As in the prior test, low $\mathrm{pH}$ values, $<1$, typically prompted full digestion of the AMDp sample with just a minor fraction of residual solids. $\mathrm{pH} 2$ tended to produce cloudy solutions, likely due to the initial formation of colloidal Fe. Higher $\mathrm{pH}$ values then produced relatively clear supernatant solutions with faster settling times. The volume of precipitated solids showed gradual increase to $\mathrm{pH}$, and higher $\mathrm{pH}$ endpoints led to reductions in the solid volume, likely due to alkaline dissolution.

Quantitative results from this test are shown in Figure 50. In this plot array, the content of REEs $(\mathrm{mg} / \mathrm{kg})$ and $\mathrm{Fe}(\%)$ in the precipitated solids are plotted as a function of endpoint $\mathrm{pH}$. In some cases (particularly $\mathrm{pH}=2$ ), the mass of precipitated solids was insufficient to permit solid analysis. Otherwise, the data indicated the assay for the material that would be sacrificially lost in a preliminary caustic precipitation stage.

In all cases (except BG- $\mathrm{H}_{2} \mathrm{SO}_{4}$, which had notably lower concentration of REEs and major metal see Table 13), a step change in REE concentration occurred between $\mathrm{pH} 4$ and $\mathrm{pH} 6$, indicating that a large quantity of REE's is precipitated from solution at $\mathrm{pH} 4$. This data also showed that REE precipitation was not sensitive to sample type or acid type (i.e. anion species in solution), as nearly all curves followed the same trend. Alternatively, the iron content did not follow a consistent pattern. Some test (like $\mathrm{HNO}_{3}, \mathrm{TT}$ ) showed a step change drop in concentration at $\mathrm{pH}=5$, while others, such as $\mathrm{DL}$, showed a steady linear decrease along the entire curve from $\mathrm{pH}=2$ to 14 . Still others, such as the BG tests passed through a maximum at $\mathrm{pH}=4$ before 
decreasing steadily at higher $\mathrm{pH}$ values. These differences clearly indicated that iron removal was significant to sample type; however, acid type may not be significant.

Data from this test and the prior test series suggest that selective precipitation of high grade REE materials should be feasible if sequential precipitation is done between $\mathrm{pH} 4$ and 6 . By $\mathrm{pH}$ 4 , nearly all iron is removed, with the grade of that material being as high as $28 \% \mathrm{Fe}$. From $\mathrm{pH} 4$ to $\mathrm{pH} 6, \mathrm{REEs}$ begin to precipitate, and the resulting grade is elevated substantially. A larger $\mathrm{pH}$ window of 4 to 8 will increase the total REE recovery; however, the additional recovery of other contaminants will lead to reduced grade. Data from this test shows that this process is extremely robust to changes in acid type (e.g., anion matrix), sample type (e.g., contaminant mix), starting REE concentration, and other uncontrollable factors. As a result, this selective precipitation process may have relevancy both for AMDp leachate as well as raw AMD.

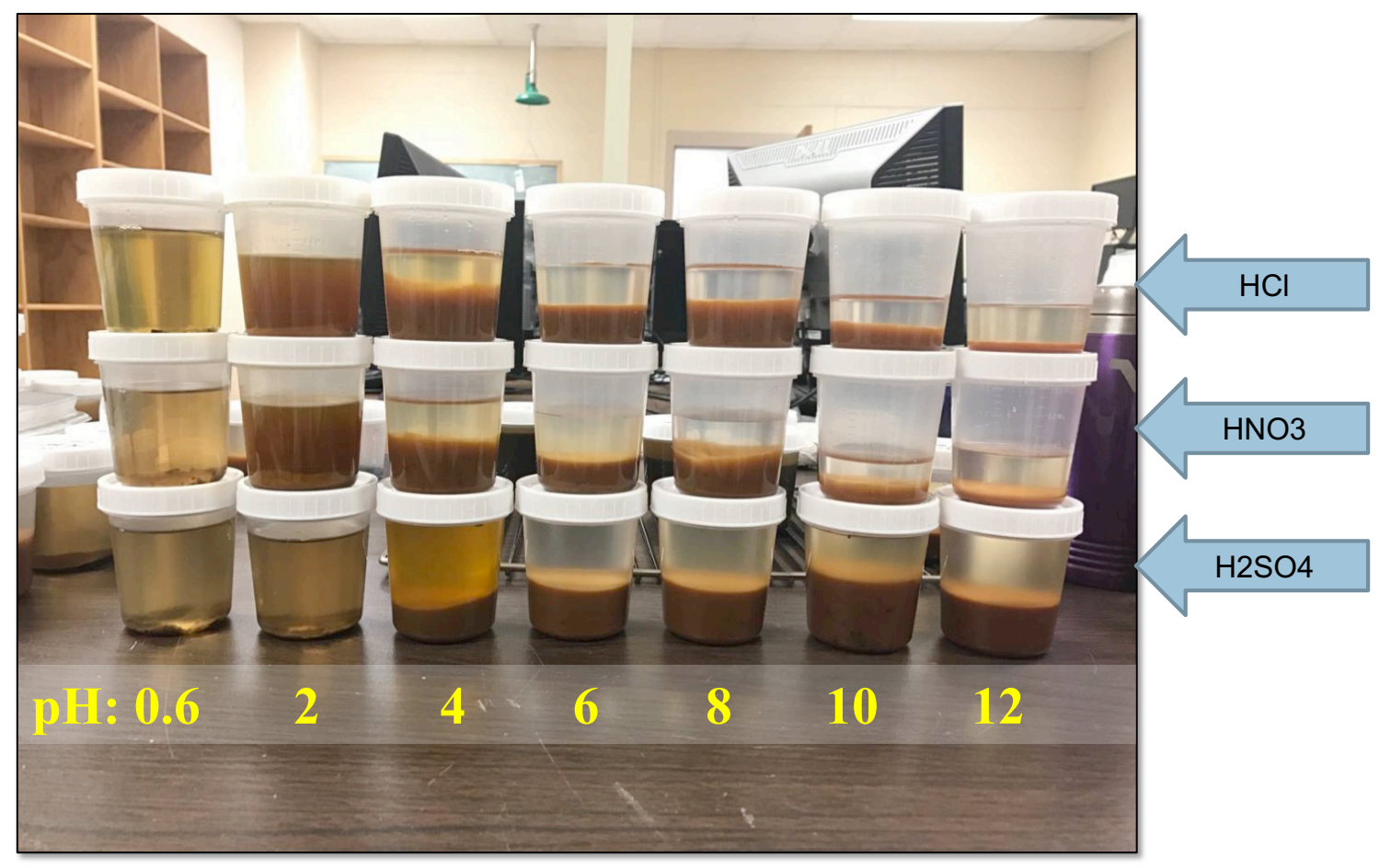

Figure 49. Indicative example of solutions produced during precipitate grade tests at various $\mathrm{pH}$ endpoints. 

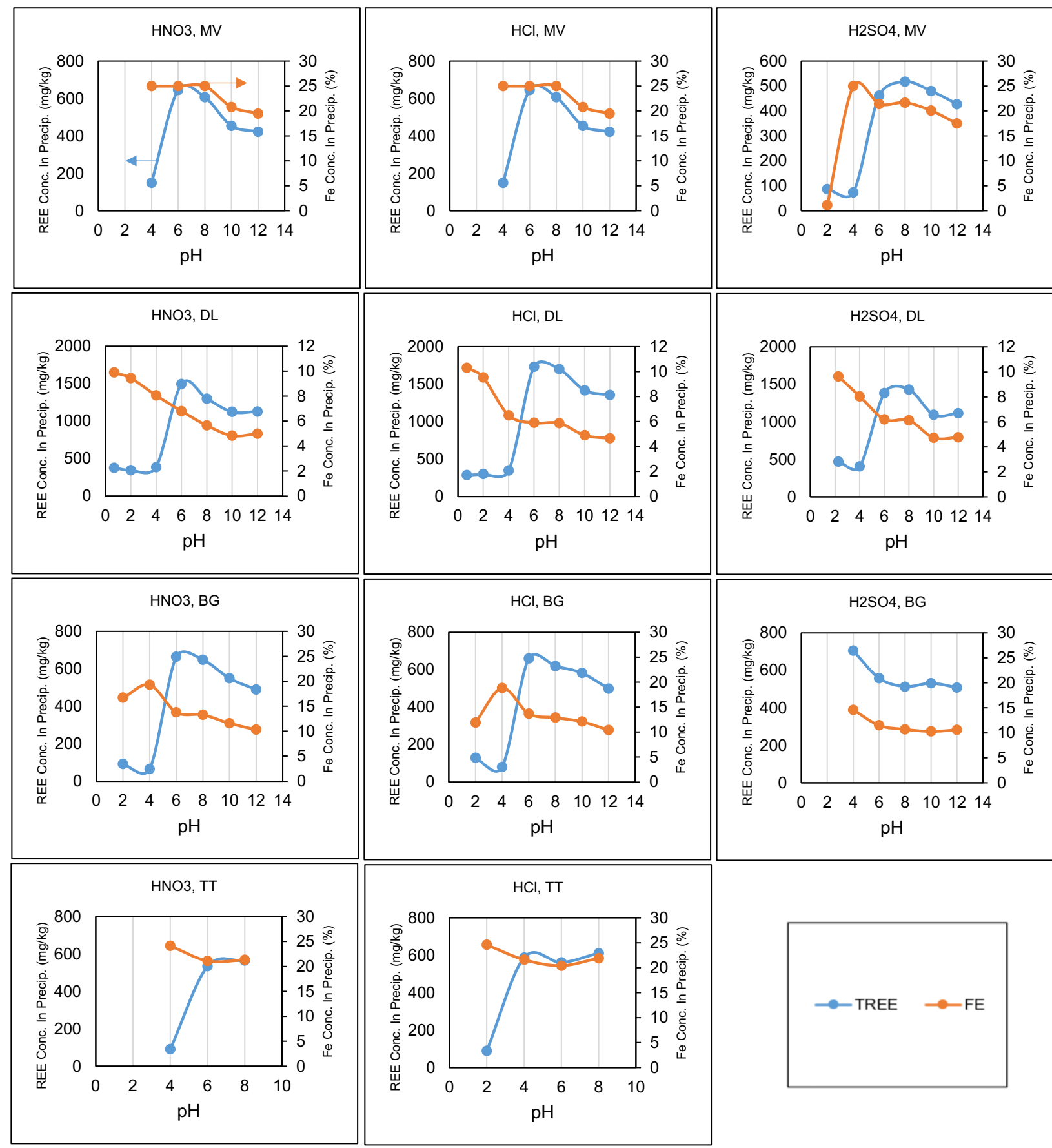

Figure 50. Precipitation test results. Data show assay of precipitated solids after full dissolution at $\mathrm{pH} \approx$ 0.5 and adjustment back to higher $\mathrm{pH}$ values. 


\subsubsection{Reagent Evaluation Test}

Data from the reagent evaluation tests are shown in Figure 51 through Figure 53 . Figure 51 shows the percent metal removed as a function of $\mathrm{pH}$ for the various reagents. With respect to TREE, all three bases performed very similarly, with the $50 \%$ removal point varying by less than $0.5 \mathrm{pH}$ points. Fe, on the other hand, showed significant sensitivity to the base type, particularly at $\mathrm{pH} 2$, where $>90 \%$ was removed with $\mathrm{MgO}, 60 \%$ with $\mathrm{NH}_{3} \mathrm{OH}$, and $30 \%$ with $\mathrm{NaOH}$. Al follows a similar trend with respect to the three reagents, with $\mathrm{MgO}$ producing the higher removal and $\mathrm{NaOH}$ producing the lower removal at the same $\mathrm{pH}$ point. As in prior examples, the precipitation behavior of the REEs closely matches that of Al, suggesting that selective separation may be challenging. The data for $\mathrm{Mn}$ and $\mathrm{Ca}$ shows that overall removal was quite low, often less than $40 \%$ for a wide range of $\mathrm{pH}$ points; however, $\mathrm{MgO}$, was successful in keeping these elements in solution. In this case, removal rates were often $10 \%$ to $20 \%$, even at fairly high $\mathrm{pH}$ points.

To further evaluate the selectivity of each reagent, separation efficiency was calculated with respect to each individual contaminant metal at each test condition. In this case, separation efficiency is defined as the \% removal of major metal minus the \% removal of REEs. Thus, a high, positive separation efficiency implies that the major metals are being precipitated while REEs are retained in solution. Alternatively, a large, negative separation efficiency implies that the major metals are being retained in solution while the REEs are precipitated. Lastly, a nearzero separation efficiency implies that major metals and REEs are being precipitated at the same rate. Thus, the absolute value of the separation efficiency is the factor governing selectivity. Selective separation can be achieved with either positive or negative values; however, near-zero values are not desired.

Figure 52 shows the separation efficiency data for each element and each test condition. Altogether, $\mathrm{MgO}$ tends to show superior performance across a range of cases, for example, with respect to $\mathrm{Fe}, \mathrm{Mg}$ is able to precipitate a large portion of $\mathrm{Fe}$ at a relatively low $\mathrm{pH}$, while retaining most of the REEs in solution. This result prompts a maximum separation efficiency at $\mathrm{pH} 3$, which exceeds the maximum values for the other two reagents. Regarding the more soluble species, $\mathrm{Ca}$ and $\mathrm{Mn}, \mathrm{MgO}$ retains these elements in solution even at high pH points, thus prompting very high negative separation efficiencies. Neither of the three elements were able to produce a high separation efficiency with $\mathrm{Al}$, since the Al/REE precipitation curves tend to align closely. While this data does suggest that $\mathrm{MgO}$ is a superior reagent, these benefits must be weighed against the costs of added $\mathrm{Mg}$ contamination in a full process design. 
TREE

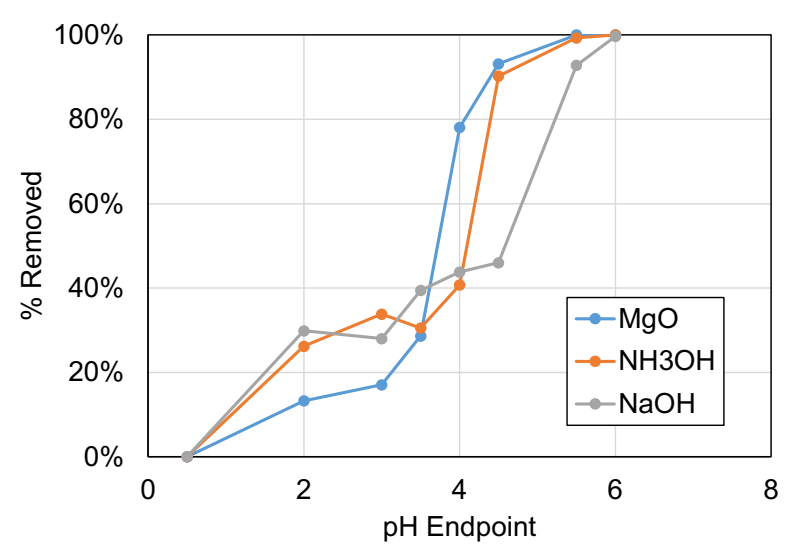

Al

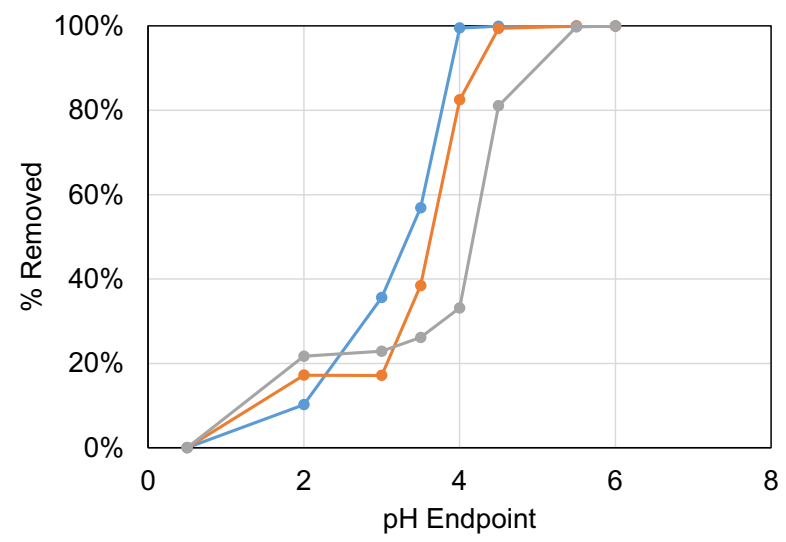

$\mathrm{Fe}$

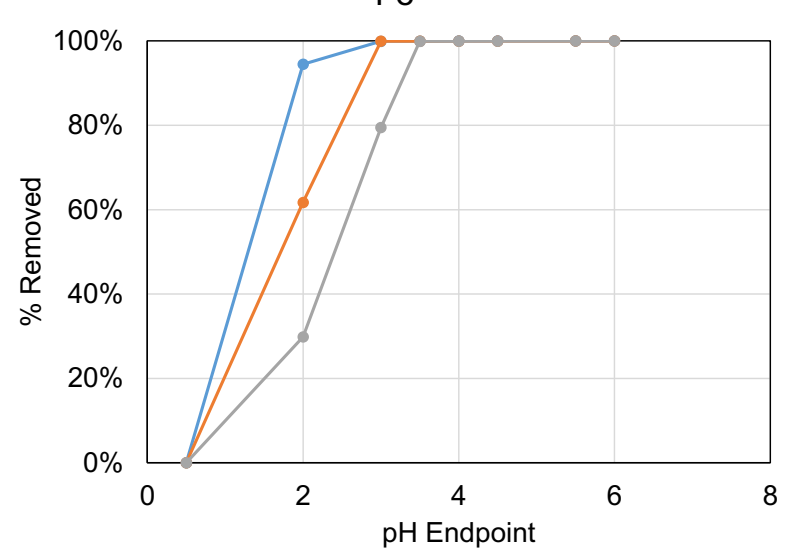

$\mathrm{Mn}$

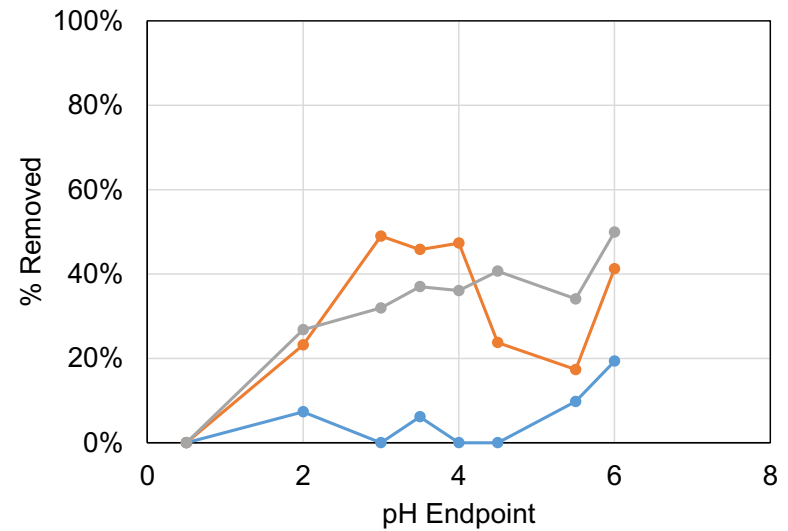

$\mathrm{Ca}$

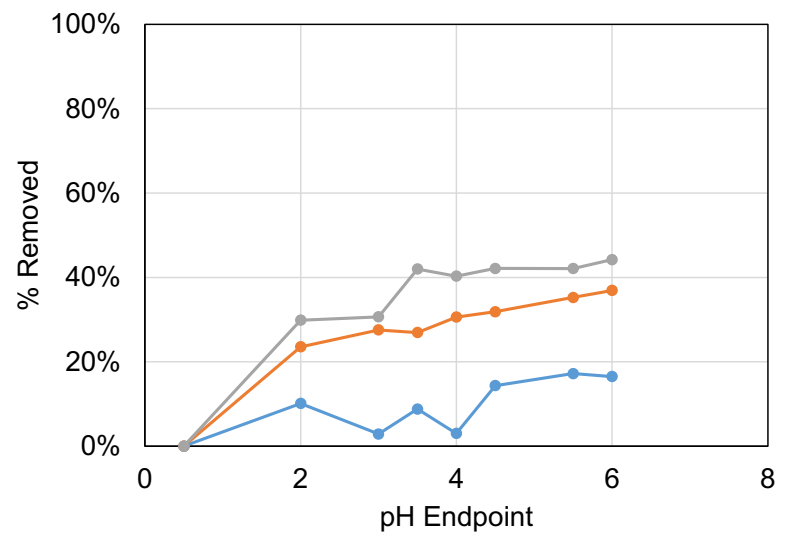

Figure 51. Reagent evaluation test result. \% removed plotted as a function of $\mathrm{pH}$ endpoint for TREE and various major metals. $\mathrm{Mg}$ has been removed from the analysis, given the additional $\mathrm{Mg}$ included in the $\mathrm{MgO}$ reagent. 
REE vs. Fe

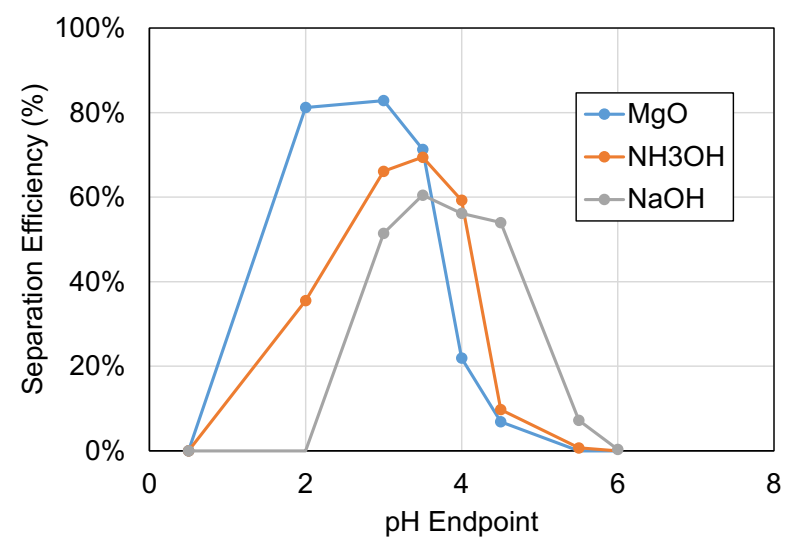

REE vs. Ca

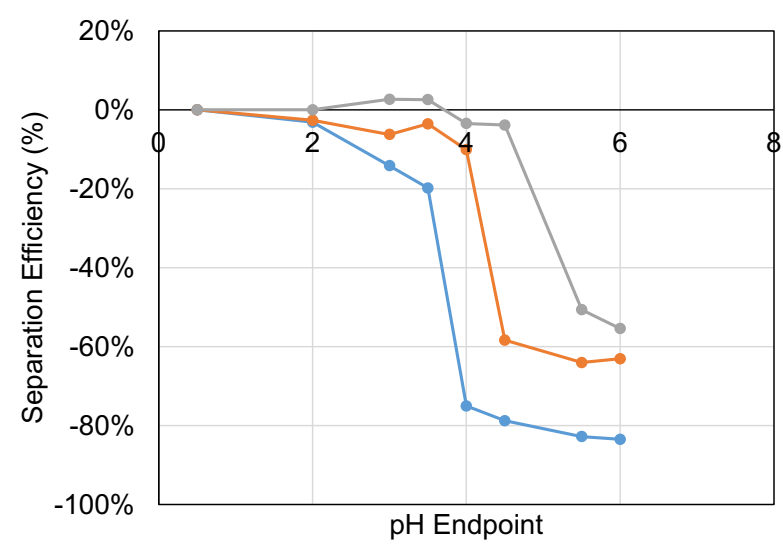

REE vs. Al

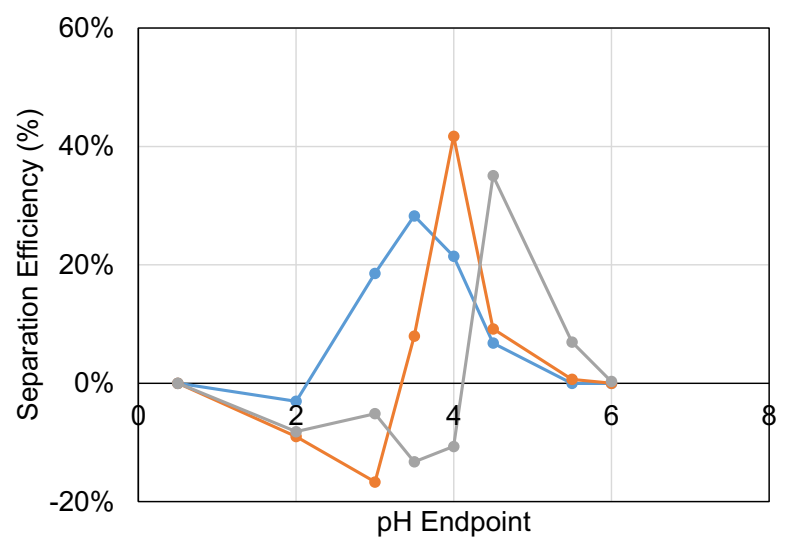

REE vs. Mn

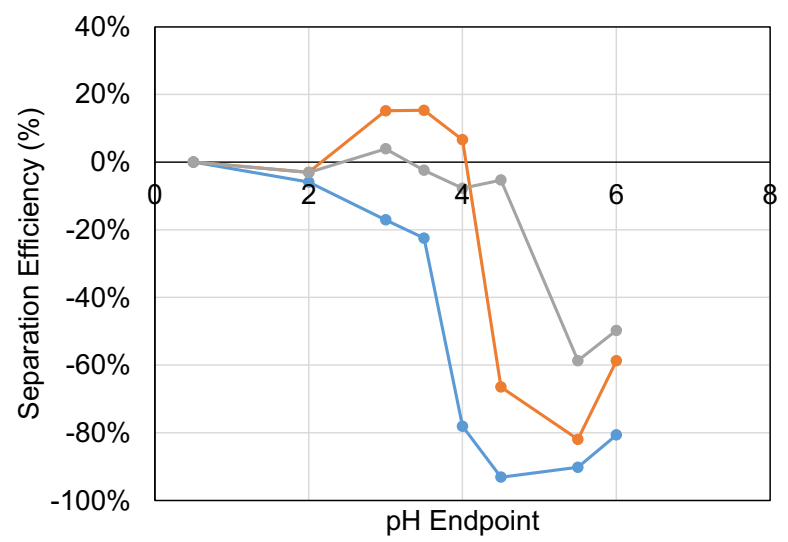

Figure 52. REE vs. major metal separation efficiency for reagent evaluation tests. Here separation efficiency is defined as \% removal of major metal minus \% removal of REES.

Figure 53 evaluates the hysteresis between leaching and precipitation of REEs in the MV sample. The leaching data is taken from the kinetic studies in Chapter 4, while the precipitation data is taken from the $\mathrm{NaOH}$ tests in the reagent evaluation test series. This data does show the solubility reaction is non-reversible, given the significant deviation between the two curves. For example, appreciable leaching is not observed until pH 4 and near complete dissolution is achieved by $\mathrm{pH} 2$. When precipitating that same solution, the first $\mathrm{pH}$ increases to 2 prompts a significant reduction in REEs; however, all REEs are not removed from solution until pH 6 . In comparing this result to the thermodynamic studies in chapter 3 , this data suggests that the REEs may be precipitating as hydroxides, as the $\mathrm{pH}$-Eh diagrams typically showed hydroxide precipitation at high $\mathrm{pH}$ points from 5 to 6 . However, the slow leaching of material at that same $\mathrm{pH}$ suggests that the original REE speciation in AMDp may include some fraction that is bound with acid resistance matrix elements. 


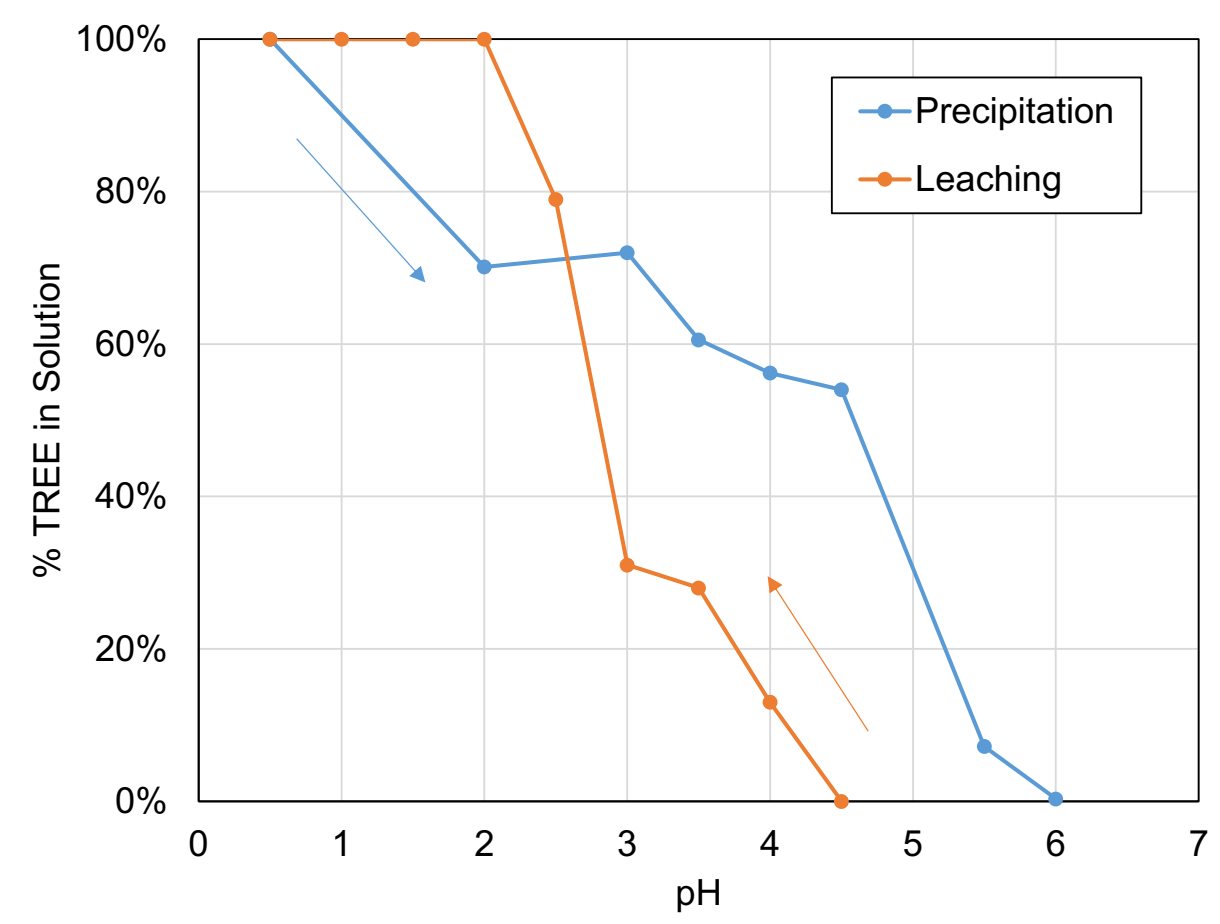

Figure 53. Comparison of REE precipitation and leaching data across similar pH points.

\subsubsection{Oxidization-Precipitation tests}

Figure 54 and Figure 55 show the from the $\mathrm{H}_{2} \mathrm{O}_{2}$ precipitation tests. The data here is presented in a similar manner to that of the reagent evaluation tests, first as \% removed versus $\mathrm{pH}$ and then as separation efficiency versus $\mathrm{pH}$. Separation efficiency is defined in the same manner as in the prior test series.

Overall, $\mathrm{H}_{2} \mathrm{O}_{2}$ did not impart a significant change in the precipitation of REEs. All of the percent removed versus $\mathrm{pH}$ cures are clustered together with no clear trend as a function of $\mathrm{H}_{2} \mathrm{O}_{2}$. $A$ similar result is shown for $\mathrm{Al}$ and $\mathrm{Fe}$, both of which have curves which largely overlap. Interestingly, the $\mathrm{H}_{2} \mathrm{O}_{2}$ did strongly influence the precipitation behavior of $\mathrm{Mn}$, as higher doses of $\mathrm{H}_{2} \mathrm{O}_{2}$ led to lower amounts of $\mathrm{Mn}$ remaining in solution. Overall, this data suggest that the Fe was either already fully oxidized or that the $\mathrm{H}_{2} \mathrm{O}_{2}$ dose was only sufficient to oxidize $\mathrm{Mn}$. The experimental data supports the former, as all Fe was removed by $\mathrm{pH} 3$, even in the control test. This behavior is often indicative of $\mathrm{Fe}^{3+}$.

Like the raw precipitation data, the separation efficiency data shows that $\mathrm{H}_{2} \mathrm{O}_{2}$ did not significantly impact the separation efficiency of REEs versus $\mathrm{Fe}, \mathrm{Al}$ or $\mathrm{Ca}$. Higher $\mathrm{H}_{2} \mathrm{O}_{2}$ doses did, however, impart higher separation efficiency between REEs and $\mathrm{Mn}$, with an optimal dose being between 0.21 and $0.42 \mathrm{M}$. 
TREE

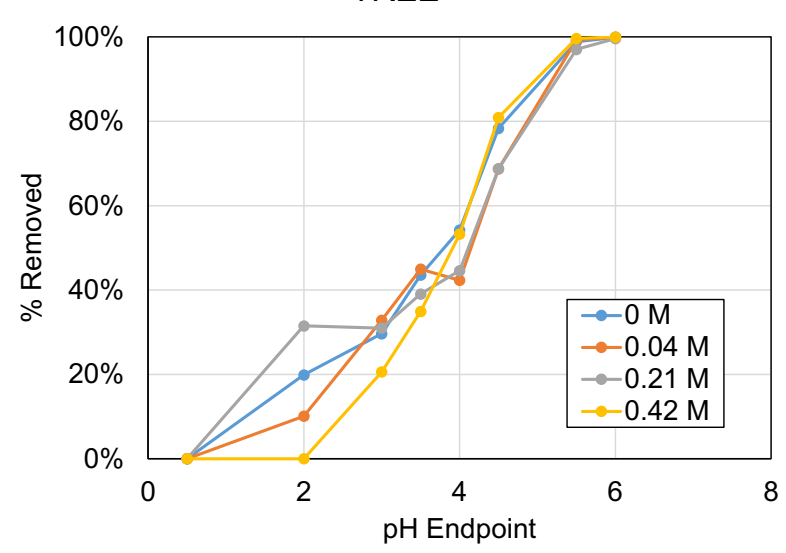

Al

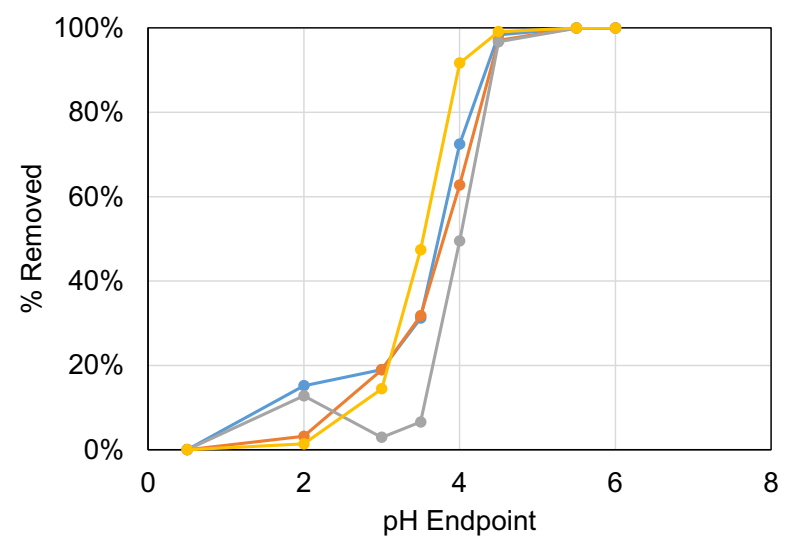

$\mathrm{Fe}$

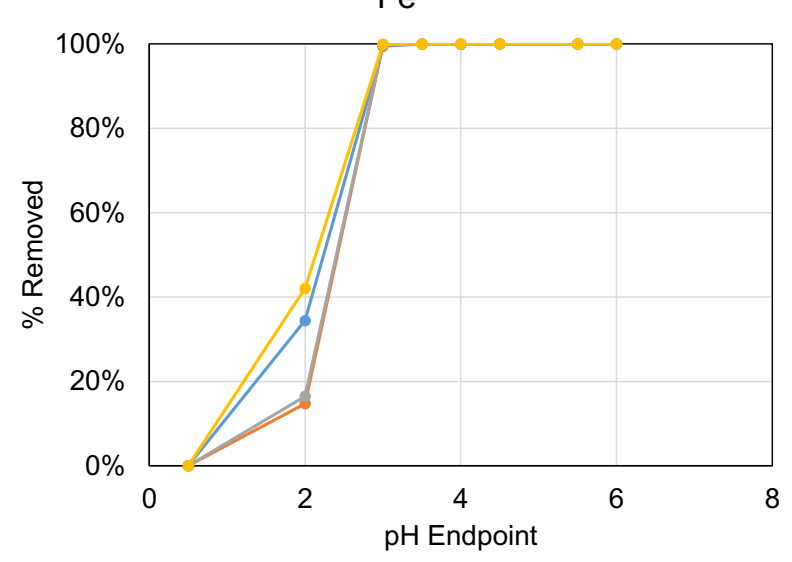

$\mathrm{Mn}$

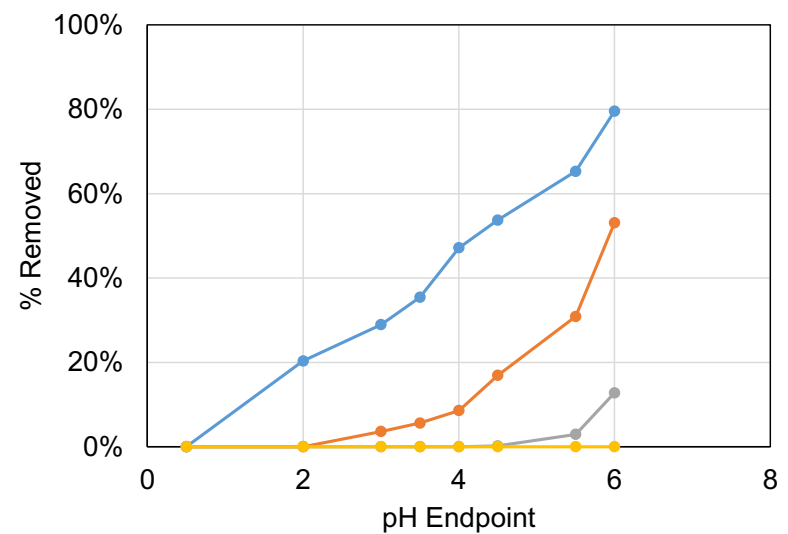

$\mathrm{Ca}$

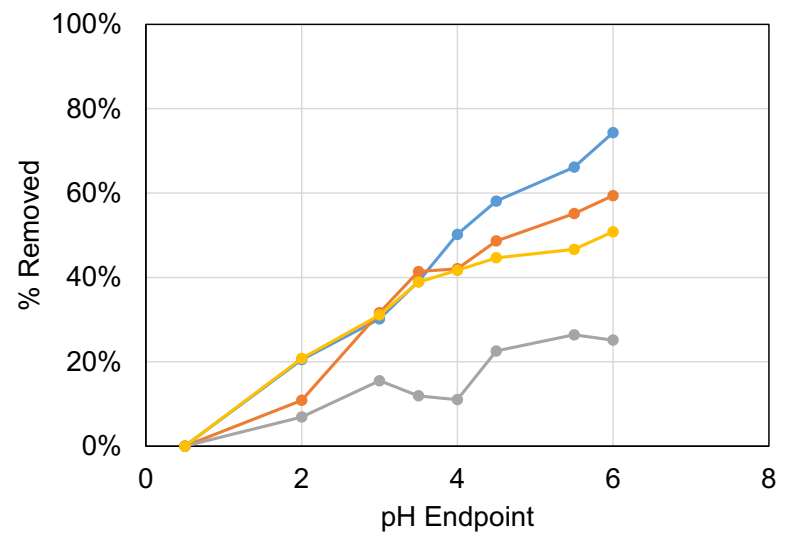

Figure 54. Oxidation-precipitation test result. \% removed plotted as a function of $\mathrm{pH}$ endpoint for TREE and various major metals. Data series show the various doses of $\mathrm{H}_{2} \mathrm{O}_{2}$. 

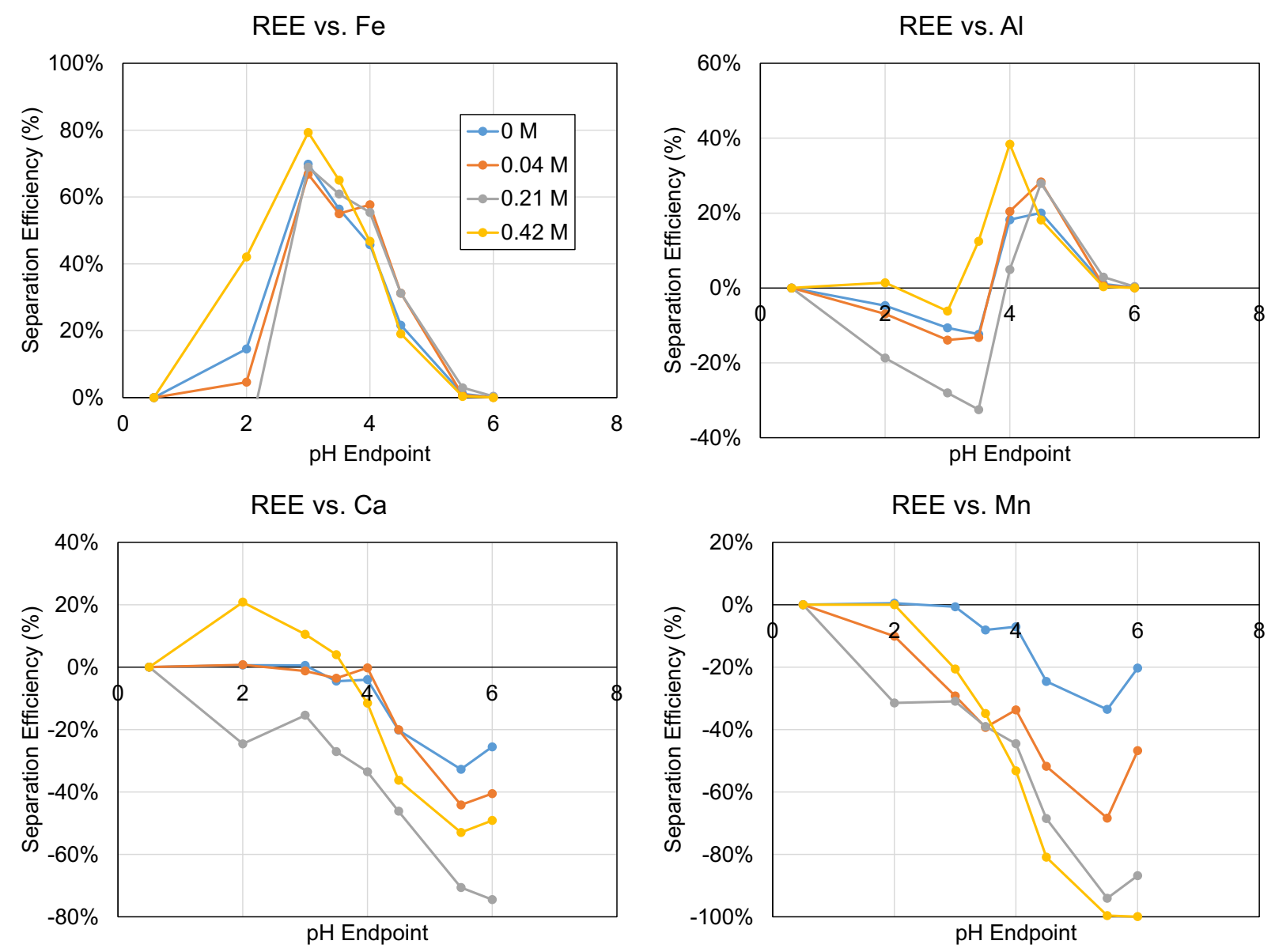

Figure 55. REE vs. major metal separation efficiency for oxidation-precipitation tests. Here separation efficiency is defined as \% removal of major metal minus \% removal of REEs.

To further analyze the data, the incremental mass of REEs and major metals precipitated between $\mathrm{pH}$ endpoints can be estimated from the cumulative data by simply assessing the slope between successive $\mathrm{pH}$ points (i.e., a steep slope indicates a larger precipitation mass). This calculation was performed using the analytical raw data to estimate the mass and composition of precipitate produced at each endpoint. The composition of these precipitates was then evaluated by calculating the ratio of TREE to total metals (i.e., TREE / (TREE + MM)) in the mass increment precipitated. This result thus provided a rough estimate of the REE grade of the precipitate that could be produced by selectively precipitating within that $\mathrm{pH}$ increment.

Data from this incremental analysis was shown in Figure 56 for each of the $\mathrm{H}_{2} \mathrm{O}_{2}$ dosages.

While the mass of major metals precipitating at most $\mathrm{pH}$ endpoint significantly exceeded that of the REEs (i.e., the REE grade is very low), an interesting anomaly was seen between $\mathrm{pH}=4.5$ and $\mathrm{pH}=5.5$. Here, a large amount of REEs precipitate, while the precipitation of major metals is minimal (the same observation can be seen visually in Figure 49 above). As a result, the REE grade of this precipitate had the potential to be very large, exceeding $2 \%$ and in some cases as 
large as $10 \%$. However, no clear trend was observed between the various $\mathrm{H}_{2} \mathrm{O}_{2}$ dosages indicating that $\mathrm{H}_{2} \mathrm{O}_{2}$ has a minimal effect in REE and major metal precipitation at the dosages that were tested. Unfortunately, the precipitates generated during these tests were of insufficient quantity to be assayed directly, and as such, this calculation only represented a rough estimate of the actual grade that may be obtained using incremental precipitation.

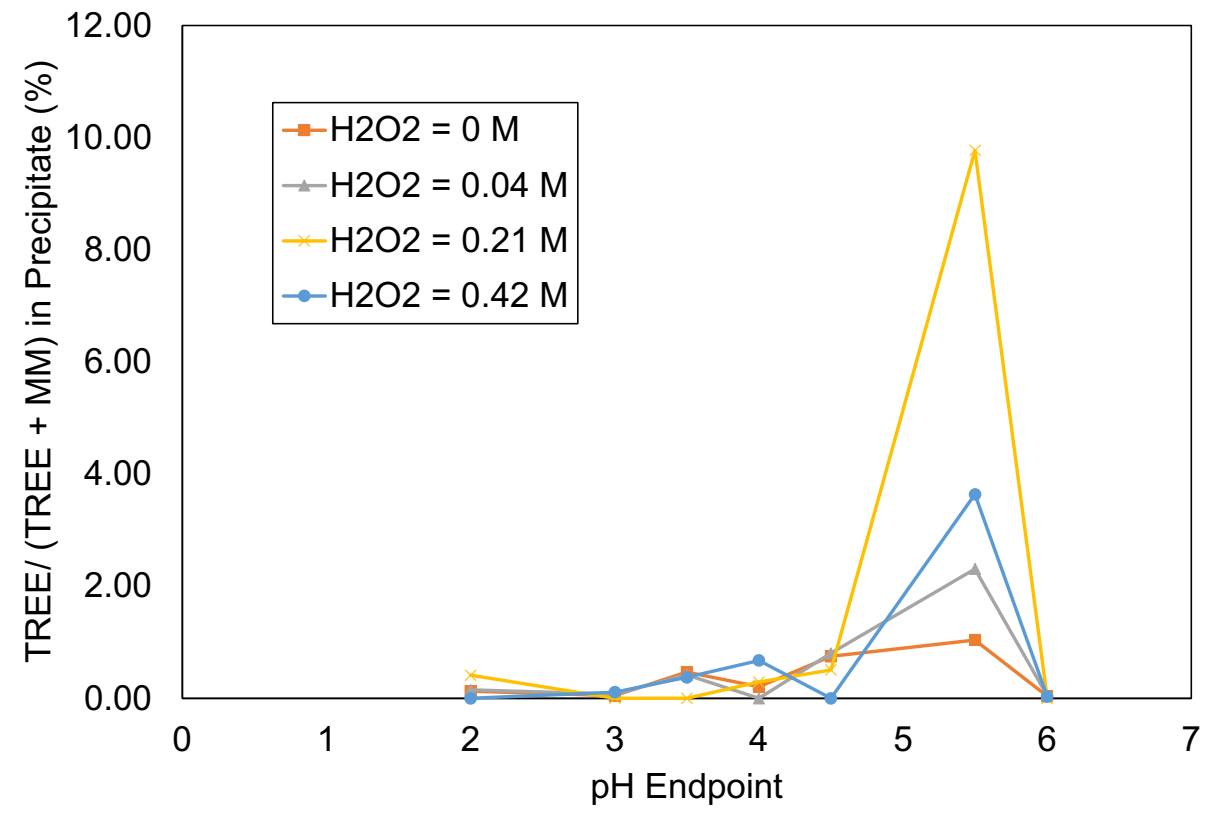

Figure 56. TREEs to total metal ratio, estimated from incremental analysis of precipitation results.

\subsubsection{Cumulative Data Analysis}

After obtained aqueous concentration from all of the leaching and precipitation tests $(n=243)$, an overall assessment of rare earth elements aqueous behavior can be determined in a broad range of condition. This aggregated dataset, which includes various leachate samples, acid types, pH points, bases, oxidation-reduction potentials, and other parameters, is shown in Figure 57 and Figure 58. Figure 57 shows REE solution concentration as a function of pH. Overall, this data shows an increasing REE concentration with lower $\mathrm{pH}$ points with almost no REEs remaining at $\mathrm{pH}$ values above 6 . This data is corroborated by the $\mathrm{pH}$-Eh diagrams in Chapter 3, which typically show solid species above $\mathrm{pH} 6$. A more interesting analysis is shown in Figure 58, which shows the individual REE concentrations as a percent of the total REEs in solution as a function of $\mathrm{pH}$. Most REEs do not show a clear trend; however, the behavior of $\mathrm{Y}$ is quite unique, showing a clear positive upward trend. This result indicates that at elevated $\mathrm{pH}$ points, $Y$ is usually the last REE remaining in solution, a factor that may be caused by the relatively high concentration of yttrium relative to the other REEs.) 


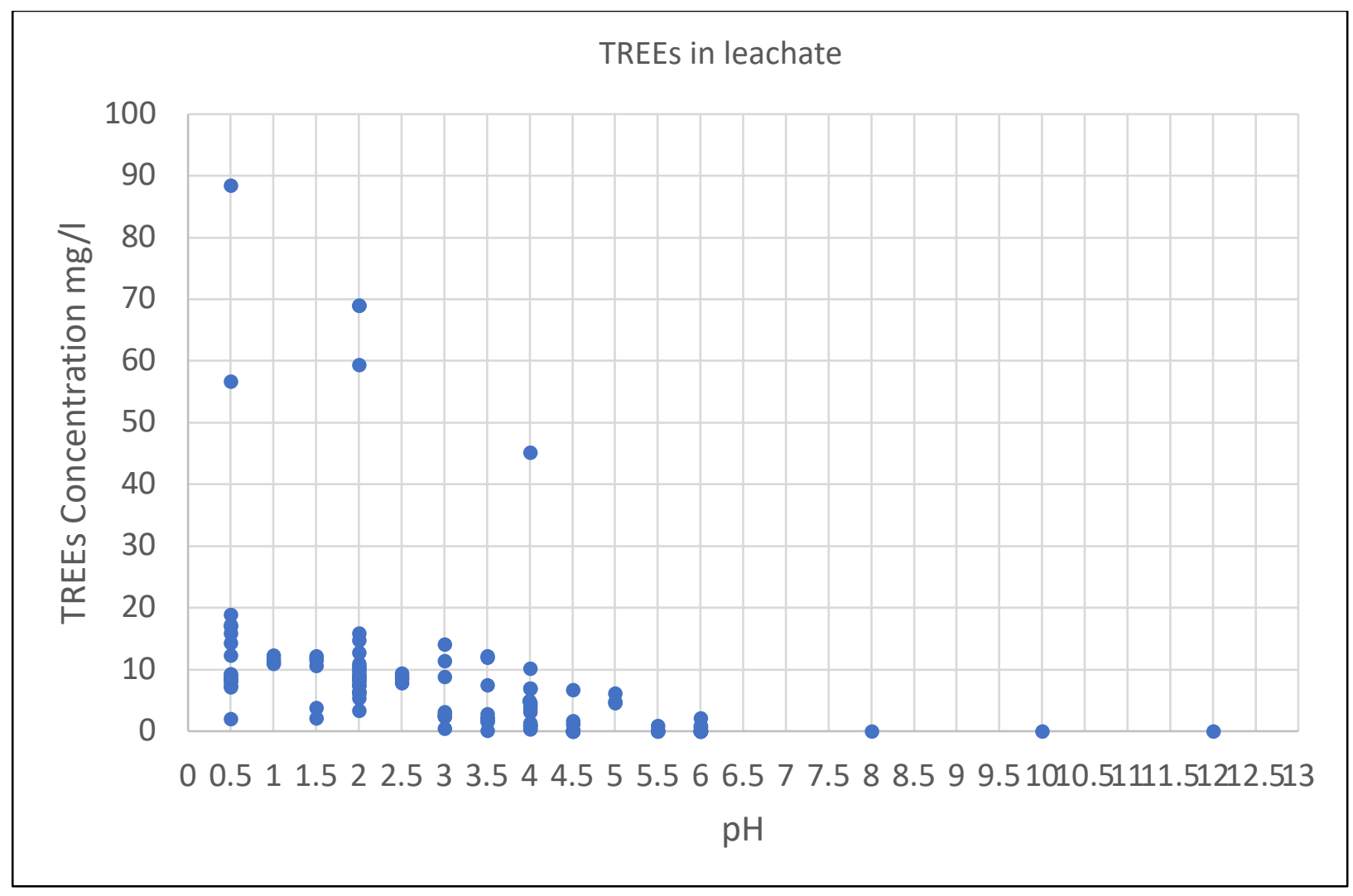

Figure 57. Aqueous TREE concentration vs. pH for all leaching and precipitation test data 

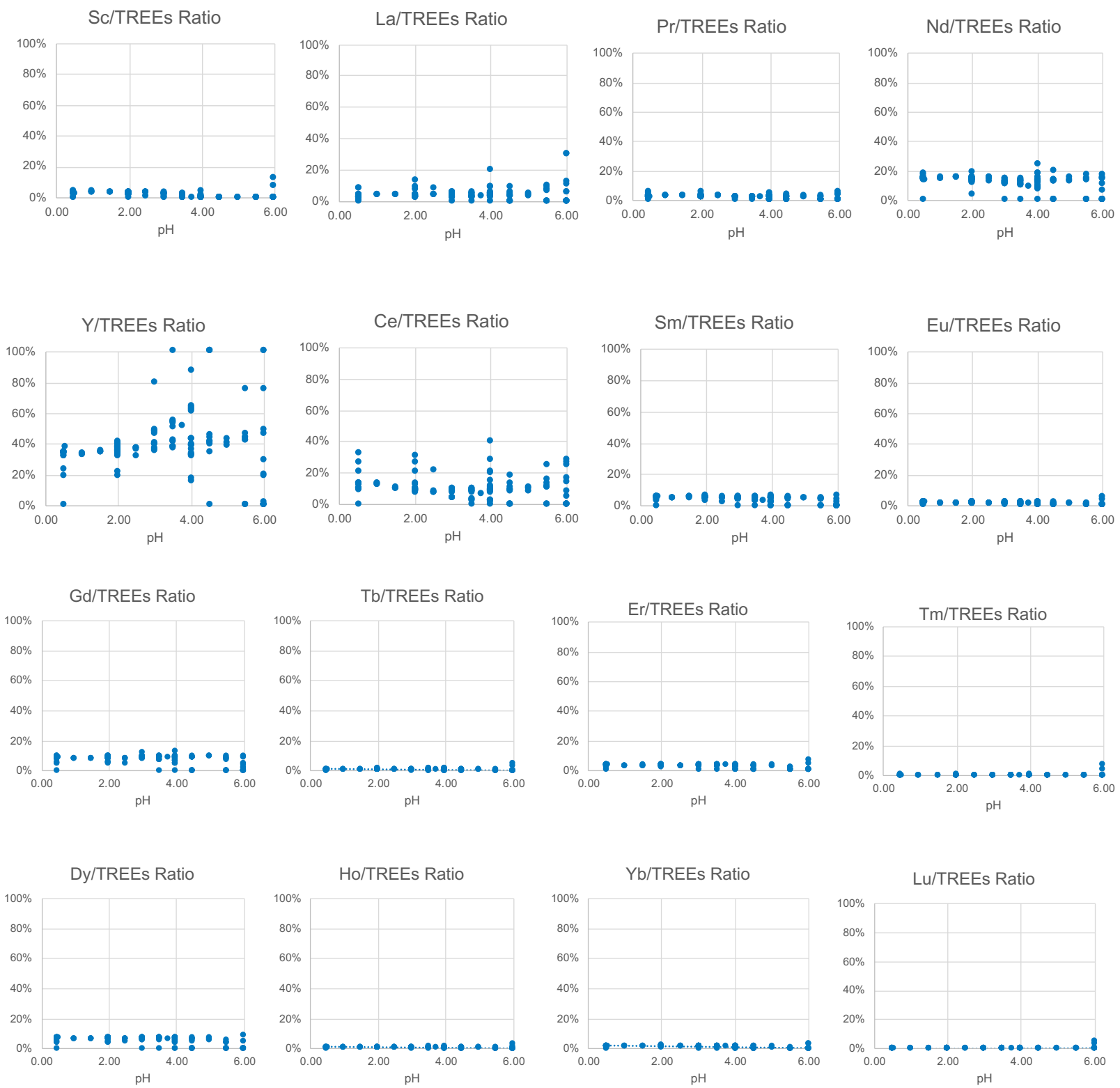

Figure 58. Individual REE/TREEs ratio vs. pH for all test conditions. 


\subsection{Conclusions}

To investigate the separation of REEs from contaminant metals in leachate solutions, a series of parametric precipitation experiments was conducted. Tests were performed in a small laboratory-scale leaching reactor by first fully dissolving the AMDp in acid at 0.5. Next, the pH was incrementally raised to various $\mathrm{pH}$ endpoints using a range of base types and other additives. From this work, several key conclusions are derived:

- Across all test conditions, REEs typically precipitated between $\mathrm{pH} 4$ and 6 with nearly complete removal of REEs occurring at $\mathrm{pH} 6$. This trend was found to be consistent across various sample types, acid types, base types, and oxidation potentials.

- Among the various contaminant metals i.e. ( $\mathrm{Fe}, \mathrm{Al}, \mathrm{Ca}, \mathrm{Mg}$, and $\mathrm{Mn}$ ), Fe showed the highest sensitivity to acid type, with $\mathrm{HNO}_{3}$ prompting lower precipitation $\mathrm{pH}$ points as compared to $\mathrm{H}_{2} \mathrm{SO}_{4}$. In both cases, however, the $\mathrm{pH}$ of Fe occurred at a significantly lower $\mathrm{pH}$ than that of the REEs suggesting selective separation is possible.

- Alternatively, the precipitation behavior of the REEs usually closely matched that of Al, with the REE precipitation occurring at a slightly higher $\mathrm{pH}$. Nevertheless, selective separation of the REEs from Al may be difficult with precipitation alone.

- Evaluation of the precipitate composition as a function of $\mathrm{pH}$ showed a significant increase in REE grade between $\mathrm{pH} 4$ and 6 . Higher increases above $\mathrm{pH} 6$ typically led to slightly lower grades as additional contaminants were precipitated.

- MgO was shown to be the superior base for selective separation of REEs from other gangue metals. MgO typically led to lower precipitation $\mathrm{pH}$ points for $\mathrm{Fe}$ and $\mathrm{Al}$, while keeping larger fractions of $\mathrm{Mn}$ and $\mathrm{Ca}$ in solution. Despite the superior performance of $\mathrm{MgO}$, these benefits must be weighed against the costs of added Mg contamination in a full process design.

- The addition of $\mathrm{H}_{2} \mathrm{O}_{2}$ did not significantly impact the precipitation of REEs, Al or Fe; however, higher doses of $\mathrm{H}_{2} \mathrm{O}_{2}$ did lead to increased solubility of $\mathrm{Mn}$. This result in turn led to lower levels of $\mathrm{Mn}$ contamination on the final precipitate.

- Comparison of the leaching data with the precipitation data clearly shows hysteresis, indicating that the solubility reactions are non-reversible. Comparisons with thermodynamic predictions suggest that the REEs are precipitating as simple hydroxides; however, the form in the initial AMDp may include some fraction that is bound with other matrix elements.

- Cumulative data from these tests show that selective precipitation of high grade REE materials should be feasible if sequential precipitation is done between $\mathrm{pH} 4$ and 6 . Given the numerous test conditions that support this conclusion, the data show that this selective precipitation process may have relevancy both for AMDp leachate as well as raw AMD. 


\section{Investigation of Rare Earth Elements Release from Coal Refuse into Acid Mine Drainage}

\subsection{Introduction and Objectives}

As described in Chapters 1 and 2, prior studies have shown that AMD and AMDp contain elevated concentrations of REEs when compared to the native rock strata. This observation has led to the inference that AMD acts as an autogenous heap leach, concentrating REEs and other metals into solution. While most studies in the literature focus on concentration and quantity of REEs in AMD, very few have investigated the weathering and leaching processes that lead to the initial REE release. To overcome this knowledge gap, the work in this chapter seeks to use humidity cell tests (HCTs) to investigate the rate of REE release into AMD and the environmental factors that control this release. This data will support better fundamental understanding on the nature of REEs in AMD and may also support future technology development efforts on controlled leaching of REEs in coal refuse.

Humidity cells are often used in environmental waste management studies and are used to define a sulfate weathering or oxidation rate for a given waste material (Maest, 2017). In a humidity cell test, 0.5 to $1.0 \mathrm{~kg}$ of refuse material is loaded into a container and continually subjected to moist or dry air. At regular intervals, the material is flushed with a rinse solution to release any leached materials. The rinse solution is then analyzed for water quality parameters (e.g. pH, conductivity, etc.) as well as elemental concentration for metals of interest. The test data is then analyzed to determine the speed of acid-producing reactions, such as pyrite oxidation. These data can in turn be used to build geochemical prediction models for a better understanding of weathering process. HCTs can vary in length from weeks to years depending on the desired data and the weathering rate of the host material.

The objectives of this work are to use a long duration HCT (approximately 1.5 years) to obtain the release rate of REEs, major metals, and sulfate from a coarse refuse material. Correlations between the release patterns of REEs and other metals will provide information on the mode of occurrence of REEs in coarse refuse.

\subsection{Methods and Materials}

\subsubsection{Material Sampling}

The feed material used in this study was collected from a surface refuse pile in Central Appalachia (Figure 59). Several 5-gallon buckets of material were collected from different locations around the site. To avoid early weathering, material at the surface was discarded and only material at depth greater than 1.5 feet was retained. All fresh samples were sealed immediately sealed in the buckets and then shipped to the laboratory for further testing. Upon receipt at the lab, all the raw materials were dried at $40^{\circ} \mathrm{C}$ in the ovens for 48 hours (Sapsford 2009), then crushed and screened to $-55 \mathrm{~mm}$. After homogenizing the material, 10 representative splits of $600 \mathrm{~g}$ each were obtained by using a Jones riffler. These splits were then retained for test feed material as well as for various characterization and analytical procedures. 


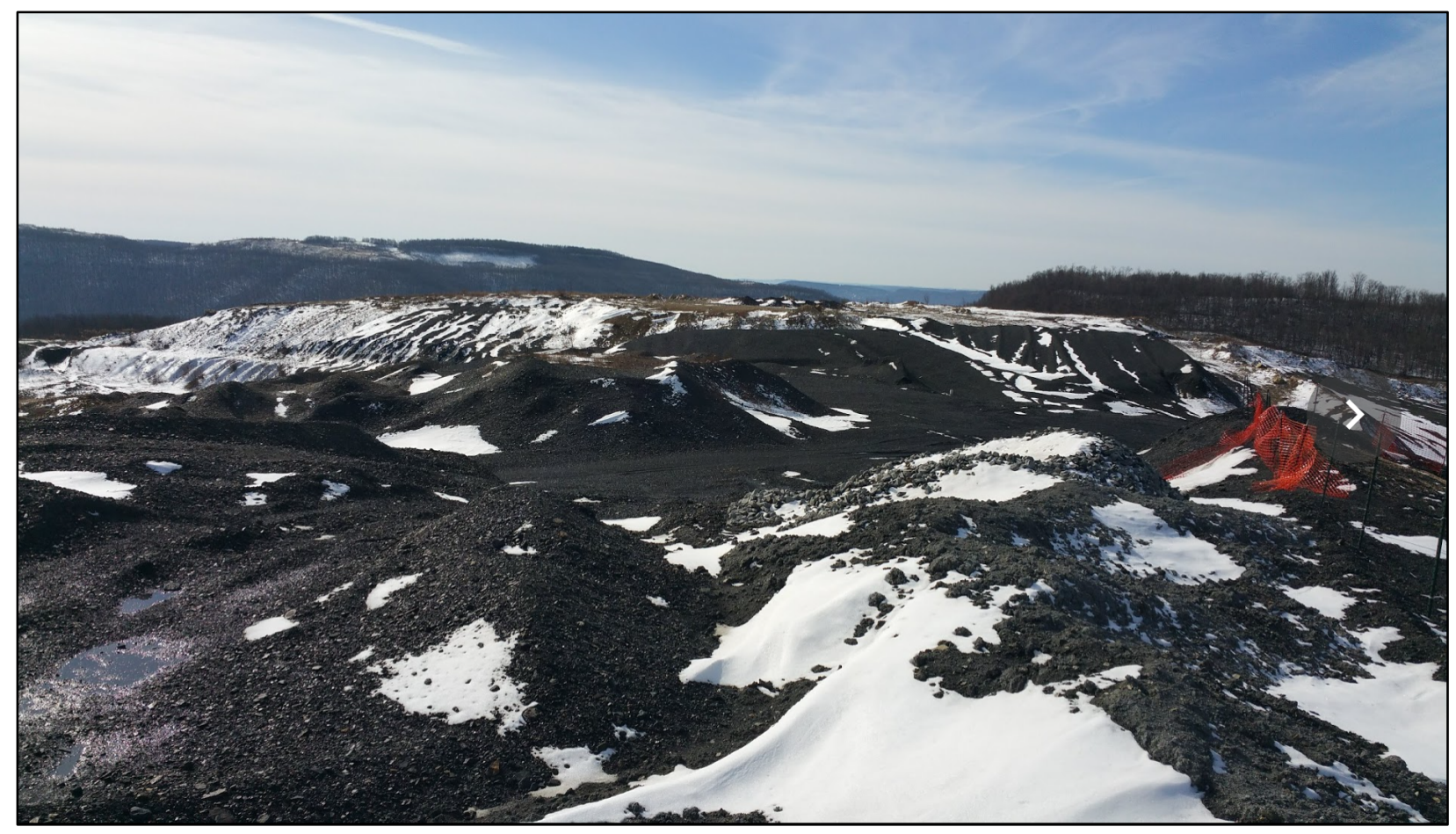

Figure 59. Surface refuse site sampled for test material.

\subsubsection{Reagents and Equipment}

The humidity cells used in this study were custom constructed from small ( 3 gallon) plastic storage containers (Figure 60). The cell design modeled after that of Ziemiewicz's research (Ziemkiewicz, 1994), is outfitted with two $\varnothing 50 \mathrm{~mm}$ holes on outer wall of the cell for ventilation. The bottom of each cells includes six $\varnothing 50 \mathrm{~mm}$ holes for collection of the leachate after each flushing cycle. The bottom of the cells contains a small filter mesh to ensure no loss of solids through the leachate collection port. A schematic of the cell design is shown in Figure 61. In total, eight such cells were used, each representing a different experimental condition.

Other laboratory equipment utilized in this study included a hydrometer (Figure 62), an air flow meter, a standard benchtop $\mathrm{pH}$ probe, and a water conductivity meter. Chemicals included nitric acid (10\%), which was used to clean the cells prior to use, and $2 \% \mathrm{H}_{2} \mathrm{O}_{2}$, which was used as a leaching accelerant for one set of experiments. All reagents were procured from Sigma Aldrich and Fisher Scientific. 


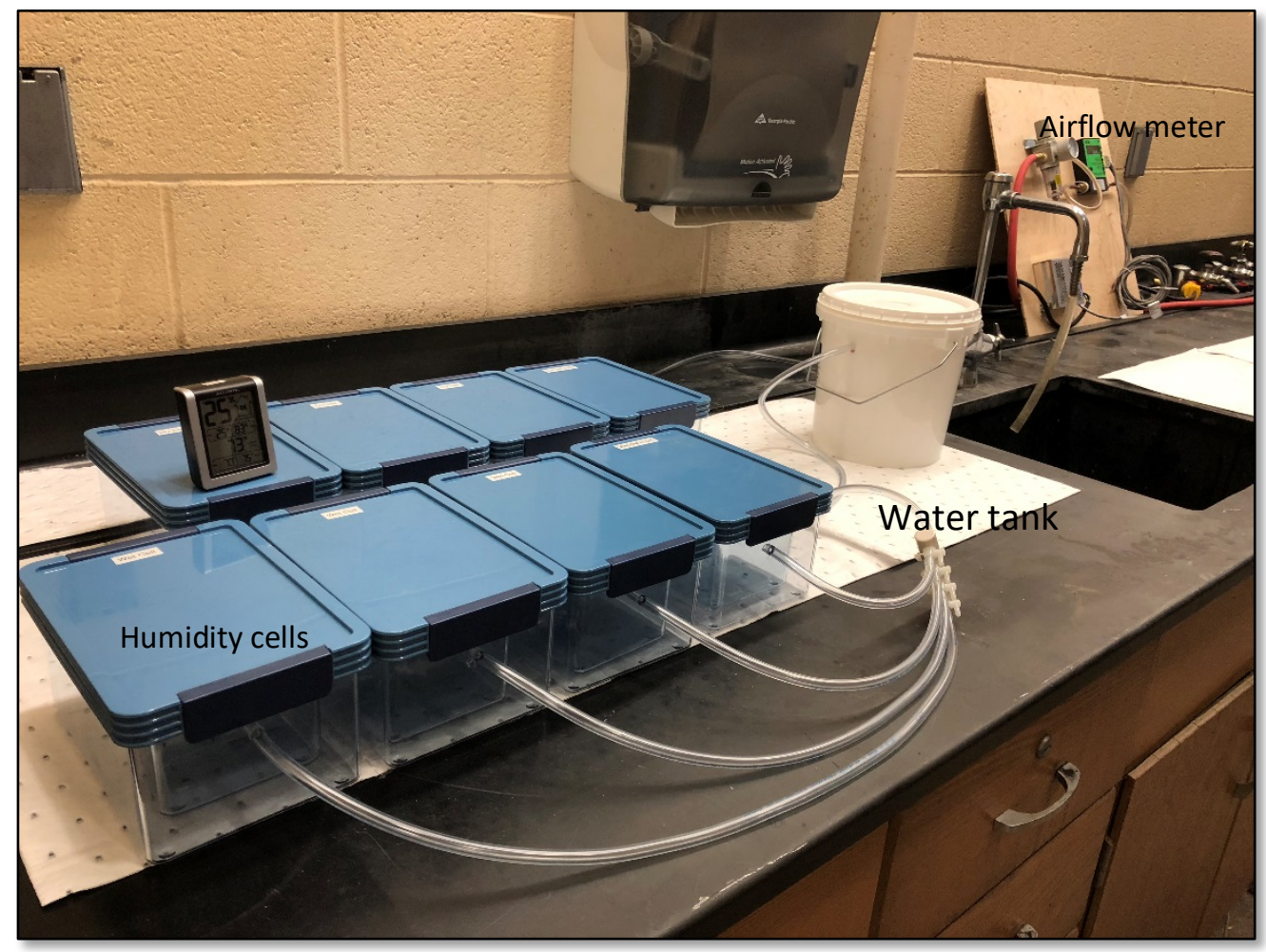

Figure 60. HCTs experimental setup.

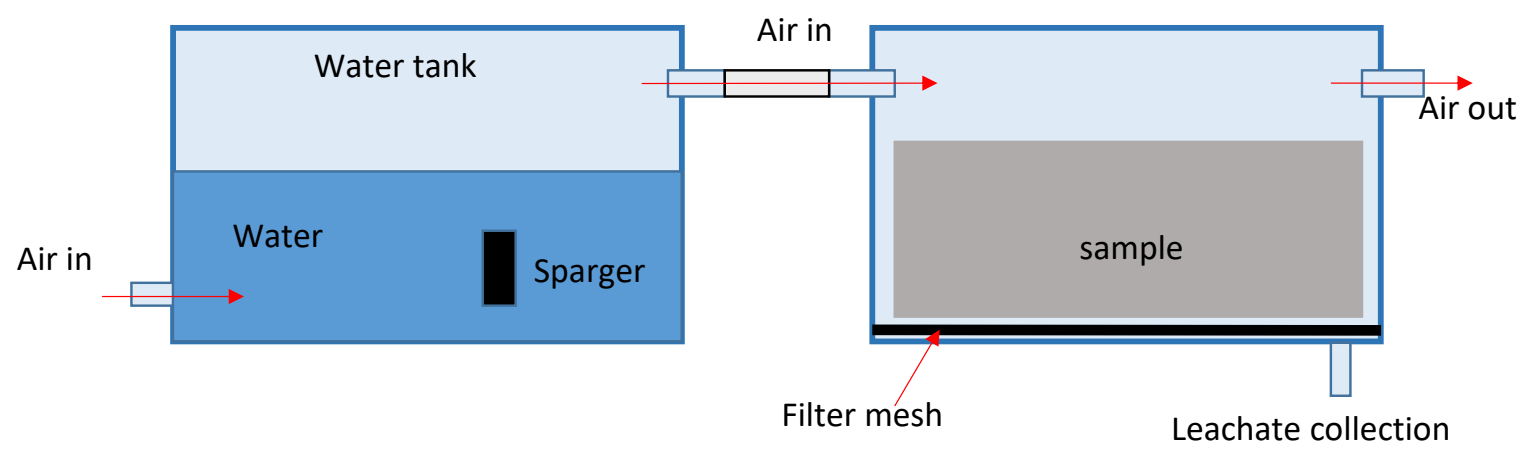

Figure 61. Humidity cell schematic. 


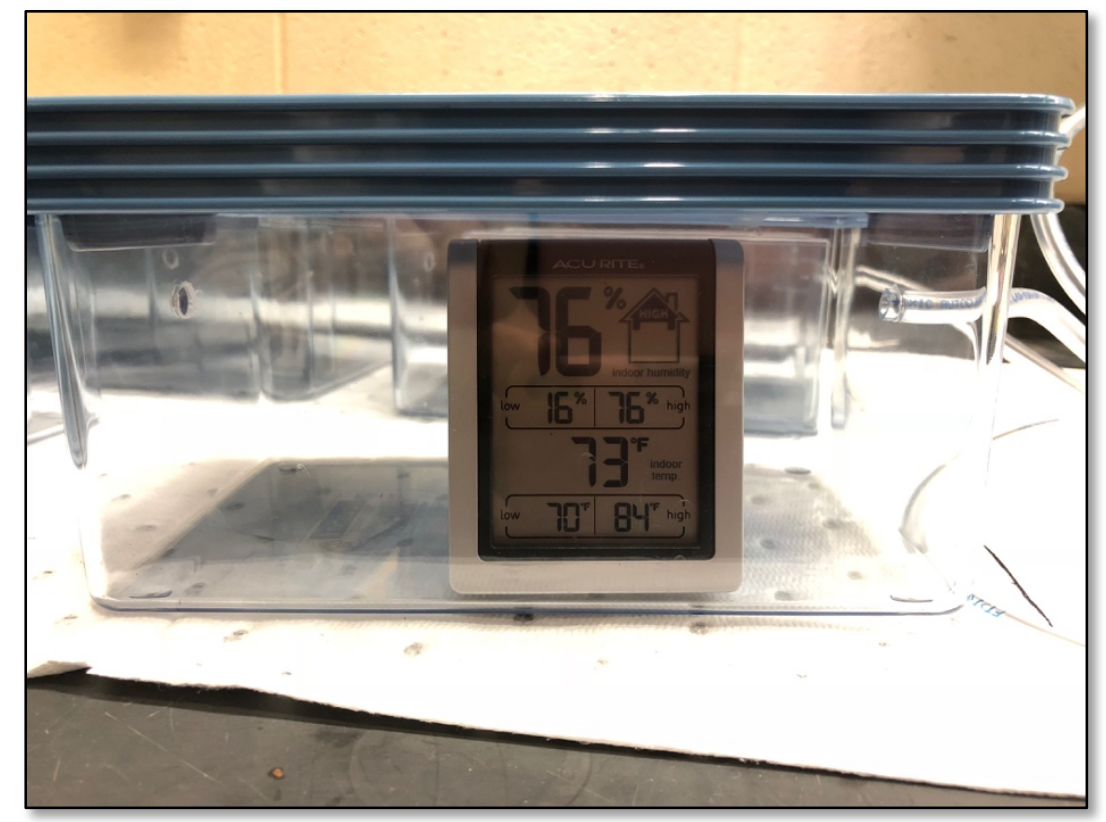

Figure 62. Hydrometer in humidity cell.

Analytical equipment used for material characterization include a Cilas 1190 Particle Size Analyzer, and a Shimadzu UV-VIS Spectrophotometer for sulfate analysis. Following each weekly flush, ICP-MS and ICP-OES analyses were used for determining the REEs and major metals concentrations, respectively. For these tests, ICP-MS was conducted at Virginia Tech Department of Civil and Environmental Engineering, while ICP-OES was performed at the NRCCE analytical lab at West Virginia University. In addition, the SEM-EDX (Hitachi S-4700) and XRD (Panalytical X'pert Pro), both accessed at the WVU Shared Facilities Laboratories, were used to determine the physical properties of the feed samples.

\subsubsection{Experimental Procedures}

The experimental design for the HCT's included two independent variables, each with two levels: (1) aeration versus non-aerated and (2) standard DI water flush versus $\mathrm{H}_{2} \mathrm{O}_{2}$ assisted flush. This configuration thus provides four unique testing conditions. Given that eight humidity cells were available for testing, three replicates were used for the aerated-DI water flush condition (denoted $A 1, A 2$, and $A 3$ ), and three additional replicates were used for the nonaerated-DI water flush condition (denoted N1, N2, and N3). In addition, one cell was used for the aerated, $\mathrm{H}_{2} \mathrm{O}_{2}$ assisted flush $(\mathrm{AH})$, and the last cell was used for the non-aerated $\mathrm{H}_{2} \mathrm{O}_{2}$ assisted flush condition (NH).

During the tests, the aerated cells followed a weekly aeration cycle to simulate the natural weathering with 3 days of dry air, 3 days of humidified air at a 1-10 l/min flowrate, which was pumped through a water tank to obtain the humidity and flushed on the seventh day of the cycle. Alternatively, the non-aerated cells were simply left to stand between cycle flushes with 
no forced air into the cell. One of each aerated and non-aerated cells were flushed by $2 \% \mathrm{H}_{2} \mathrm{O}_{2}$ solution weekly for extra oxidization to accelerate the leaching process. As shown in Figure 62, the humidity in the aerated cell during wet session reached at $76 \%$ that offered more moisture in the cells.

Prior to sample addition, all cells were washed with $10 \% \mathrm{HNO}_{3}$, and then rinsed three times with DI water to remove all the chemical and biological residues on the cell walls. All cells were loaded with $1 \mathrm{~kg}$ prepared dry samples, which was placed on the $25 \mu \mathrm{m}$ polypropylene meshes in the small cells with holes on the bottom without lids. All samples were rinsed daily with $500 \mathrm{ml}$ DI water for the first three days (denoted as week 0 ) to remove any dust or reside that was accumulated during the sample preparations. These daily flush volume were discharged.

Staring in week 1 , the four aerated cells followed a weekly aeration cycle described above, which includes 3 days of humid air followed by 3 days of dry air. On the seventh day of the cycle, $500 \mathrm{ml}$ DI water was added slowly from the top of three cells to flush the interstitial liquid generated in the cell. After approximately 24 hours, the flush liquid (now denoted as leachate) was collected from the bottom of each cells. The four non-aerated cell were also flushed on the seventh day, with the leachate being collected approximately 24 hours after the flush.

After collecting the leachate from each cell, the volumes of leachate was recorded. Leachate $\mathrm{pH}$, conductivity, redox potential and sulfate concentration were measured in the lab immediately. For each sample, $20 \mathrm{ml}$ of leachates was filtered by $0.5 \mu \mathrm{m}$ syringe filter, stored, and ultimately sent to the appropriate analytical laboratories for ICP-M and ICP-OES analysis. Laboratory temperature and relative humidity were measured three times a week, and the average values were determined and logged. The same weekly aeration, flush, and analysis cycles were performed through a total period of 82 weeks.

In addition to the eight sample splits used for the humidity cell testing, several additional representative lots were retained for particle and bulk chemical characterization.

\subsection{Results and Discussion}

\subsubsection{Material Characterization}

A Cilas laser particle size analyzer was used to analyze the particle size distribution of the HCT feed material. This measurement was repeated 3 times on 2-gram dry sample lots. The average data from this analysis is shown in Figure 63 as percent retained versus sieve size (i.e. a Rosin-Rammler distribution). The data shows that the material is intermediate to fine with approximately $83 \%$ larger than $1 \mathrm{~mm}$. The material sufficiently coarse to allow good percolation of leachate through the particle bed, while also being fine enough to expose sufficient surface area for leaching. Thus, the size distribution is deemed to be adequate for this test. 


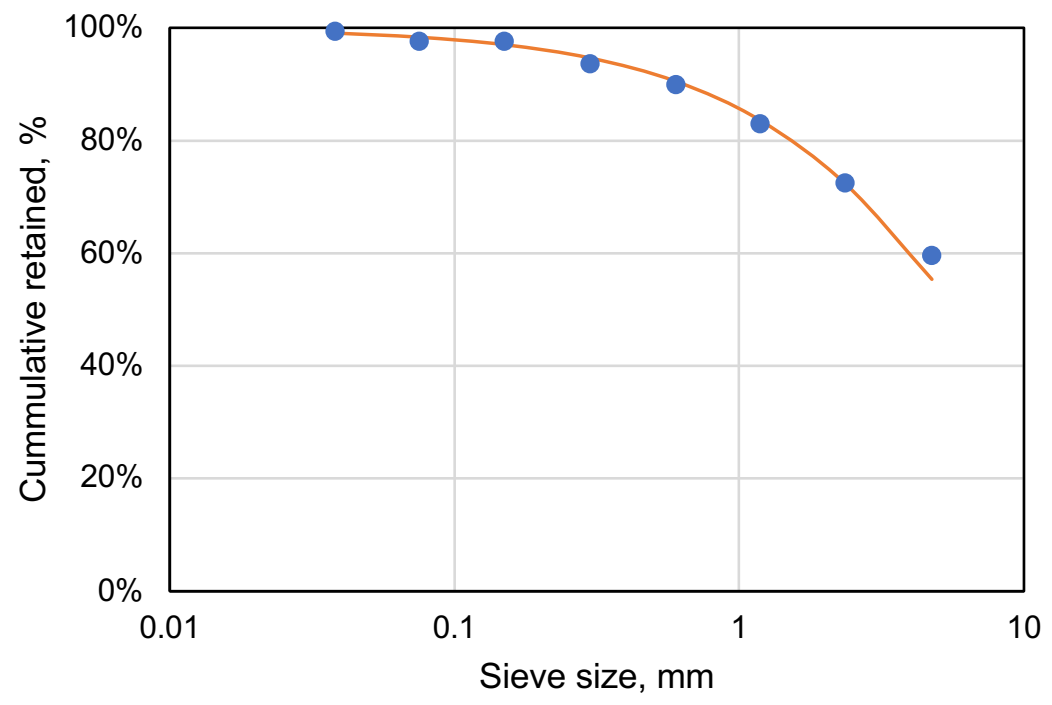

Figure 63. Sample size distribution.

The dried grinded samples were analyzed in the Panalytical X'pert Pro XRD. As shown in Figure 64 , these results indicate the major mineral species is $\mathrm{SiO}_{2}$, which is typical for coarse coal mine refuse material.

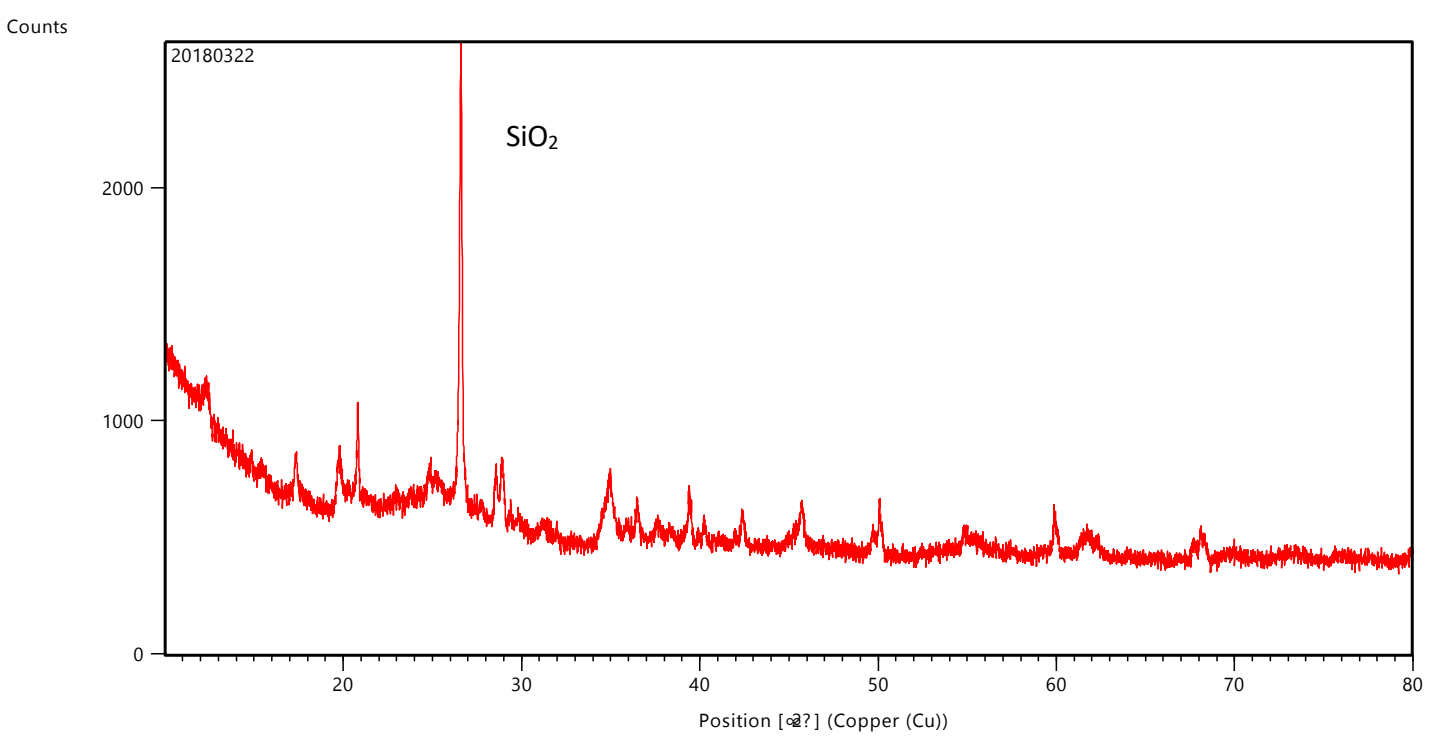

Figure 64. Feed sample XRD results 
To evaluate the particle morphology and assess the reactions on the sample surfaces under different test conditions, the Hitachi S-4700 Scanning Electron Microscope was used to visually assess the refuse material before, during, and after the humidity cell test procedure. EDX analysis was also conducted on various particle regions and areas to further investigate the behavior or specific elemental species. Figure 65 and Figure 66 show various SEM micrographs from the study. In addition, data from the EDS analysis is shown in Table 15. Unless otherwise indicated, the EDS data represents the average composition from a scan of the entire image.

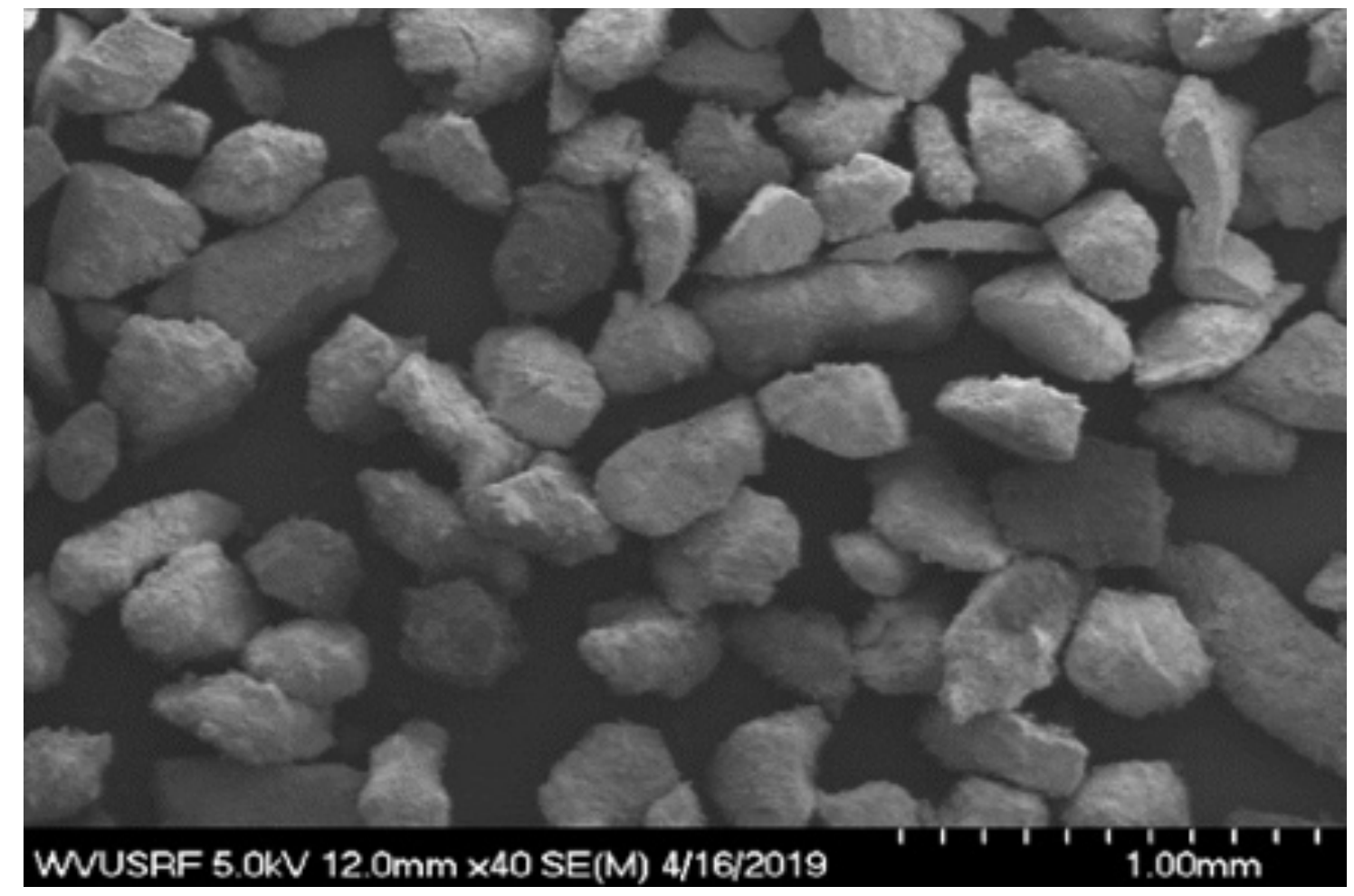

Figure 65. SEM Micrograph of feed sample with $1.00 \mathrm{~mm}$ scale bar. 


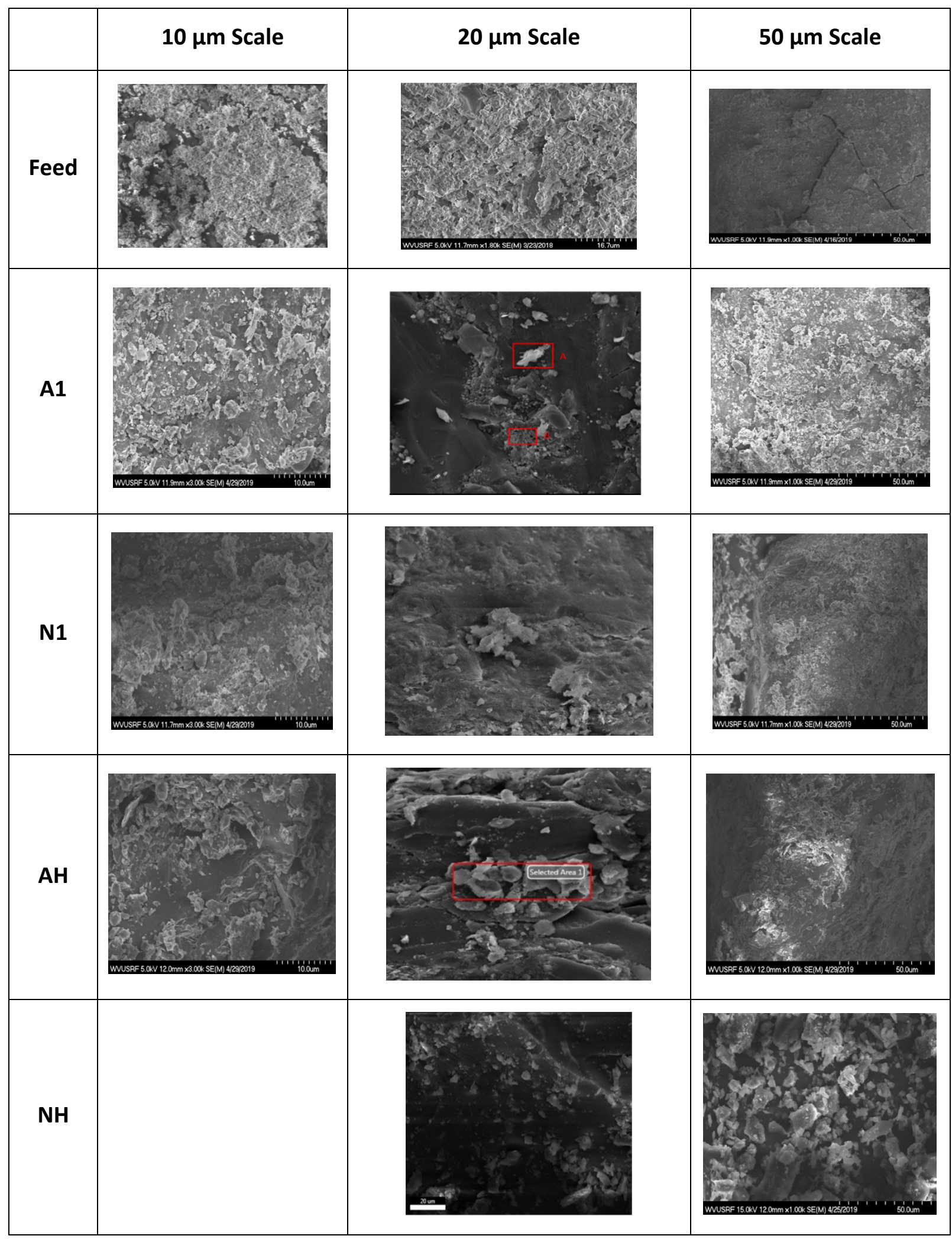

Figure 66. SEM Micrograph of various HCT samples after 40-weeks of test progression. 
Table 15. EDX Results for HCT Samples

\begin{tabular}{|c|c|c|c|c|c|c|c|c|}
\hline \multirow[b]{2}{*}{ Elements } & \multicolumn{8}{|c|}{ Weight (\%) } \\
\hline & $\begin{array}{l}\text { Feed } \\
10 \mu \mathrm{m}\end{array}$ & $\begin{array}{c}\text { A1 } \\
\text { Area A }\end{array}$ & $\begin{array}{c}\text { A1 } \\
\text { Area B }\end{array}$ & $\begin{array}{c}\text { N1 } \\
\text { Area A }\end{array}$ & $\begin{array}{c}\text { AH } \\
\text { Area A }\end{array}$ & $\begin{array}{c}\text { A1 } \\
50 \mu \mathrm{m}\end{array}$ & $\begin{array}{c}A H \\
50 \mu \mathrm{m}\end{array}$ & $\begin{array}{c}\text { N1 } \\
50 \mu \mathrm{m}\end{array}$ \\
\hline C & 16.0 & 52.1 & 79.7 & 10.0 & 46.3 & 42.7 & 16.0 & 32.0 \\
\hline 0 & 25.5 & 27.0 & 12.9 & 13.0 & 32.6 & 30.7 & 19.0 & 22.0 \\
\hline $\mathrm{Al}$ & 7.5 & 1.6 & 0.9 & 50.0 & 5.8 & 6.0 & 22.0 & 17.0 \\
\hline $\mathrm{Si}$ & 11.7 & 19.2 & 0.9 & 20.0 & 6.2 & 14.2 & 28.0 & 23.0 \\
\hline $\mathrm{Fe}$ & 2.7 & 10.1 & ND & 2.0 & 6.6 & 1.4 & 1.0 & 3.0 \\
\hline $\mathrm{Mn}$ & 0.0 & ND & ND & ND & ND & ND & 1.0 & 1.0 \\
\hline $\mathrm{Mg}$ & 0.7 & ND & ND & ND & ND & ND & 3.0 & ND \\
\hline K & ND & ND & ND & ND & 0.4 & 1.1 & ND & ND \\
\hline $\mathrm{Ca}$ & ND & ND & ND & ND & ND & ND & 8.0 & ND \\
\hline Sc & ND & ND & ND & ND & ND & 0.2 & ND & ND \\
\hline Y & ND & ND & ND & 1.0 & ND & ND & 1.0 & 1.0 \\
\hline $\mathrm{Ce}$ & 0.7 & ND & ND & ND & ND & ND & 1.0 & 1.0 \\
\hline $\mathrm{Nd}$ & ND & ND & ND & ND & ND & 0.5 & ND & ND \\
\hline Dy & 0.2 & ND & ND & 1.0 & ND & ND & ND & ND \\
\hline
\end{tabular}

The SEM micrograph of the feed material (Figure 65) confirms that the size distribution is relatively narrow, with most particles being of similar size and shape. The surfaces of the feed samples on the $10 \mu \mathrm{m}$ image (Figure 66- top row) were very rough and covered by fine complex structures, which were determined to be metal oxide compounds.

The EDX was performed to evaluate other interesting structures on the 40-week aerated and non-aerated samples. For the A1 aerated samples, the structure A was highlighted out due to its high carbon content which was very sensitive to the high electronic beam in the SEM. Its EDX result also verified this result. The structure $B$ on the $A 1$ aerated sample had more Fe content within a smaller complex. The complex structure on the 40-week non-aerated sample surface was composed of significant amount of $\mathrm{Sc}$ and $\mathrm{Nd}$ except the major $\mathrm{C}, \mathrm{O}$ and $\mathrm{Si}$. The standalone particles on the 40-week $\mathrm{AH}$ aerated cell sample surface were observed with $\mathrm{C}, \mathrm{O}, \mathrm{Si}$ and Fe as the main components. From the observations above, the REEs tended to attach to the finer complexes on the sample surfaces. Moreover, the larger particles were primarily composed of $\mathrm{C}$ and $\mathrm{SiO}_{2}$.

At 40 weeks, the aerated sample surface was smoother than the feed sample's with less fine complexes. It also was observed during testing that the weekly flush became less turbid as the test progressed. This result is likely because the sulfate acid that generated in the cells further dissolved the oxide compounds on the sample surfaces. Then more metal elements were dissolved by the sulfate acid into the moisture that were flushed and collected very week. Meanwhile, the colloidal particles were dissolved and removed as well. 
The SEM micrograph of the 40 weeks $\mathrm{H}_{2} \mathrm{O}_{2}$ cell samples showed that the surface was smoother than the feed and aerated samples with less fine complex structures. It also was observed that the weekly flush was less turbid than the regular aerated cells. Both of these results can be explained by the rapid acid generation produced with this test condition.

The 40 weeks non-aerated cell N1 SEM shows a smoother surface than the feed samples but a rougher surface than the aerated samples. Unlike the traditional humidity cell tests, the samples in the non-aerated cells sit still in a sealed environment with limited oxygen and moisture. This modification caused less acid generated compared with the same week aerated cells. Therefore, the reactions in the non-aerated cells were relatively slow. The larger amount of fine complex structures remaining on the surfaces verified the results. The EDX results also showed more $O$ content (22\%) than the aerated cells (13\% and $19 \%)$ due to the slower leaching process. As will be discussed below, this result was also verified by the $\mathrm{pH}$ profiles over time.

\subsection{2 pH Profiles}

Throughout the full duration of the HCT, 15,432 data points were obtained over the 84-week experiments. The weekly dataset included $\mathrm{pH}$, Eh, conductivity, sulfate concentration, rare earth elements concentration and major metal concentration of the flush leachate. The analysis of all the data provides a comprehensive understanding of how rare earth elements released from coal refuse into acid mine drainage.

Figure 67 shows the $\mathrm{pH}$ over time throughout the test. As is well known, the generation of acid mine drainage is a time dependent process where the oxidation of the sulfate minerals caused the sulfate release and the acidity generation. The generation of sulfuric acid is the main factor that dominates the humidity cell leaching tests. However, the weathering of carbonate and calcium compounds in the samples can produce sufficient alkalinity to neutralize the $\mathrm{pH}$. Meanwhile the reaction between sulfate oxidation products and alkaline products would further buffer the $\mathrm{pH}$. This description explains why the $\mathrm{pH}$ was much higher starting at $\mathrm{pH} 8$ at the beginning of the tests. Therefore, the amount of time for the acidic condition to develop, i.e. the lag time, is also important to understand the mechanism of the REE release. For this experiment, the lag time was defined at the point in time where the $\mathrm{pH}$ dropped below $\mathrm{pH} 5$ This $\mathrm{pH}$ point was chosen to ensure that the acidic conditions were due to sulfuric acid generated in the humidity cells, rather than the equilibrium with atmospheric carbon dioxide (Sexsmith 2015). For the water-flushed aerated and non-aerated cells, pH 5 was achieved after 62 weeks. For the $\mathrm{H}_{2} \mathrm{O}_{2}$ flushed samples, this acid generation process was significantly accelerated, with only 10 weeks needed to achieve $\mathrm{pH}<5$. 


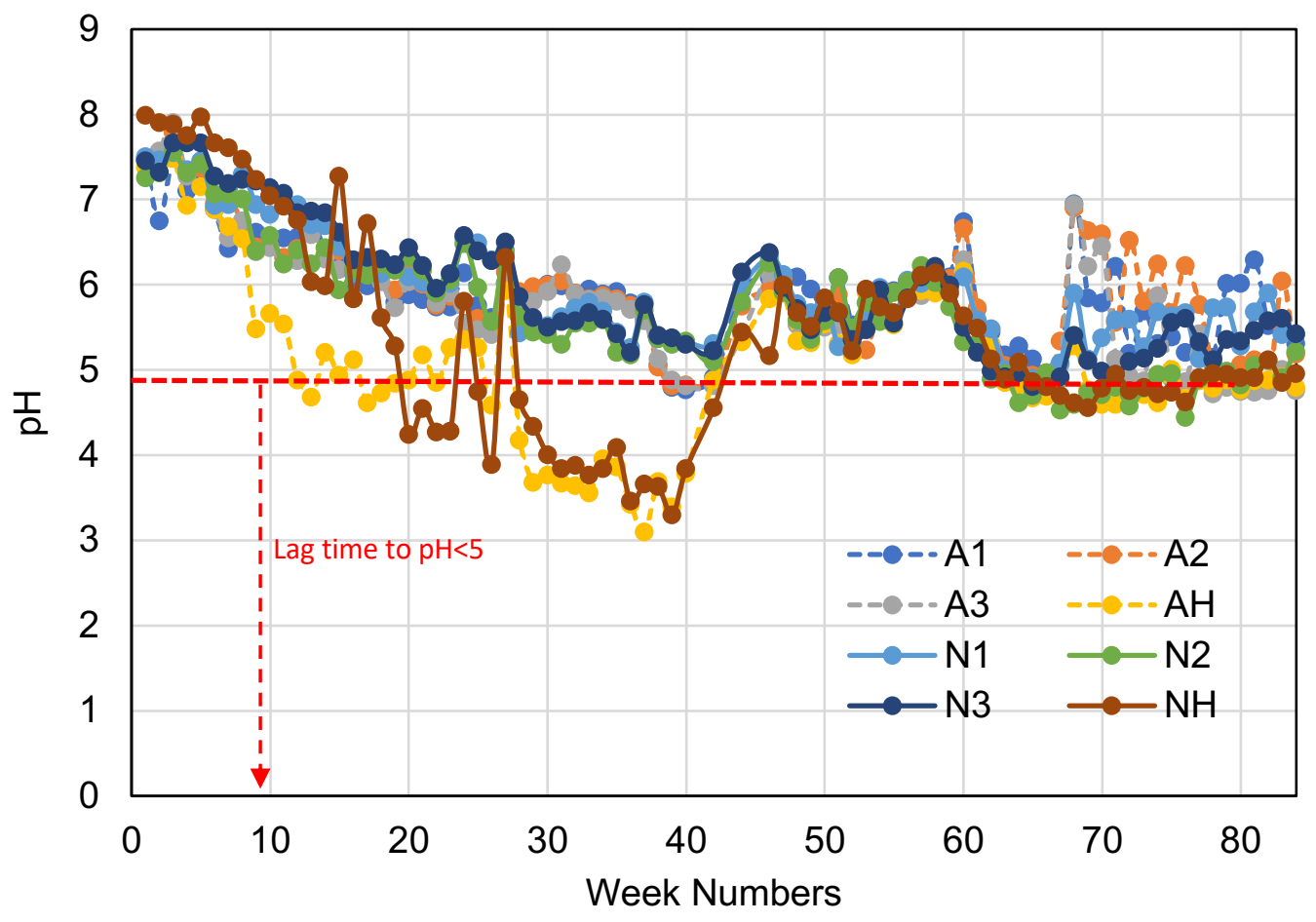

Figure 67. $\mathrm{pH}$ of HCT flush liquid as a function of week number.

The $\mathrm{pH}$ profiles from the eight cells showed a similar range of patterns as they all fluctuated in the a similar manner. In All cases, the $\mathrm{pH}$ started from 7 to 8 at week 0 , then gradually dropped over the time. These alkaline conditions at earlier weeks were due to the dissolve of calcium oxides into the moisture around the sample particles. The release of calcium started as high as $160 \mathrm{mg}$ at week 1 (see Figure 72 below), then rapidly decreased until week 20, after that maintained at a constant level till week 50 and slightly dropped again. That was the reason the lag time for the majority samples around week 62 .

The aerated cells acidic conditions developed sooner than the non-aerated cells due to more moisture was pumped into the aerated cells that caused more sulfuric acid generated at earlier weeks From week 26 to 37, the pH of non-aerated cells dropped below the aerated cells' due to more calcium were dissovled into the flush in the non-aerated cells. From week 37, the pH of the areated cells dropped rapidly below the non-aereted cells' again.

Some significant $\mathrm{pH}$ fluctuation occurred in the aerated cells from week 68 due to the increase of the calcium release in the aerated cell. The increased amount of calcium in the flush neutralized the $\mathrm{pH}$ that caused the $\mathrm{pH}$ in the aerated cells went up.

The $\mathrm{pH}$ of $\mathrm{NH}$ and $\mathrm{AH}$ samples dropped rapidly from the beginning due to the $\mathrm{H}_{2} \mathrm{O}_{2}$ addition that contributed to the alkane neutralization. However, after week 42, the addition of $\mathrm{H}_{2} \mathrm{O}_{2}$ didn't dominate the $\mathrm{pH}$ profiles that much anymore. That was because the sulfate acid was generated mainly before week 50 and from week 60 maintained at a constant low level. 
In all cases, extremely low $\mathrm{pH}$ values were not observed. Both the $\mathrm{AH}$ and $\mathrm{NH}$ cells shows $\mathrm{pH}$ values below 3.5; however, these conditions were not sustained, as the final equilibrium $\mathrm{pH}$ settled at about 5.0. This result implies that the initial refuse is only slightly acidic or even net alkaline, either due to the natural mineralogy or through an alkaline amendment that was added to the refuse. Site information to this end was not provided. In either case, since low $\mathrm{pH}$ values were not sustained; high values of REE leaching are not anticipated; however, the results can still provide insight on the mobilization of REEs in mildly acidic conditions.

\subsubsection{Total Dissolved Solid (TDS)}

Throughout the test cycles, the conductivity (EC) of the flushed water was measured. The EC can be converted into total dissolved solid (TDS) which refer to any minerals, salts, metals, cations or anions dissolved in water. The conversion can be done by the following equation.

TDS=Factor $x \mathrm{EC}_{25}$

The TDS factor for strong ionic solutions is 0.5 and for weak iconic solutions such as fertilizers it is 0.7. It is important to note that the TDS conversion factors are different for every solid. But in most cases the factor is set to 0.50, which is what was used in this study (Rusydi, 2019).

The principal constituents of TDS are usually calcium, magnesium, sodium, and potassium cations and carbonate, hydrogen carbonate, chloride, sulfate, and nitrate anions. The analysis of TDS in the weekly flushed water gave us a further understanding of the HCTs. As shown Figure 68, the TDS decreased sharply during the first 10 weeks primarily due to the dissolution of calcium. The TDS in $\mathrm{H}_{2} \mathrm{O}_{2}$ cells were higher than the regular cells until week 60 because of the extra $\mathrm{H}^{+}$introduced into the system. After the $60^{\text {th }}$ week, no significant difference of TSD was observed between $\mathrm{H}_{2} \mathrm{O}_{2}$ cells and regular cells due to the exhaustion of sulfate in the cells. 


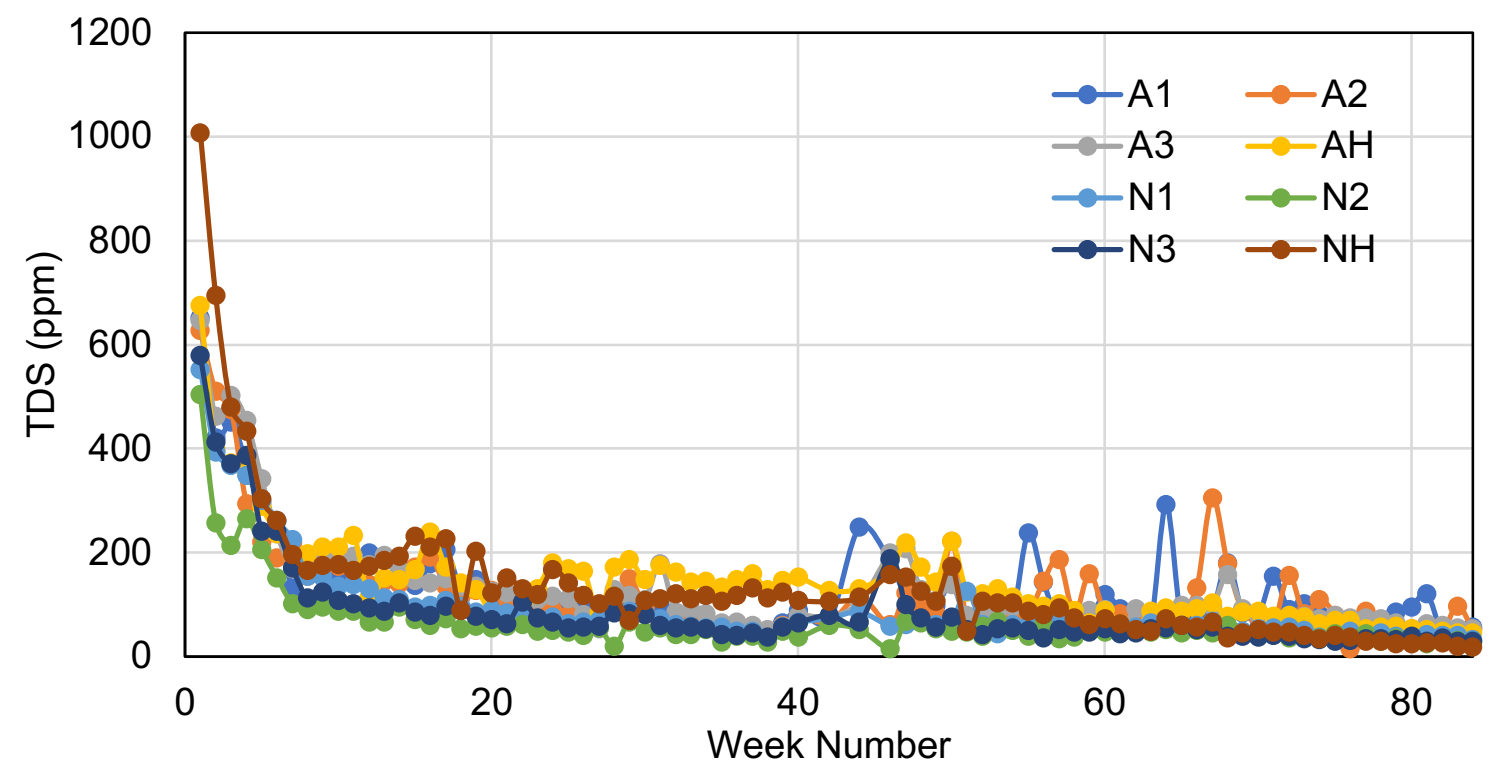

Figure 68. TDS of HCTs flush liquid as a function of week number.

\subsubsection{Sulfate Release over time}

The acidic condition in the humidity cells controlled the leaching process. Therefore, the sulfate release rate was investigated to determine the rare earth elements releasing pattern. Brough's research (2017) also indicated that the sulfate release analysis in humidity cells could be used to help with the termination decision making of humidity cells.

As shown in Figure 69, the amount of sulfate released into the flush started at very high values about $1400 \mathrm{mg}$ in each cell, and then dropped sharply till week 20 . From week 50 , the sulfate release slowed down and maintained at a steady pace. The significant fluctuations of the aerated cells occurred after week 54 due to the humidity changes of the ambient air that pumped into the cells. 


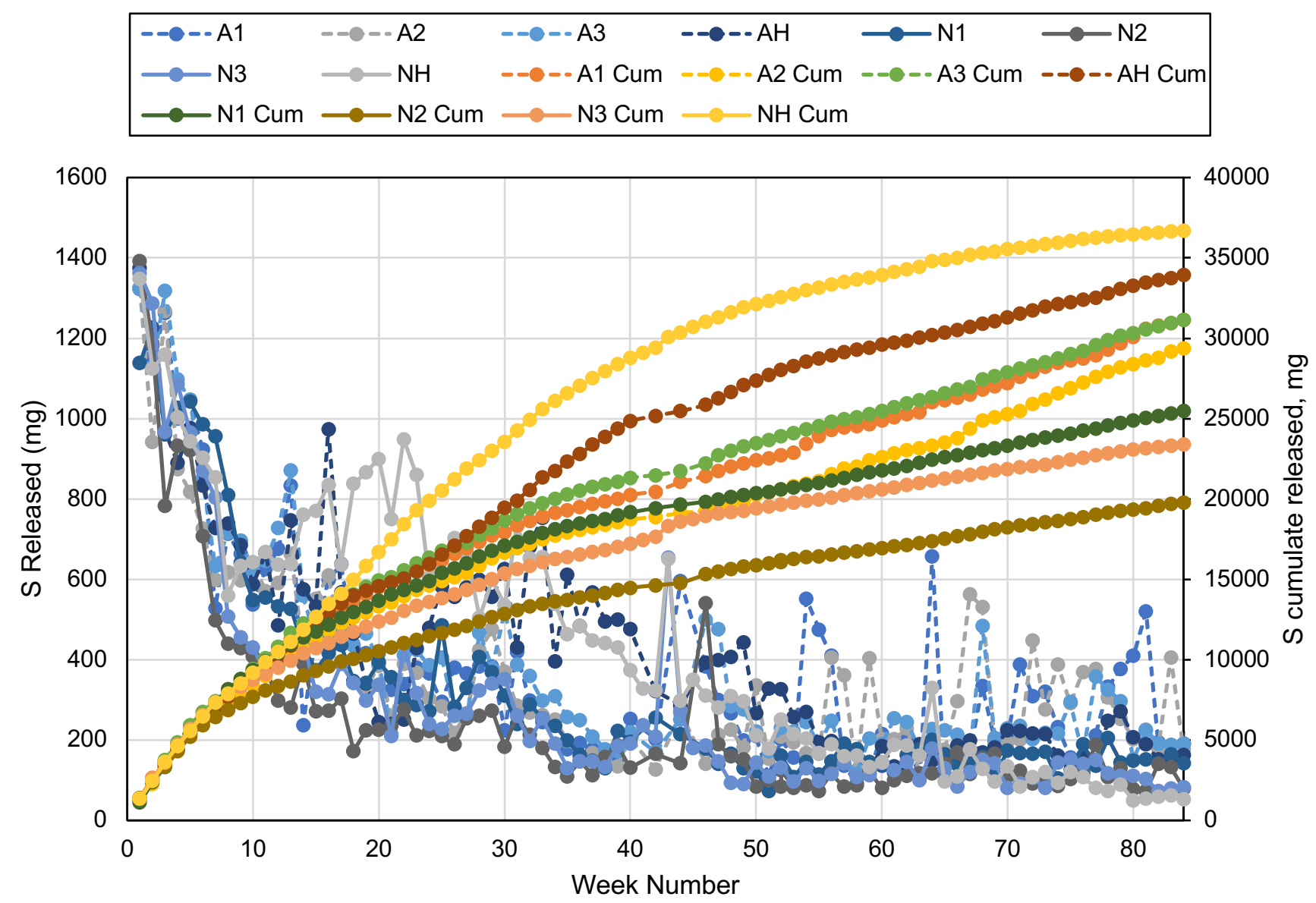

Figure 69. Sulfate release over time.

Generally, the $\mathrm{H}_{2} \mathrm{O}_{2}$ cells released more sulfate each cycle due to the additional oxidant. Overall, the aerated cells produced more sulfate than the non-aerated cells because of the additional oxygen and moisture that pumped into to the cells.

\subsubsection{Rare Earth Elements Release}

The main objective of this humidity cell test was to investigate the rare earth elements release from coal refuse into acid mine drainage. By simulating the natural weathering process in laboratory, a kinetic solution equilibrium was presented. The total rare earth elements that were released into the leachate during the entire tests are shown in Figure 70 (cumulative data) and Figure 71 (individual weeks, water-flushed samples only). 

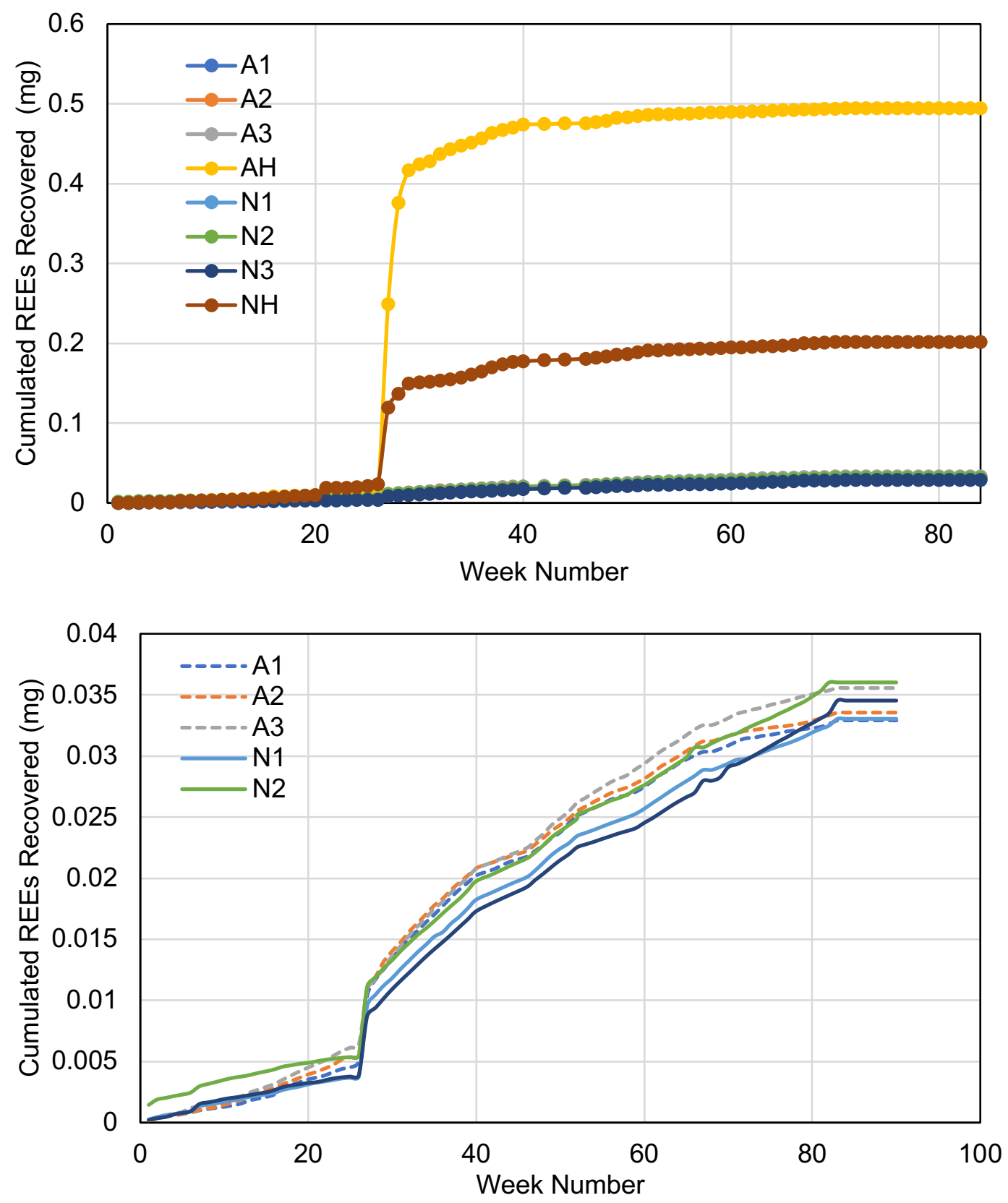

Figure 70. Cumulative release of REE into HCT leach solution over time, top = all data, bottom $=$ waterflushed cells only. 


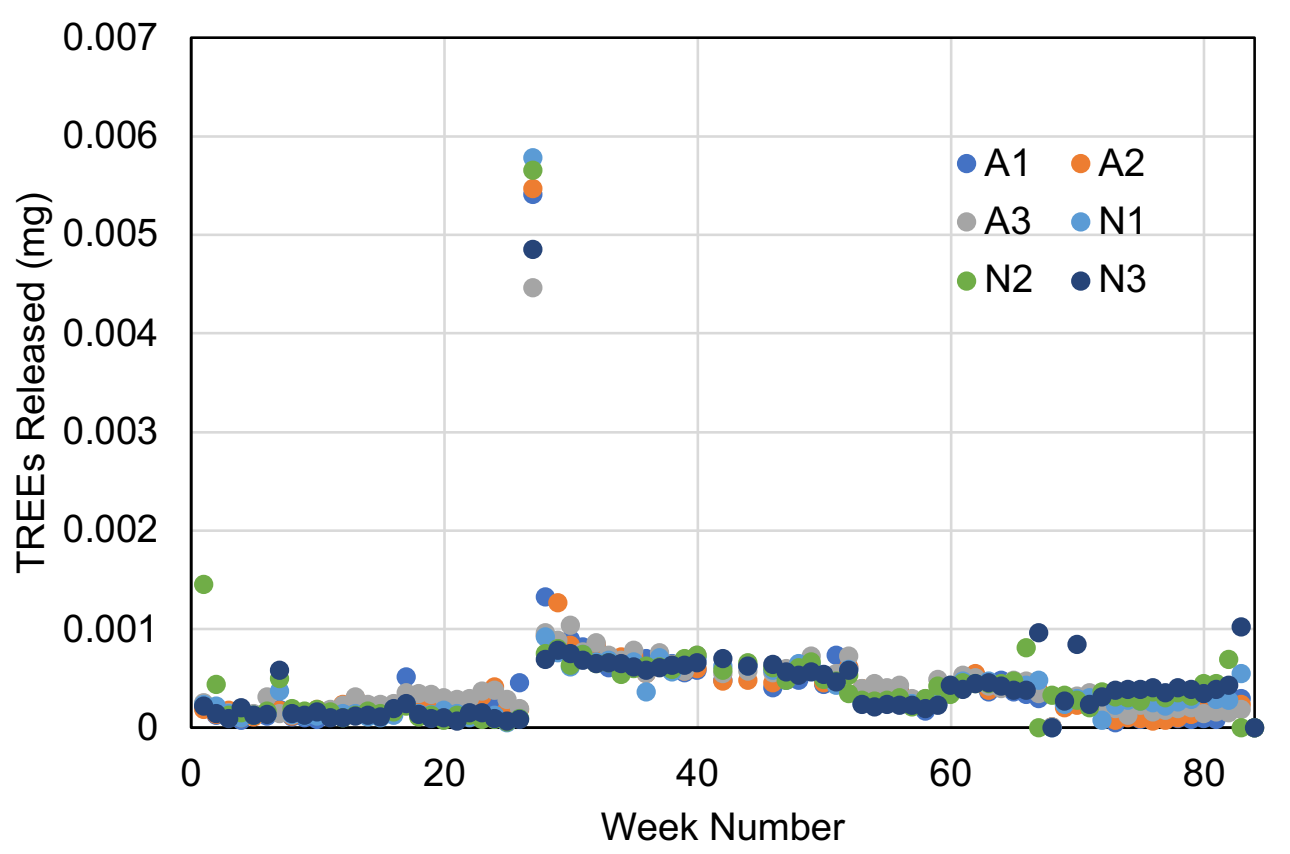

Figure 71. Weekly release of REEs from $\mathrm{No}-\mathrm{H}_{2} \mathrm{O}_{2}$ cells over time.

The cumulated total rare earth elements release increased gradually over the time as shown in Figure 70. The total rare earth elements release started slowly from week 1 but followed a pattern that increased dramatically around every 10 weeks. At week 27, the total rare earth elements release peaked as high as $0.006 \mathrm{mg}$, then dropped to $0.002 \mathrm{mg}$ at week 28 . From week 28 , the amount of rare earth elements released slightly slowed down and maintained at a steady level around $0.001 \mathrm{mg}$ in each cell till the end of 84 weeks. Figure 70 also shows that the aerated cells released more rare earth elements than the non-aerated cells.

One reason for the sharp increase in REE release at week 27 is an association with Fe, which also showed an increased release at that time. As shown in Figure 72 below, the Fe release fluctuated similar as the REEs where the amount released jumped in a cycle and peaked at week 27 as well. The similar every 10 to 20 weeks fluctuation release behaviors were also observed in $\mathrm{pH}, \mathrm{S}, \mathrm{Mg}$ and $\mathrm{Mn}$ through the entire test period. This migration of elements during chemical weathering of rocks or coal refuse is part of the biogeochemical cycle caused by the rain off and runoff. According to the comprehensive biogeochemical process, the elements naturally fluctuate between different stages. This is also the first time that the element migration fluctuation behavior was observed in laboratory scale humidity cell tests.

\subsubsection{Major Metals Release}

Figure 72 shows the release of major metals as a function of week number, while Figure 73 shows the correlation between REE release and major metal release for all test weeks. As shown, the calcium release started at a higher level around $100 \mathrm{mg}$ from week 0 , then decreased sharply till week 10 to $20 \mathrm{mg}$, and dropped below $5 \mathrm{mg}$ after week 20 . After week 65 , 
the amount of calcium released in the flush dropped below $2 \mathrm{mg}$. The calcium dissolved in the flush water at room temperature due to the higher solubility of its compounds. This is the reason that the flush $\mathrm{pH}$ was higher than 7 at the first 10 weeks. As shown in Figure 72, the aerated cells released calcium faster than the non-aerated cells because of the presence of carbon dioxide that constantly pumped into the aerated cells. The carbon dioxide reacted with calcium and formed calcium hydrogen carbonate whose solubility is 5 times higher than noncarbon dioxide presence. The $\mathrm{H}_{2} \mathrm{O}_{2}$ cells also released calcium faster than the regular cells until week 60 due to the extra $\mathrm{H}^{+}$added in.

All the cells released magnesium quickly in the first 10 weeks from $2 \mathrm{mg}$ to $0.4 \mathrm{mg}$, after 10 weeks, the magnesium released in the flush water decreased slowly and maintained at the $0.2 \mathrm{mg}$ till 84 weeks. From Figure 72 , aerated cells released magnesium faster than the nonaerated cells due to the extra $\mathrm{O}_{2}$ and $\mathrm{CO}_{2}$ pumped into the system that increased the solubility of magnesium compounds. It was observed that the $A 1$ and $A 2$ cells magnesium increased dramatically from week 56 to 80 up to $2.5 \mathrm{mg}$ due to the sulfate increased (Figure 69) during the same period which improved the magnesium's solubility. The additional oxides from $\mathrm{H}_{2} \mathrm{O}_{2}$ cells also accelerated magnesium release than the regular cells till week 60.

The iron had different release behaviors in HCTs. First, the iron release in all the cells started from very low value almost 0 but fluctuated in a 10-week cycle through entire tests. The iron release is generally low due the neutral $\mathrm{pH}$ to slight acidic $\mathrm{pH}$ in the system during the 84 weeks where the solubility of iron compounds is very low. Secondly, the non-aerated cells released more iron than the aerated cells due to less $\mathrm{CO}_{2}$ that decreases iron compounds solubility. Thirdly, the additional acidity in the $\mathrm{H}_{2} \mathrm{O}_{2}$ cells reduced insoluble $\mathrm{Fe}^{3+}$ compounds to $\mathrm{Fe}^{2+}$ that increased the water solubility. Therefore, more iron was released in the $\mathrm{H}_{2} \mathrm{O}_{2}$ cells than the regular ones. The iron release cycle also matched the REEs' indicating the association between iron and REEs at mineral phase and during dissolution process (see Figure 73).

Manganese compounds are readily soluble and very sensitive to $\mathrm{pH}$, Eh and other existing anions. From Figure 72, manganese was released in water at a very high level about $0.15 \mathrm{mg}$ at week 0 then dropped rapidly during the first 10 weeks due to the high Ca anions concentration in the system. From week 10 the manganese that dissolved in water slowly increased over the time as the $\mathrm{pH}$ decreased in the regular cells. The $\mathrm{H}_{2} \mathrm{O}_{2}$ cells released $\mathrm{Mn}$ faster than the regular ones due to the higher $\mathrm{pH}$, and after week 60 slowed down but still more than the regular cells. More manganese was leached from soils in the aerated cells than the non-aerated cells because of more active anions presented in the aerated cells like $\mathrm{S}$ and $\mathrm{Mg}$.

The most abundant aluminum compounds are aluminum oxide and aluminum hydroxide, and those are water insoluble. However, aluminum oxide may be present in water as $\mathrm{AlO}_{2}^{-}$in acidic environment. That is why more Al was released in the $\mathrm{H}_{2} \mathrm{O}_{2}$ cells particularly from week 20 to 50 as shown in Figure 72. During the same period the REEs release peaked as well indicating their correlation (see Figure 73). But the overall aluminum release in the regular cells was below $0.01 \mathrm{mg}$. No significant differences between aerated and non-aerated cells were observed. 

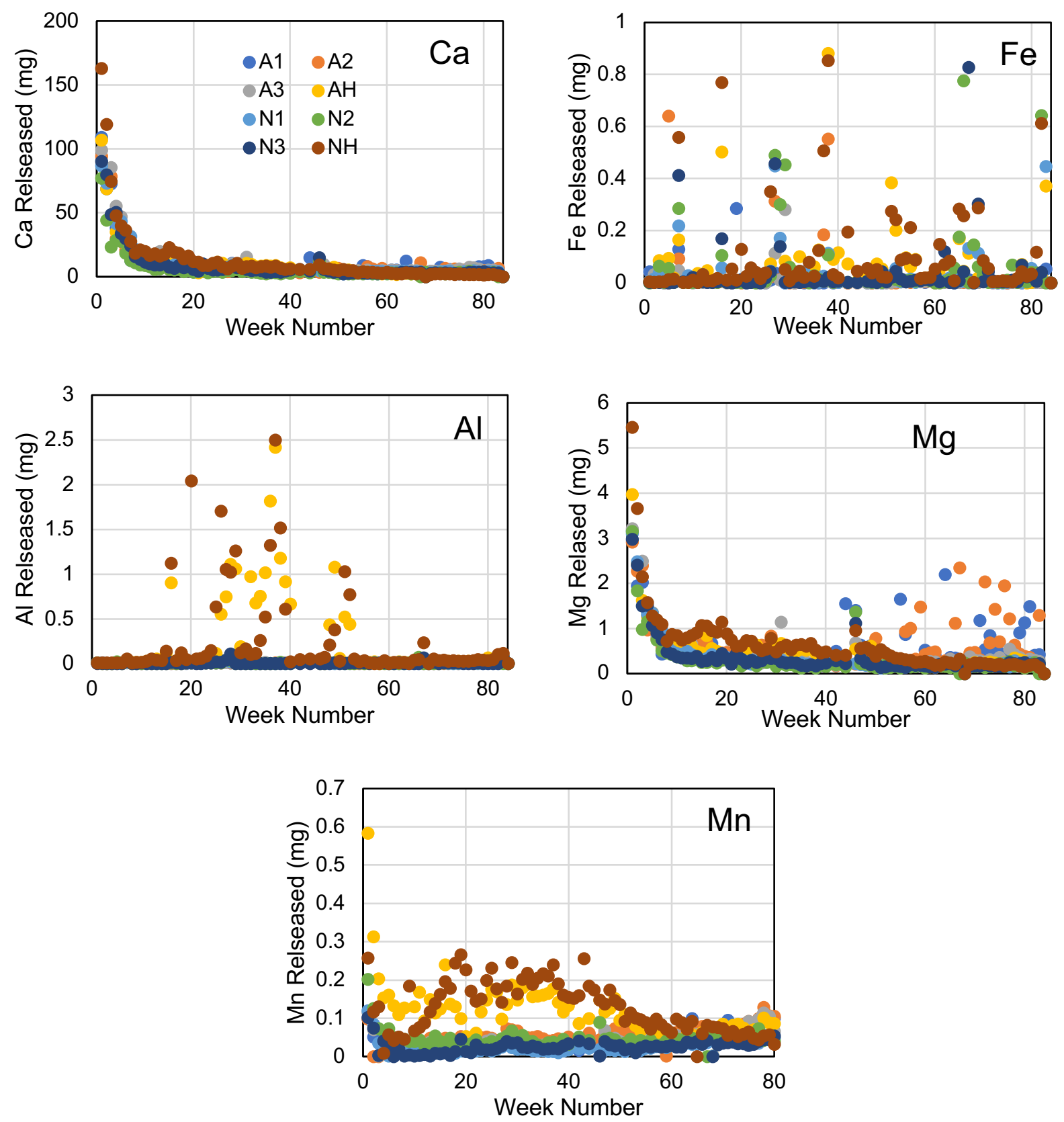

Figure 72. Weekly release of major metals over time. 

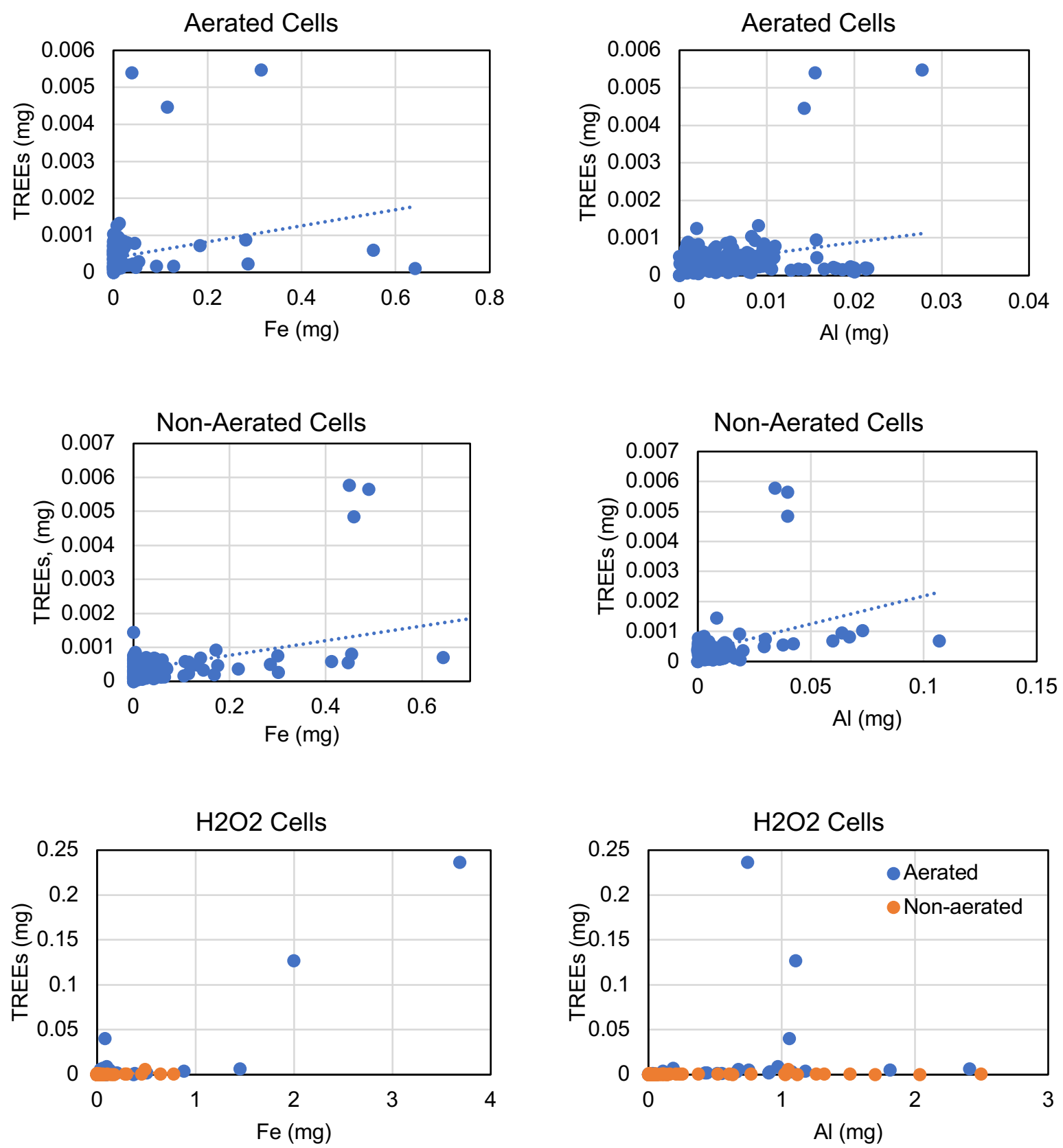

Figure 73. Relationship between REE and major metal release. 


\subsubsection{Influence of $\mathrm{pH}$ on Rare Earth Elements Release}

Figure 74 shows the relationship between REEs released and $\mathrm{pH}$ for all samples included in the test. In this study, the total rare earth elements generally were dissolved in water from $\mathrm{pH} 4.5$ to 7 , more specifically $\mathrm{pH} 4.7$ to 7 in aerated cells, $\mathrm{pH} 4.5$ to 6.5 in non-areared cells and $\mathrm{pH} 3$ to 6 in $\mathrm{H}_{2} \mathrm{O}_{2}$ cells. The additional humidity offered more oxidized environment that shift the REEs solubility to relatively higher $\mathrm{pH}$ than the non-aerated cells. The $\mathrm{H}_{2} \mathrm{O}_{2}$ cells provided extra $\mathrm{H}^{+}$ that decreased the REEs leaching $\mathrm{pH}$ during the tests, also accelerated the leaching process.

\subsubsection{Influence of pH on Major Metal Release}

Likewise, Figure 75 shows the release of major metals as a function of solution $\mathrm{pH}$. In all cases, the water flushed cells released major metals between $\mathrm{pH} 4$ to 8 , while $\mathrm{pH} 3$ to 8 were observed in $\mathrm{H}_{2} \mathrm{O}_{2}$ cells. The magnitude of release from the $\mathrm{H}_{2} \mathrm{O}_{2}$ flushed cells was notably higher.

Because calcium is very water soluble, therefore most of the calcium was released at the very beginning of this work and raised $\mathrm{pH}$ around 7.6. The calcium in the aerated cells was dissolved faster than the non-aerated cells due to more water content in the aerated cells. The small amount of $\mathrm{H}_{2} \mathrm{O}_{2}$ helped dissolve the calcium in water faster than the regular cells. And this caused higher $\mathrm{pH}$ at 8 of the flush water. Also, the additional $\mathrm{H}_{2} \mathrm{O}_{2}$ helped the leaching of calcium at a lower $\mathrm{pH}$ of 2.5 at the end of the tests than the regular cells.

The results showed that the aluminum generally was released between $\mathrm{pH} 4.5$ to 8 in the regular cells with a small amount because aluminum compounds are water insoluble. However, aluminum oxide may be present in water as $\mathrm{AlO}_{2}{ }^{-}$in acidic environment. That is why more $\mathrm{Al}$ was released in the $\mathrm{H}_{2} \mathrm{O}_{2}$ cells particularly from $\mathrm{pH} 2.5$ to 6 .

As shown in Figure 75, the non-aerated cells released more iron than the aerated cells because of less $\mathrm{CO}_{2}$ that decreases iron compounds solubility. The extra acidity in the $\mathrm{H}_{2} \mathrm{O}_{2}$ cells reduced insoluble $\mathrm{Fe}^{3+}$ compounds to $\mathrm{Fe}^{2+}$ that increased the water solubility. Therefore, more iron was released in the $\mathrm{H}_{2} \mathrm{O}_{2}$ cells than the regular ones. The average $\mathrm{pH}$ that the iron was released was between 4.5 to 8 in the regular cells, and 3 to 8 in the $\mathrm{H}_{2} \mathrm{O}_{2}$ cells.

Most of the magnesium was released at the beginning of the tests that caused a higher flush water $\mathrm{pH}$ between 7 and 8 . The aerated cells released magnesium more than the non-aerated cells between 4.5 to 7 due to the additional $\mathrm{O}_{2}$ and $\mathrm{CO}_{2}$ pumped into the system that increased the solubility of magnesium compounds. The extra oxidant and acidity in the $\mathrm{H}_{2} \mathrm{O}_{2}$ cells helped $\mathrm{Mg}$ to be dissolved faster at the beginning and more at the end of the tests.

In all the cells, significant amount of manganese was released between $\mathrm{pH} 7$ to 8 at the beginning of the tests due to $\mathrm{Ca}$ anions existence. But most manganese dissolved in water between $\mathrm{pH} 4.5$ to 6.5 in the regular cells and $\mathrm{pH} 3$ to 6 in the $\mathrm{H}_{2} \mathrm{O}_{2}$ cells. From Figure 75 , more manganese was released in the aerated cells than the non-aerated cells because of the present of active ions like $\mathrm{S}$ and $\mathrm{Mg}$. The additional oxidant and acidity in the $\mathrm{H}_{2} \mathrm{O}_{2}$ cells accelerated the manganese release than the regular cells. 


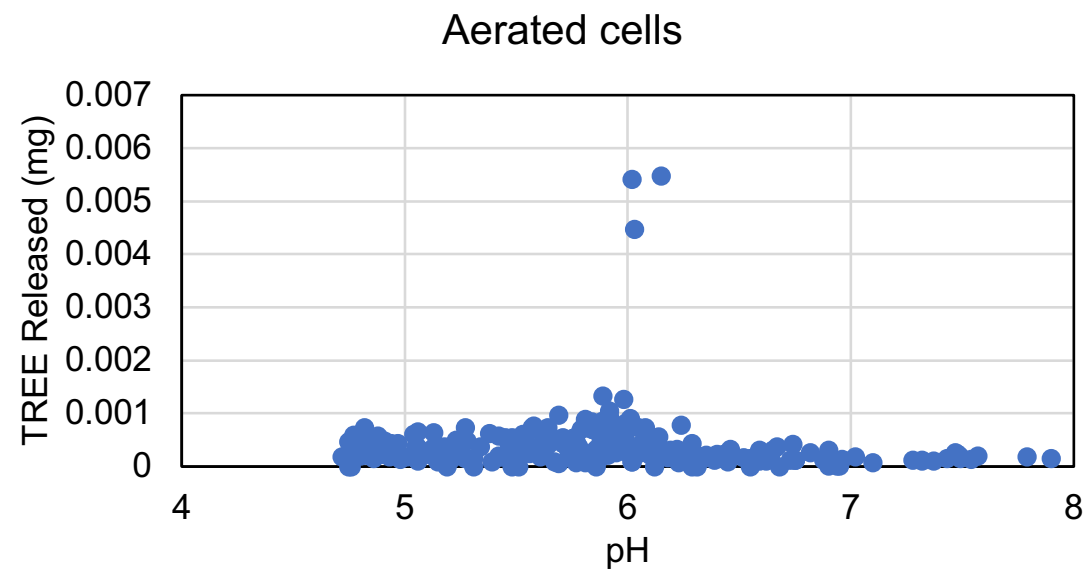

Non-aerated cells

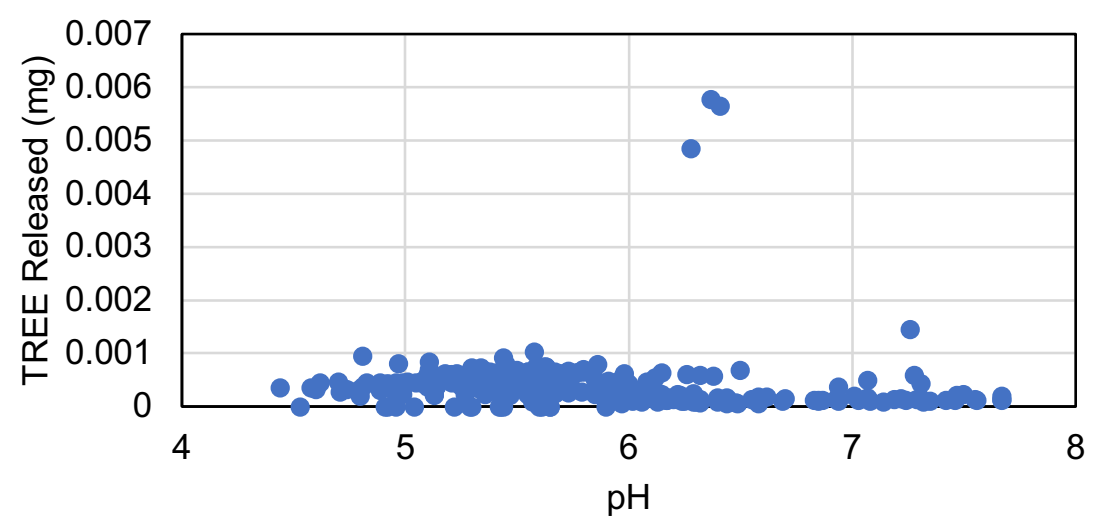

$\mathrm{H} 2 \mathrm{O} 2$ cells

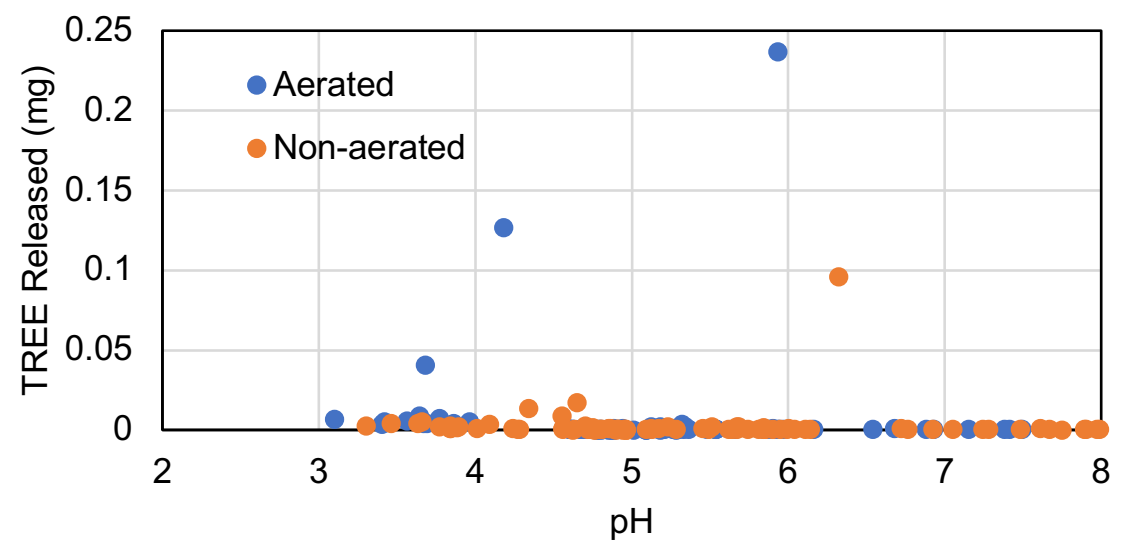

Figure 74. REEs release as a function of $\mathrm{pH}$. 

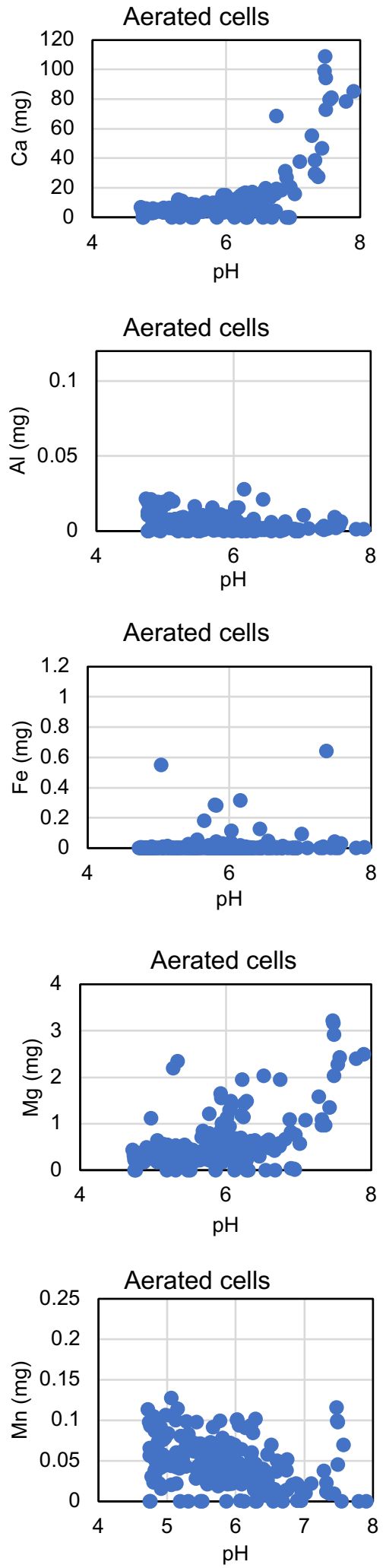
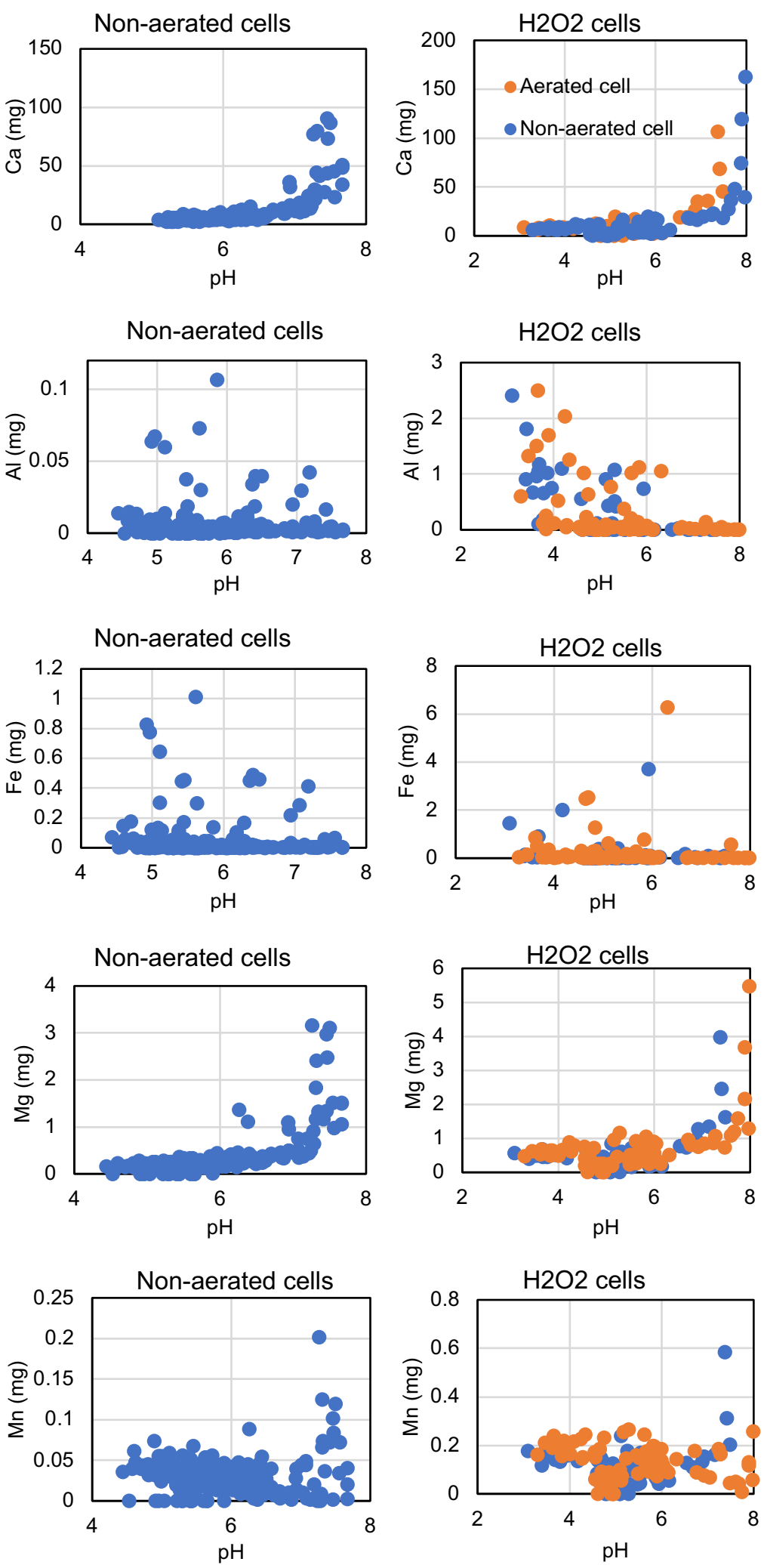

Figure 75. Major metal release as a function of $\mathrm{pH}$. 


\subsubsection{Study Limitations}

Throughout the prolonged humidity cell tests, some limitations were observed. First, during the 84-week experiment period, the acid production was not sufficient to reach the lower values of $\mathrm{pH}$ needed to fully mobilize REEs. For the non- $\mathrm{H}_{2} \mathrm{O}_{2}$ cells, the acid production was quite slow, requiring nearly 52 weeks to reach a $\mathrm{pH}$ value of 5 . After that point, the $\mathrm{pH}$ in several cells actually increased to an equilibrium value of 5 to 6 . The $\mathrm{H}_{2} \mathrm{O}_{2}$ cells did show a faster acid production and lower $\mathrm{pH}$ values; however, these low values were not sustained as the cells ultimately settled at an equilibrium $\mathrm{pH}$ of approximately 5 . This data indicates that the pyrite content and subsequently the acid production capacity were not sufficient to overcome the acid consumers. This result was particularly noteworthy, as the site selected for this study is noted as a high acid producer, with an AMD pH of approximately 3.0. Given prior information on the site, acid-base accounting was not performed prior to the humidity cells tests. Nevertheless, the combination of the prior knowledge and the results of this study likely indicates that either an alkaline amendment was added to the refuse in the location of the sampling or that the sampling was taken from a location with an anomalously low pyrite content. In either case, these implication and interpretation of these results must be limited to cases with moderate $\mathrm{pH}$ AMD.

Since lower $\mathrm{pH}$ values between 2 and 3 often correlate to higher REE loading in raw AMD (Vass et al, 2019b), the moderate $\mathrm{pH}$ values achieved in this test were deemed to be not sufficient to promote a significant amount of REE leaching. Nevertheless, the release data does show some release of REEs, particularly HREEs, indicating that net alkaline drainage does prompt some leaching of REEs. Given the close correlation with iron, this leaching may be dictated by the dissolution of iron oxides or similar mineral species. However, this conclusion is only relevant for net alkaline drainage, as lower $\mathrm{pH}$ values may have prompted different release patterns.

\subsection{Conclusions}

Humidity cells tests were conducted to evaluate the release of REEs into AMD and how that release correlates to that of major metal species. Several key conclusions are derived from this work:

- The SEM-EDX results showed significant morphological differences among the aerated cells, non-aerated cells and $\mathrm{H}_{2} \mathrm{O}_{2}$ cells during the test sequence. The sample surfaces in the aerated cells were smoother than the non-aerated cells after 40-weeks due to the additional acid generated through the humidity cycles. Moreover, the $\mathrm{H}_{2} \mathrm{O}_{2}$ accelerated the oxidization on the sample surfaces that made the surfaces even smoother than the regular cells.

- The $\mathrm{pH}$ of all eight cells decreased gradually over the 84-week tests reaching a minimum of approximately 3.0 to 3.5 for the $\mathrm{H}_{2} \mathrm{O}_{2}$ cells and 4.5 for the remaining cells. In most cases, the $\mathrm{pH}$ actually rose in the latter test cycles reaching an equilibrium value between 5.0 and 6.0 after the 84 week test duration. The addition of $\mathrm{H}_{2} \mathrm{O}_{2}$ accelerated the leaching process, as these cells reached their minimum values much quicker than that of the other cells. 
- Total dissolved solid (TDS) was calculated from the conductivity (EC) to evaluate the overall leaching process happened in the humidity cells. The TDS in all the eight cells decreased over the time because of $\mathrm{Ca}$ and $\mathrm{S}$ dropping off from the HTC system. And this reflected the natural weathering process in a close system and how the leaching process proceeded.

- The sulfate in the HCT affected the $\mathrm{pH}$ and the leaching behaviors of many other metals. Overall sulfate dissolved in the flush water decreased over the time. The sulfate release was also controlled by the humidity in the cells. Generally, the $\mathrm{H}_{2} \mathrm{O}_{2}$ cells released more sulfate each cycle due to the additional oxidant. Overall, the aerated cells produced more sulfate than the non-aerated cells because of the additional oxygen and moisture that pumped into to the cells.

- The cumulated total rare earth elements release increased gradually over the time. And the total rare earth elements release started slowly from week 1 but flowed a pattern that increased dramatically around every 10 weeks. At week 27 , the total rare earth elements release peaked as high as $0.006 \mathrm{mg}$, then dropped to $0.002 \mathrm{mg}$ at week 28 . From week 28, the amount of rare earth elements released slightly slowed down and maintained at a steady level around $0.001 \mathrm{mg}$ in each cell till the end of 84 weeks. It was also observed that the aerated cells released more rare earth elements than the nonaerated cells.

- Rare earth elements solubilities were shown to be sensitive to $\mathrm{pH}$. In the HTCs, the total rare earth elements generally were dissolved in water from $\mathrm{pH} 4.5$ to 7 , more specifically $\mathrm{pH} 4.7$ to 7 in aerated cells, $\mathrm{pH} 4.5$ to 6.5 in non-areared cells and $\mathrm{pH} 3$ to 6 in $\mathrm{H}_{2} \mathrm{O}_{2}$ cells. The additional humidity offered more oxidized environment that shift the REEs solubility to relatively higher $\mathrm{pH}$ than the non-aerated cells. The $\mathrm{H}_{2} \mathrm{O}_{2}$ cells provided extra $\mathrm{H}^{+}$that decreased the REEs leaching $\mathrm{pH}$ during the tests, also accelerated the leaching process. Therefore, the rare earth elements weathering behaviors not only depend on the $\mathrm{pH}$ and humidity, also the other existing ions in the system.

- The Ca, Fe, Al, Mn and Mg leaching behaviors were also invested in this work. Generally, they reacted differently to $\mathrm{pH}$, humidity and additional oxidant. The Ca dropped off the first and the fastest that raised the $\mathrm{pH}$ up to 8. The release of Fe and $\mathrm{Mn}$ fluctuated over the time similarly as the REEs. $\mathrm{Mn}$ and $\mathrm{Mg}$ were also sensitive to the $\mathrm{S}$ in the HCTs.

Except Fe release more in the non-aerated cells, all other metals released more in the aerated cells. The $\mathrm{H}_{2} \mathrm{O}_{2}$ accelerated the weathering processes of all the five metals. Also, Fe and Al had positive correlation with REEs release. 


\section{Summary, Conclusions, and Recommendations}

\subsection{Summary}

Rare earth elements are critical materials essential for modern society. Given the numerous challenges and deficiencies in the current supply chain, several private and public entities have sought to develop alternative resources from unique and non-conventional sources. Recent studies have shown that acid mine drainage may be a viable source to augment domestic US demand.

To investigate the potential of recovering REEs from AMD, this research included a number of fundamental and empirical studies to better understand the implication of REE solubility on process design and analysis. Initially, a thermodynamic study was conducted to investigate the sensitivity of REEs and major metal ions to changes in $\mathrm{pH}$ and oxidation-reduction potential. In this phase of the study, Eh-pH diagrams of REEs and major ions were generated using HSC9.0 and analyzed to identify regions where selective precipitation may be feasible. Next, to investigate the solubility of REEs in AMDp, a parametric laboratory leaching study was conducted. Experiments in this phase of the research evaluated the influence of acid type, sample type, leaching time, and leaching circuit configuration on the leaching of REEs and major metals from AMDp. After developing a suitable leaching process, the selective separation of REEs from contaminant metals in leachate solutions was assessed using selective precipitation. Precipitation experiments explored the influence of sample type, acid type, base type, and oxidation reduction potential on the selective recovery of REEs and various major metals. Lastly, humidity cells tests were conducted to evaluate the release of REEs into AMD and how that release correlates to that of major metal species over 86 weeks.

Ultimately, this work has contributed to the development of an integrated process to recover REEs from AMDp. This process is shown as a block flow diagram in Figure 76. Blocks highlighted in yellow have been investigated in this study.

\subsection{Conclusions}

From the fundamental and empirical studies included in this dissertation, several conclusions are derived:

\section{Aqueous stability modeling}

- The Eh-pH diagrams show that the precipitation of REEs to their hydroxides is anticipated to occur between $\mathrm{pH} 4.2$ (for $\mathrm{Y}$ ) to 8.75 (for $\mathrm{Lu}$ ) following the order of: $\mathrm{Y}<\mathrm{Sc}<\mathrm{Dy}<\mathrm{Er}<\mathrm{Nd}<\mathrm{Pr}<\mathrm{Ho}<\mathrm{Ce}<\mathrm{Yb}<\mathrm{Sm}<\mathrm{Tm}<\mathrm{Eu}<\mathrm{Gd}<\mathrm{La}<\mathrm{Lu}$. While there is some disparity between the $\mathrm{pH}$ point of neighboring REEs, selective precipitation of individual REEs from each other may be challenging due to the tight $\mathrm{pH}$ control and overlapping solubility curves

- Conversely, major contaminants, such as $\mathrm{Al}, \mathrm{Fe}$, and $\mathrm{Ca}$ showed precipitation points well outside this range suggesting that selective precipitation of REEs from major metals may be feasible. For the conditions evaluated in the study, Al and Fe ions in AMDp could be simply removed by $\mathrm{pH}$ adjustment at $\mathrm{pH} 3$ to 4 while leaving all REEs and other soluble 
species in solution. More soluble elements like $\mathrm{Ca}$ are expected to remain in solution as the REEs are precipitated between $\mathrm{pH} 4$ and 8.

\section{REE Leaching from AMDp}

- Leaching kinetics tests with $3 \mathrm{M}$ nitric acid showed extremely rapid kinetics, with equilibrium conditions often achieved at the first-time increment (3.75 min). This effect was particularly noted at the low pH points below 1.5 .

- The leaching recovery vs. $\mathrm{pH}$ data show that the REEs begin dissolving around $\mathrm{pH} 3.0$ and reach full dissolution at $\mathrm{pH}$ 2.0. These values are lower than those predicted by the Eh-pH diagrams and suggest that the speciation of REEs in AMDp may not be simple hydroxides but possibly chelated or adsorbed to other species.

- The dissolution curves for REEs fall between that of Fe (which occurs at a lower pH) and $\mathrm{Al}$ (higher $\mathrm{pH}$ ). With respect to the other contaminant metals, $\mathrm{Ca}$ and $\mathrm{Mn}$ did not show distinguishable solubility patterns (possibly due to ionic strength limits), and $\mathrm{Mg}$ was fully dissolved at all $\mathrm{pH}$ points. When compared to the actinides, the acid solubility of REEs closely matches that of the $U$ and is slightly higher than that of Th.

\section{$\underline{\text { REE Precipitation from Acidic Solutions }}$}

- Across a broad range of test conditions, REEs typically precipitated between $\mathrm{pH} 4$ and 6 with nearly complete removal of REEs occurring at $\mathrm{pH} 6$.

- Among the various contaminant metals i.e. (Fe, $\mathrm{Al}, \mathrm{Ca}, \mathrm{Mg}$, and $\mathrm{Mn}$ ), Fe showed the highest sensitivity to acid type, with $\mathrm{HNO}_{3}$ prompting lower precipitation $\mathrm{pH}$ points as compared to $\mathrm{H}_{2} \mathrm{SO}_{4}$. In both cases, however, the $\mathrm{pH}$ of Fe occurred at a significantly lower $\mathrm{pH}$ than that of the REEs suggesting selective separation is possible

- Alternatively, the precipitation behavior of the REEs usually closely matched that of Al, with the REE precipitation occurring at a slightly higher $\mathrm{pH}$. Nevertheless, selective separation of the REEs from Al may be difficult with precipitation alone.

- While $\mathrm{MgO}$ showed better technical performance, $\mathrm{NaOH}$ was selected to be the best base overall candidate given its relatively low cost as well as issues with $\mathrm{Mg}$ contamination. The addition of $\mathrm{H}_{2} \mathrm{O}_{2}$ did not significantly impact the precipitation of $\mathrm{REEs}, \mathrm{Al}$, or $\mathrm{Fe}$; however, higher doses of $\mathrm{H}_{2} \mathrm{O}_{2}$ did lead to increased solubility of $\mathrm{Mn}$. This result in turn led to lower levels of $\mathrm{Mn}$ contamination on the final precipitate.

- Comparison of the leaching data with the precipitation data clearly shows hysteresis, indicating that the solubility reactions are non-reversible. Comparisons with thermodynamic predictions suggest that the REEs are precipitating as simple hydroxides; however, the form in the initial AMDp may include some fraction that is bound with other matrix elements.

- Selective precipitation of high grade REE materials is feasible if sequential precipitation is done between $\mathrm{pH} 4$ and 6 . Given the numerous test conditions that support this conclusion, the data show that this selective precipitation process may have relevancy both for AMDp leachate as well as raw AMD. 


\section{Humidity Cell Tests}

- Rare earth elements were generally dissolved from the coarse refuse samples from $\mathrm{pH}$ 4.5 to 7 , more specifically pH 4.7 to 7 in aerated cells, pH 4.5 to 6.5 in non-areared cells and $\mathrm{pH} 3$ to 6 in $\mathrm{H}_{2} \mathrm{O}_{2}$ cells.

- The additional humidity in the aerated cells offered a stronger oxidizing environment that shifted the REE solubility to relatively higher $\mathrm{pH}$ than the non-aerated cells.

- The $\mathrm{H}_{2} \mathrm{O}_{2}$ cells provided an accelerated production of acid and improved the overall leaching process for all REEs and major metals. The content of REEs leached in these cells was more than an order of magnitude greater than that of the simple waterflushed cells.

- The leaching of major metals varied with respect to leachate $\mathrm{pH}$, humidity and additional oxidant. The $\mathrm{Ca}$ content in the leachate was initially high, but dropped off significantly week to week, following a clear decay trend and eventually reaching a minimum around 20 weeks.

- The release of $\mathrm{Fe}$ and $\mathrm{Mn}$ fluctuated over the time in a manner similarly to that of the REEs. $\mathrm{Mn}$ and $\mathrm{Mg}$ were also sensitive to the $\mathrm{S}$ in the leachate. Other than $\mathrm{Fe}$ and $\mathrm{Al}$, all other metals released more in the aerated cells. The $\mathrm{H}_{2} \mathrm{O}_{2}$ accelerated the weathering processes of all the five metals.

- The content of REEs in the leach solution showed a strong positive relationship with that of Fe and particularly Al. This finding suggests that the REEs in coarse refuse may be bound or otherwise associated with Al-containing strata, such as clays and shales.

\subsection{Recommendations}

Given the limitations of this study as well as the knowledge gaps discovered through this work, the author recommends the following items for continued research:

- To reduce the impurities of leachate from the leaching/precipitation stages before the downstream solvent extraction, a further selective process is recommended for the future work. For example, ion exchange resin may be applied on the acid leachate to absorb $\mathrm{Fe}, \mathrm{Mg}$ and other major metal ions.

- Rare earth elements may be separated through one simple step prior to solvent extraction such as mesoporous materials. For example, molecular sieve can be used after acid leaching or precipitation on the leachate. Different molecular sieves target on different ions that achieve the separation of individual REEs.

- Longer humidity test duration up to 520 weeks (Sexsmith, 2015) is recommended to obtain parameters such as total inorganic carbons and neutralization potential for developing a simulated lag time module and rate of acidification. The longer cell tests may be more appropriate for hard rock mine drainage as opposed to coal mine drainage given the differences in particle structure in the pyrite minerals (i.e. standard vs. framboidal crystaline structure. 
- The use of other leaching accelerants or other doses of hydrogen peroxide should be explored to optimize the production of REEs from coarse refuse material. This work may support the development of engineered heap leach pads designed to emulate and optimize the natural processes occurring in AMD.

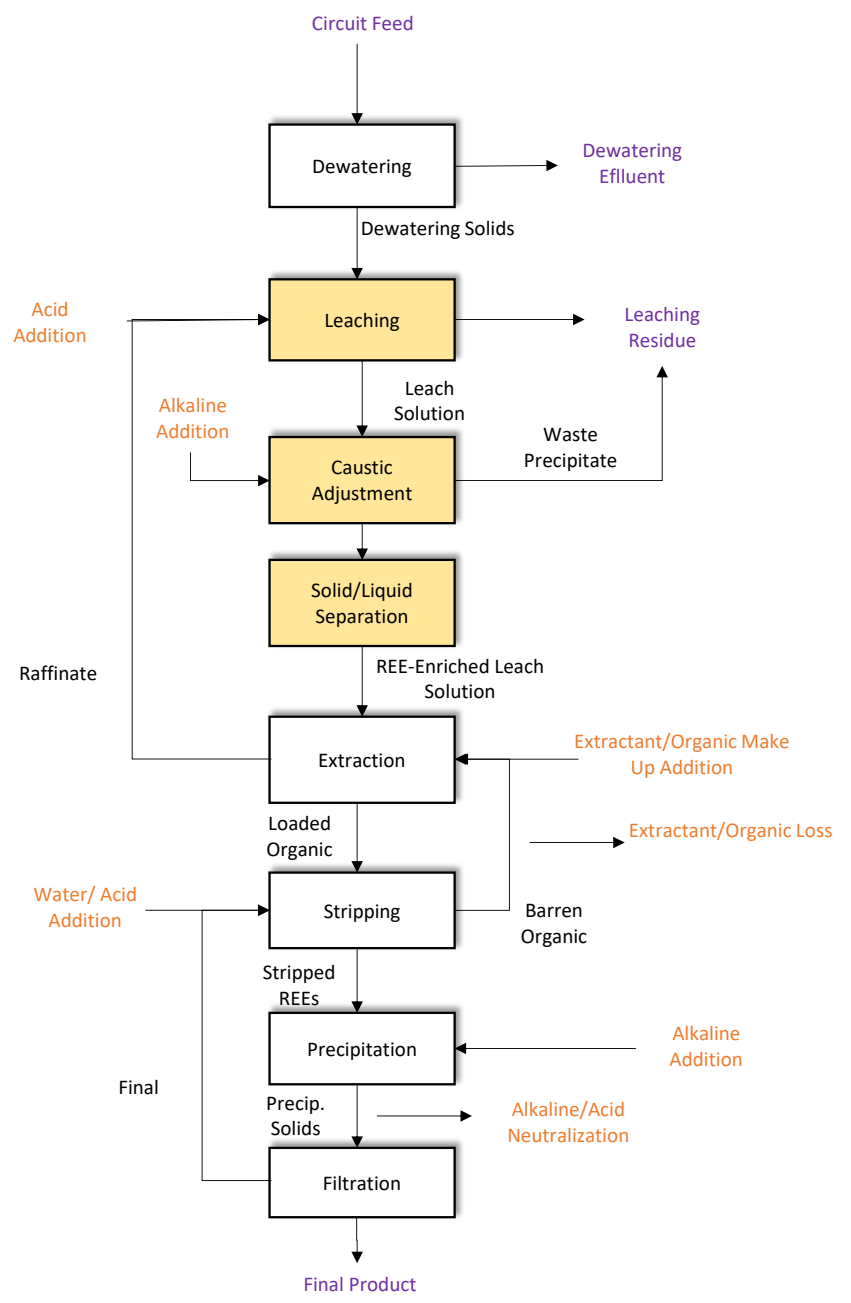

Figure 76. Block flow diagram showing a process to recover REEs from AMDp. Blocks highlighted in yellow were the focus of this study. 


\section{References}

Abreu, R. D. (2014). Study on separation of heavy rare earth elements by solvent extraction with organophosphorus acids and amine reagents. Minerals Engineering, 82-87.

Akcil, A. (2006). Acid Mine Drainage (AMD): causes, treatment and case studies. Journal of Cleaner Production, 1139-1145.

Akcil, A. (2017). Overview On Extraction and Separation of Rare Earth Elements from Red Mud: Focus on Scandium. Mineral Processing and Extractive Metallurgy Review , 145151.

Ayora, C. (2016). Recovery of Rare Earth Elements and Yttrium from Passive-Remediation Systems of Acid Mine Drainage. Environmental Science \& Technology, 8255-8262.

Baker, B. J. (2003). Microbial communities in acid mine drainage. Microbiology Ecology, 139152.

Banerjee, D. (2014). Acid drainage potential from coal mine wastes: environmental assessment through static and kinetic tests. Int. J. Environ. Sci. Technol, 1365-1378.

Battsengel, A. (2018). Recovery of light and heavy rare earth elements from apatite ore using sulphuric acid leaching, solvent extraction and precipitation. 179.

Bau, M. (1999). Scavenging of dissolved yttrium and rare earths by precipitating iron oxyhydroxide: experimental evidence for Ce oxidation, Y-Ho fractionation, and lanthanide tetrad effec. Geochimica et Cosmochimica Acta, 67-77.

Beltrami, D. (2015). Recovery of yttrium and lanthanides from sulfate solutions with high concentration of iron and low rare earth content. Hydrometallurgy, 356-362.

Bian, Y. (2015). Extraction of Rare Earth Elements from Permanent Magnet Scraps by FeOB2O3 Flux Treatment. Journal of Sustainable Metallurgy, 151-160.

Binnemans, K. (2013). Recovery of rare earths from industrial waste residues: a concise review. Slag Valorisation Symposium.

Binnemans, K. (2015). Towards zero-waste valorisation of rare-earth-containing industrial process residues: a critical review. 99.

Bradbury, M. (2002). Sorption of Eu on Na- and Ca-Montmorillonites: Experimental Investigations and Modelling with Cation Exchange and Surface Complexation. Geochimica et Cosmochimica Acta, 2325-2334.

Brewer, A. (2019). Microbe Encapsulation for Selective Rare-Earth Recovery from Electronic Waste Leachates. Environmental Science \& Technology, 13888-13897.

Brookins, D. (1978). Eh-pH diagrams for elements from $\mathrm{Z}=40$ to $\mathrm{Z}=52$ : Application to the Oklo natural reactor, Gabon. 23(1-4).

Brookins, D. G. (1988). Eh-pH Diagrams for Geochemistry. Springer.

Cánovas, C. R. (2018). Mobility of rare earth elements, yttrium and scandium from a phosphogypsum stack: Environmental and economic implications Author links open overlay panel. Science of The Total Environment, 847-857. 
Cao, X. (2001). Effects of redox potential and $\mathrm{pH}$ value on the release of rare earth elements from soil. Chemosphere, 655-661.

Cetiner, Z. S. (2005). The aqueous geochemistry of the rare earth elements. Part XIV. The solubility of rare earth element phosphates from 23 to $150^{\circ} \mathrm{C}$. Chemical Geology, 147169.

Chakhmouradian, A. R. (2012). Rare Earth Elements: Minerals, Mines, Magnets (and More). Elements, 333-340.

Chen, Z. (2011). Global rare earth resources and scenarios of future rare earth industry. Journal of Rare Earths, 1-6.

Cheng, X. (2003). Effect of rare earth elements on the erosion resistance of nitrided 40Cr steel. $254(5)$.

Chesworth, W. (2006). geochemistry of the Earth's land surface, with application to peatlands. 9.

Condie, K. C. (1991). Another look at rare earth elements in shales. Geochimica et Cosmochimica Acta, 2527-2531.

Cordier, D. (2013, may 12). Retrieved from https://USGS.OVG

COTF. (2004). Retrieved from http://www.cotf.edu/ete/modules/waterq/wqchemistry.html

Creelman, R. A. (1996). A scanning electron microscope method for automated, quantitative analysis of mineral matter in coal. 30(3).

DanutaSmolka-Danielowska. (2010). Rare earth elements in fly ashes created during the coal burning process in certain coal-fired power plants operating in Poland - Upper Silesian Industrial Region. Journal of Environmental Radioactivity, 965-968.

Davri, P. (2016). Selective leaching of rare earth elements from bauxite residue (red mud), using a functionalized hydrophobic ionic liquid. Hydrometallurgy, 125-135.

Dent, P. C. (2012). Rare earth elements and permanent magnets (invited). Journal of Applied Physics.

Diagboya, P. N. (2018). Silica-based mesoporous materials; emerging designer adsorbents for aqueous pollutants removal and water treatment. Microporous and Mesoporous Materials, 252-267.

DOE. (2017). Report on Rare Earth Elements from Coal and Coal Byproducts. DOE.

Donskoi, E. (2013). Comparative study of iron ore characterisation using a scanning electron microscope and optical image analysis. 122(4).

Dunn, T. L. (2009). Analysis of ordinary chondrites using powder X-ray diffraction: 1. Modal mineral abundances.

Dyer, J. A. (2006). A practical guide for determining the solubility of metal hydroxides and oxides in water. Environmental Progress.

Fernandez, V. (2017). Rare-earth elements market: A historical and financial perspective. Resources Policy, 26-45. 
Florek, J. (2016). Functionalization of mesoporous materials for lanthanide and actinide extraction. Dalton Transactions.

Fourie, M. (2018). Retrieved from Environment: https://www.environment.co.za/acid-minedrainage-amd/a-rising-acid-tide-on-the-witwatersrand.html

Franus, W. (2015). Coal fly ash as a resource for rare earth elements. Environmental Science and Pollution Research, 9464-9474.

Fray, D. J. (2000). Separating Rare Earth Elements. CHEMICAL ENGINEERING, 2295-2296.

Gammonsa, h. H. (2005). Hydrogeochemistry and rare earth element behavior in a volcanically acidified watershed in Patagonia, Argentina. Chemical Geology, 249-267.

Gazea, B. (1996). A review of passive systems for the treatment of acid mine drainage. Minerals Engineering, 23-42.

Gergoric, M. (2018). Leaching and Recovery of Rare-Earth Elements from Neodymium Magnet Waste Using Organic Acids. Metals, 721.

Gibert, O. (2004). Chemical characterisation of natural organic substrates for biological mitigation of acid mine drainage. Water Research, 4186-4196.

Guo, F. (2008). Study of rare earth elements on the physical and mechanical properties of a $\mathrm{Cu}-$ Fe-P-Cr alloy. 147(1).

Gupta, C. K. (1992). Extractive metallurgy of rare earths. International Materials Reviews, 197248.

H.Johannesson, A. 1. (1996). Geochemistry of the rare-earth elements in hypersaline and dilute acidic natural terrestrial waters: Complexation behavior and middle rare-earth element enrichments. Chemical Geology, 125-144.

Habashi, F. (2013). Extractive metallurgy of rare earths. Canadian Metallurgical Quarterly, 224-233.

Harmer, M. A. (2001). Solid acid catalysis using ion-exchange resins. Applied Catalysis A: General, 45-62.

He, H. (2019). Thermodynamic analysis of hot water leaching of sulphur from desulphurisation slag by Eh-pH diagrams of the Ca-S-H2O system. 128(3).

Hérès, X. (2018). Selective Extraction of Rare Earth Elements from Phosphoric Acid by Ion Exchange Resins. Metals, 682.

Hidayah, N. N. (2018). The evolution of mineral processing in extraction of rare earth elements using liquid-liquid extraction: A review Author links open overlay panel. 121.

Hower, J. C. (2016). Notes on Contributions to the Science of Rare Earth Element Enrichment in Coal and Coal Combustion Byproducts. 6(2).

Hu, Z. (2006). Rare Earth Elements in Soils. Communications in Soil Science and Plant Analysis , 1381-1420.

Huang, Z. (2020). Rare earth elements of fly ash from Wyoming's Powder River Basin coal. $38(2)$. 
Innocenzi, V. (2016). Rare earths from secondary sources: profitability study. Advances in Environmental Research, 125-140.

Isshiki, M. (1996). Purification of rare earth metals. Vacuum, 885-887.

Itoh, M. (2009). Novel rare earth recovery process on Nd-Fe-B magnet scrap by selective chlorination using NH4Cl. Journal of Alloys and Compounds, 484-487.

Jenner, G. (1990). ICP-MS — A powerful tool for high-precision trace-element analysis in Earth sciences: Evidence from analysis of selected U.S.G.S. reference samples. Chemical Geology, 133-148.

Johnson, B. (2005). Acid mine drainage remediation options: a review. Science of The Total Environment, 3-14.

Jordens. (2003). A review of the beneficiation of rare earth element bearing minerals. 41 .

Jorjani, E. (2016). The production of rare earth elements group via tributyl phosphate extraction and precipitation stripping using oxalic acid. Arabian Journal of Chemistry, 1532-1539.

Jowitt, S. M. (2018). Recycling and Secondary Sources of the Rare Earth Elements; An Overview . 2018.

Jurkovic, J. (2014). CHEMICAL CHARACTERISATION OF ACID MINE DRAINAGE FROM AN ABANDONED GOLD MINE SITE. 2014.

Kanazawa, Y. (2006). Rare earth minerals and resources in the world. Journal of Alloys and Compounds, 1339-1343.

Kim, D. (2015). Selective Extraction of Rare Earth Elements from Permanent Magnet Scraps with Membrane Solvent Extraction. Environmental Science \& Technology, 9452-9459.

Kim, E. (2012). Aqueous stability of thorium and rare earth metals in monazite hydrometallurgy: Eh- $\mathrm{pH}$ diagrams for the systems Th-, $\mathrm{Ce}-, \mathrm{La}-, \mathrm{Nd}-(\mathrm{PO} 4)-(\mathrm{SO} 4)-\mathrm{H} 2 \mathrm{O}$ at $25^{\circ} \mathrm{C}$. Hydrometallurgy, 67-78.

Kleinmann, R. L. (1981). Biogeochemistry of acid mine drainage and a method to control acid formation . Mining Engineering.

Kumari, A. (2018). Recovery of rare earths from spent NdFeB magnets of wind turbine: Leaching and kinetic aspects. Waste Management, 486-498.

Kynicky, J. (2012). Diversity of Rare Earth Deposits: The Key Example of China. Elements, 361-367.

Li, X. (2017). Geochemical characteristics of dissolved rare earth elements in acid mine drainage from abandoned high-As coal mining area, southwestern China. Environmental Science and Pollution Research, 20540-20555.

$\mathrm{Li}, \mathrm{Z}$. (2019). Comparative life cycle analysis for value recovery of precious metals and rare earth elements from electronic waste. Resources, Conservation and Recycling, 20-30.

Lim, M. H. (1999). Comparative Studies of Grafting and Direct Syntheses of Inorganic-Organic Hybrid Mesoporous Materials. Chemistry of Materials, 3285-3295. 
Lin, R. (2017). Enrichment of rare earth elements from coal and coal by-products by physical separations. Fuel, 506-520.

Lokshin, E. P. (2005). A Study of the Solubility of Hydrated Orthophosphates of Yttrium, Lanthanum, Cerium, and Neodymium in Sulfuric-Phosphoric Acid Solutions at $20^{\circ} \mathrm{C}$. Russian Journal of Applied Chemistry volume, 1913-1916.

Long, K. R. (2010). The Principal Rare Earth Elements Deposits of the United States: A Summary of Domestic Deposits and a Global Perspective. USGS.

Long, K. R. (2010). The Principal Rare Earth Elements Deposits of the United States: A Summary of Domestic Deposits and a Global Perspective. U.S. Geological Survey.

Longerich, H. (1987). Effects of operating conditions on the determination of the rare earth elements by inductively coupled plasma-mass spectrometry (ICP-MS). 42(1).

Lozano, A. (2019). Solid and Aqueous Speciation of Yttrium in Passive Remediation Systems of Acid Mine Drainage. Environmental Science \& Technology, 11153-11161.

Luís, A. T. (2009). Impact of Acid Mine Drainage (AMD) on Water Quality, Stream Sediments and Periphytic Diatom Communities in the Surrounding Streams of Aljustrel Mining Area (Portugal). Water, Air, and Soil Pollution, 147-167.

Lukacs, H. A. (2013). The Relationship of Place Re-Making and Watershed Group Participation in Appalachia. Society \& Natural Resources , 55-69.

Maest, A. S. (2017). A geochemical examination of humidity cell tests. Applied Geochemistry(81), 109-131.

Massari, S. (2013). Rare earth elements as critical raw materials: Focus on international markets and future strategies. Resources Policy, 36-43.

Matsumoto, A. (2014). Adsorption Characteristics of Organosilica Based Mesoporous Materials. Langmuir, 7139-7145.

McLaren, J. W. (1990). Applications of ICP-MS in marine analytical chemistry. Fresenius' Journal of Analytical Chemistry, 721-728.

Merten, D. (2004). Determination of rare earth elements in acid mine drainage by inductively by inductively coupled plasma mass spectrometery. 148 .

Mishra, R. K. (1978). Electron microscopy of some rare earth-cobalt alloy magnets. 49.

Mitsch, W. J. (1998). Water quality, fate of metals, and predictive model validation of a constructed wetland treating acid mine drainage. Water Research, 1888-1900.

Moghadam, A. (2015). Effect of rare earth elements on sorption characteristics of nanostructured $\mathrm{Zr}-\mathrm{Co}$ sintered porous getters. 111.

Moldoveanu, G. A. (2013). Recovery of rare earth elements adsorbed on clay minerals: II. Leaching with ammonium sulfate. 131.

Morteani, C. P. (1989). The Industrial Applications of Rare Earth Elements. Lanthanides, Tantalum and Niobium, 359-370. 
Nasab, M. E. (2011). Determination of optimum process conditions for the separation of thorium and rare earth elements by solvent extraction. 106.

Natarajan, K. (2008). Microbial aspects of acid mine drainage and its bioremediation. Transactions of Nonferrous Metals Society of China, 1352-1360.

Nordstrom, D. K. (2009). Acid rock drainage and climate change. Journal of Geochemical Exploration, 97-104.

Ouhadi, V. (2003). Impact of clay microstructure and mass absorption coefficient on the quantitative mineral identification by XRD analysis. 23(1).

Pahan, S. (2019). Preparation of chitosan functionalized polyamidoamine for the separation of trivalent lanthanides from acidic waste solution. Radiochimica Acta.

Pan, J. (2020). Recovery of rare earth elements from coal fly ash by integrated physical separation and acid leaching. Chemisphere, 126112.

Parian, M. (2015). Analysis of mineral grades for geometallurgy: Combined element-to-mineral conversion and quantitative X-ray diffraction. 82(15).

Pin, C. (1997). Sequential separation of light rare-earth elements, thorium and uranium by miniaturized extraction chromatography: Application to isotopic analyses of silicate rocks. Analytica Chimica Acta, 79-89.

Preston, J. (1996). The recovery of rare earth oxides from a phosphoric acid by-product. Part 1: Leaching of rare earth values and recovery of a mixed rare earth oxide by solvent extraction. 41(1).

Price, W. (1998). Guidelines for metal leaching and acid rock drainage at minesites in British Columbia, Ministry of Energy and Mines. In mine drainage and surface mine reclamation, 1: mine water and mine waste.

Quinn, K. A. (2006). Sorption of yttrium and rare earth elements by amorphous ferric hydroxide: Influence of $\mathrm{pH}$ and ionic strength. Marine Chemistry, 128-150.

R.Mueller, S. (2015). A geological reconnaissance of electrical and electronic waste as a source for rare earth metals. Waste management, 226-234.

Rademaker, J. H. (2013). Recycling as a Strategy against Rare Earth Element Criticality: A Systemic Evaluation of the Potential Yield of NdFeB Magnet Recycling. 47(18).

Rivera, R. M. (2018). Extraction of rare earths from bauxite residue (red mud) by dry digestion followed by water leaching. Minerals Engineering, 82-92.

Rozelle, P. L. (2016). A Study on Removal of Rare Earth Elements from U.S. Coal Byproducts by Ion Exchange. Metallurgical and Materials Transactions, 6-17.

Rusydi, A. F. (2019). Correlation between conductivity and total dissolved solid in various type of water: A review. IOP Conference Series: Earth and Environmental Science.

S.Al-Thyabat. (2015). REE extraction from phosphoric acid, phosphoric acid sludge, and phosphogypsum. Mineral Processing and Extractive Metallurgy, 143-150. 
Sadri. (2017). A review on the cracking, baking and leaching processes of rare earth element concentrates. 35(8).

Salem, M. (2019). Phosphoric acid purification sludge: Potential in heavy metals and rare earth elements. Waste Management, 46-56.

Sapsford, D. (2009). Humidity cell tests for the prediction of acid rock drainage. 22(1).

Sato, M. (1992). Persistency-field Eh-pH diagrams for sulfides and their application to supergene oxidation and enrichment of sulfide ore bodies. 56(8).

Seredin, V. V. (2012). Coal deposits as potential alternative sources for lanthanides and yttrium. 94.

Sexsmith, K. (2015). Comparison of Actual and Calculated Lag Times in Humidity Cell Tests. 10th ICARD IMWA 2015.

Shokes, T. E. (1999). Removal of Dissolved Heavy Metals from Acid Rock Drainage Using Iron Metal. Environmental Science \& Technology, 282-287.

Simate, G. S. (2014). Acid mine drainage: Challenges and opportunities. Journal of Environmental Chemical Engineering, 1785-1803.

Simmons, J. (2002). Use of Steel Slag Leach Beds for the Treatment of Acid Mine Drainage. 21.

Singh, G. (1987). Mine water quality deterioration due to acid mine drainage. International journal of mine water, 49-61.

Siriwardane, H. J. (2003). Use of Waste Materials for Control of Acid Mine Drainage and Subsidence. 129(10).

Skousen, J. (2017). Review of Passive Systems for Acid Mine Drainage Treatment. 36(1).

Skousen, J. (2017). Review of Passive Systems for Acid Mine Drainage Treatment. 36, 133-153.

Skousen, J. G. (1995). Acid Mine Drainage Control and Treatment.

Skousen, J. G. (2005). Acid Mine Drainage: Sources and Treatment in the United States.

Stewart, B. W. (2017). Rare earth element resources in coal mine drainage and treatment precipitates in the Appalachian Basin, USA. 169.

Tack, F. (1996). Metal solubility as a function of $\mathrm{pH}$ in a contaminated, dredged sediment affected by oxidation. Environmental Pollution, 199-208.

Tang, M. (2019). Study on extraction of rare earth elements from coal fly ash through alkali fusion - Acid leaching. 136.

Tsakanika, L. V. (2004). Investigation of the separation of scandium and rare earth elements from red mud by use of reversed-phase HPLC. Analytical and Bioanalytical Chemistry, 796-802.

USGS. (n.d.). Retrieved from https://USGS.OVG

USU. (n.d.). Retrieved from

http://ion.chem.usu.edu/ sbialkow/Classes/3650/Carbonate/Carbonic\%20Acid.html 
USU. (2004). Retrieved from http://ion.chem.usu.edu/ sbialkow/Classes/3650/Carbonate/Carbonic\%20Acid.html

Vahidi, E. (2016). Life Cycle Analysis for Solvent Extraction of Rare Earth Elements from Aqueous Solutions. REWAS , 113-120.

Vahidi, E. (2017). Environmental life cycle assessment on the separation of rare earth oxides through solvent extraction. Journal of Environmental Management, 255-263.

Vass, C. R. (2019a). The occurrence and concentration of rare earth elements in acid mine drainage and treatment byproducts: Part 1 - Initial survey of the northern Appalachian Coal Basin. 50 .

Vass, C. R. (2019b). The Occurrence and Concentration of Rare Earth Elements in Acid Mine Drainage and Treatment Byproducts. Part 2: Regional Survey of Northern and Central Appalachian Coal Basins. 36(5).

Verplanck, P. L. (2004). Rare earth element partitioning between hydrous ferric oxides and acid mine water during iron oxidation. Applied Geochemistry, 1339-1354.

Wag, A. S. (1987). Occurrence of scandium and rare earth elements in Jamaican bauxite waste. Economic Geology, 757-761.

Walawalkar, M. (2016). Process investigation of the acid leaching of rare earth elements from phosphogypsum using $\mathrm{HCl}, \mathrm{HNO} 3$, and $\mathrm{H} 2 \mathrm{SO} 4.166$.

Wang, H. (2009). Photoluminescence properties of the rare-earth ions in the TiO2 host nanofibers prepared via electrospinning. 44(2).

Wang, R. (2000). Effect of rare earth on the microstructures and properties of a low expansion superalloy. 311(1).

Watten, B. J. (2005). Acid neutralization within limestone sand reactors receiving coal mine drainage. Environmental Pollution, 295-304.

Wert, C. A. (1987). Applications of transmission electron microscopy to coal chemistry. 66(7).

Wiktor, C. (2017). Transmission electron microscopy on metal-organic frameworks - a review. (29).

Xie. (2014). A critical review on solvent extraction of rare earths from aqueous solutions. 56.

Xie, F. (2014). A critical review on solvent extraction of rare earths from aqueous solutions. Minerals Engineering, 10-28.

Yang, X. (2019). Rare Earth Occurrences in Streams of Processing a Phosphate Ore. Metals, 262.

Yang, X. J. (2013). China's ion-adsorption rare earth resources, mining consequences and preservation. Environmental Development, 131-136.

$\mathrm{Yu}$, D. (2004). Improvement on the microstructure stability, mechanical and wetting properties of $\mathrm{Sn}-\mathrm{Ag}-\mathrm{Cu}$ lead-free solder with the addition of rare earth elements. 37(1).

Zhan, X. (2019). Recovery of iron and rare earth elements from red mud through an acid leaching-stepwise extraction approach. Journal of Central South University, 458-466. 
Zhang, J. (1996). Rare earth elements and yttrium in seawater: ICP-MS determinations in the East Caroline, Coral Sea, and South Fiji basins of the western South Pacific Ocean. 60(23).

Zhang, L. (2016). Rare earth extraction from wet process phosphoric acid by emulsion liquid membrane. Journal of Rare Earths, 717-723.

Zhang, W. (2015). A Review of the Occurrence and Promising Recovery Methods of Rare Earth Elements from Coal and Coal By-Products. 35(6).

Zhang, W. (2020). Mineralogy characterization and recovery of rare earth elements from the roof and floor materials of the Guxu coalfield. 270.

Zhao, F. (2007). The geochemistry of rare earth elements (REE) in acid mine drainage from the Sitai coal mine, Shanxi Province, North China. International journal of coal geology, 184-192.

Zhu, Y. (2004). Determination of Rare Earth Elements in Seawater by ICP-MS After Preconcentration with a Chelating Resin-Packed Minicolumn. Alloys and Compounds, 985-988.

Ziemkiewicz, P. (1994). Early Weathering Behavior of Pyritic Coal Spoil Piles Interstratified with Chemical Amendments. Proceedings, International Land Reclamation and Mine Drainage Conference and the Third International Conference on the Abatement of Acidic Drainage.

Zmemla, R. (2020). Tunisian phosphogypsum tailings: Assessment of leaching behavior for an integrated management approach. Korean Society of Environmental Engineers, 12261025. 